\author{
Universidade de Brasília - UnB \\ Instituto de Geociências - IG \\ Programa de Pós-graduação em Geologia Regional
}

Coprólitos dos sítios paleontológicos Peirópolis e Serra da Galga (Membro Serra da Galga, Formação Marília) da região de Uberaba, Minas Gerais, Brasil

Fábio Antônio de Oliveira

Dissertação de mestrado n. 362 


\author{
Universidade de Brasília - UnB \\ Instituto de Geociências - IG \\ Programa de Pós-graduação em Geologia Regional
}

\title{
Coprólitos dos sítios paleontológicos Peirópolis e Serra da Galga (Membro Serra da Galga, Formação Marília) da região de Uberaba, Minas Gerais, Brasil
}

Fábio Antônio de Oliveira

Dissertação de mestrado n. 362

Orientador: Prof. Dr. Rodrigo Miloni Santucci

Dissertação de mestrado apresentada ao Instituto de Geociências da Universidade de Brasília como requisito parcial para obtenção do título de Mestre em Geologia, na área de concentração em Geologia Regional. 
Banca examinadora

Prof. Dr. Rodrigo Miloni Santucci (UnB)

Profa. Dra. Fresia Soledad Ricardi Torres Branco (UNICAMP)

Prof. Dr. Ricardo Lourenço Pinto (UnB) 
Dissertação apresentada na forma de artigo conforme Art. 35 do Regimento da Pósgraduação do Instituto de Geociências da Universidade de Brasília. 


\section{AGRADECIMENTOS}

Esta dissertação só foi concebida graças ao apoio de diversas pessoas e instituições. Foram dois anos de trabalho onde pude contar com o apoio de profissionais e amigos de distintas áreas. Acredito que podemos crescer muito como profissionais quando caminhamos por outras áreas e o conhecimento dos outros é transmitido. Acredito também que crescemos como pessoas quando nosso conhecimento é compartilhado. Este trabalho é de vocês, por vocês e para vocês:

- À Coordenação de Aperfeiçoamento de Pessoal de Nível Superior (CAPES) pela concessão da bolsa de estudos, sem a qual não seria possível desenvolver este trabalho;

- Ao Laboratório de Difração de Raios-X do Instituto de Geociências (IG) da Universidade de Brasília (UnB), pela análise de difração das amostras;

- Ao Dr. Luiz Carlos Borges Ribeiro e funcionários do Museu dos Dinossauros e Centro de Pesquisas Paleontológicas Llewellyn Ivor Price por todo apoio durante o desenvolvimento do trabalho, especialmente durante a etapa de campo.

- À Profa. Dra. Maira Barberi do Laboratório de Paleoecologia da Pontifícia Universidade Católica de Goiás (PUC-GO), por ceder local e material para preparação e análise palinológica das amostras e por dividir comigo a alegria de encontrar um pólen de Podocarpus dentro de um cocô;

- Aos amigos da empresa Biota Projetos e Consultoria Ambiental, local onde foi disponibilizada estrutura e material para triagem das amostras. Agradeço ao apoio dos proprietários Claudio Veloso Mendonça e Pablo Vinícius Clemente Mathias, da gerente técnica e administrativa Joyce Costa de Carvalho e do Dr. Ronaldo Leal Carneiro;

- A toda comunidade de software livre, da qual também faço parte, sempre prestativa e pronta para ajudar nas dúvidas e solução de problemas;

- Agradeço aos estagiários (agora biólogos) Brenda Camara Cardoso, Henrique Aires da Silva e Nayara Lima Batista pela ajuda na triagem das amostras;

- Aos meus amigos Giovanna de Carvalho Quinta, Bruno Cezarotti Padilha e Gabriel de Avila Batista pelos momentos de discussões, sugestões e auxílio técnico no trabalho;

- À minha amiga Alice Francener Nogueira Gonzaga pelo apoio, momentos de discussões e conselhos ainda antes mesmo de ingressar no mestrado; 
- Ao Prof. Dr. Jalles Teixeira Chaves Filho pelas discussões sobre os resíduos vegetais encontrados nas amostras;

- Um agradecimento especial à minha esposa Luana Cristina da Silva pelo apoio nos momentos de dificuldade e por auxiliar em diversos momentos: triagem de amostras e preparação de materiais. Obrigado por caminhar essa estrada ao meu lado, jamais conseguiria sem você;

- Aos meus pais, Antônio e Maria e irmãos, Fernando e Ana Cristina que sempre me incentivaram na busca dos meus objetivos e com quem sempre pude contar;

- Aos colegas/amigos de pós-graduação Henrique Zimmermann Tomassi, Joyce Celerino de Carvalho, Lucila Monteiro de Souza, Adriano Santos Mineiro, Roberto de Souza Dias Ricart, Felipe Mendes dos Santos Cardia, Marcos Vitor Dumont Júnior e Glauber Oliveira Cunha, companheiros da paleonto que dividem o mesmo orientador;

- Ao meu orientador Prof. Dr. Rodrigo Miloni Santucci pela oportunidade de desenvolver este trabalho. Obrigado pela orientação, pelas excelentes aulas de Paleontologia, pela paciência, pelo apoio nos momentos de dificuldade e por acreditar na minha capacidade. 
“...O pão de ló, brevidade da vovó

O fondue e o mocotó Pavarotti e Xororó

Minha éguinha pocotó Ninguém vai escapar do pó Sua boca e seu loló Tudo vira bosta..." Rita Lee (Tudo Vira Bosta)

"A mais simples porcaria talvez seja mais significativa que a nossa maior crítica" Anton Ego (in Ratatouille)

"Uma vez cocô para sempre cocô" Alice Francener 


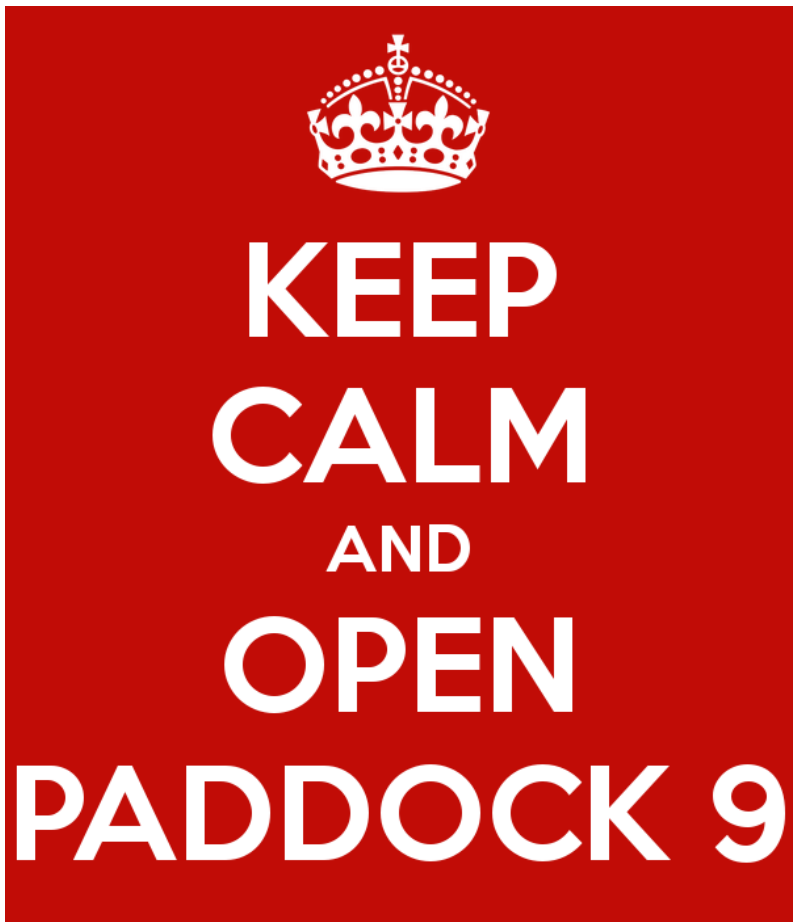




\section{SUMÁRIO}

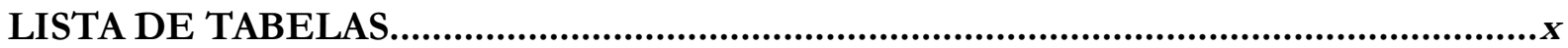

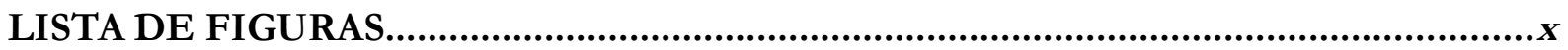

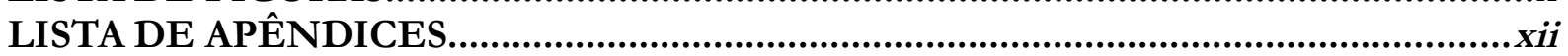

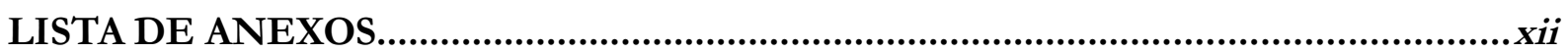

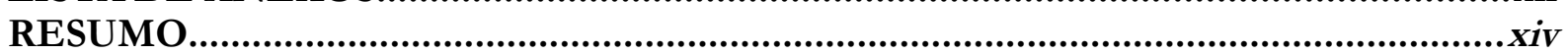

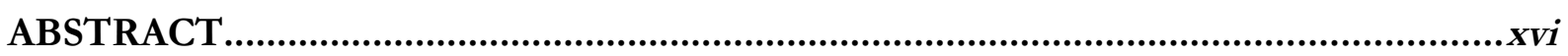

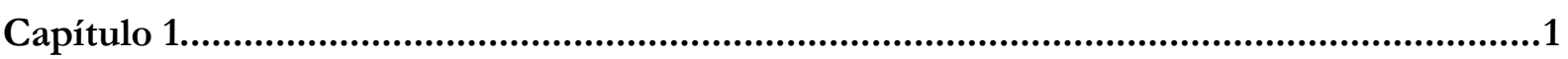

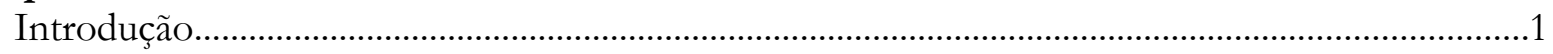

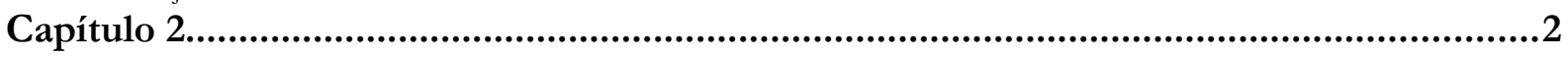

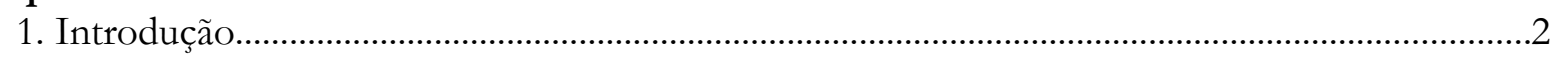

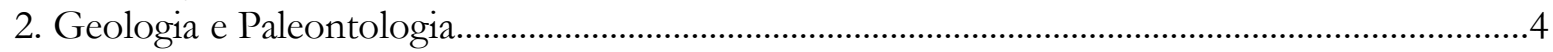

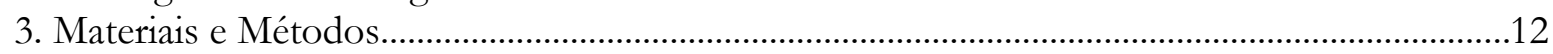

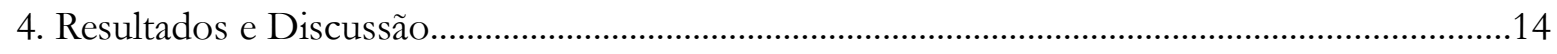

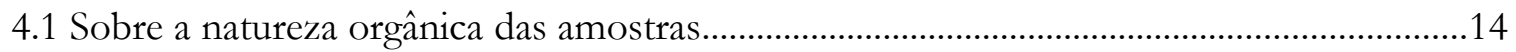

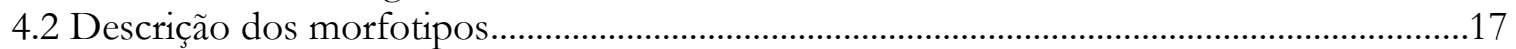

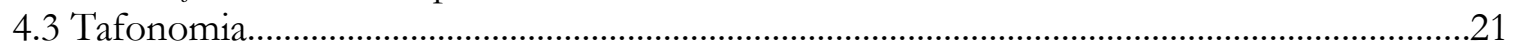

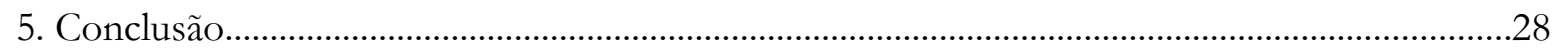

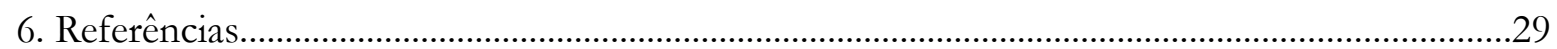

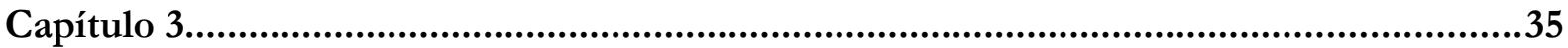

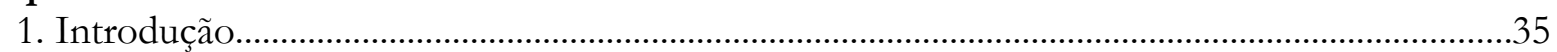

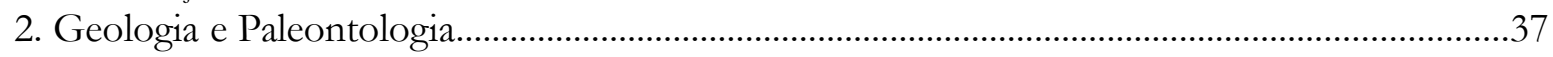

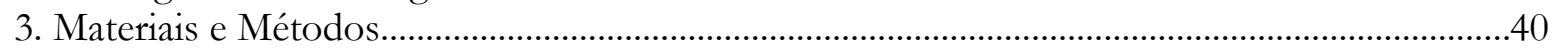

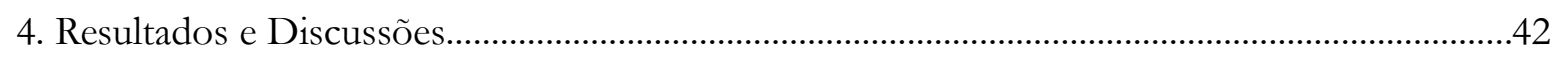

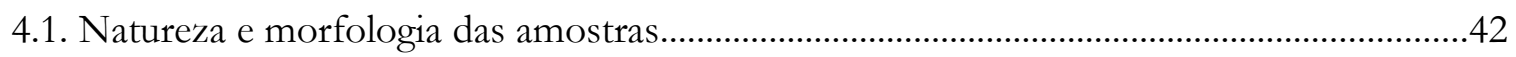

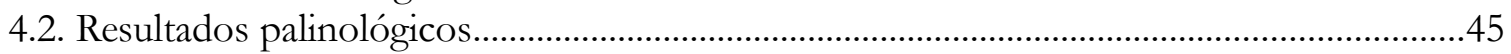

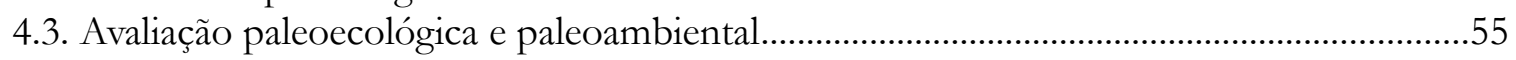

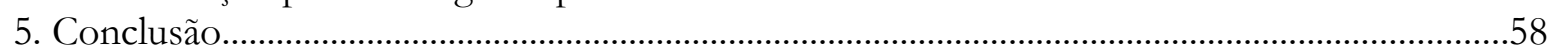

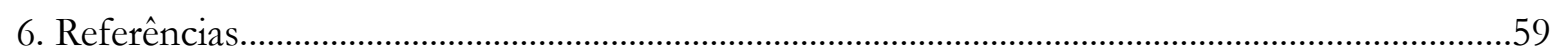

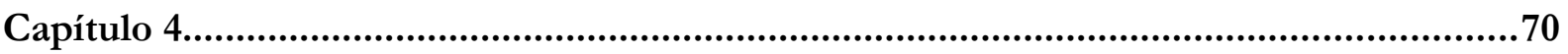

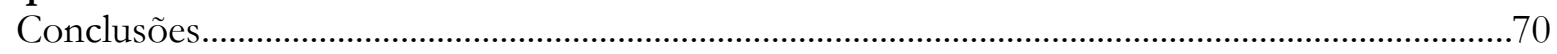

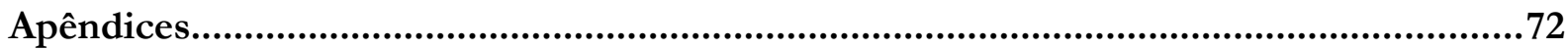

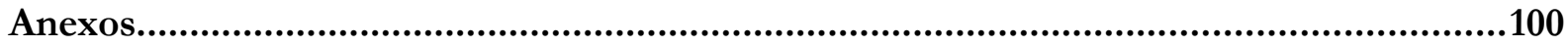




\section{LISTA DE TABELAS}

\section{Capítulo 3}

Tabela 1. Parâmetros físicos das amostras dos sítios paleontológicos Peirópolis e Serra da Galga utilizadas na preparação palinológica

Tabela 2. Palinomorfos encontrados em coprólitos dos sítios paleontológicos Peirópolis e Serra da Galga, Uberaba, Minas Gerais, Brasil 46

\section{LISTA DE FIGURAS}

\section{Capítulo 2}

Figura 1. Mapa de localização do Grupo Bauru e dos depósitos da Formação Marília na região de Uberaba, Minas Gerais, Brasil. Modificado de Fernandes and Coimbra (1996) e Fernandes (1998).

Figura 2. Seção cronoestratigráfica das unidades cretáceas da Bacia do Paraná. Modificado de Milani et al. (2007).... 5

Figura 3. Mapa de localização da área de estudo em território brasileiro. A) Localização do afloramento denominado Ponto 1 do Price ou Caieira, no Sítio Paleontológico Peirópolis, Uberaba, Minas Gerais. B) Localização do afloramento no km 153 da BR-050 (B), no Sítio Paleontológico Serra da Galga, Uberaba, Minas Gerais....

Figura 4. Afloramentos localizados no Ponto 1 do Price ou Caieira (A), Sítio Peirópolis e km 153 da BR-050 (B), Sítio Serra da Galga, Uberaba, Minas Gerais, Brasil. A1) Afloramento do Ponto 1 do Price (Caieira); A2) Setas indicando seixos dispostos caoticamente; A3) Coprólito in situ no nível dos seixos; B1) Afloramento do km 153 da BR-050; B2) Setas indicando seixos orientados horizontalmente; B3) Coprólito fragmentado in situ no nível dos seixos. Escalas $=1 \mathrm{~m} \mathrm{~A} 1$ e B1 e $1 \mathrm{~cm}$ em A2-3 e B2-3.

Figura 5. Coluna estratigráfica dos afloramentos do Membro Serra da Galga, localizados no Ponto 1 do Price, no Sítio Paleontológico Peirópolis (A) e no km 153 da BR-050, no Sítio Paleontológico Serra da Galga (B), Uberaba, Minas Gerais, Brasil.

Figura 6. Esquematização da amostra FUP-000125, evidenciando os seis estágios de abrasão dos coprólitos dos sítios Peirópolis e Serra da Galga, Uberaba, Minas Gerais, Brasil. O coprólito em questão é do Estágio 0, e os demais desenhos são meramente ilustrativos. Sem escala. Desenho por Bruno Cezarotti Padilha....

Figura 7. Boxplot da variação de densidade de coprólitos e pseudocoprólitos encontrados nos sítios Peirópolis e Serra da Galga, Município de Uberaba, Minas Gerais, Brasil. No eixo x estão representados os dois grupos de amostras (Coprólitos, $n=199$; Pseudocoprólitos, $n=141$ ). As linhas centrais indicam a mediana e divide a metade inferior e superior das amostragens, os retângulos indicam o quartil, as linhas verticais representam os valores mínimo e máximo (whisker) e, por fim, os asteriscos indicam os valores extremos (outliers).....

Figura 8. Comparação entre a porção superior (A) e inferior (B) da amostra FUP-000206 com a porção superior (C) e inferior (D) de fezes recente de bovino (Bos taurus). As fezes de bovino ficaram por 20 dias expostas ao meio. A porção superior das amostras (A e C) apresenta maior quantidade de rachaduras de ressecamento. Por outro lado, a porção inferior, (B e D) que fez contato com o solo, apresenta menos rachaduras e exibe marcas de adesão do

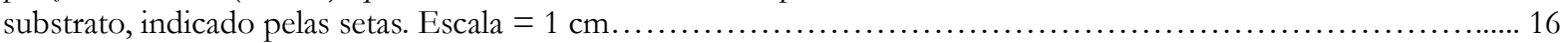

Figura 9. Conteúdo micropaleontológico encontrado nos coprólitos dos sítios Peirópolis e Serra da Galga, Município de Uberaba, Minas Gerais, Brasil. A) Esporo de fungo no centro e acima o marcador exótico Kochia scoparia na amostra FUP-000145; B-C) Possíveis fragmentos vegetais nas amostras FUP-000145 (B) e FUP-000156 (C); D) Possível cutícula vegetal com estômatos e acima grãos de pólen do marcador exótico Kochia scoparia na amostra FUP-000195. Escala $=20 \mu \mathrm{m}$. 
Figura 10. Registro fotográfico dos morfotipos encontrados nos sítios Peirópolis e Serra da Galga, Município de Uberaba, Minas Gerais, Brasil. A) Morfotipo 1 - cilíndrico, FUP-000154; B) Morfotipo 2 - ovoide, FUP-000135; C) Morfotipo 3 - cônico, FUP-000047; D) Morfotipo 4 - dômico, FUP-000145; E-F) Indeterminados - coprólitos em avançado estado de desgaste como FUP-000309 (E), provocando arredondamento das porções polares, e fragmentação como FUP-000134 (F) impossibilitam a correta identificação do morfotipo; G-H) Pseudocoprólitos nódulos carbonáticos inorgânicos como as amostras FUP-000007 (G) e FUP-000167 (H). Escala = $1 \mathrm{~cm} \ldots \ldots \ldots \ldots . .18$

Figura 11. Características gerais dos coprólitos e pseudocoprólitos dos sítios Peirópolis (A) e Serra da Galga (B), Município de Uberaba, Minas Gerais, Brasil. Na figura são apresentados os valores mínimo e máximo para cada morfotipo. Em dimensões são apresentados comprimento e largura, respectivamente.

Figura 12. Padrão de rachaduras encontradas nos coprólitos dos sítios Peirópolis e Serra da Galga, Uberaba, Minas Gerais, Brasil. Rachaduras de ressecamento ou dessecação na amostra FUP-000125 (A) e do tipo sinerese na amostra FUP-000103 (B). Escala $=1 \mathrm{~cm}$. 22

Figura 13. Variação dos valores de abundância (A) e porcentagem (B) por estágio de abrasão dos coprólitos dos sítios Peirópolis e Serra da Galga, Uberaba, Minas Gerais, Brasil. Notar que o maior número de coprólitos do Sítio Peirópolis pertence ao Estágio 2, enquanto que no Sítio Serra da Galga pertencem ao Estágio 3....................23

Figura 14. Principais características observadas nos coprólitos dos Sítios Peirópolis e Serra da Galga, Membro Serra da Galga, Formação Marília, Minais Gerais. A-B) coprólitos inteiros, aparentemente sem quebras e com rachaduras profundas, evidenciado que não houve desgaste nas amostras FUP-000125 (A) e FUP-000135 (B); C) coprólito desgastado com seixos de quartzo incrustados e molde de seixo (setas), onde observa-se que o seixo também está desgastado na amostra FUP-000227; D) coprólito arredondado sem rachaduras superficiais, provavelmente em

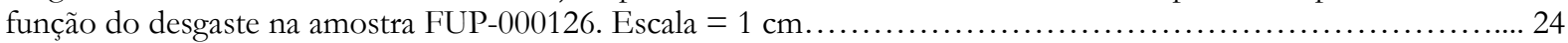

Figura 15. Fezes recentes de mamíferos depositadas em diferentes tipos de substratos. Note como as partículas presentes no substrato podem ficar aderidas ou deixar moldes nas fezes. A-B) Fezes de Chrysocyon brachyurus (loboguará) depositadas em local cascalhoso (A) e arenoso (B); C) Fezes de Puma concolor (suçuarana) depositada em local arenoso; D) Fezes de Cerdocyon thous (cachorro-do-mato) depositada em local cascalhoso, com seta indicando seixo aderido às fezes; E) Fezes de Puma yagonaroundi (gato-mourisco) com seta indicando fragmento de solo aderido; F) Fezes de Sylvilagus brasiliensis (tapiti) depositadas entre restos de milharal; G) Fezes de Hydrochoerus bydrochaeris (capivara) envoltas por grãos de areia. As imagens são do acervo da Biota Projetos e Consultoria Ambiental. Fotos A, B, D, E e G por Fábio Antônio de Oliveira e fotos C e F por Camila Castro de Araújo. Escala = $1 \mathrm{~cm} \ldots \ldots \ldots \ldots \ldots .25$

Figura 16. Esquema de transporte de coprólitos até os afloramentos dos sítios Serra da Galga e Peirópolis, Membro Serra da Galga, Formação Marília. Podendo haver produção de fezes em substrato de seixos seguido de ressecamento por longo tempo de exposição, onde o material se acumula em ambiente subaéreo e é transportado por leques aluviais (Sítio Peirópolis); ou produção e acumulação de fezes também em ambiente subaéreo e transporte por fluxo aquoso, com preservação em depósitos de canais fluviais (Sítio Serra da Galga)........................... 27

\section{Capítulo 3}

Figura 1. Mapa de localização do Grupo Bauru e dos depósitos da Formação Marília na região de Uberaba, Minas Gerais, Brasil. Modificado de Fernandes and Coimbra (1996) e Fernandes (1998)............................... 38

Figura 2. Mapa de localização e afloramentos localizados no Ponto 1 do Price ou Caieira (A), Sítio Peirópolis e km 153 da BR-050 (B), Sítio Serra da Galga, Uberaba, Minas Gerais, Brasil. A1) Afloramento do Ponto 1 do Price (Caieira); A2) Coprólito in situ; B1) Afloramento do km 153 da BR-050; B2) Coprólito fragmentado in situ. Escalas =

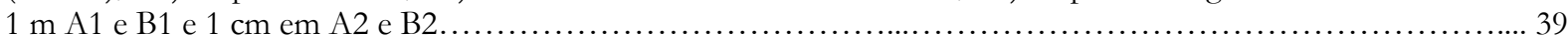

Figura 3. Boxplot da variação de densidade de coprólitos e pseudocoprólitos encontrados nos sítios Peirópolis e Serra da Galga, Município de Uberaba, Minas Gerais, Brasil. No eixo x estão representados os dois grupos de amostras (Coprólitos, $\mathrm{n}=17$; Pseudocoprólitos, $\mathrm{n}=13$ ). As linhas centrais indicam a mediana e divide a metade inferior e superior das amostragens, os retângulos indicam o quartil, as linhas verticais representam os valores mínimo e máximo (whisker) e, por fim, os asteriscos indicam os valores extremos (outliers)....

Figura 4. Coprólitos dos sítios paleontológicos Peirópolis e Serra da Galga, Uberaba, Minas Gerais, Brasil. Morfotipo cilíndrico: A) FUP-000154; Morfotipo cônico: B) FUP-000144, C) FUP-000195 e D) FUP-000280; Morfotipo dômico: E) FUP-000156 e F) FUP-000145; Indeterminados: G) FUP-000128, H) FUP-000130, I) FUP- 
000134, J) FUP-000159, K) FUP-000204, L) FUP-000209, M) FUP-000217, N) FUP-000242, O) FUP-000282, P) FUP-000325 e Q) FUP-000328. Escala $=1 \mathrm{~cm}$

Figura 5. Pseudocoprólitos dos sítios paleontológicos Peirópolis e Serra da Galga, Uberaba, Minas Gerais, Brasil. A) FUP-000002, B) FUP-000005, C) FUP-000119, D) FUP-000137, E) FUP-000155, F) FUP-000263, G) FUP-000160, H) FUP-000175, I) FUP-000178, J) FUP-000185, K) FUP-000197, L) FUP-000322 e M) FUP-000333. Escala = 1

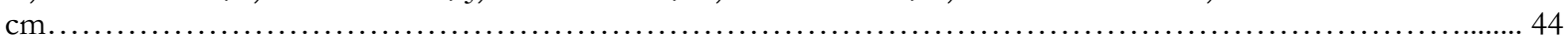

Figura 6. Palinomorfos encontrados em coprólitos dos sítios Peirópolis e Serra da Galga, Uberaba, Minas Gerais, Brasil. Grãos de pólen: A1-2) Podocarpidites sp., amostra FUP-000144 - lâmina C144/1; B) Equisetosporites sp.1, amostra FUP-000195 - lâmina C195/1; C) Equisetosporites sp.2, amostra FUP-000159 - lâmina C159/2; D) Equisetosporites sp.3, amostra FUP-000144 - lâmina C144/2; E); Gnetaceaepollenites sp., amostra FUP-000209 - lâmina C209/1; F) Cycadopites sp., amostra FUP-000195 - lâmina C195/1; G) Classopollis sp.1, amostra FUP-000145 - lâmina C145/1; H) Classopollis sp.2, amostra FUP-000130 - lâmina C130/1; I) Classopollis sp.3, amostra FUP-000328 lâmina C328/2; J) Palinomorfo 1 - Afropollis?, amostra FUP-000145 - lâmina C145/1; K) Palinomorfo 2 Arecaceae?, amostra FUP-000282 - lâmina C282/1. Fungos: L) Pluricellaesporites sp., amostra FUP-000145 - lâmina C145/1; M) Multicellites sp., amostra FUP-000325 - lâmina C325/1; N) Quilonia sp., amostra FUP-000325 - lâmina C325/2; O) Fungo 1, amostra FUP-000130 - lâmina C130/1; P) Fungo 2, amostra FUP-000144 - lâmina C144/1; Q) Fungo 3, amostra FUP-000144 - lâmina C144/2; R) Fungo 4, amostra FUP-000282 - lâmina C282/2. Escala = $10 \mu \mathrm{m}$.

Figura 7. Prováveis fragmentos vegetais encontrados em coprólitos dos sítios paleontológicos Peirópolis e Serra da Galga, Uberaba, Minas Gerais, Brasil. A-F) Matéria vegetal não digerida nas amostras FUP-000134 - lâmina C134/2 (A), FUP-000144 - lâmina C144/1 (B), FUP-000145 - lâmina C145/2 (C), FUP-000156 - lâmina C156/2 (D), FUP000217 - lâmina C217/1 (E) e FUP-000242 - lâmina C242/1 (F); G) Provável cutícula vegetal com estômatos da

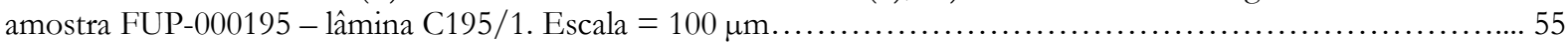

Figura 8. Concentração estimada de palinomorfos presentes em um centímetro cúbico de amostra.... 56

\section{LISTA DE APÊNDICES}

Apêndice 1. Tabela de dados físicos dos coprólitos e pseudocoprólitos dos sítios paleontológicos Peirópolis e Serra da Galga, região de Uberaba, Minas Gerais, Brasil. 73

Apêndice 2. Registro fotográfico dos coprólitos e pseudocoprólitos dos sítios paleontológicos Peirópolis e Serra da Galga, região de Uberaba, Minas Gerais, Brasil.. 80

\section{LISTA DE ANEXOS}

Anexo 1. Espectro de difração de raios-X da amostra FUP-000002.. 100

Anexo 2. Espectro de difração de raios-X da amostra FUP-000005...

Anexo 3. Espectro de difração de raios-X da amostra FUP-000128. 101

Anexo 4. Espectro de difração de raios-X da amostra FUP-000144... 102

Anexo 5. Espectro de difração de raios-X da amostra FUP-000145.

Anexo 6. Espectro de difração de raios-X da amostra FUP-000154... 
Anexo 7. Espectro de difração de raios-X da amostra FUP-000156. 103

Anexo 8. Espectro de difração de raios-X da amostra FUP-000159. 104

Anexo 9. Espectro de difração de raios-X da amostra FUP-000175. 104

Anexo 10. Espectro de difração de raios-X da amostra FUP-000204. 105

Anexo 11. Espectro de difração de raios-X da amostra FUP-000282. 105

Anexo 12. Espectro de difração de raios-X da amostra FUP-000325. 106

Anexo 13. Espectro de difração de raios-X da amostra FUP-000328. 106

Anexo 14. Espectro de difração de raios-X da amostra FUP-000333. 107 


\section{RESUMO}

\section{Coprólitos dos sítios paleontológicos Peirópolis e Serra da Galga (Membro Serra da Galga, Formação Marília) da região de Uberaba, Minas Gerais, Brasil}

Autor: Fábio Antônio de Oliveira

Orientador: Prof. Dr. Rodrigo Miloni Santucci

A região de Uberaba, em Minas Gerais, contém rica fauna de vertebrados em rochas do Membro Serra da Galga, Formação Marília, Grupo Bauru, de idade maastrichtiana. Entretanto, em meio à grande diversidade faunística, os elementos vegetais que compõem a paleobiota são praticamente ausentes no registro fóssil. Associados aos fósseis de vertebrados também foram encontrados grande quantidade de coprólitos em duas localidades, aqui chamadas de Sítio Peirópolis e Sítio Serra da Galga. Até o momento, estes coprólitos foram pouco estudados. Em campo, foram coletadas 340 amostras e, posteriormente, preparadas e analisadas em laboratório. Com a determinação de parâmetros como: peso, densidade, composição química e conteúdo, foi possível separar 199 coprólitos verdadeiros e 141 nódulos inorgânicos (pseudocoprólitos). Algumas amostras de coprólitos foram selecionadas e submetidas a uma preparação palinológica com $\mathrm{HCl}$ 10\% e HF 40\%. Os coprólitos foram divididos em quatro morfotipos, comumente associados a organismos de formas e tamanhos variados. O estudo tafonômico com base em caracteres morfológicos tais como desgaste, presença ou marcas de seixos e rachaduras de ressecamento revelaram a ocorrência de mistura temporal e espacial desse material para os dois sítios estudados. Neste trabalho também apresentamos os primeiros registros de parte da vegetação que existiu onde hoje se encontram os sítios Peirópolis e Serra da Galga. Foram encontrados tipos polínicos como Classopollis, Equisetosporites, Gnetaceaepollenites, Cycadopites e Podocarpidites. O conjunto polínico demonstra que parte da vegetação era representada por elementos arbustivos (gnetófitas), arbóreos (coníferas) e cicadáceas que viviam em um ambiente de clima árido. Aparentemente, os coprólitos depositados em local com presença de seixos passaram por longo período de seca, como indicam os palinomorfos encontrados, e foram posteriormente transportados em períodos 
de maior umidade. $\mathrm{O}$ mesmo padrão tafonômico pode ter ocorrido para os demais fósseis dessas localidades, que ocorrem em elevada abundância na região. Dessa forma, esse aspecto tafonômico se torna um importante parâmetro a ser levado em conta em futuros estudos sobre a paleobiota da região.

Palavras-chave: coprólitos, mistura temporal e espacial, palinomorfos, Formação Marília, Cretáceo 


\begin{abstract}
Coprolites from the paleontological sites Peirópolis and Serra da Galga (Serra da Galga Member, Marília Formation) of Uberaba, Minas Gerais, Brazil
\end{abstract}

Author: Fábio Antônio de Oliveira

Advisor: Prof. Dr. Rodrigo Miloni Santucci

The region of Uberaba, Minas Gerais state, contains a rich maastrichtian vertebrate fauna collected from rocks of the Serra da Galga Member, Marilia Formation, Bauru Group. Despite the great faunal diversity, the fossil record of plants, except for a few exceptions, is completely unknown. Together with vertebrate fossils, a large amount of coprolites has been also found in two locations, here called Peirópolis Site and Serra da Galga Site. There are few studies about these coprolites until now. In this study, 340 samples has been collected, prepared, and analyzed in the laboratory. Parameters such as weight, density, chemical composition, and content were determined. From this samples, 199 true coprolites have been identified whereas 141 samples have been assigned as to inorganic nodules (pseudocoprolites). Some coprolite samples were selected and subjected to a palynological preparation by using $\mathrm{HCl} 10 \%$ and $\mathrm{HF} 40 \%$. The coprolites were divided into four morphotypes, commonly associated with varied shapes and sizes organisms. The taphonomic study based on morphological characters such as wear, presence or casts of pebbles, and dissecation cracks revealed the occurrence of time averaging and spatial mixing for the samples of both sites. Moreover, we also present the first clues on how the vegetation, at the time of deposition of the rocks of the Peirópolis and Serra da Galga sites, looked like. The following palynological types were found: Classopollis, Equisetosporites, Gnetaceaepollenites, Cycadopites, and Podocarpidites. This palynomorph set shows that the vegetation was represented by shrubby elements (gnetophytes), arboreal (conifers), and cycads living in an arid climate environment. Apparently, the coprolites deposited in a place with the presence of pebbles underwent long exposure periods, as indicated by the palynomorphs found inside them. Afterwards, they were transported during periods of higher humid. The same taphonomic 
pattern may have occurred to other fossil in these sites, which occur in high abundance on the region. Thus, this taphonomic aspect becomes an important parameter to be taken into account in future studies about the biota found in these deposits.

Keywords: coprolites, time averaging, palinomorphs, Marília Formation, Cretaceous. 


\section{Capítulo 1}

\section{Introdução}

O formato dessa dissertação segue o Regulamento do Programa de Pós-graduação em Geologia da Universidade de Brasília, conforme o Art. 35 do Regimento. São discutidos os aspectos tafonômicos e o conteúdo de um conjunto de coprólitos encontrados em rochas do Membro Serra da Galga, Formação Marília, Grupo Bauru, Cretáceo Superior, da região de Uberaba-MG. Tal discussão está dividida em dois manuscritos escritos em Português que compõem os dois capítulos principais desse texto. O Capítulo 2 discute essencialmente a descrição dos morfotipos e os aspectos tafonômicos desses coprólitos e o Capítulo 3 discute o conteúdo palinológico encontrado em alguns coprólitos. Nos dois manuscritos é discutida a natureza orgânica das amostras.

Cada um desses capítulos (em forma de manuscrito) apresenta um resumo, introdução com justificativa e objetivo, materiais e métodos, resultados e discussão, conclusões e referências bibliográficas específicos. Os textos (ainda em português) foram elaborados seguindo o modelo para submissão do periódico Palaeontology. As figuras, tabelas e citações bibliográficas estão em inglês e já apresentam o formato padrão do periódico. Por fim, no Capítulo 4 é apresentado um tópico final de conclusão integrando os dois manuscritos e indicando perspectivas de estudos futuros. Adicionalmente, é apresentada uma tabela com os parâmetros físicos das 340 amostras (Apêndice 1), um registro fotográfico completo das amostras estudadas (Apêndice 2) e, finalmente, os resultados da difração de raios-X (Anexo 1 a 14). 


\section{Capítulo 2}

\section{Tafonomia de coprólitos dos sítios paleontológicos Peirópolis e Serra da Galga (Membro Serra da Galga, Formação Marília) em Uberaba, Minas Gerais, Brasil}

Resumo - A região de Uberaba, em Minas Gerais, contém rica fauna de vertebrados em rochas do Membro Serra da Galga, Formação Marília, Grupo Bauru, de idade maastrichtiana. Associados a esses fósseis também foram encontrados grande quantidade de coprólitos em duas localidades, aqui chamadas de Sítio Peirópolis e Sítio Serra da Galga. Em campo, foram coletadas 340 amostras e, posteriormente, preparadas e analisadas em laboratório. Com a determinação de parâmetros como: peso, densidade, composição química e conteúdo, foi possível separar 199 coprólitos verdadeiros e 141 nódulos inorgânicos (pseudocoprólitos). Os coprólitos foram divididos em quatro morfotipos, comumente associados a organismos de formas e tamanhos variados. $\mathrm{O}$ estudo tafonômico com base em algumas características tais como desgaste, presença ou marcas de seixos e rachaduras de ressecamento revelaram a ocorrência de mistura temporal e espacial desse material para os dois sítios estudados. O mesmo padrão tafonômico pode ter ocorrido para os demais fósseis dessas localidades, que ocorrem em elevada abundância na região. Dessa forma, esse aspecto tafonômico se torna um importante parâmetro a ser levado em conta em futuros estudos sobre a biota da região.

Palavras-chave: coprólitos, Formação Marília, Cretáceo, mistura temporal e espacial.

\section{Introdução}

Os sítios paleontológicos Peirópolis e Serra da Galga se encontram em uma grande unidade geológica do Grupo Bauru (Milani et al. 1994, 2007; Milani 1997) que ocupa a porção centro-sul da Plataforma Sul-americana. A principal unidade fossilífera na região dos sítios é o Membro Serra da Galga, da Formação Marília. Essas localidades já revelaram diversas espécies de microfósseis e macrofósseis e apresentam uma das mais ricas faunas de vertebrados e invertebrados do Cretáceo brasileiro (Ribeiro and Carvalho 2009).

O extenso registro fóssil inclui algas carófitas e invertebrados (Mezzalira 1974; Campanha et al. 1993; Magalhães-Ribeiro and Ribeiro 1999; Senra and Silva-e-Silva 1999; Gobbo-Rodrigues 2002; Ghilardi et al. 2011), peixes (Gayet and Brito 1989; Bertini et al. 1993; Martinelli et al. 2013), 
anfíbios (Báez and Peri 1989; Báez et al. 2012), lagartos (Estes and Price 1973), quelônios (França and Langer 2005; Gaffney et al. 2011), crocodilomorfos (Price 1955; Carvalho et al. 2004; Kellner et al. 2011) dinossauros (Santucci and Bertini 2001; Campos et al. 2005; Kellner et al. 2005; Novas et al. 2005, 2008; Candeiro et al. 2006; Salgado and Carvalho 2008; Martinelli et al. 2011, 2015) e aves (Candeiro et al. 2012). Adicionalmente, também são conhecidos ovos de dinossauros (Magalhães-Ribeiro 2002; Grellet-Tinner and Zaher 2007).

Nos sítios Peirópolis e Serra da Galga também ocorrem coprólitos em abundância significativa que foram pouco estudados até o momento. Em alguns casos, tais coprólitos aparecem apenas citados no estudo de outros materiais fósseis (Carvalho et al. 2004; Salgado and Carvalho 2008; Ribeiro et al. 2012, 2015; Ribeiro 2014). Souto (2003) analisou cerca de 200 coprólitos das bacias cretáceas brasileiras. Porém, apenas 31 amostras pertenciam ao Grupo Bauru e apenas sete eram de Uberaba. Segundo o mesmo autor, o quartzo foi o mineral com maior presença nas amostras da Formação Marília, mas também foram encontradas concentrações elevadas de fósforo e cálcio, associadas à substituição por hidroxiapatita e calcita, além de coprólitos ricos em silício e cálcio, onde a silicificação foi relacionada com uma dieta rica em celulose. Mais recentemente, Francischini et al. (2014) relataram preliminarmente a presença de icnofósseis de invertebrados em coprólitos de Peirópolis, relacionadas com algum tipo de inseto em fase de pupação. Contudo, no trabalho final publicado (Francischini et al. 2016) consideraram as 16 amostras analisadas como pseudocoprólitos e descreveram os vestígios superficiais de nove amostras como uma nova icnoespécie, Asthenopodichnium fallax, que seria produzida por invertebrados em ambiente de água doce. Segundo os autores, o material não apresenta indícios diagnósticos característicos de coprólitos e seriam clastos de calcrete retrabalhados. Por fim, uma compilação também recente (Souto and Fernandes 2015) apresentou um registro atualizado das principais ocorrências de coprólitos no Brasil. Duas amostras são de Peirópolis e análises de difração e fluorescência revelaram cálcio e sílica, com pequenas quantidades de alumínio e ferro, sugerindo, junto com outras características, que foram produzidos por herbívoros.

Do ponto de vista tafonômico, os trabalhos no Grupo Bauru são relativamente raros (Souto 2003; Azevedo 2012). Alguns estudos relatam preservação de fósseis relacionada a etologia, como no caso de Uberabasuchus terrificus, que teria hábito escavador e por isso se preservou articulado (Vasconcellos and Carvalho 2006). Porém, sabe-se que fósseis de vertebrados fragmentados são predominantes em relação a ossos isolados e esqueletos articulados ou parcialmente articulados na região (Azevedo 2012). Neste contexto, os mesmos processos que ocorreram com os coprólitos devem ter ocorrido com os demais fósseis. As fezes, quando 
expostas por longo período ao ambiente, podem apresentar rachaduras de ressecamento (Vogeltanz 1965). Além disso, quando as fezes são expelidas podem sofrer a adesão de partículas presentes no substrato, indicando o tipo de ambiente em que foram depositadas (Northwood 2005). Todas essas assinaturas presentes nos coprólitos podem ser importantes na obtenção de dados sobre o paleoambiente e sobre seus aspectos tafonômicos. Ademais, na região de Uberaba já foi observado que coprólitos apresentam evidências de rolamento (Souto 2003). Desta forma, devido à grande ocorrência, variedade de formas, particularidades bioestratinômicas e estado de preservação, os coprólitos se tornam uma ferramenta útil para estudos de tafonomia nesses depósitos. Este trabalho apresenta o estudo tafonômico de 340 amostras, das quais 300 são provenientes do chamado Ponto 1 do Price (Caieira), no Sítio paleontológico de Peirópolis e 40 são do Sítio Serra da Galga, no km 153 da BR-050. Além disso, diferentemente da interpretação de Francischini et al. (2016), a natureza orgânica dos materiais, como resultado da atividade de excreção de vertebrados, também é discutida e reforçada. Em termos tafonômicos, a análise destes coprólitos pode fornecer pistas mais concretas para a interpretação da grande quantidade de outros fósseis encontrados na região.

\section{Geologia e Paleontologia}

As unidades geológicas que compõem o Grupo Bauru (Milani et al. 1994, 2007; Milani 1997) representam uma das mais extensas sequências sedimentares continentais de idade cretácea da América do Sul (Fig. 1). O Grupo Bauru abrange a maior parte do Planalto Ocidental Paulista, aflorando também no Triângulo Mineiro, sul de Goiás, norte do Paraná e sudeste do Mato Grosso (Carvalho 2001; Ghilardi et al. 2011). Os depósitos do Grupo Bauru são representados principalmente por rochas siliciclásticas (Carvalho, 2001) e assentam-se predominantemente sobre basaltos da Formação Serra Geral (Fernandes 2004; Milani et al. 2007). Os depósitos sedimentares do Grupo Bauru (Fig. 2) correspondem essencialmente a arenitos, siltitos e argilitos/folhelhos, depositados por diversos sistemas deposicionais, como eólico, aluvial, fluvial e lacustre raso (Dias-Brito et al. 2001). O Grupo Bauru é constituído pelas formações Araçatuba, Adamantina, Uberaba e Marília, onde praticamente todos os registros fossilíferos conhecidos situam-se na parte oriental, abrangendo uma área de aproximadamente $180.000 \mathrm{~km}^{2}$ (Fernandes 2004). 


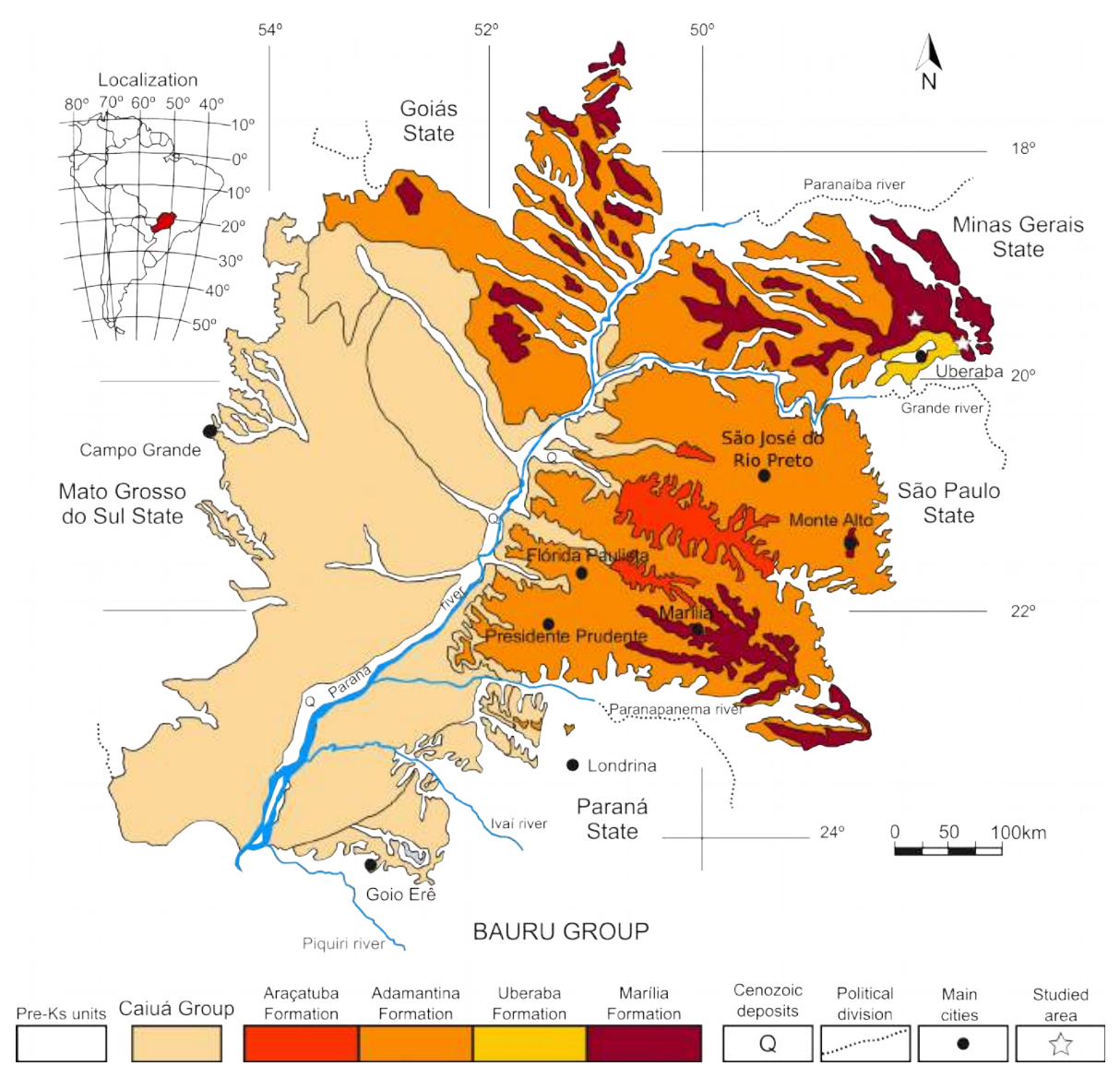

Figura 1. Mapa de localização do Grupo Bauru e dos depósitos da Formação Marília na região de Uberaba, Minas Gerais, Brasil. Modificado de Fernandes and Coimbra (1996) e Fernandes (1998).

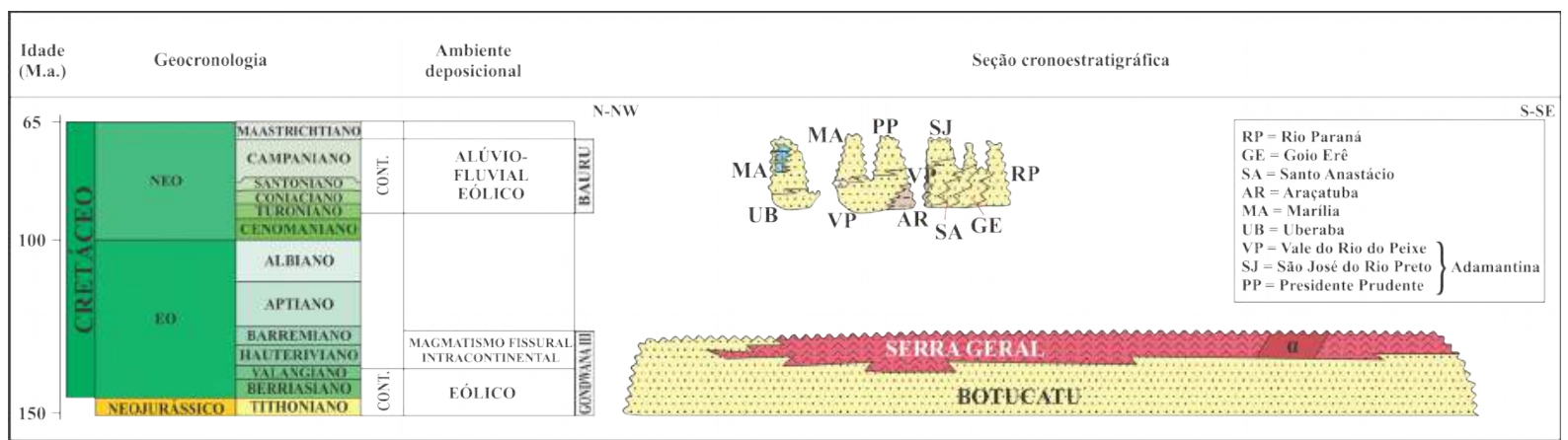

Figura 2. Seção cronoestratigráfica das unidades cretáceas da Bacia do Paraná. Modificado de Milani et al. (2007).

A Formação Marília é composta por três membros: Serra da Galga, Ponte Alta e Echaporã (Milani et al. 2007), representando depósitos essencialmente fluviais e aluviais (Fernandes 2010). Na região de Uberaba afloram rochas dos membros Serra da Galga e Ponte Alta nos sítios de Peirópolis e Serra da Galga, que já forneceram um vasto registro fóssil, incluindo carófitas, invertebrados e vertebrados, entre eles quelônios, crocodilomorfos e dinossauros (Santucci and Bertini 2001; Gobbo-Rodrigues 2002; Vasconcellos and Carvalho 2006; Milani et al. 2007), se destacando como uma das unidades mais importantes do Grupo Bauru. Os coprólitos analisados neste trabalho foram coletados em Peirópolis, no Ponto 1 do 
Price e no km 153 da BR-050 (Fig. 3). As descrições dos dois afloramentos estudados são apresentadas na sequência (Fig. 4 e 5).

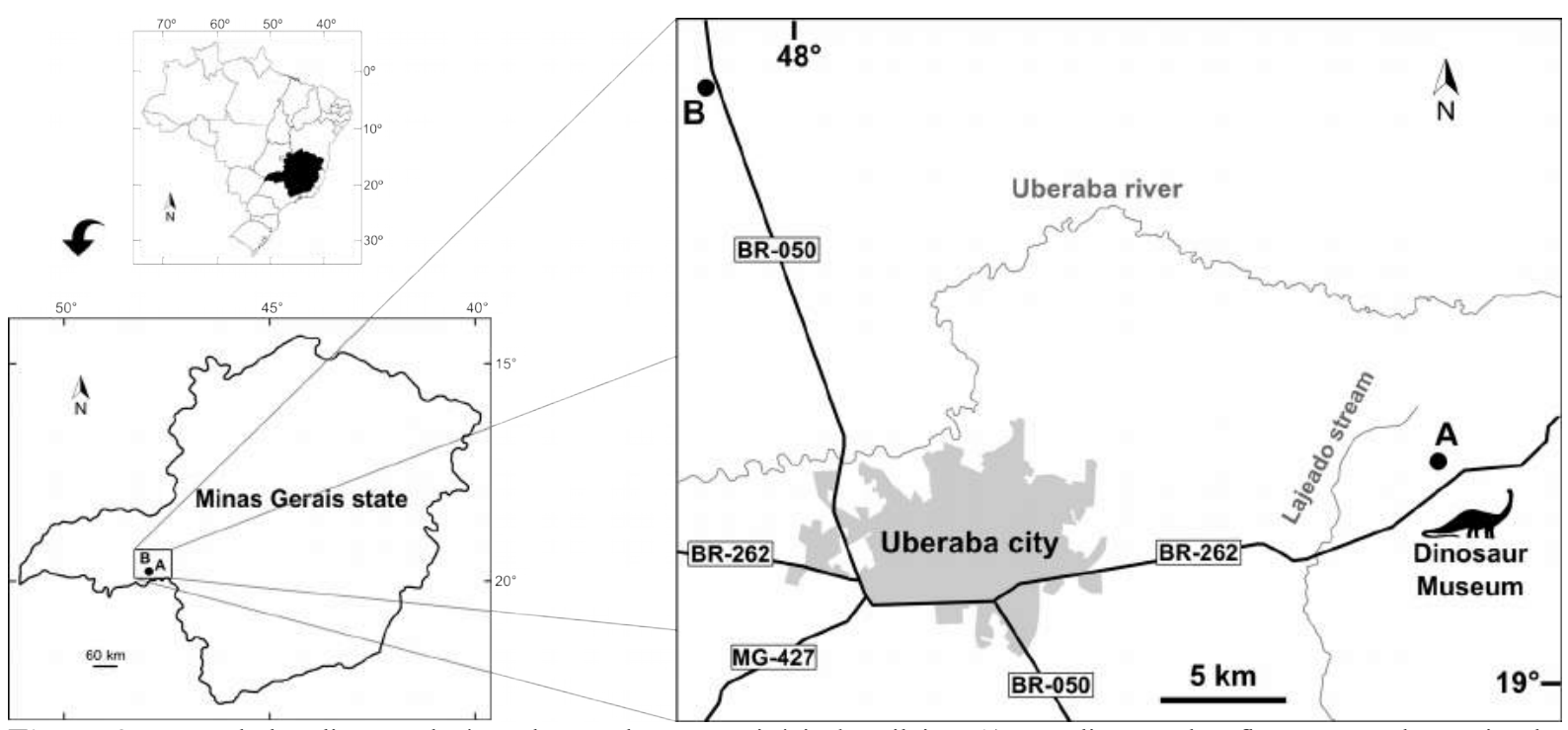

Figura 3. Mapa de localização da área de estudo em território brasileiro. A) Localização do afloramento denominado Ponto 1 do Price ou Caieira, no Sítio Paleontológico Peirópolis, Uberaba, Minas Gerais. B) Localização do afloramento no km 153 da BR-050 (B), no Sítio Paleontológico Serra da Galga, Uberaba, Minas Gerais.

- Sítio Peirópolis (Fig. 4A e 5A). O afloramento está localizado nas proximidades de Peirópolis e já recebeu várias denominações na literatura como Ponto 1 do Price ou Caieira (Fig. 4A-1). Consiste de uma grande exposição vertical de rochas do Membro Serra da Galga sobrepostas a uma base, essencialmente de calcrete, atribuída ao Membro Ponte Alta.

A) Acima do contato erosivo com o calcrete do Membro Ponte Alta ocorre um corpo de conglomerado arenítico do Membro Serra da Galga. Não foi possível determinar a geometria do pacote e nem observar seu contato com a camada sobrejacente. A parte visível tem aproximadamente $50 \mathrm{~cm}$ de espessura e lateralmente se estende por, pelo menos, dez metros. A base é composta por um conglomerado suportado por seixos que são, geralmente, bem arredondados com formato esférico, alongados ou tabulares e polimíticos (mas predominantemente quartzosos). Existem também seixos de rochas metamórficas (gnaisses) e do próprio calcrete Ponte Alta. O tamanho varia de subcentimétrico a centimétrico, mas os seixos de calcrete são, geralmente, maiores podendo chegar a $20 \mathrm{~cm}$, principalmente nos primeiros centímetros na base do pacote. Os seixos estão, aparentemente, caoticamente dispersos. A porção arenosa é constituída por, essencialmente, grãos de quartzo mal selecionados (areia fina até muito grossa). Os grãos variam de bem arredondados a angulosos. Para o topo desse pacote de $50 \mathrm{~cm} \mathrm{a}$ quantidade de seixos diminui gradualmente, e se torna um conglomerado suportado pela matriz. 


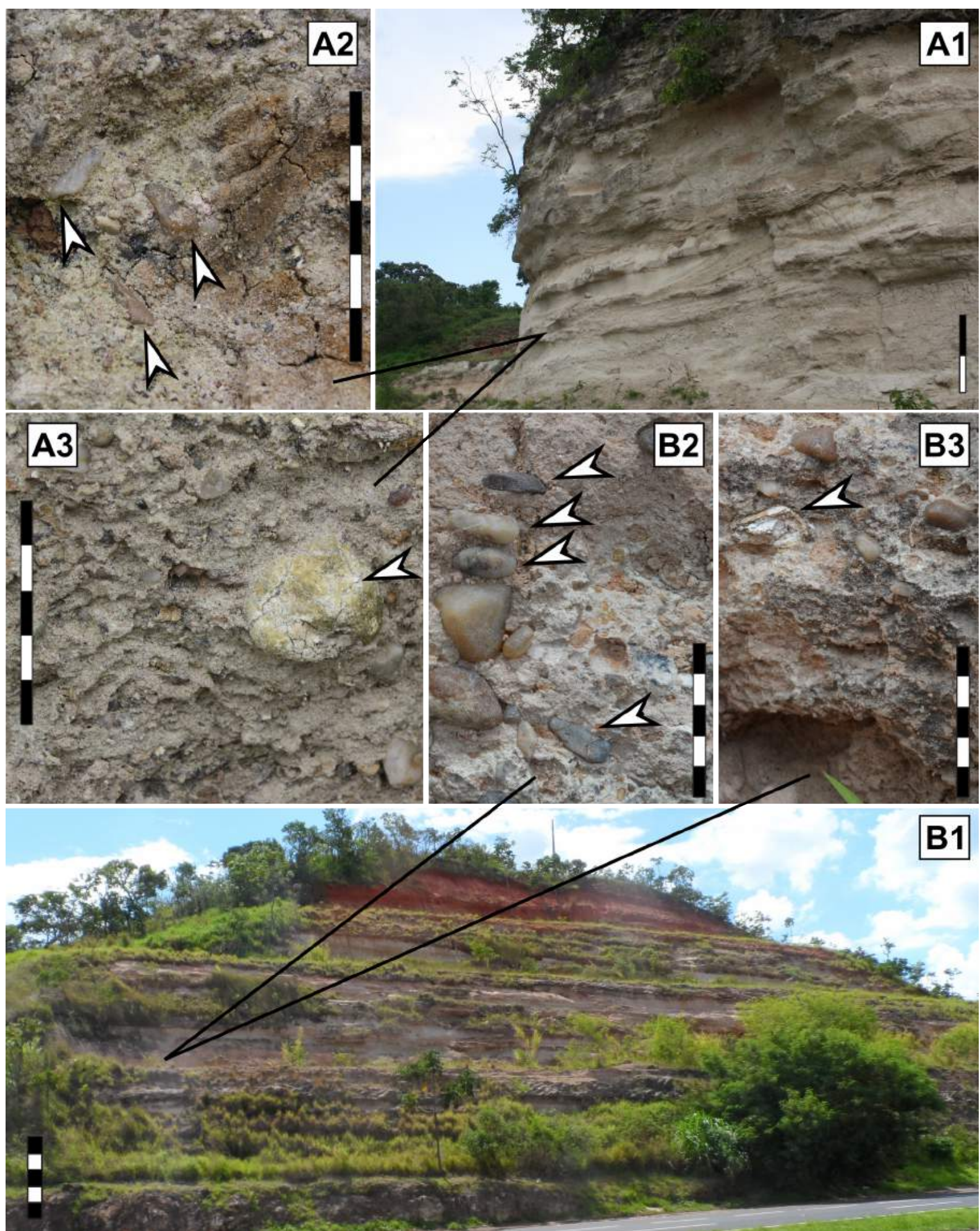

Figura 4. Afloramentos localizados no Ponto 1 do Price ou Caieira (A), Sítio Peirópolis e km 153 da BR-050 (B), Sítio Serra da Galga, Uberaba, Minas Gerais, Brasil. A1) Afloramento do Ponto 1 do Price (Caieira); A2) Setas indicando seixos dispostos caoticamente; A3) Coprólito in situ no nível dos seixos; B1) Afloramento do km 153 da BR-050; B2) Setas indicando seixos orientados horizontalmente; B3) Coprólito fragmentado in situ no nível dos seixos. Escalas $=1 \mathrm{~m}$ A1 e B1 e $1 \mathrm{~cm}$ em A2-3 e B2-3. 
Coprolite

Bone fragments

$\because$ Clay intraclasts

Disruption of the original stratification

Mudstone

Climbing ripples

Bioturbation

Carbonate level

Sandstone

Conglomerate

Horizontal stratification

Cross-bedding

Caliche
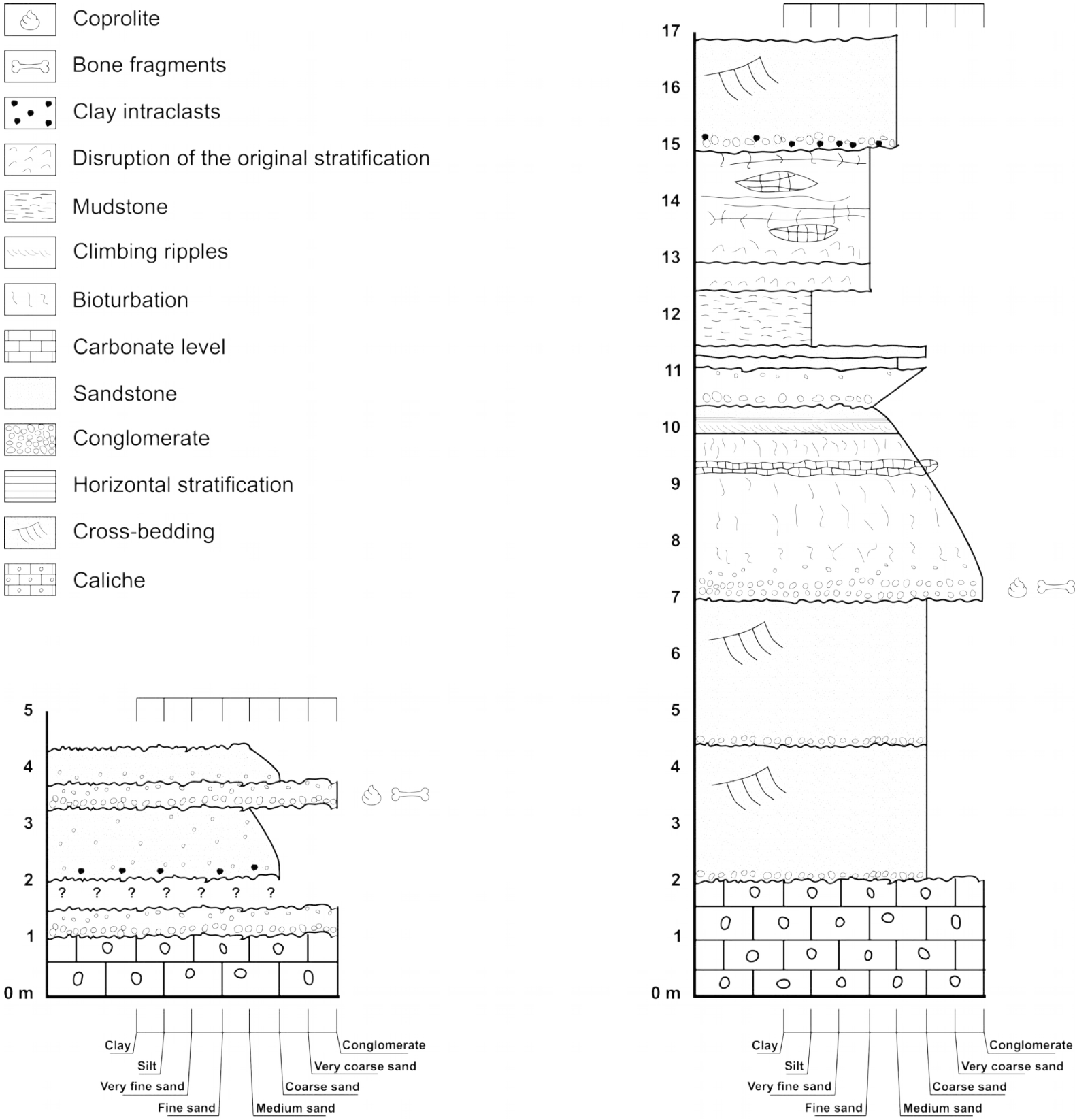

A. Peirópolis SIte

B. Serra da Galga Site

Figura 5. Coluna estratigráfica dos afloramentos do Membro Serra da Galga, localizados no Ponto 1 do Price, no Sítio Paleontológico Peirópolis (A) e no km 153 da BR-050, no Sítio Paleontológico Serra da Galga (B), Uberaba, Minas Gerais, Brasil.

B) Esta camada representa um pacote de 1,3 m de espessura e, lateralmente, se estende por aproximadamente dez metros. Apresenta contato erosivo com a camada abaixo (provavelmente o topo da camada A). A base é um arenito conglomerático. Nos primeiros centímetros apresenta uma linha de seixos subcentimétricos, polimíticos e arredondados. Há também nesse contato seixos (fragmentos) de intraclastos de argila, podendo alcançar $20 \mathrm{~cm}$ de tamanho. Os seixos não apresentam orientação preferencial (Fig. 4A-2). A fração areia é mal selecionada (fina a grossa) com grãos angulosos e arredondados, predominantemente de quartzo. No meio do pacote os 
seixos praticamente desaparecem e a areia varia de média a fina. No topo da sequência a areia muda para média a muito fina. Não se observa nenhum tipo de estrutura sedimentar e a rocha é essencialmente maciça.

C) Ocorre por contato erosivo com a camada inferior. Trata-se de um pacote com $40 \mathrm{~cm}$ de espessura e 3,2 m de largura. Possui uma forma aproximadamente triangular formada, provavelmente, pela erosão das suas porções laterais. Consiste em conglomerado suportado pela matriz, com seixos geralmente de quartzo, geralmente subcentimétricos e polimíticos, que podem ser arredondados, esféricos, alongados e tabulares. Neste nível ocorrem coprólitos (Fig. 4A-3) e fragmentos ósseos. Apresenta estratificação cruzada, possivelmente acanalada. Matriz de arenito mal selecionado, com os grãos grossos arredondados e grãos médios e finos angulosos, sugerindo tratar-se de depósito de fluxo de detritos.

D) Muito semelhante à camada $\mathrm{B}$, porém sem os intraclastos de argila. Apresenta contato erosivo com a camada $\mathrm{C}$ e possui, aproximadamente, $60 \mathrm{~cm}$ de espessura no ponto do perfil e cerca de dez metros de largura. Aparentemente, possui estratificação cruzada acanalada na linha dos seixos, que são tabulares e estão orientados de acordo com a estratificação. Neste nível também ocorrem coprólitos, porém de pequenas dimensões. Direção da paleocorrente N 221․

A partir desse ponto não foi possível acessar a rocha devido à altura da exposição. Entretanto, os depósitos parecem ser mais semelhantes aos da camada D, descrita anteriormente, essencialmente formados por arenitos com estratificação cruzada e maior extensão lateral.

- Sítio Serra da Galga (Fig. 4B e 5B). O afloramento está localizado no km 153 da BR-050 (Fig. 4B-1) e também representa uma ampla área de exposição de rochas do Membro Serra da Galga que, essencialmente, difere do Sítio Peirópolis por apresentar rochas arenosas com menor quantidade de seixos e maior continuidade lateral. Nessa localidade foram coletados os materiais do titanossauro descrito como Uberabatitan ribeiroi (Salgado and Carvalho 2008). Na beira da rodovia ocorre um nível de calcrete do Membro Ponte Alta com cerca de $2 \mathrm{~m}$ de espessura. Contato não visível com Membro Serra da Galga, mas possivelmente é erosivo.

A) Conjuntos de arenito conglomerático com estratificação cruzada, possivelmente tabular, de baixo ângulo. Arenito mal selecionado (areia fina a grossa), maior parte dos grãos angulosos com seixos polimíticos, geralmente de quartzo e bem arredondados, de formato esférico, alongado e 
tabular, de tamanho subcentimétrico a centimétrico. Seixos tabulares orientados de acordo com a estratificação. A quantidade de seixos diminui para o topo dos conjuntos. Observa-se pouquíssimos seixos de calcrete e nenhum coprólito. Em alguns conjuntos, a base apresenta bolsões de argila, parecida com algumas camadas do Sítio Peirópolis.

B) Semelhante ao pacote A, porém sem a grande quantidade de seixos, que quando aparecem também são semelhantes aos do pacote A. Os seixos se concentram na base de cada conjunto de arenito com estratificação cruzada, formando uma linha de poucos centímetros de espessura. No restante do conjunto predominam arenitos mal selecionados com estratificação cruzada de baixo ângulo.

C) Após a sequência de conjuntos de estratificações cruzadas mais arenosas, aparece um pacote mais espesso. $\mathrm{Na}$ base ocorre um conglomerado com aproximadamente $40 \%$ de seixos. Os seixos são polimíticos, essencialmente de quartzo, subcentimétricos a centimétricos, de formato arredondado, alongado e tabulares. Os seixos tabulares estão, predominantemente, na horizontal (Fig. 4B-2). Ocorrência de coprólitos, geralmente mais arredondados ou fragmentados (Fig. 4B3) e fragmentos ósseos. Após $50 \mathrm{~cm}$ o conglomerado começa a gradar para arenito. Até onde se pode observar, o conglomerado possui, aproximadamente, 10 a $15 \mathrm{~m}$ de largura. Todo pacote de arenito acima da parte conglomerática possui cimentação carbonática. Após a gradação de conglomerado para arenito, este representa um pacote de, aproximadamente, $2 \mathrm{~m}$ de espessura sem estratificação aparente, mas intensamente bioturbado. $O$ arenito é mal selecionado, com grãos finos a grossos, mas estes últimos são mais raros. Na parte superior os grãos variam de muito finos a grossos. Nos dois casos são, essencialmente, angulosos. Após essa sequência, ocorre uma camada de, aproximadamente, 20 a $30 \mathrm{~cm}$ de arenito intensamente cimentado por carbonato, formando um nível extremamente duro. Após o nível de arenito calcretizado, ocorre um novo nível de, aproximadamente, $50 \mathrm{~cm}$ de arenito mal selecionado, com grãos finos a grossos e angulosos. Apresenta estrutura maciça e com bioturbação semelhante ao anterior, mas em menor quantidade.

D) Ocorre por contato erosivo acima do nível de calcrete de 2 a $3 \mathrm{~cm}$ de espessura. Possui $50 \mathrm{~cm}$ de espessura e é composto por arenito muito fino a médio, anguloso, apresentando na base ondulações cavalgantes (climbing ripples) truncadas no topo por estratificação plano-paralela. Grada para o topo para arenito fino a muito fino. Presença de intensa bioturbação (perfurações 
centimétricas), muitas vezes obliterando a estratificação plano-paralela. Mais para o topo a estrutura fica maciça, com redução dos icnofósseis.

E) Inicia-se por contato erosivo com a camada D. O pacote apresenta $70 \mathrm{~cm}$ de espessura. A base consiste de arenito conglomerático. Seixos aparentemente sem orientação preferencial, com alguns seixos tabulares na posição vertical. $\mathrm{O}$ arenito varia de muito fino a grosso, com grãos predominantemente muito finos. Para o topo a quantidade de seixos diminui em número e em tamanho. Apresenta estrutura maciça e sem icnofósseis.

F) Contato erosivo com a camada E. Este pacote apresenta duas camadas de $20 \mathrm{~cm}$ cada. A primeira é de arenito maciço fino a médio. A segunda de arenito fino a grosso com forte cimentação carbonática.

G) Corpo aparentemente lenticular com espessura máxima de $1 \mathrm{~m}$ e largura de, pelo menos, 20 m. Possui contato erosivo com a camada inferior, às vezes, preenchendo depressões acentuadas, parecendo paleocanais. Trata-se de lamito arenoso de estrutura maciça, de cor marrom e ocorrência de, pelo menos, um icnofóssil que apresenta menisco de cabeça para baixo (convexidade para cima).

H) Pacote de arenito fino siltoso com aproximadamente $50 \mathrm{~cm}$ de espessura. Contato erosivo com a camada inferior. $\mathrm{Na}$ base, observa-se a estratificação original rompida, provavelmente por carga. Presença de icnofósseis, onde se observam perfurações preenchidas por argila, Skolithos preenchidos por calcita e perfurações com menisco assimétrico.

I) Pacote com aproximadamente $2 \mathrm{~m}$ de espessura, composto por camadas de espessura decimétrica de arenito fino, ora com laminação plano-paralela, ora com estrutura maciça. A transição de arenito com estratificação plano-paralela para o arenito maciço parece ser gradacional. A passagem do arenito maciço para o arenito com estratificação plano-paralela parece ser abrupta. Nos níveis de arenito maciço ocorrem icnofósseis, semelhantes à icnofábrica anterior. No topo da sequência aparece uma perfuração com um único menisco, aparentemente invertido. $\mathrm{Na}$ base é cortado por outro icnofóssil. Também ocorrem lentes de espessuras decimétricas e com alguns metros de largura de arenito fino com forte cimentação carbonática. 
J) Inicia-se por contato erosivo, apresentando na base um conglomerado polimítico semelhante aos anteriores. Passa para uma sequência de arenito grosso, mal selecionado com grãos angulosos, apresentando conjuntos de estratificações cruzadas de grande porte. $\mathrm{Na}$ base de cada conjunto, que tem espessura de aproximadamente $50 \mathrm{~cm}$, aparecem níveis de seixos centimétricos, polimíticos e arredondados. Há seixos maiores que correspondem a intraclastos de argila (argilito). Ocorrem possíveis coprólitos no nível conglomerático de um dos primeiros conjuntos de estratificações cruzadas. Também foram encontrados rolados alguns fragmentos ósseos e de casco de tartaruga. Acima desse pacote ocorre solo.

\section{Materiais e Métodos}

As amostras avaliadas neste estudo provêm de duas localidades do Município de Uberaba (Fig. 3, 4 e 5). Em campo, a coleta das amostras foi realizada em duas etapas entre os anos de 2010 e 2011, no Ponto 1 do Sítio Paleontológico de Peirópolis (Caieira: 1943’44’S e

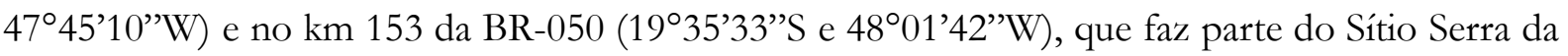
Galga. Foram obtidas 300 amostras do Ponto 1, em Peirópolis. Os espécimes encontravam-se, na maioria das vezes, ex situ na base do afloramento. Na BR-050, 40 espécimes foram coletados in situ em três pontos, depositados em rochas conglomeráticas, aparentemente representando paleocanais.

O estado de conservação dos coprólitos varia desde fragmentos quebrados a massas fecais aparentemente inteiras. Devido à fragilidade e raridade do material, foram necessários procedimentos de preparação que possibilitaram o máximo de preservação (Amstutz 1958; Häntzschel et al. 1968). Desta forma, a preparação consistiu principalmente da retirada da matriz de arenito que envolvia os fósseis. Logo após tratadas, as amostras foram tombados na coleção científica com número de registro FUP-000001 a FUP-000340.

A técnica de difratometria de raios-X foi aplicada em 14 amostras (FUP-000002, FUP000005, FUP-000128, FUP-000144, FUP-000145, FUP-000154, FUP-000156, FUP-000159, FUP-000175, FUP-000204, FUP-000282, FUP-000325, FUP-000328 e FUP-000333), selecionadas especificamente para representar toda a gama de tamanhos, forma, densidade e estado de preservação, e enviadas para o Laboratório de Difração de Raios-X da Universidade de Brasília. A descrição dos coprólitos consistiu na determinação dos caracteres morfológicos e morfométricos seguindo os trabalhos de Thulborn (1991) e Hunt et al. (1994). Durante essa etapa, a análise dos aspectos macroscópicos e tafonômicos foi realizada sob microscópio 
estereoscópico (Opton). As medidas de comprimento e largura foram tomadas com um paquímetro (Mitutoyo) e o peso aferido com uma balança digital de precisão (Diamond). Adicionalmente, também foram mensurados espessura, volume e densidade de cada amostra (Jepsen 1963). Por fim, diversas características presentes, tais como fraturas, perfurações, rachaduras, desgaste, presença ou marcas de seixos foram anotadas.

Com base nos caracteres morfológicos, os coprólitos foram agrupados em diferentes morfotipos (Chin 2002; Souto 2003; Eriksson et al. 2011; Owocki et al. 2012). Todas as informações coletadas foram compiladas numa base de dados no software Calc do pacote LibreOffice (The Document Foundation). Para cada parâmetro morfométrico foram calculados a média e desvio padrão. Adicionalmente, todos os gráficos foram plotados no software QtiPlot (Vasilief 2011), e os desenhos criados no Inkscape e Gimp. Todos os softwares citados foram utilizados no sistema operacional Debian GNU/Linux.

A tafonomia possui natureza interdisciplinar, envolvendo processos geológicos, biológicos, ecológicos e paleontológicos (Azevedo 2012), onde processos de preservação afetam a informação no registro fossilífero (Behrensmeyer and Kidwell 1985). Avaliando os coprólitos dos sítios Peirópolis e Serra da Galga, observamos que muitos apresentavam diferentes estágios de desgaste (Fig. 6) e muitos continham seixos ou marcas de seixos. Com base nas observações, os coprólitos foram agrupados em seis estágios, de acordo com a abrasão: Estágio 0, amostra sem nenhum indício de abrasão com rachaduras profundas e ausência ou presença de seixos; Estágio 1, indício de abrasão com rachaduras ainda profundas, ausência ou presença de seixos ou marcas de seixos; Estágio 2, indícios de abrasão com rachaduras mais rasas, ausência ou presença de seixos ou marcas de seixos; Estágio 3, indícios de abrasão com rachaduras muito suaves ou ausentes, mas ainda mantendo a forma básica do morfotipo, ausência ou presença de seixos ou marcas de seixos; Estágio 4, abrasão em estágio avançado, com amostra quase arredondada ou facetada, ausência ou presença de seixos bem polidos ou marcas de seixos; Estágio 5, amostra totalmente arredondada ou facetada e ausência total de seixos ou marcas de seixos.

Em alguns casos foi possível observar uma diferença na quantidade e profundidade de rachaduras de ressecamento, em cada lado do coprólito. Aventada a possibilidade de ter relação com um efeito tafonômico, foi realizado um experimento em campo com fezes recentes de bovino (Bos taurus). Durante o mês de agosto de 2014, período de seca no bioma Cerrado onde se registram altas temperaturas, fezes que acabaram de ser expelidas pelo gado no pasto foram monitoradas por 20 dias. Os principais objetivos foram observar a formação de rachaduras e a influência do substrato nas fezes. Após este período as fezes foram recolhidas para comparação com os coprólitos e fotografadas. Adicionalmente, também foram obtidos registros fotográficos 
de fezes de algumas espécies de mamíferos do Cerrado, depositadas em diferentes tipos de substratos.

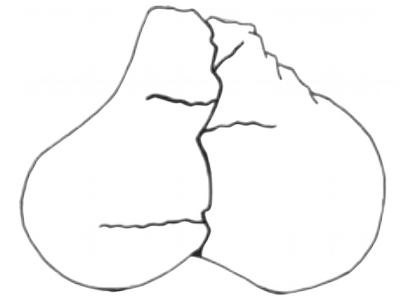

Stage 0

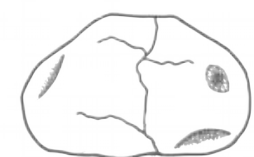

Stage 3

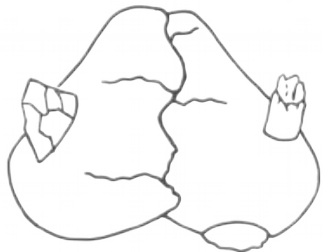

Stage 1

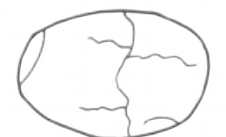

Stage 4

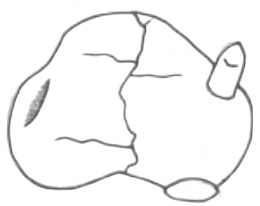

Stage 2

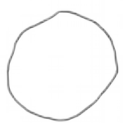

Stage 5

Figura 6. Esquematização da amostra FUP-000125, evidenciando os seis estágios de abrasão dos coprólitos dos sítios Peirópolis e Serra da Galga, Uberaba, Minas Gerais, Brasil. O coprólito em questão é do Estágio 0, e os demais desenhos são meramente ilustrativos. Sem escala. Desenho por Bruno Cezarotti Padilha.

Por fim, foram obtidos $2 \mathrm{~cm}^{3}$ do interior de três amostras (FUP-000145, FUP-000156 e FUP-000195) que foram submetidas a uma preparação palinológica com as seguintes etapas: $\mathrm{HCl}$ 10\%; HF 40\%; tamisação; e coloração. Após secagem na estufa foram montadas duas lâminas de cada amostra e observadas em microscópio óptico.

\section{Resultados e Discussão}

\subsection{Sobre a natureza orgânica das amostras}

Francischini et al. (2016) avaliaram 16 amostras do Ponto 1 em Peirópolis. Os espécimes foram descritos macroscopicamente, mas apenas duas amostras (CPPLIP-0101 e CPPLIP-0443) foram selecionadas para petrografia e difração de raios-X e uma (CPPLIP-1083) foi submetida à tomografia computadorizada. Estes autores não consideraram o material como coprólitos verdadeiros por apresentar morfologia irregular, ausência de marcas de adesão, sulcos ou evidência de coprofagia. Além disso, também consideraram a presença de grãos minerais, ausência de fosfato na composição química dos exemplares analisados e ausência de sinais de conteúdo não digerido ou aberturas internas como indicativo da origem inorgânica das amostras analisadas. 
De fato, das 340 amostras aqui analisadas 141 apresentam caracteres incomuns para coprólitos como formato irregular, com projeções e reentrâncias mais pronunciadas e grande quantidade de grãos minerais. Também foi observado que essas amostras reagem em contato com ácido clorídrico e, principalmente, possuem densidade consideravelmente mais elevada, acima de 1,8 g/ $\mathrm{cm}^{3}$ (Fig. 7). Além disso, também não apresentam marcas de ressecamento e nem os icnofósseis reportados por Francischini et al. (2016). A difração de raios-X de algumas amostras com essas características citadas (FUP-000002, FUP-000005, FUP-000175 e FUP000333) revelaram composição carbonática. Estes resultados sugerem que, de fato, essas amostras não são coprólitos. Desta forma, foram estabelecidos alguns critérios para identificar, com certa segurança, um pseudocoprólito: forma irregular (presença de projeções e reentrâncias muito irregulares), composição carbonática e densidade maior que $1,8 \mathrm{~g} / \mathrm{cm}^{3}$. Neste caso, a origem desse material pode estar relacionada com os calcretes do Membro Ponte Alta ou a processos de maior cimentação carbonática de sedimentos erodidos do próprio Membro Serra da Galga.

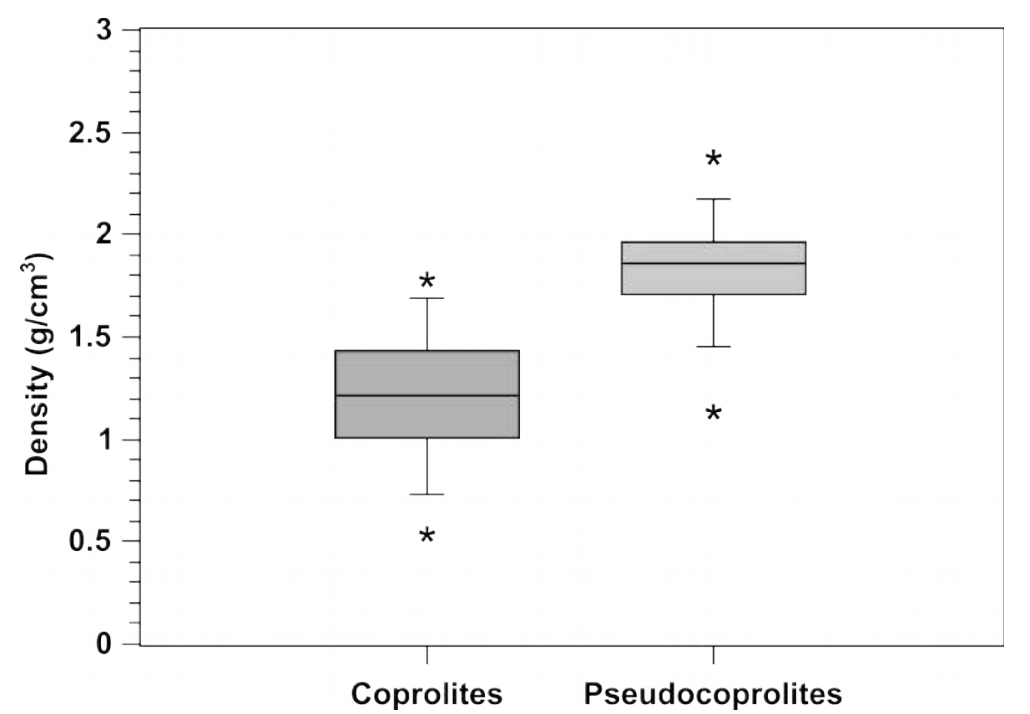

Figura 7. Boxplot da variação de densidade de coprólitos e pseudocoprólitos encontrados nos sítios Peirópolis e Serra da Galga, Município de Uberaba, Minas Gerais, Brasil. No eixo x estão representados os dois grupos de amostras (Coprólitos, $\mathrm{n}=199$; Pseudocoprólitos, $\mathrm{n}=141$ ). As linhas centrais indicam a mediana e divide a metade inferior e superior das amostragens, os retângulos indicam o quartil, as linhas verticais representam os valores mínimo e máximo (whisker) e, por fim, os asteriscos indicam os valores extremos (outliers).

As demais 199 amostras são consideradas coprólitos por apresentarem: 1) rachaduras de ressecamento; 2) uma massa homogênea no interior; 3) densidade baixa, algumas vezes menor que a da água (Fig. 7); 4) marcas de adesão, variando de grãos de areia a seixos ou moldes de seixos; 5) restos vegetais não digeridos. Especificamente, com relação às marcas de ressecamento, observa-se em alguns coprólitos que estas são mais desenvolvidas na porção superior (em contato direto com o ar) do que na base (em contato com o substrato). Isso ocorre devido à diferença na velocidade de ressecamento das duas superfícies. Nós encontramos um padrão semelhante 
observando fezes recentes de bovinos (Bos taurus), espécie que se alimenta de gramíneas. Após um período de 20 dias em exposição ao ambiente seco, houve diferença entre as marcas da porção superior e da base, em contato com o substrato (Fig. 8). Também observamos que essas fezes quando secas, reduziram de tamanho e apresentam densidade semelhante aos coprólitos. Ademais, a difração de raios-X mostrou que na composição mineralógica dessas amostras predominam minerais do grupo dos silicatos (como, FUP-000128, FUP-000144, FUP-000145, FUP-000154, FUP-000156, FUP-000159, FUP-000204, FUP-000282, FUP-000325 e FUP000328), resultados semelhantes aos encontrados em outros trabalhos (Souto 2003; Souto and Fernandes 2015).

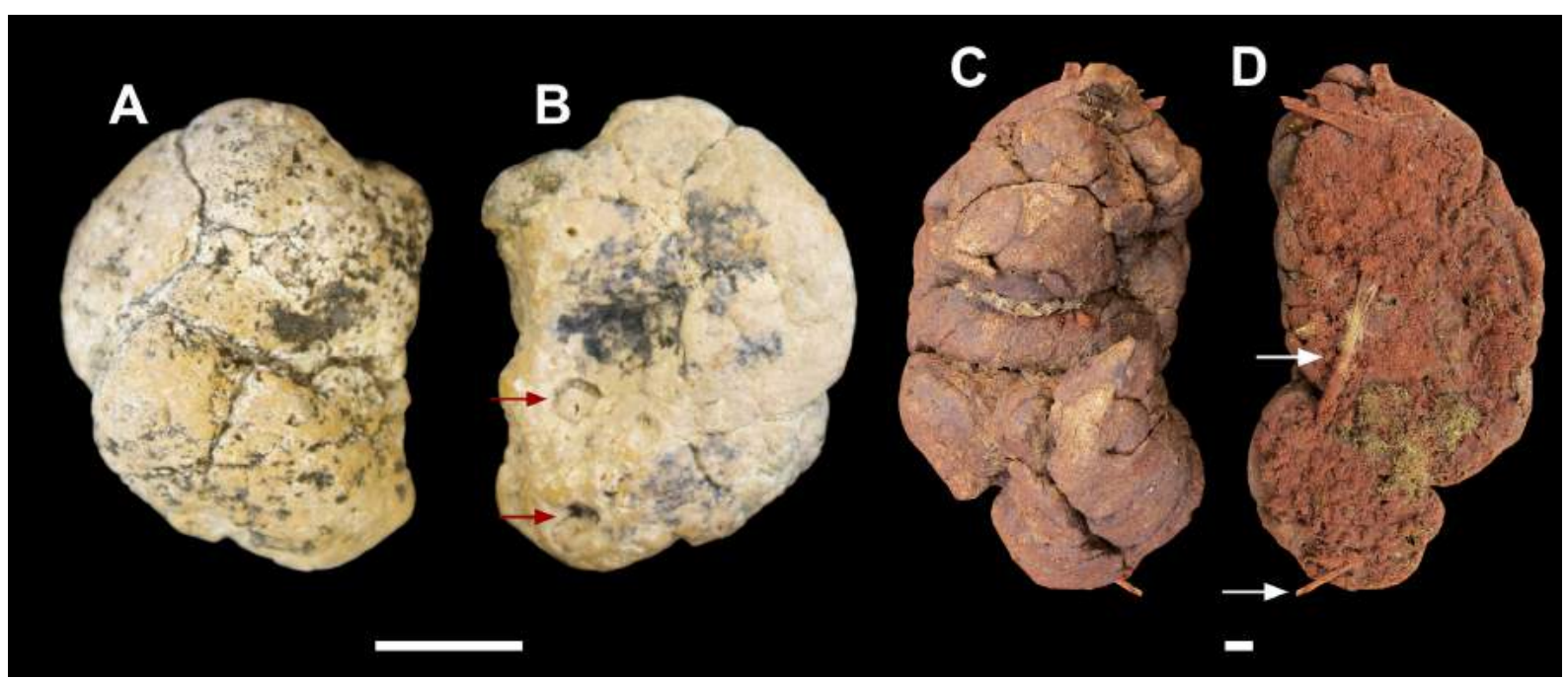

Figura 8. Comparação entre a porção superior (A) e inferior (B) da amostra FUP-000206 com a porção superior (C) e inferior (D) de fezes recente de bovino (Bos taurus). As fezes de bovino ficaram por 20 dias expostas ao meio. A porção superior das amostras (A e C) apresenta maior quantidade de rachaduras de ressecamento. Por outro lado, a porção inferior, (B e D) que fez contato com o solo, apresenta menos rachaduras e exibe marcas de adesão do substrato, indicado pelas setas. Escala $=1 \mathrm{~cm}$.

Adicionalmente, as três amostras processadas para palinologia (FUP-000145, FUP-000156 e FUP-000195) revelaram a presença de matéria vegetal amorfa (cutículas ou fibras vegetais) e palinomorfos (Fig. 9). Por fim, grande parte dos coprólitos apresenta na superfície uma espécie de "brilho gorduroso" (internamente um pó mais aveludado), muitas vezes com superfície bem lisa e suave. A diferença na textura entre coprólitos e a rocha sedimentar pode ser usada na distinção de nódulos inorgânicos e concreções (Thulborn 1991). Este tipo de "brilho gorduroso" encontrado em coprólitos de vertebrados também já foi citado por outros autores (e.g. Friedman 2012). Assim, é possível ter certo grau de certeza com relação à natureza orgânica dessas amostras utilizando algumas características de fácil constatação em campo, como: presença de fraturas de ressecamento, superfície lisa, presença de massa interior homogênea, marcas de seixos e baixa densidade. Ainda, um grau maior de certeza pode ser alcançado, pelo menos em relação 
aos coprólitos produzidos por animais herbívoros, com a análise de seu conteúdo, geralmente apresentando cutículas ou fibras vegetais parcialmente digeridas.

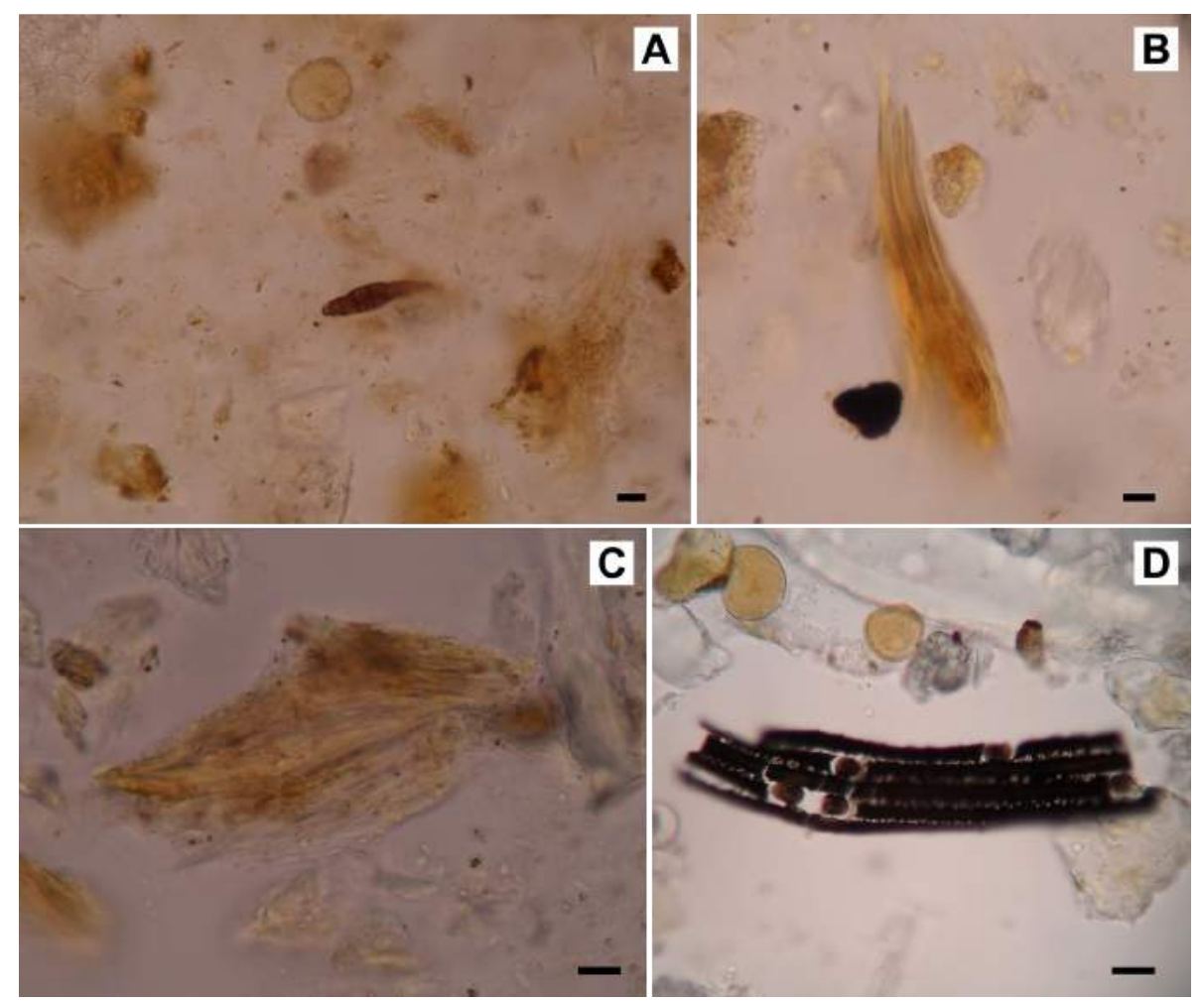

Figura 9. Conteúdo micropaleontológico encontrado nos coprólitos dos sítios Peirópolis e Serra da Galga, Município de Uberaba, Minas Gerais, Brasil. A) Esporo de fungo no centro e acima o marcador exótico Kochia scoparia na amostra FUP-000145; B-C) Possíveis fragmentos vegetais nas amostras FUP-000145 (B) e FUP-000156 (C); D) Possível cutícula vegetal com estômatos e acima grãos de pólen do marcador exótico Kochia scoparia na amostra FUP-000195. Escala $=20 \mu \mathrm{m}$.

\subsection{Descrição dos morfotipos}

Após a avaliação da natureza orgânica das amostras, foi determinado que das 340 amostras coletadas, 141 são pseudocoprólitos e 199 são coprólitos verdadeiros (168 do sítio de Peirópolis e 31 do sítio Serra da Galga), compreendendo um número de diferentes tipos morfológicos, com amostras variando de $8,5 \mathrm{~mm}$ a $9,23 \mathrm{~cm}$ de comprimento. Com base nos caracteres morfológicos, os coprólitos foram subdivididos em quatro morfotipos: cilíndrico, ovoide, cônico e dômico (Fig. 10). Porém, 126 coprólitos foram agrupados na categoria indeterminado por estarem muito fragmentados ou em avançado estado de desgaste, impossibilitando a correta identificação morfológica. As características gerais dos diferentes morfotipos, incluindo os pseudocoprólitos, estão resumidas na Fig. 11. 


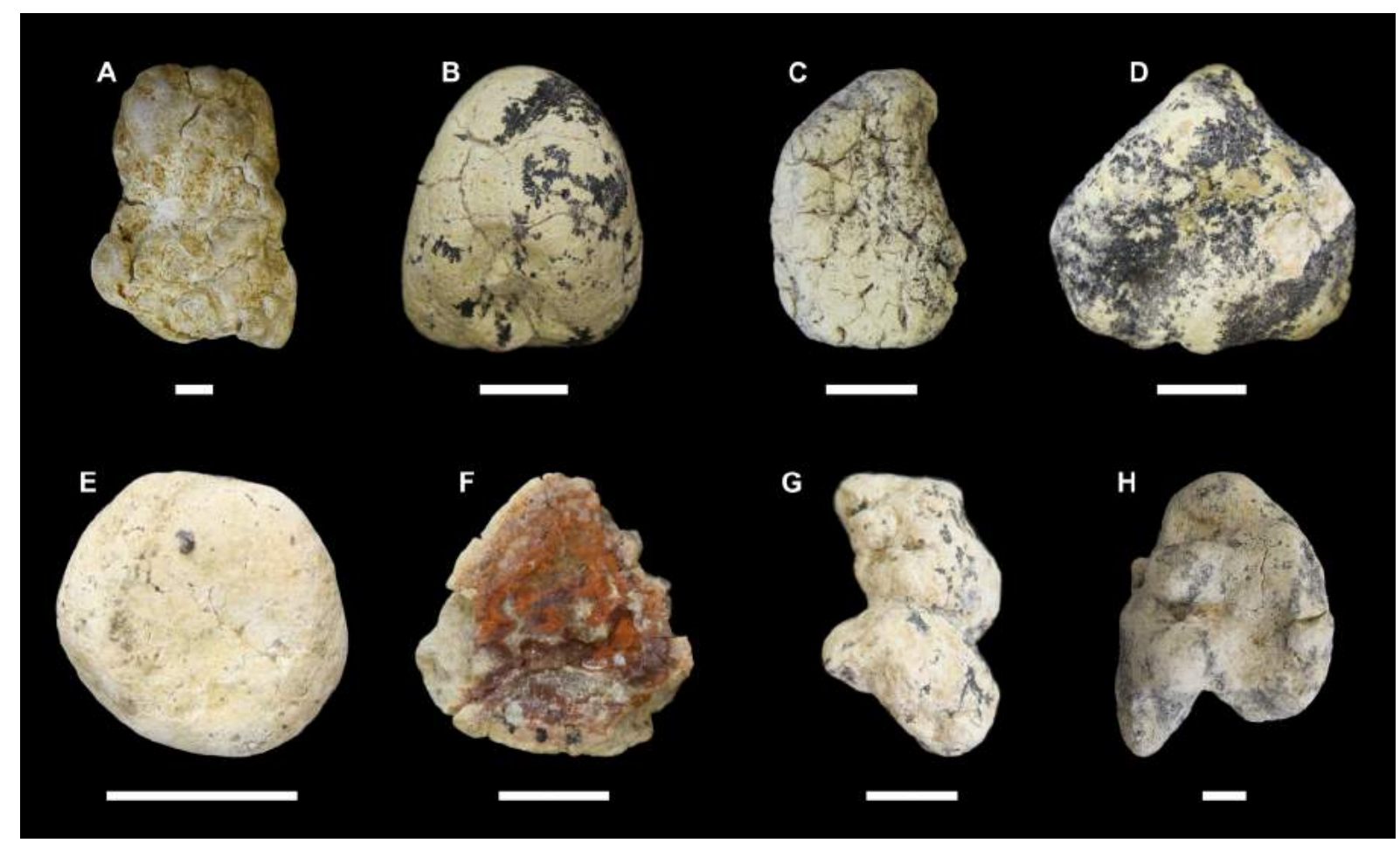

Figura 10. Registro fotográfico dos morfotipos encontrados nos sítios Peirópolis e Serra da Galga, Município de Uberaba, Minas Gerais, Brasil. A) Morfotipo 1 - cilíndrico, FUP-000154; B) Morfotipo 2 - ovoide, FUP-000135; C) Morfotipo 3 - cônico, FUP-000047; D) Morfotipo 4 - dômico, FUP-000145; E-F) Indeterminados - coprólitos em avançado estado de desgaste como FUP-000309 (E), provocando arredondamento das porções polares, e fragmentação como FUP-000134 (F) impossibilitam a correta identificação do morfotipo; G-H) Pseudocoprólitos nódulos carbonáticos inorgânicos como as amostras FUP-000007 (G) e FUP-000167 (H). Escala $=1 \mathrm{~cm}$.

\begin{tabular}{|c|c|c|c|c|c|c|c|c|}
\hline \multirow{2}{*}{ Morphotype } & \multirow{2}{*}{ Morphology } & \multicolumn{2}{|c|}{$\begin{array}{l}\text { Number of } \\
\text { specimens }\end{array}$} & \multirow{2}{*}{$\begin{array}{l}\text { Size range } \\
(\mathrm{cm})\end{array}$} & \multirow{2}{*}{$\begin{array}{l}\text { Thickness } \\
\text { (cm) }\end{array}$} & \multirow{2}{*}{$\begin{array}{l}\text { Weight } \\
\text { (g) }\end{array}$} & \multirow{2}{*}{$\begin{array}{c}\text { Volume } \\
\left(\mathrm{cm}^{3}\right)\end{array}$} & \multirow{2}{*}{$\begin{array}{l}\text { Density } \\
\left(\mathrm{g} / \mathrm{cm}^{3}\right)\end{array}$} \\
\hline & & $A$ & B & & & & & \\
\hline Morphotype 1 & Cylindrical & 14 & 2 & $\begin{array}{l}1.45-8.08 \\
0.92-5.24\end{array}$ & $2.88-16.45$ & $0.69-107.19$ & $0.5-78$ & $0.81-1.77$ \\
\hline Morphotype 2 & Ovoid & 32 & - & $\begin{array}{l}1.16-5.81 \\
0.93-5.35\end{array}$ & $2.92-16.79$ & $0.48-86.93$ & $0.5-50$ & $0.57-1.78$ \\
\hline Morphotype 3 & Conical & 20 & 1 & $\begin{array}{c}1.28-6.5 \\
1.08-4.44\end{array}$ & $3.39-13.94$ & $0.63-82.2$ & $0.8-55$ & $0.78-1.78$ \\
\hline Morphotype 4 & Domical & 4 & - & $\begin{array}{l}1.46-9.23 \\
1.23-7.39\end{array}$ & $3.86-23.20$ & $1.27-201$ & $1.1-140$ & $0.63-1.47$ \\
\hline Indeterminates & - & 98 & 28 & $\begin{array}{l}0.85-6.06 \\
0.66-4.35\end{array}$ & $2.07-13.65$ & $0.11-28.73$ & $0.15-27$ & $0.55-1.79$ \\
\hline Pseudocoprolites & - & 132 & 9 & $\begin{array}{c}1.08-15.5 \\
0.79-12.07\end{array}$ & $2.48-37.89$ & $0.47-1295$ & $0.3-751.5$ & $1.14-2.39$ \\
\hline
\end{tabular}

Figura 11. Características gerais dos coprólitos e pseudocoprólitos dos sítios Peirópolis (A) e Serra da Galga (B), Município de Uberaba, Minas Gerais, Brasil. Na figura são apresentados os valores mínimo e máximo para cada morfotipo. Em dimensões são apresentados comprimento e largura, respectivamente.

Morfotipo 1 - Incluem 16 amostras de forma cilíndrica (Fig. 10A e 11), das quais apenas duas são do sítio Serra da Galga, e são caracterizados por estruturas alongadas que apresentam diâmetro constante em todo seu comprimento. Apresentam extremidades isopolar ou anisopolar, 
com comprimento médio de 3,19 $\mathrm{cm} \pm 1,57$ e largura de 2,15 cm $\pm 1,06$. Quase todos os coprólitos cilíndricos apresentam coloração esbranquiçada ou um pouco amarelada. Apenas as amostras FUP-000161, FUP-000323 e FUP-000327 apresentam uma tonalidade mais bege. Uma amostra cilíndrica (FUP-000154) apresenta calcita na composição.

Morfotipo 2 - Foram encontrados 32 coprólitos ovoides (Fig. 10B e 11) apenas no sítio de Peirópolis. Estas amostras variam de subformas esféricas a oblongas, apresentando as laterais mais convexas. Algumas amostras apresentaram extremidades isopolares, mas a maioria é anisopolar. A superfície das amostras é lisa, algumas são levemente ásperas e, diferentemente do morfotipo anterior, a grande maioria das amostras é de tonalidade amarelada. Adicionalmente, mais de $80 \%$ das amostras apresentaram um "brilho gorduroso". O comprimento médio foi de $2,44 \mathrm{~cm} \pm 1,08$ e a largura de $1,93 \mathrm{~cm} \pm 0,94$.

Morfotipo 3 - Foram encontrados 21 coprólitos de forma cônica (Fig. 10C e 11), que apresentam um afinamento excessivo em uma das extremidades, com razoável estreitamento na porção mediana em alguns casos. Apenas uma amostra é do Sítio Serra da Galga. Todas as amostras deste morfotipo apresentam extremidades anisopolares, com comprimento médio de $2,97 \mathrm{~cm} \pm 1,19$ e largura de 2,32 cm \pm 0,87. Para a coloração também foi encontrado o mesmo padrão que nas amostras anteriores, onde a maioria é amarelada, de superfície lisa ou levemente áspera, em alguns casos. O "brilho gorduroso" está presente na maioria das amostras deste morfotipo. Adicionalmente, a composição de uma amostra cônica (FUP-000144) é basicamente de minerais silicáticos.

Morfotipo 4 - Este morfotipo foi descrito pela primeira vez na Bacia Bauru por Souto (2003), denominado de "esborrado". Neste trabalho utilizaremos o termo dômico (Fig. 10D e 11). Os coprólitos dômicos são resultantes da ingestão de alimento junto com sedimento e água (Souto 2003). Deste morfotipo foram encontradas apenas quatro coprólitos do sítio Peirópolis. Coprólitos dômicos apresentam extremidade anisopolar, comprimento médio de 4,09 $\mathrm{cm} \pm 3,53$ e largura de 3,44 \pm 2,76. Comparado aos demais morfotipos, o elevado desvio padrão ocorreu porque a amostra FUP-000156 apresenta dimensão bem superior às demais. Quanto à coloração, este morfotipo apresenta padrão semelhante aos demais, com tonalidade amarelada, textura lisa e presença de "brilho gorduroso". A composição das amostras FUP-000145 e FUP-000156 revelam a presença de minerais silicáticos, incluindo quartzo. 
Indeterminados - nesta categoria foram anotadas 126 amostras, representando quase $65 \%$ dos coprólitos. Esta categoria abrange as amostras muito fragmentadas ou em avançado estado de abrasão (Fig. 10E-F e 11), impossibilitando uma avaliação morfológica precisa. As extremidades também não puderam ser determinadas. O comprimento médio foi $2,31 \mathrm{~cm} \pm 0,86$ e largura de $1,79 \pm 0,69$. A textura dos coprólitos também foi muito semelhante aos demais, a grande maioria de superfície lisa e algumas levemente ásperas. Entretanto, o "brilho gorduroso" está presente em 54 amostras. Normalmente, amostras em desgaste avançado não apresentam o "brilho gorduroso".

Pseudocoprólitos - Estas amostras geralmente apresentam forma bastante irregular. Entretanto, algumas podem ser mais semelhantes aos morfotipos descritos anteriormente (Fig. 10G-H e 11), mas uma análise mais apurada revela características não observadas nos coprólitos, especialmente pela composição carbonática. O total encontrado foi de 141 amostras de comprimento médio $3,53 \mathrm{~cm} \pm 1,76$ e largura de 2,78 \pm 1,4. Diferentemente dos coprólitos verdadeiros, muitos pseudocoprólitos apresentam superfície com textura áspera. Algumas amostras são amareladas, mas a maioria é esbranquiçada ou bege. Os pseudocoprólitos apresentam composição rica em carbonato de cálcio, reagindo fortemente ao $\mathrm{HCl} \mathrm{10 \%} \mathrm{e} \mathrm{geralmente} \mathrm{apresentam} \mathrm{uma} \mathrm{densidade}$ mais alta que os coprólitos verdadeiros.

Os coprólitos do Morfotipo 2 foram os mais frequentes e representaram, aproximadamente, $45 \%$ das amostras, considerando apenas os quatro morfotipos. Normalmente, no registro fóssil de coprólitos, ocorre dominância dos produzidos por carnívoros. Entretanto, na região do Triângulo Mineiro ocorre dominância de coprólitos ovoides, que podem ter sido produzidos por animais de dieta herbívora (Souto 2003) e podem pertencer a diferentes grupos como anfíbios, répteis, aves e mamíferos (Murie 1974; Halfpenny and Biesiot 1986). Segundo Souto (2003) o Morfotipo 3 é associado a animais de dieta onívora, enquanto o Morfotipo 4 está relacionado a dinossauros saurópodes de menor porte e quelônios.

Em diversos casos, os coprólitos do Morfotipo 1 podem ser associados a organismos de origem marinha (Souto 2003; Eriksson et al. 2011). Entretanto, os sedimentos siliciclásticos da Formação Marília foram depositados por sistemas de rios entrelaçados e de leques aluviais (Fernandes 2004; Ribeiro and Carvalho 2009), onde ocorreu uma fauna de inúmeros táxons continentais (Candeiro et al. 2004). No Grupo Bauru os coprólitos do Morfotipo 1 têm sido associados a animais de dieta carnívora, como os crocodilomorfos (Souto 2003). Somente na região de Uberaba foram encontrados os crocodilomorfos Itasuchus jesuinoi (Price 1955), 
Peirosaurus tormini (Price 1955) e Uberabasuchus terrificus (Carvalho et al. 2004). Adicionalmente, fósseis de diversos grupos foram encontrados em sedimentos da Formação Marília, no Triângulo Mineiro. Dentre eles encontram-se os anfíbios Baurubatrachus pricei (Báez and Peri 1989) e Uberabatrachus carvalhoi (Báez et al. 2012), o iguanídeo Pristiguana brasiliensis (Estes and Price 1973), a tartaruga Cambaremys langertoni (França and Langer 2005), dinossauros terópodes Abelisauridae e Carcharodontosauridae e os saurópodes Baurutitan britoi, Trigonosaurus pricei e Uberabatitan ribeiroi (Campos et al. 2005; Candeiro 2005a; Kellner et al. 2005; Salgado and Carvalho 2008). Desta forma, é provável que os coprólitos encontrados pertençam a diferentes grupos de vertebrados, justificando a elevada abundância e variação morfométrica. O Morfotipo 4 é associado a animais de grande e pequeno porte (Souto 2003), o que justifica o valor mais discrepante observado no desvio padrão (veja na descrição do Morfotipo 4), que deve representar uma variabilidade inerente dos elementos da paleofauna que habitou a região.

\subsection{Tafonomia}

Uma vez depositado, dois fatores essenciais para a preservação de coprólitos são o soterramento e litificação rápida (Eriksson et al. 2011). Estes icnofósseis podem ser facilmente transportados por agentes naturais, como a água (Thulborn 1991). Alguns detalhes observados na superfície dos coprólitos auxiliaram no entendimento dos processos tafonômicos que atuaram na deposição desses fósseis. Grande parte dos coprólitos apresentou fragmentação, em maior ou menor escala. Entretanto, matéria fecal completa raramente é preservada no registro fóssil (Hunt et al. 1994). A maioria dos coprólitos apresentou na superfície uma espécie de "brilho gorduroso", conforme já relatado anteriormente. Dos 199 coprólitos, 110 apresentam rachaduras na sua superfície, geradas por ressecamento. Observa-se, em diversos casos, que as rachaduras de ressecamento se desenvolvem mais na superfície que ficou inicialmente voltada para cima do que aquela que esteve em contato com o substrato, mais plana (Fig. 8A-B). Este mesmo processo pode ser observado em fezes de animais recentes (Fig. 8C-D), sugerindo que os coprólitos foram primeiramente depositados em terra firme, onde posteriormente se formaram rachaduras do tipo dessecação. Isso deve ter ocorrido pela diferença na taxa de ressecamento entre a parte que estava em contato com o solo e sua superfície exterior, a qual perde muito mais umidade. Por outro lado, 15 coprólitos apresentam avançado estado de desgaste (Estágios 4 e 5), o que pode ter eliminado possíveis rachaduras que estiveram presentes. A preservação das fezes depende de 
vários fatores como a composição e consistência da matéria fecal, o tipo de ambiente deposicional e o grau de alteração diagenética (Hunt et al. 1994; Chin et al. 2003).

Experimentos com fezes atuais indicam que as rachaduras surgem após longo período de exposição (Vogeltanz 1965). Aparentemente, fezes desidratadas podem ser friáveis e facilmente destruídas pelo vento, chuva ou organismos coprófagos. Entretanto, em alguns casos, as fezes podem durar anos expostas (Thulborn 1991). Desta forma, a presença de rachaduras na superfície sugere que parte dos coprólitos aqui avaliados passaram por certo período de exposição subaérea. Em estado fresco é pouco provável que o material resistiria ao processo de transporte. Após desidratadas as fezes podem ter endurecido e se comportado como seixos, sendo transportadas e soterradas (Thulborn 1991). Adicionalmente, quase todas as rachaduras encontradas eram do tipo dessecação e apenas três do tipo sinerese (Fig. 12). Diferente das rachaduras de dessecação, o tipo sinerese se caracteriza por fendas distribuídas ao redor do coprólito e indica deposição em condições subaquosas, reforçando a ideia que o paleoambiente apresentava certa umidade ou presença de corpos d'água por, pelo menos, certos períodos de tempo (Souto 2003).

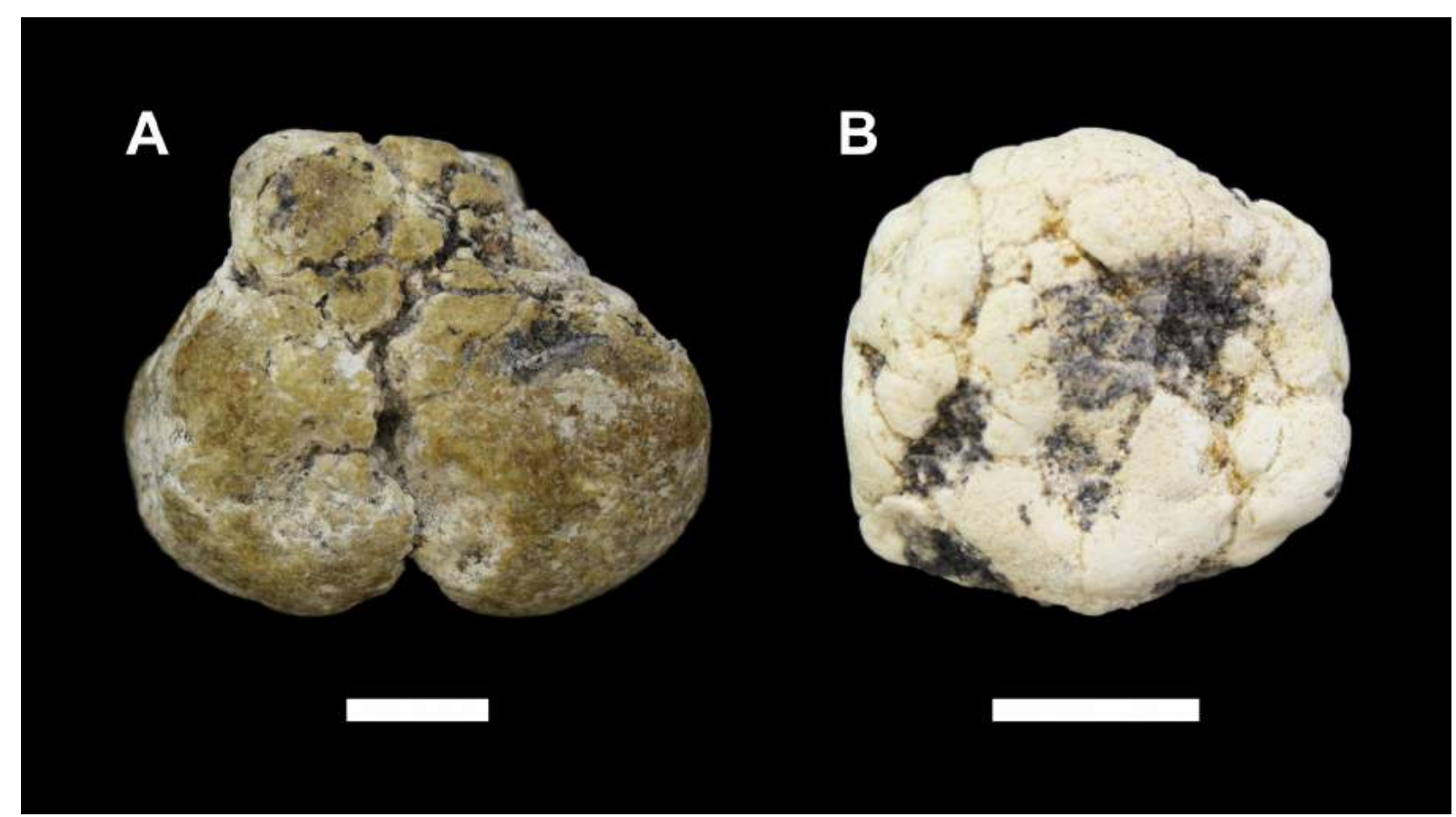

Figura 12. Padrão de rachaduras encontradas nos coprólitos dos sítios Peirópolis e Serra da Galga, Uberaba, Minas Gerais, Brasil. Rachaduras de ressecamento ou dessecação na amostra FUP-000125 (A) e do tipo sinerese na amostra FUP-000103 (B). Escala $=1 \mathrm{~cm}$.

Considerando agora os estágios de abrasão, dos 168 coprólitos encontrados no Sítio Peirópolis apenas 17 parecem não ter sofrido desgaste, evidenciando material inteiro (Estágio 0). Os demais 151 coprólitos apresentam algum grau de desgaste, sobretudo pelo arredondamento 
das porções polares. No mesmo nível dos coprólitos foram encontrados fragmentos de ossos e seixos tabulares dispersos caoticamente em meio a matriz arenosa (Fig. 4A-2), indicando deposição aluvial para algumas das camadas do afloramento. Por outro lado, no Sítio Serra da Galga não foram encontrados coprólitos do Estágio 0. Neste caso, os 31 coprólitos possuem diferentes graus de desgaste que, diferente do Sítio Peirópolis, apresentam facetas de desgaste. Nos níveis onde ocorrem os coprólitos também foram encontrados fragmentos ósseos e de carapaças de quelônios. Os seixos tabulares e os coprólitos estavam dispostos horizontalmente (Fig. 4B-2), indicando deposição fluvial.

Os coprólitos desgastados apresentaram diferentes estágios de abrasão. Existe relação entre o desgaste e grau de preservação. Expressando graficamente a abundância de coprólitos por estágio de abrasão, observa-se que os coprólitos inteiros foram encontrados em menor quantidade (Fig. 13A). Em seguida, há um significativo aumento dos coprólitos dos estágios 2 e 3. Logo após, os valores reduzem significativamente nos estágios seguintes, ilustrando que os coprólitos que sofreram maior transporte tiveram menor probabilidade de chegar ao local do afloramento. O gráfico de porcentagem, em relação ao quantitativo de amostras em cada sítio, demonstra que os coprólitos do Sítio Serra da Galga parecem ter sofrido mais transporte que os coprólitos do Sítio Peirópolis (Fig. 13B).
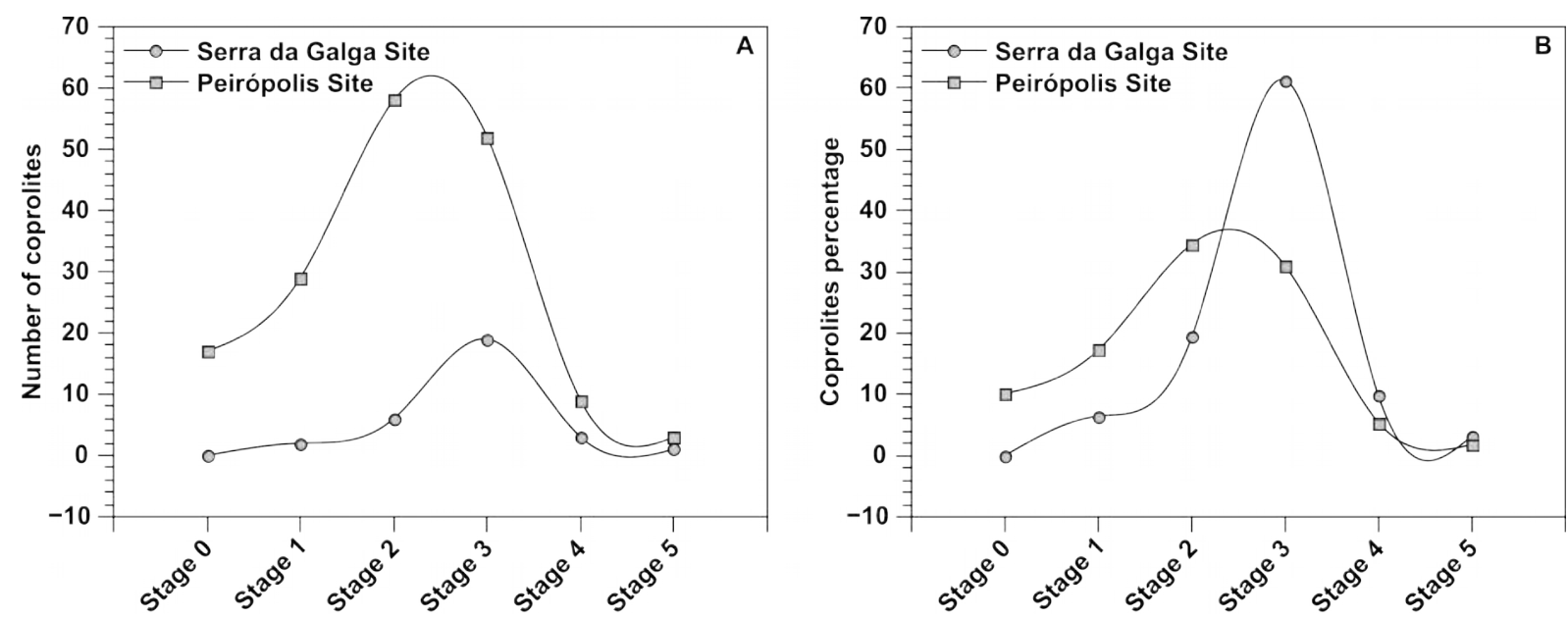

Figura 13. Variação dos valores de abundância (A) e porcentagem (B) por estágio de abrasão dos coprólitos dos sítios Peirópolis e Serra da Galga, Uberaba, Minas Gerais, Brasil. Notar que o maior número de coprólitos do Sítio Peirópolis pertence ao Estágio 2, enquanto que no Sítio Serra da Galga pertencem ao Estágio 3.

Quanto às assinaturas tafonômicas, as 17 amostras do Sítio Peirópolis do Estágio 0 apresentam rachaduras de ressecamento profundas e nove delas, aparentemente, não exibem fragmentação (Fig. 14A-B), indicando que são amostras preservadas inteiras. Estes resultados sugerem pouco ou nenhum transporte destes coprólitos até a área fonte, onde se localiza o afloramento. Por outro lado, uma característica a ser ressaltada é a presença de seixos de quartzo 
de coloração escura (ou moldes destes), aderidos em 86 coprólitos (Fig. 14C). Entretanto, todos os coprólitos que continham seixos também apresentavam algum estágio de desgaste. Em diversos casos, coprólitos e seixos estavam desgastados (Fig. 14C). Os resultados indicam dois cenários distintos onde, em princípio, as fezes foram depositadas.

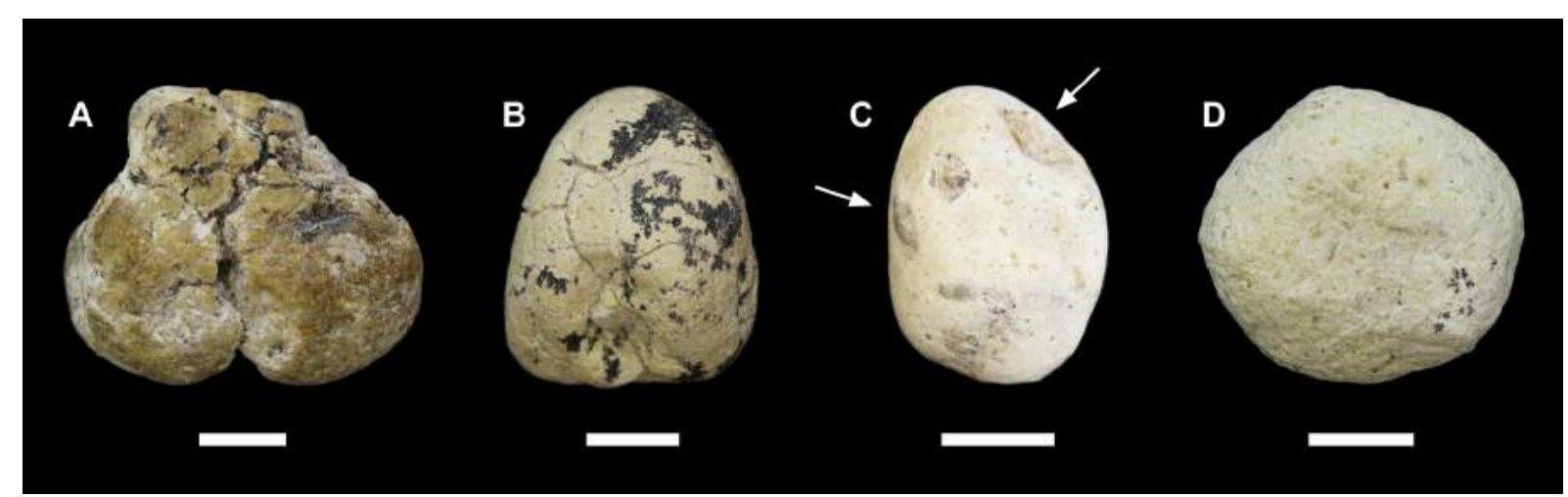

Figura 14. Principais características observadas nos coprólitos dos Sítios Peirópolis e Serra da Galga, Membro Serra da Galga, Formação Marília, Minais Gerais. A-B) coprólitos inteiros, aparentemente sem quebras e com rachaduras profundas, evidenciado que não houve desgaste nas amostras FUP-000125 (A) e FUP-000135 (B); C) coprólito desgastado com seixos de quartzo incrustados e molde de seixo (setas), onde observa-se que o seixo também está desgastado na amostra FUP-000227; D) coprólito arredondado sem rachaduras superficiais, provavelmente em função do desgaste na amostra FUP-000126. Escala $=1 \mathrm{~cm}$.

Quando as fezes são expelidas, assim que entram em contato com o substrato, podem ficar com a marca do local onde tocaram o substrato. Observamos que fezes recentes de mamíferos podem apresentar marcas de adesão ou partículas (grãos de areia, seixos ou restos vegetais) encravadas, de acordo com as características do local em que são expelidas (Fig. 15). Desta forma, os seixos, ou moldes destes, presentes nos coprólitos indicam um ambiente terrestre de deposição (Northwood 2005), neste caso com maior quantidade de seixos e diferente do local onde foram encontrados (arenito com estratificação cruzada). Ademais, oito coprólitos apresentam apenas marcas de seixos na superfície. Estas amostras apresentam avançado estágio de desgaste, sugerindo que os seixos podem ter se desprendido dos coprólitos durante o transporte, ou que as marcas sejam do substrato em que as fezes foram excretadas. Diversos coprólitos exibem quebras ou desgaste mais avançado, provavelmente devido ao transporte, que pode ter eliminado completamente o indício de seixos (Fig. 14D). 

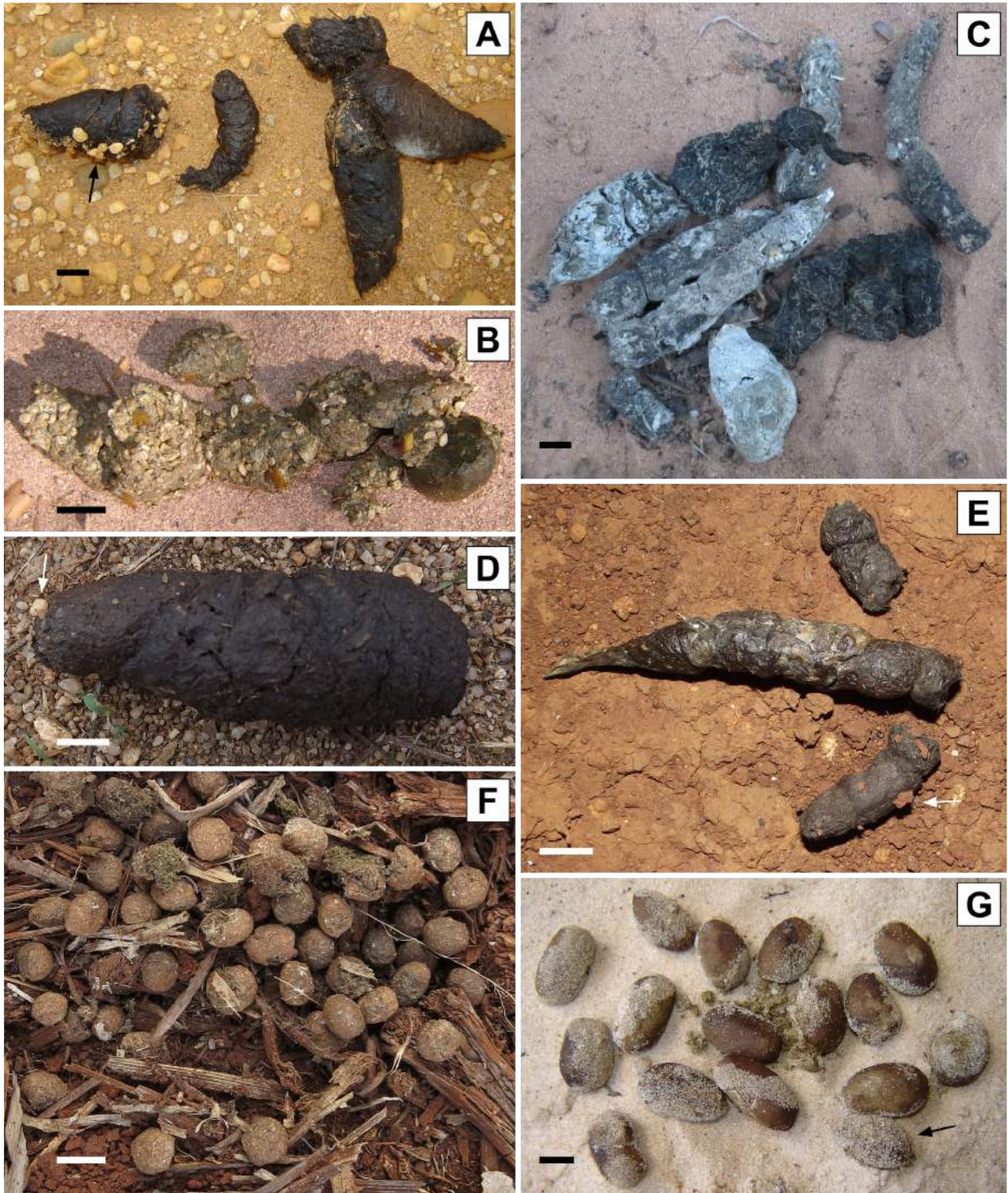

Figura 15. Fezes recentes de mamíferos depositadas em diferentes tipos de substratos. Note como as partículas presentes no substrato podem ficar aderidas ou deixar moldes nas fezes. A-B) Fezes de Chrysocyon brachyurus (loboguará) depositadas em local cascalhoso (A) e arenoso (B); C) Fezes de Puma concolor (suçuarana) depositada em local arenoso; D) Fezes de Cerdocyon thous (cachorro-do-mato) depositada em local cascalhoso, com seta indicando seixo aderido às fezes; E) Fezes de Puma yagouaroundi (gato-mourisco) com seta indicando fragmento de solo aderido; F) Fezes de Sylvilagus brasiliensis (tapiti) depositadas entre restos de milharal; G) Fezes de Hydrochoerus bydrochaeris (capivara) envoltas por grãos de areia. As imagens são do acervo da Biota Projetos e Consultoria Ambiental. Fotos A, B, D, E e G por Fábio Antônio de Oliveira e fotos C e F por Camila Castro de Araújo. Escala $=1 \mathrm{~cm}$.

Avaliando todos os resultados de forma integrada, do total de 199 coprólitos analisados apenas 17 não apresentam evidências de abrasão. Destes, nove estavam, aparentemente, inteiros e 
oito apresentam algum grau de fragmentação. Coprólitos da Formação Adamantina também podem exibir quebras parciais ou estarem totalmente fragmentadas (Brandt-Neto et al. 1992; Souto 2003). Todos estes coprólitos sem evidência de abrasão são do Sítio de Peirópolis, que é representado por arenito fino a grosso esbranquiçado, com baixa presença de seixos de quartzo (Azevedo 2012). Coprólitos com estas características não foram observados no Sítio Serra da Galga. É interessante observar que os coprólitos do afloramento em Peirópolis parecem ter sofrido menos transporte do que aqueles do sítio Serra da Galga (vide Fig. 13B), que estavam em canal fluvial. Desta forma, a presença de rachaduras muito profundas, a completa ausência de desgaste e ausência de seixos ou marcas de seixos encravados nestes coprólitos sugere pouco transporte para parte desse material. Assim, este contexto sedimentar não explica a presença ou marcas de seixos encontradas em 86 coprólitos.

As rachaduras muito profundas nos coprólitos, provavelmente, foram produzidas em condições de ambiente com elevada temperatura e baixa umidade (Souto 2003), caracterizando certa aridez. Por outro lado, a presença de alguns coprólitos com rachaduras do tipo sinerese sugerem maior umidade. Abaixo do nível dos coprólitos ocorrem icnofósseis tubulares sugerindo a presença de um meio aquoso onde os coprólitos podem ter sido depositados em momentos climáticos distintos, relacionado com os tipos de rachaduras observadas. De fato, o contexto deposicional onde os fósseis ocorrem é citado como arenitos depositados em inundações após longos períodos de seca (Ribeiro and Carvalho 2009).

Nossa análise sedimentológica do afloramento mostra que esses coprólitos estão contidos essencialmente em arenitos conglomeráticos suportados por matriz arenosa mal selecionada, com estratificação cruzada tabular a acanalada e com seixos dispostos de forma caótica na matriz, indicando que se trata, entre outros, de depósitos de leques aluviais. Diversos coprólitos apresentam evidências de rolamento, produzindo o arredondamento das porções polares. $\mathrm{O}$ mesmo padrão foi observado por Souto (2003) em coprólitos da mesma formação. Os dados sugerem que esses coprólitos foram produzidos em local onde o substrato era constituído de seixos, ao contrário do local onde os mesmos foram coletados. Além disso, grande parte dos coprólitos apresenta desgaste, alguns em avançado estágio de arredondamento ou facetamento. Esses resultados demonstram que houve transporte de coprólitos a partir da área fonte até o local onde hoje se encontra o afloramento, representando deposição alóctone (Fig. 16). 


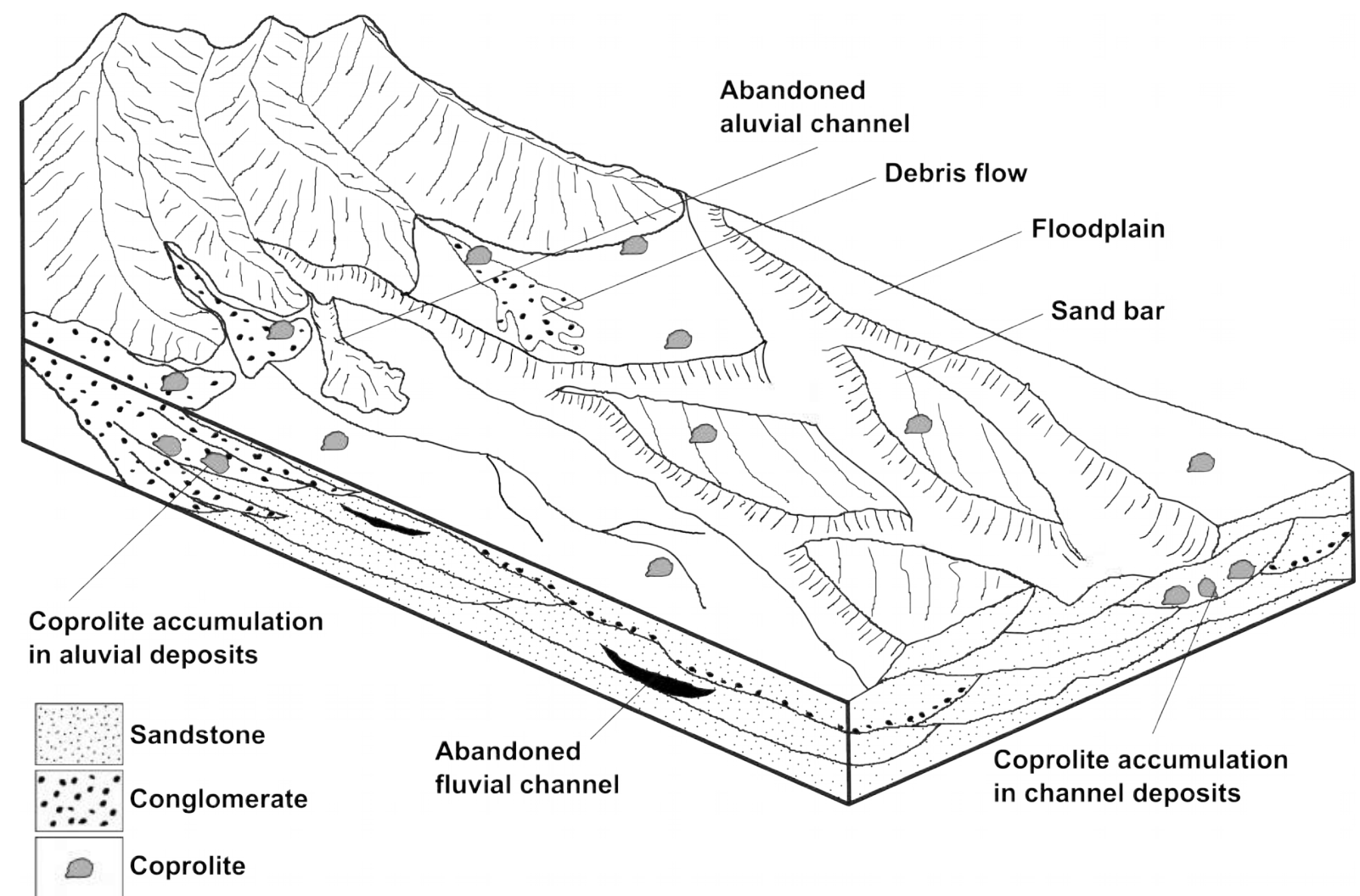

Figura 16. Esquema de transporte de coprólitos até os afloramentos dos sítios Serra da Galga e Peirópolis, Membro Serra da Galga, Formação Marília. Podendo haver produção de fezes em substrato de seixos seguido de ressecamento por longo tempo de exposição, onde o material se acumula em ambiente subaéreo e é transportado por leques aluviais (Sítio Peirópolis); ou produção e acumulação de fezes também em ambiente subaéreo e transporte por fluxo aquoso, com preservação em depósitos de canais fluviais (Sítio Serra da Galga).

Conforme já citado, os sítios paleontológicos Peirópolis e Serra da Galga apresentam uma das mais ricas faunas de vertebrados e invertebrados do Cretáceo brasileiro (Ribeiro and Carvalho 2009), com grande destaque para crocodilomorfos e dinossauros. Vasconcellos and Carvalho (2006) demostraram que o holótipo de Uberabasuchus terrificus seria autóctone com notável preservação, evitando a desarticulação. Porém, outros autores atentam que exemplares bem preservados e articulados são mais raros, e a maioria dos registros é de material fragmentado (Souto and Magalhães-Ribeiro 1999; Azevedo 2012). Todos os fósseis dos sítios foram depositados junto com os coprólitos analisados neste estudo. Contudo, se a maioria dos coprólitos encontrados representa um evento de deposição alóctone, apresentando tanto mistura temporal como espacial, como apontam as evidências, é de se esperar que os demais fósseis encontrados nesses afloramentos também tenham histórias tafonômicas semelhantes, o que explicaria a maioria dos registros de vertebrados ser de materiais fragmentados. Os mesmos princípios tafonômicos que afetaram os coprólitos podem ter afetado os demais fósseis, mesmo com pequenas ou significativas diferenças. Paleontólogos e paleoartistas retratam a assembleia fóssil encontrada na região convivendo no mesmo ambiente e intervalo temporal (Candeiro 
2005b; Ribeiro and Carvalho 2009). Porém, essas interpretações podem não ser verdadeiras, pois muitas dessas espécies podem não ter convivido no mesmo espaço ao mesmo tempo.

\section{Conclusão}

Nos sítios Peirópolis e Serra da Galga ocorrem coprólitos e pseudocoprólitos nos mesmos níveis estratigráficos. Algumas técnicas simples podem ser adotadas para diferenciar os dois tipos. O método é eficiente quando se considera amostras com baixa e alta densidade. A ocorrência de diferentes morfotipos e quantidade de material presente na área de estudo são indicadores da variedade de organismos que habitaram os paleoambientes em questão. Os morfotipos estão em concordância com outras ocorrências na literatura paleontológica, e podem ser associados a animais com diversas formas e tamanhos, de dieta carnívora, herbívora e onívora. Porém, a grande quantidade de coprólitos encontrada nos afloramentos sugere relação com um efeito tafonômico. A análise dos coprólitos indica que houve mistura temporal e espacial. Poucos exemplares foram considerados parautóctones. A maioria das amostras foi considerada como alóctone, devido à presença de desgaste e de seixos aderidos ao material ou marcas dos mesmos. Aparentemente, pela presença de seixos ou marcas de seixos observados, esses coprólitos foram produzidos em local com substrato mais cascalhento e menos arenoso, bem diferente da matriz arenosa onde foram encontrados. O padrão tafonômico que gerou a acumulação dos coprólitos sugere que os demais fósseis encontrados na região podem ter sofrido o mesmo efeito. Tal fato fica mais relevante com a grande quantidade de material fragmentado citado na literatura, tão abundantes na região, somado a um local de condições mais severas de um ambiente árido. A possibilidade de mistura temporal e espacial fornece novas informações para a reconstituição paleoambiental da região, comumente retratada com todos os indivíduos dividindo o mesmo ambiente.

Agradecimentos: os autores agradecem a Luiz Carlos Borges Ribeiro (Museu dos Dinossauros/CPP L. I. Price) por todo apoio durante o desenvolvimento do trabalho. Agradecemos também ao Laboratório de Difração de Raios-X do Instituto de Geociências da UnB, pela análise das amostras, ao Laboratório de Paleoecologia da PUC-GO, onde foram preparadas amostras palinológicas e a empresa Biota Projetos e Consultoria Ambiental, que disponibilizou estrutura e material para triagem das amostras e fotos de fezes de mamíferos. 


\section{Referências}

AMSTUTZ, G. C. 1958. Coprolites: a review of the literature and a study of specimens from Southern Washington. Journal of Sedimentary Petrology, 28, 498-508.

AZEVEDO, K. L. 2012. Aspectos tafonômicos de vertebrados da parte oriental do Grupo Bauru, Cretáceo Superior. MS Dissertation, Setor de Ciências da Terra, Universidade Federal do Paraná, Curitiba, 122 pp.

BÁEZ, A. M. and PERI, S. 1989. Baurubatrachus pricei, nov. gen. et sp., un anuro del Cretacico Superior de Minas Gerais, Brasil. Anais da Academia Brasileira de Ciências, 61, 447-458.

BÁEZ, A. M., GÓMEZ, R. O., RIBEIRO, L. C. B., MARTINELLI, A. G., TEIXEIRA, V. P. A. and FERRAZ, M. L. F. 2012. The diverse Cretaceous neobatrachian fauna of South America: Uberabatrachus carvalhoi, a new frog from the Maastrichtian Marília Formation, Minas Gerais, Brazil. Gondwana Research, 22, 1141-1150.

BEHRENSMEYER, A. K. and KIDWELL, S. M.. 1985. Taphonomy's contributions to paleobiology. Paleobiology, 11,105-119.

BERTINI, R. J., MARSHALL, L. G., GAYET, M. and BRITO, P. 1993. The vertebrate fauna of the Adamantina and Marília Formations, Upper Cretaceous of the Paraná Basin, southeast Brazil. Neues Jahrbuch für Geologie und Paläontologie, 188, 71-101.

BRANDT-NETO, M., MANZINI, F. F. and BERTINI, R. J. 1992. Ocorrência de coprólitos em sedimentos da Formação Adamantina $(\mathrm{K})$ na região de Ibirá (SP). $2^{\text {nd }}$ Simpósio sobre Bacias Cretácicas Brasileiras, Rio Claro, pp. 165-166.

CAMPANHA, V. A., ETCHEBEHERE, M. L. C., SAAD, A. R. and FULFARO, V. J. 1993. Novas ocorrências fossilíferas no Grupo Bauru na região do Triângulo Mineiro, MG. Geociências, 12, 353-372.

CAMPOS, D. A., KELLNER, A. W. A., BERTINI, R. J. and SANTUCCI, R. M. 2005. On a titanosaurid (Dinosauria, Sauropoda) vertebral column from the Bauru Group, Late Cretaceous of Brazil. Arquivos do Museu Nacional, 63, 565-593.

CANDEIRO, C. R. A. 2005a. Bauru Group (Late Cretaceous) vertebrates from Triângulo Mineiro region and western São Paulo State, Brazil: an introduction. Sociedade \& Natureza, 17, $27-35$.

CANDEIRO, C. R. A. 2005b. Geologia e paleontologia de vertebrados da Formação Marília (Neomaastrichtiano) no Sítio Paleontológico de Peirópolis. Caminhos de Geografia, 11, 117-124. 
CANDEIRO, C. R. A., AGNOLIN, F., MARTINELli, A. G. and BUCKUP, P. A. 2012. First bird remains from the Upper Cretaceous of the Peirópolis site, Minas Gerais State, Brazil. Geodiversitas, 34, 617-624.

CANDEIRO, C. R. A., MARINHO, T. S. and OLIVEIRA, E. C. 2004. Distribuição geográfica dos dinossauros da Bacia Bauru (Cretáceo Superior). Sociedade \& Natureza, 16, 33-55.

CANDEIRO, C. R. A., SANTOS, A. R., RICH, T. H., MARINHO, T. S. and OLIVEIRA, E. C. 2006. Vertebrate fossils from the Adamantina Formation (Late Cretaceous), Prata paleontological district, Minas Gerais State, Brazil. Geobios, 39, 319-327.

CARVALHO, I. S. 2001. A bacia Bauru. 167-177. In BRITO I. M. (ed). Geologia histórica. Edufu, Uberlândia, 413 pp.

CARVALHO, I. S., RIBEIRO, L. C. B. and AVILLA, L. S. 2004. Uberabasuchus terrificus sp. nov., a new Crocodylomorpha from the Bauru Basin (Upper Cretaceous), Brazil. Gondwana Research, 7, 975-1002.

CHIN, K. 2002. Analyses of coprolites produced by carnivorous vertebrates. Paleontological Society Press, 8, 43-50.

CHIN, K., EBERTH, D. A., SCHWEITZER, M. H., RANDO, T. A., SLOBODA, W. J. and HORNER, J. R. 2003. Remarkable preservation of undigested muscle tissue within a Late Cretaceous tyrannosaurid coprolite from Alberta, Canada. Palaios, 18, 286-294.

DIAS-BRITO, D., MUSACCHIO, E. A., CASTRO, J. C., MARANHÃO, M. S. A. S., SUÁREZ, J. M. and RODRIGUES, R. 2001. Grupo Bauru: uma unidade continental do Cretáceo no Brasil - concepções baseadas em dados micropaleontológicos, isotópicos e estratigráficos. Revue de Paléobiologie, 20,245-304.

ERIKSSON, M. E., LINDGREN, J., CHIN, K. and MÅNSBY, U. 2011. Coprolite morphotypes from the Upper Cretaceous of Sweden: novel views on an ancient ecosystem and implications for coprolite taphonomy. Lethaia, 44, 455-468.

ESTES, R. and PRICE, L. I. 1973. Iguanid lizard from the Late Cretaceous of Brazil. Science, 180, 748-751.

FERNANDES, L. A. 1998. Estratigrafia e evolução geológica da parte Oriental da Bacia Bauru (Ks, Brasil). PhD Thesis, Programa de Pós-graduação em Geociências, Universidade de São Paulo, São Paulo, 216 pp.

FERNANDES, L. A. 2004. Mapa litoestratigráfico da parte oriental da Bacia Bauru (PR, SP, MG), escala 1:1.000.000. Boletim Paranaense de Geociências, 55, 53-66.

FERNANDES, L. A. 2010. Calcretes e registros de paleossolos em depósitos continentais neocretáceos (Bacia Bauru, Formação Marília). Revista Brasileira de Geociências, 40, 19-35. 
FERNANDES, L. A. and COIMBRA, A. M. 1996. A Bacia Bauru (Cretáceo Superior, Brasil). Anais da Academia Brasileira de Ciências, 68, 195-205.

FRANÇA, M. A. G. and LANGER, M. C. 2005. A new freshwater turtle (Reptilia, Pleurodira, Podocnemidae) from the Upper Cretaceous (Maastrichtian) of Minas Gerais, Brazil. Geodiversitas, 27, 391-411.

FRANCISCHINI, H., PAES-NETO, V. D., MARTINELli, A. G., PEREIRA, V. P., MARINHO, T. S., TEIXEIRA, V. P. A., FERRAZ, M. L. F., SOARES, M. B. and SCHULTZ, C. L. 2016. Invertebrate traces in pseudo-coprolites from the Upper Cretaceous Marília Formation (Bauru Group), Minas Gerais State, Brazil. Cretaceous Research, 57, 29-39.

FRANCISCHINI, H., PAES-NETO, V. D., MARTINELLI, A. G., SOARES, M. B., SCHULTZ, C. L., MARINHO, T. S., FERRAZ, M. L. F. and TEIXEIRA, V. P. A. 2014. Invertebrate trace fossils on vertebrate coprolites from the Upper Cretaceous Marília Formation (Bauru Group) of Uberaba (Minas Gerais State, Brazil). $4^{\text {th }}$ International Palaeontological Congress, Mendoza, pp. 239.

FRIEDMAN, V. 2012. Vertebrate coprolites from the lower Eagle Ford Group of north central Texas and their paleoecological significance. New Mexico Museum of Natural History, 57, 221228.

GAFFNEY, E. S., MEYLAN, P. A., WOOD, R. C., SIMONS, E. and CAMPOS, D. A. 2011. Evolution of the side-necked turtles: the family Podocnemididae. Bulletin of the American Museum of Natural History, 350, 1-237.

GAYET, M. and BRITO, P. M. 1989. Ichtyofaune Nouvelle du Crétacé Supérieur du Groupe Bauru (États de São Paulo et Minas Gerais, Brésil). Geobios, 22, 841-847.

GHILARDi, R. P., D’ÁGOSTA, F. C. P., ALVES, K. and CAMPOS, A. C. A. 2011. Tafonomia de moluscos fósseis do Grupo Bauru (Cretáceo Superior, Bacia Bauru), na região do município de Monte Alto, São Paulo, Brasil. Boletim do Museu Paraense Emílio Goeldi, 6, $197-$ 206.

GOBBO-RODRIGUES, S. R. 2002. Caulóides de Charophyta maastrichtianos na Formação Marília (Grupo Bauru) na região de Uberaba (MG), Brasil. $6^{\text {th }}$ Simpósio sobre o Cretáceo do Brasil / $2^{\text {nd }}$ Simposio sobre el Cretácico de América del Sur, São Pedro, pp. 395-399.

GRELLET-TINNER, G. and ZAHER, H. 2007. Taxonomic identification of the Megaloolithid egg and eggshells from the Cretaceous Bauru Basin (Minas Gerais, Brazil): comparison with the Auca Mahuevo (Argentina) titanosaurid eggs. Papéis Avulsos de Zoologia, 47, 105-112.

HALFPENNY, J. C. and BIESIOT, E. A. 1986. A field guide to mammal tracking in North America. $2^{\text {nd }}$ edn. Johnson Books, Boulder, 161 pp. 
HÄNTZSCHEL, W, EL-BAZ, F. and AMSTUTZ, G. C. 1968. Coprolites: an annotated bibliography. Memoir Geological Society of America, 108, 1-132.

HUNT, A. P., CHIN, K. and LOCKLEY, M. G. 1994. The palaeobiology of vertebrate coprolites. 221-240. In DONOVAN, S. K. (ed). The palaeobiology of trace fossils. John Hopkins University Press, Baltimore, 308 pp.

JEPSEN, G. L. 1963. Eocene vertebrates coprolites and plants in the Golden Valley Formation of Western North Dakota. Bulletin of Geological Society America, 74, 673-684.

KELlner, A. W. A., CAMPOS, D. A. and TROTTA, M. N. F. 2005. Description of a titanosaurid caudal series from the Bauru Group, Late Cretaceous of Brazil. Arquivos do Museu Nacional, 63, 529-564.

KELlnER, A. W. A., CAMPOS, D. A., RIFF, D. and ANDRADE, M. B. 2011. A new crocodylomorph (Sphagesauridae, Notosuchia) with horn-like tubercles from Brazil. Zoological Journal of the Linnean Society, 163, 57-65.

MAGALHÃES-RIBEIRO, C. M. 2002. Ovo e fragmentos de cascas de ovos de dinossauros provenientes da região de Peirópolis, Uberaba, Minas Gerais. Arquivos do Musen Nacional, 60, 223-228.

MAGALHÃES-RIBEIRO, C. M. and RIBEIRO, L. C. B. 1999. Um ovo de dinossauro em sucessões fluviais da Formação Marília (Cretáceo Superior), em Peirópolis (Uberaba, Minas Gerais). $\sigma^{\text {th }}$ Simpósio de Geologia do Sudeste, São Pedro, pp. 76.

MARTinelli, A. G., BOGAN, S., AGNOLIN, F. L., RiBEIRO, L. C. B., CAVELLANI, C. L., FERRAZ, M. L. F. and TEIXEIRA, V. P. A. 2013. First fossil record of amiid fishes (Halecomorphi, Amiiformes, Amiidae) from the Late Cretaceous of Uberaba, Minas Gerais State, Brazil. Alcheringa, 37, 105-113.

MARTINELLI, A. G., MARINHO, T. F., FILIPPI, L. S., RIBEIRO, L. C. B., FERRAZ, M. L. F., CAVELLANI, C. L. and TEIXEIRA, V. P. A. 2015. Cranial bones and atlas of titanosaurs (Dinosauria, Sauropoda) from Late Cretaceous (Bauru Group) of Uberaba, Minas Gerais State, Brazil. Journal of South American Earth Sciences, 61, 164-170.

MARTINELLI, A. G., RIFF, D. and LOPES, R. P. 2011. Discussion about the occurrence of the genus Aeolosaurus Powell 1987 (Dinosauria, Titanosauria) in the Upper Cretaceous of Brazil. Gaea-Journal of Geoscience, 7, 34-40.

MEZZALIRA, S. 1974. Contribuição ao conhecimento da estratigrafia e paleontologia do arenito Bauru. Boletim do Instituto Geográfico e Geológico, 51, 1-163.

MILANI, E. J. 1997. Evolução tectono-estratigráfica da bacia do Paraná e seu relacionamento com a geodinâmica Fanerozóica do Gondwana Sul-Ocidental. PhD Thesis, Programa de 
Pós-graduação em Geociências, Universidade Federal do Rio Grande do Sul, Porto Alegre, 255 pp.

MILANI, E. J., FRANÇA, A. B. and Schneider, R. L. 1994. Bacia do Paraná. Boletim de Geociências da Petrobras, 8, 69-82.

MILANI, E. J., MELO, J. H. G, SOUZA, P. A., FERNANDES, L. A. and FRANÇA, A. B. 2007. Bacia do Paraná. Boletim de Geociências da Petrobras, 15, 265-287.

MURIE, O. J. 1974. A field guide to animal tracks. $2^{\text {nd }}$ edn. Houghton Mifflin, Boston, 374 pp.

NORTHWOOD, C. 2005. Early Triassic coprolites from Australia and their palaeobiological significance. Palaeontology, 48, 49-68.

NOVAS, F. E., CARVALHO, I. S., RIBEIRO, L. C. B. and MENDEZ, A. H. 2008. First abelisaurid bone remains from the Maastrichtian Marília formation, Bauru Group, Brazil. Cretaceous Research, 29, 625-635.

NOVAS, F. E., RIBEIRO, L. C. R. and CARVALHO, I. S. 2005. Maniraptoran theropod ungual from the Marilia Formation (Upper Cretaceous), Brazil. Revista del Museo Argentino de Ciencias Naturales, 7, 31-36.

OWOCKI, K., NIEDŹWIEDZKI, G., SENNIKOV, A. G., GOLUBEV, V. K., JANISZEWSKA, K. and SULEJ, T. 2012. Upper Permian vertebrate coprolites from Vyazniki and Gorokhovets, Vyatkian regional stage, Russian Plataform. Palaios, 27, 867-877.

PRICE, L. I. 1955. Novos crocodilídeos dos arenitos da Série Bauru, Cretáceo do Estado de Minas Gerais. Anais da Academia Brasileira de Ciências, 27, 487-498.

RIBEIRO, L. C. B. 2014. Geoparque Uberaba - terra dos dinossauros do Brasil. PhD Thesis, Programa de Pós-graduação em Geologia, Universidade Federal do Rio de Janeiro, Rio de Janeiro, 123 pp.

RIBEIRO, L. C. B. and CARVALHO, I. S. 2009. Peirópolis e Serra da Galga, Uberaba, MG. 389402. In WINGE, M., SCHOBBENHAUS, C., SOUZA, C. R. G., FERNANDES, A. C. S., QUEIROZ, E. T., BERBERT-BORN, M. and CAMPOS, D. A. (eds). Sitios geológicos e paleontológicos do Brasil. CPRM, Brasília, v. 2, 515 pp.

RIBEIRO, L. C. B., CARVALHO, I. S. and NETO, F. M. 2015. Geopark Uberaba: Relevance of the Geological Heritage. Geoheritage, 7, 261-273.

RiBEIRO, L. C. B., TREVISOL, A., CARVALHO, I. S., NETO, F. M., MARTINS, L. A. and TEIXEIRA, V. P. A. 2012. Geoparque Uberaba - terra dos dinossauros do Brasil (MG). 583616. In SCHOBBENHAUS, C. and SILVA, C. R. (orgs). Geoparques do Brasil - propostas. CPRM, Rio de Janeiro, v. 1, 748 pp. 
SALGADO, L. and CARVALHO, I. S. 2008. Uberabatitan ribeiroi, a new titanosaur from the Marília Formation (Bauru Group, Upper Cretaceous), Minas Gerais, Brazil. Palaeontology, 51, 881-901.

SANTUCCI, R. M. and BERTINI, R. J. 2001. Distribuição paleogeográfica e biocronológica dos titanossauros (Saurischia, Sauropoda) do Grupo Bauru, Cretáceo Superior do sudeste brasileiro. Revista Brasileira de Geociências, 31, 307-314.

SENRA, M. C. E. and SILVA-E-SILVA, L. H. 1999. Moluscos dulçaquícolas e microfósseis vegetais associados da Formação Marília, Bacia Bauru (Cretáceo Superior), Minas Gerais, Brasil. $5^{\text {th }}$ Simpósio sobre o Cretáceo do Brasil, Serra Negra, pp. 497-500.

SOUTO, P. R. F. 2003. Coprólitos do Cretáceo do Brasil. PhD Thesis, Instituto de Geociências, Universidade Federal do Rio de Janeiro, Rio de Janeiro, 237 pp.

SOUTO, P. R. F. and FERNANDES, M. A. 2015. Fossilized excreta associated to dinosaurs in Brazil. Journal of South American Earth Sciences, 57, 32-38.

SOUTO, P. R. F. and MAGALHÃES-RIBEIRO, C. M. 1999. Fragmentos de cascas de ovos fósseis e coprólitos da Bacia Bauru (KS): aplicação na interpretação paleoambiental. $5^{\text {th }}$ Simpósio Sobre o Cretáceo do Brasil, Serra Negra, pp. 501-507.

THULBORN, R. A. 1991. Morphology, preservation and palaeobiological significance of dinosaur coprolites. Palaeogeography, Palaeoclimatology, Palaeoecology, 83, 341-366.

VASCONCELLOS, F. M. and CARVALHO, I. S. 2006. Condicionante etológico na tafonomia de Uberabasuchus terrificus (Crocodyliformes, Peirosauridae) da Bacia Bauru (Cretáceo Superior). Geociências, 25, 225-230.

VASILIEF, I. 2011. QtiPlot - Data Analysis and Scientific Visualisation. Version 0.9.8.9 svn 2288 copyright (C) 2004-2011. www.qtiplot.com.

VOGELTANZ, R. 1965. Austrocknungsstrukturen bei koprolithen. Neues Jabrbuch für Geologie und Paläontologie, 3, 362-371. 


\section{Capítulo 3}

\section{Análise palinológica de coprólitos dos sítios paleontológicos Peirópolis e Serra da Galga (Membro Serra da Galga, Formação Marília) em Uberaba, Minas Gerais, Brasil}

Resumo - A região de Uberaba, em Minas Gerais contém rica fauna de vertebrados em rochas do Membro Serra da Galga, Formação Marília, Grupo Bauru, de idade maastrichtiana. Entretanto, em meio à grande diversidade faunística, os elementos vegetais que compõem a paleobiota são ausentes no registro fóssil, exceto pelo registro de carófitas. No mesmo local, também ocorrem coprólitos em relativa abundância que, até o momento, foram pouco estudados. No caso de espécies herbívoras, é possível que palinomorfos sejam ingeridos junto com as folhas e outras partes, que após passar pelo trato digestivo acabam sendo expelidos junto com as fezes. Neste trabalho apresentamos registros de elementos da vegetação que existiu onde hoje se encontram os sítios Peirópolis e Serra da Galga. Foram selecionados 17 coprólitos e 13 pseudocoprólitos e em seguida submetidos a uma preparação palinológica com $\mathrm{HCl} 10 \%$ e HF 40\%. Nos coprólitos foram encontrados tipos polínicos como Classopollis, Equisetosporites, Gnetaceaepollenites, Cycadopites e Podocarpidites. O conjunto polínico demonstra que parte da vegetação era representada por elementos arbustivos (gnetófitas), arbóreos (coníferas) e cicadáceas que habitavam em um ambiente de clima árido.

Palavras-chave: coprólitos, palinomorfos, Formação Marília, Cretáceo.

\section{Introdução}

Para o Grupo Bauru existem apenas três trabalhos que relatam a ocorrência de palinomorfos, todos se referem a um mesmo depósito sedimentar no Município de São Carlos, no Estado de São Paulo. O primeiro deles relata a descoberta de um rico conteúdo palinológico em uma nova unidade geológica, que se caracteriza por ser o primeiro registro de palinomorfos do Cretáceo do Grupo Bauru (Lima et al. 1986). Posteriormente, essa nova unidade geológica foi denominada de Formação São Carlos (Castro et al. 2002). No primeiro momento, com base na palinoestratigrafia, a idade da Formação São Carlos foi atribuída ao Coniaciano (Lima et al. 1986). Entretanto, de posse de novos dados palinoestratigráficos, foi sugerido que a associação palinológica encontrada tem a idade no intervalo Coniaciano-Santoniano (Castro et al. 2002). Já 
no trabalho mais recente, Arai et al. (2015) determinaram que o conjunto polínico, sobretudo pela presença de Anacolosidites sp.A e ausência de Steevesipollenites nativensis, apontam para uma idade neossantoniana. Também relacionados ao Grupo Bauru, os sítios paleontológicos Peirópolis e Serra da Galga são notadamente conhecidos pela grande diversidade de vertebrados, representando uma das mais ricas faunas do Cretáceo brasileiro (Ribeiro and Carvalho 2009). Entretanto, os dados relativos aos elementos vegetais ainda são desconhecidos, exceto pelo registro de algas carófitas (Gobbo-Rodrigues 2002).

Dentre a grande diversidade de fósseis encontrados nos sítios Peirópolis e Serra da Galga, também ocorrem coprólitos que, até o momento, foram pouco estudados. Uma das primeiras referências (Souto 2003) apresentou a descrição de sete coprólitos do Sítio Peirópolis. Posteriormente, os coprólitos de Peirópolis apareceram citados no estudo de outros materiais fósseis (Carvalho et al. 2004; Salgado and Carvalho 2008; Ribeiro et al. 2012, 2015; Ribeiro 2014). Em seguida foi relatada de forma preliminar a presença de icnofósseis de invertebrados em coprólitos de Peirópolis, relacionados com algum tipo de inseto em fase de pupação (Francischini et al. 2014). Em compilação recente, Souto and Fernandes (2015) apresentaram um registro atualizado das principais ocorrências de coprólitos no Brasil. Duas amostras são de Peirópolis e análises de difração e fluorescência revelaram a presença de cálcio e sílica, com pequenas quantidades de alumínio e ferro, sugerindo, junto com outras características, que foram produzidos por herbívoros. Por fim, as amostras relatadas preliminarmente por Francischini et al. (2014) foram consideradas como pseudocoprólitos por Francischini et al. (2016) e os vestígios superficiais encontrados nesses pseudocoprólitos foram considerados como uma nova icnoespécie, Asthenopodichnium fallax, que seria produzida por invertebrados em ambiente de água doce.

Em se tratando de coprólitos, existe uma gama de trabalhos que podem ser aplicados, passando até mesmo por fatos curiosos como relações tróficas entre dinossauros e caracóis (Chin et al. 2009), infecção de parasitas intestinais em Iguanodon (Poinar and Boucot 2006), marca de mordida de tubarão em coprólito de crocodilomorfo, indicando predação ou coprofagia abortada (Godfrey and Smith 2010) e até mesmo sequenciamento de DNA, como no caso do coprólito da hiena-das-cavernas (Bon et al. 2012). Em anos recentes surgiu uma nova aplicação no estudo de coprólitos, a análise do conteúdo palinológico. Entretanto, a maioria dos trabalhos é de cunho arqueológico (coprólitos humanos) ou coprólitos de animais quaternários. Palinomorfos preservados em coprólitos humanos foram utilizados para identificar e descrever plantas medicinais utilizadas por comunidades de, aproximadamente, oito mil anos que ocuparam o local do Sítio de Pedra Furada, no Estado do Piauí, nordeste brasileiro (Chaves and Renault-Miskovsky 
1996; Chaves 1996, 2000, 2001). Ademais, a palinologia é importante na obtenção de dados sobre a dieta de comunidades humanas pré-históricas e questões como origem da agricultura (Bryant 2003). Com relação à fauna, para citar alguns exemplos, existem trabalhos que tratam do conteúdo palinológico do coprólito de hienas - Crocuta crocuta (Scott 1987; Carrión et al. 2001; González-Sampériz et al. 2003; Yll et al. 2006), texugos - Meles meles (Carrión et al. 2005) e o kakapo - Strigops habroptilus da Nova Zelândia (Wood et al. 2012).

Com relação aos períodos anteriores ao Pleistoceno, existem poucos trabalhos relacionados à copropalinologia. Entretanto, alguns já citam esporomorfos em coprólitos antigos do Carbonífero (Cutlip and Raymond 1999) e Devoniano (Habgood 2002). Para o Mesozoico, um trabalho relacionado com a Formação Oldman em Alberta, Canadá revelou em sete coprólitos de répteis uma microflora representada por licopódios, samambaias, coníferas e angiospermas (Waldman and Hopkins 1970). Um caso em paralelo com os Sítios Peirópolis e Serra da Galga ocorreu na Formação Maleri, Triássico Superior na Índia. Não havia registros fósseis de vegetais ou palinomorfos. Entretanto, havia coprólitos cujo conteúdo revelou palinomorfos (esporos, pólen e fungos) e outros resíduos vegetais (Vijaya and Singh 2009). Desta forma, a ocorrência de coprólitos nos sítios paleontológicos Peirópolis e Serra da Galga, abre uma oportunidade para estudos de cunho palinológicos. Este trabalho apresenta o estudo palinológico de 30 amostras, das quais 26 são do Ponto 1 do Price (Caieira), no Sítio paleontológico de Peirópolis e quatro são do Sítio Serra da Galga, no km 153 da BR-050. São apresentados os primeiros registros palinológicos e os primeiros indícios de parte da vegetação que, somado aos animais, compunham a paleobiota da região. Tais dados são importantes, pois adicionam informações para melhor suportar os estudos paleoclimáticos e paleoambientais nas rochas da região, bem como podem fornecer pistas sobre a dieta dos animais herbívoros encontrados nessas rochas.

\section{Geologia e Paleontologia}

As unidades geológicas que compõem o Grupo Bauru (Milani et al. 1994, 2007; Milani 1997) representam uma das mais extensas sequências sedimentares continentais de idade cretácea da América do Sul (Fig. 1). O Grupo Bauru abrange a maior parte do Planalto Ocidental Paulista, aflorando também no Triângulo Mineiro, sul de Goiás, norte do Paraná e sudeste do Mato Grosso (Carvalho 2001; Ghilardi et al. 2011). Os depósitos do Grupo Bauru são representados principalmente por rochas siliciclásticas (Carvalho, 2001) e assentam-se predominantemente 
sobre basaltos da Formação Serra Geral (Fernandes 2004; Milani et al. 2007). Os depósitos sedimentares do Grupo Bauru correspondem essencialmente a arenitos, siltitos e argilitos/folhelhos, depositados em diversos contextos ambientais, como eólico, aluvial, fluvial e lacustre raso (Dias-Brito et al. 2001). O Grupo Bauru é constituído pelas formações Araçatuba, Adamantina, Uberaba e Marília, onde praticamente todos os registros fossilíferos conhecidos situam-se na parte oriental, abrangendo uma área de aproximadamente $180.000 \mathrm{~km}^{2}$ (Fernandes 2004).

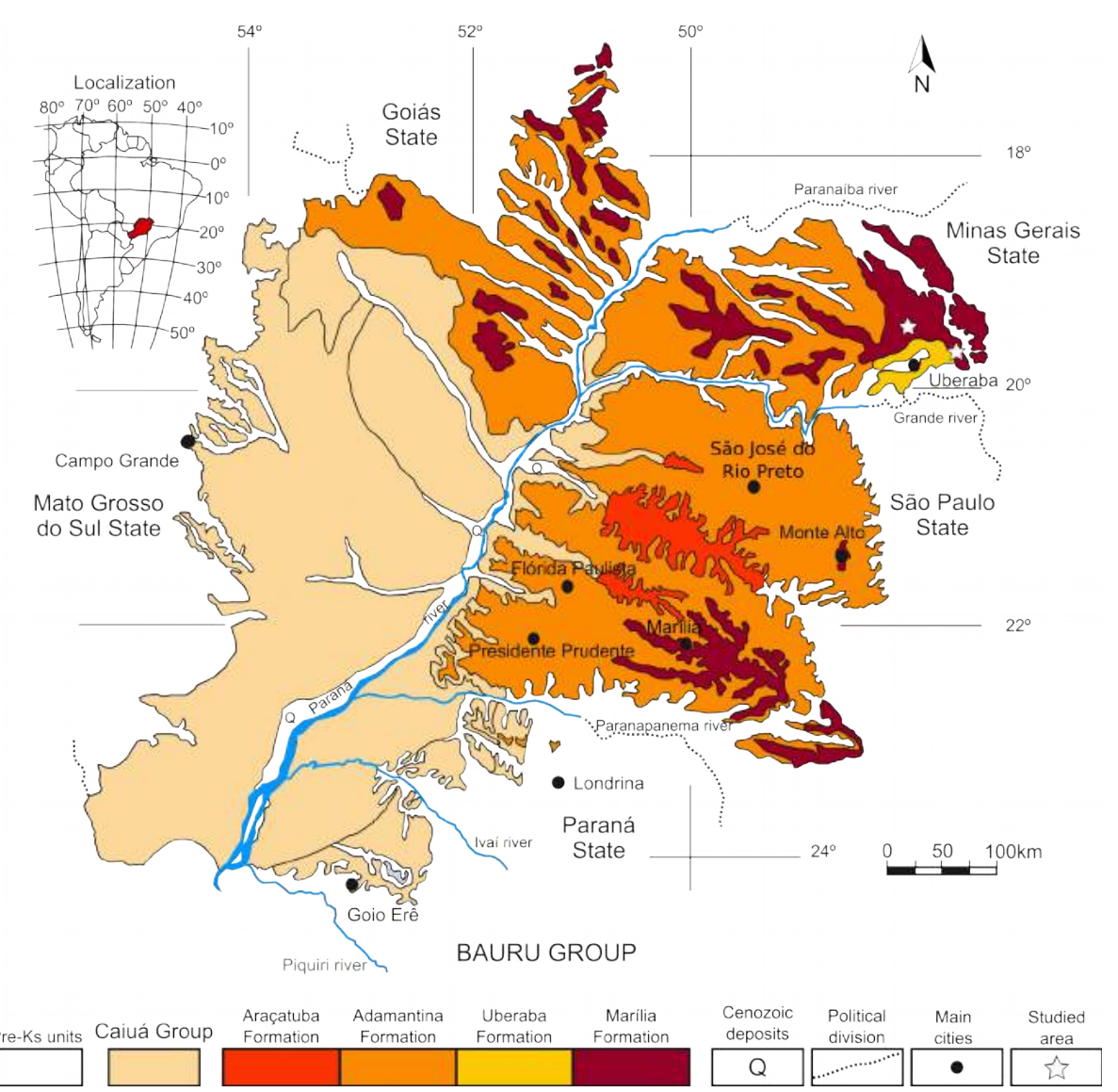

Figura 1. Mapa de localização do Grupo Bauru e dos depósitos da Formação Marília na região de Uberaba, Minas Gerais, Brasil. Modificado de Fernandes and Coimbra (1996) e Fernandes (1998).

A Formação Marília é composta por três membros: Serra da Galga, Ponte Alta e Echaporã (Milani et al. 2007) e que representam depósitos de rios entrelaçados e leques aluviais associados (Fernandes 2010). Na região de Uberaba afloram rochas dos membros Serra da Galga e Ponte Alta nos sítios de Peirópolis e Serra da Galga, que já forneceram raros exemplares de vegetais, como carófitas (Gobbo-Rodrigues 2002) e um vasto registro de invertebrados e vertebrados, entre eles quelônios, crocodilomorfos e dinossauros (Santucci and Bertini 2001; Vasconcellos and Carvalho 2006; Milani et al. 2007), se destacando como uma das unidades mais 
importantes do Grupo Bauru. Os coprólitos analisados neste trabalho foram coletados em Peirópolis, no Ponto 1 do Price e no km 153 da BR-050 (Fig.2).
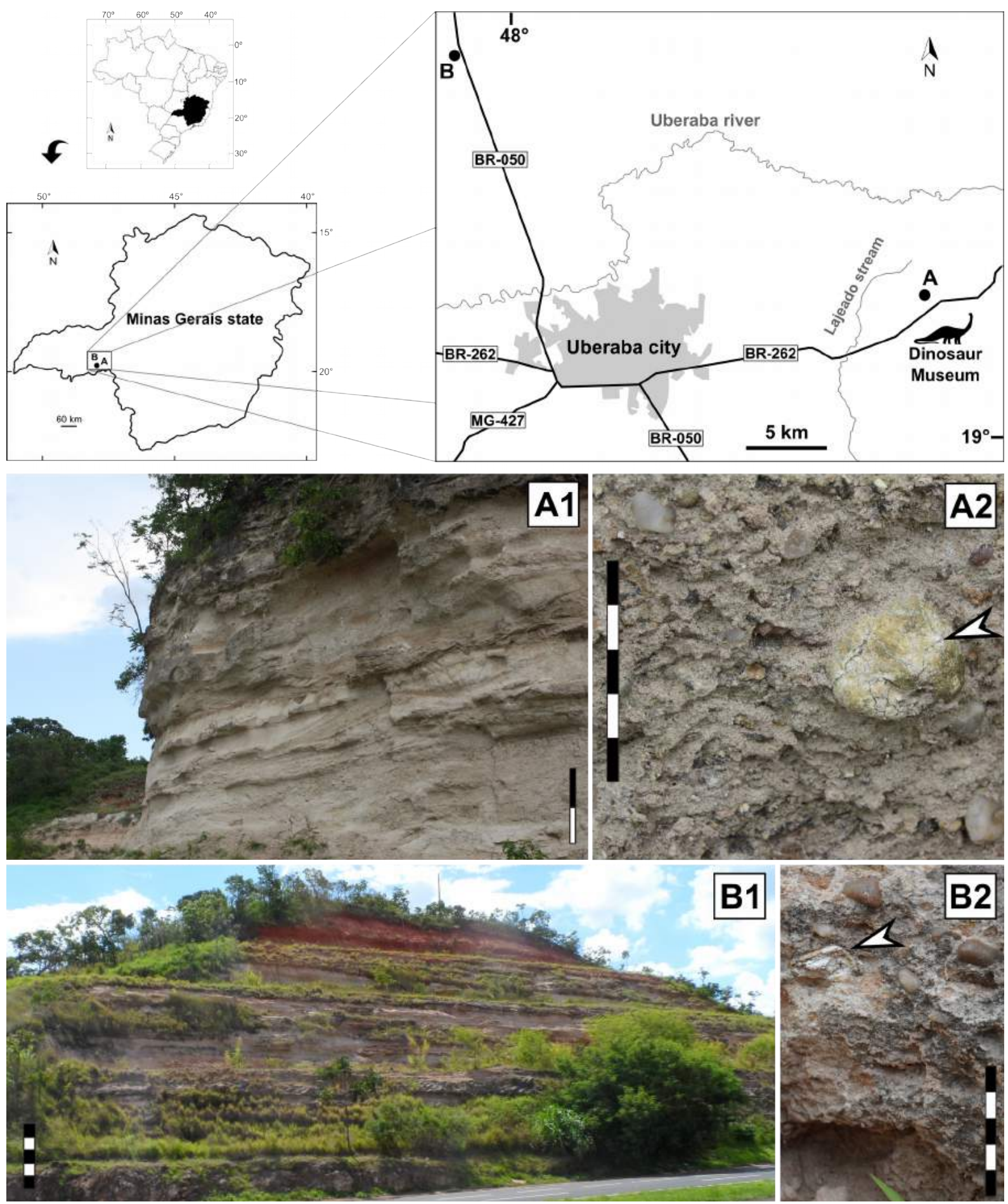

Figura 2. Mapa de localização e afloramentos localizados no Ponto 1 do Price ou Caieira (A), Sítio Peirópolis e km 153 da BR-050 (B), Sítio Serra da Galga, Uberaba, Minas Gerais, Brasil. A1) Afloramento do Ponto 1 do Price (Caieira); A2) Coprólito in situ; B1) Afloramento do km 153 da BR-050; B2) Coprólito fragmentado in situ. Escalas = $1 \mathrm{~m} \mathrm{~A} 1$ e B1 e $1 \mathrm{~cm}$ em A2 e B2. 


\section{Materiais e Métodos}

As amostras avaliadas neste estudo foram coletadas em duas etapas de campo entre os anos de 2010 e 2011, em duas localidades do Município de Uberaba (Fig. 2). Foram coletadas 300 amostras no Ponto 1 do Sítio Paleontológico Peirópolis (Caieira: 1943’44”S e 4745’10”W), onde os espécimes encontravam-se, na maioria das vezes, ex situ na base do afloramento. No km 153 da BR-050, Sítio Paleontológico Serra da Galga (19³5’33’'S e 4801'42’'W), foram coletadas in situ 40 amostras em três pontos, depositados em rochas representando um sistema fluvial.

O estado de conservação das amostras varia desde fragmentos quebrados a massas fecais aparentemente inteiras. Devido à fragilidade e raridade do material, foram necessários procedimentos que mantiveram o máximo de preservação (Amstutz 1958; Häntzschel et al. 1968). Desta forma, a preparação consistiu principalmente da retirada da matriz de arenito que envolvia os fósseis. Logo depois de tratados, os coprólitos foram tombados na coleção científica com número de registro FUP-000001 a FUP-000340. As amostras foram descritas quanto à morfologia e morfometria de acordo com referências clássicas (Thulborn 1991; Hunt et al. 1994). Durante essa etapa, a análise dos aspectos macroscópicos foi realizada sob microscópio estereoscópico (Opton). As medidas de comprimento e largura foram tomadas com um paquímetro (Mitutoyo) e o peso aferido com uma balança digital de precisão (Diamond). Adicionalmente, também foram mensurados espessura, volume e densidade de cada amostra (Jepsen, 1963). Por fim, diversas características presentes tais como fraturas, perfurações, rachaduras, desgaste, presença ou marcas de seixos foram anotadas. Com base nos caracteres morfológicos, os coprólitos foram agrupados em diferentes morfotipos (Chin 2002; Souto 2003; Eriksson et al. 2011; Owocki et al. 2012). Do total de 340 amostras, 30 foram selecionadas, representando toda a gama de tamanhos, forma, densidade e estado de preservação, para preparação palinológica (FUP-000002, FUP-000005, FUP-000119, FUP-000128, FUP-000130, FUP-000134, FUP-000137, FUP-000144, FUP-000145, FUP-000154, FUP-000155, FUP-000156, FUP-000159, FUP-000160, FUP-000175, FUP-000178, FUP-000185, FUP-000195, FUP-000197, FUP-000204, FUP-000209, FUP-000217, FUP-000242, FUP-000263, FUP-000280, FUP-000282, FUP-000322, FUP-000325, FUP-000328 e FUP-000333). Todas as informações coletadas foram compiladas numa base de dados no software Calc do pacote LibreOffice (The Document Foundation). Os gráficos foram plotados no software QtiPlot (Vasilief 2011) e os desenhos criados no Inkscape e Gimp. Todos os softwares citados foram utilizados no sistema operacional Debian GNU/Linux. A técnica de difratometria de raios-X foi aplicada em 14 amostras (FUP-000002, FUP-000005, FUP-000128, FUP-000144, FUP-000145, FUP-000154, FUP-000156, FUP-000159, FUP-000175, 
FUP-000204, FUP-000282, FUP-000325, FUP-000328 e FUP-000333), enviadas para o Laboratório de Difração de Raios-X da Universidade de Brasília.

A preparação palinológica foi realizada com técnicas convencionais, adaptadas neste estudo para extração e concentração dos palinomorfos. De cada uma das amostras foi obtido um pequeno testemunho cilíndrico entre 3 e $5 \mathrm{~cm}$ de comprimento, dependendo do tamanho do coprólito, por $5 \mathrm{~mm}$ de largura, sendo considerada na preparação palinológica apenas a fração mais interna. A fração mais externa (aproximadamente $3 \mathrm{~mm}$ ) foi desconsiderada porque muitas amostras ficaram certo tempo expostas nos afloramentos, prevenindo assim que possíveis palinomorfos recentes e fungos fossem adicionados. Em material sedimentar, o volume a ser amostrado pode variar de acordo com a constituição do sedimento e com o teor de matéria orgânica (Barberi 2001), entre $1 \mathrm{~cm}^{3}$, no caso de turfas (Ybert et al. 1992) até $8 \mathrm{~cm}^{3}$, para terraços fluviais (Oliveira et al. 2007). No caso das amostras deste estudo, que apresentam variação morfológica e algumas com pequenas dimensões, o testemunho retirado de cada amostra foi transferido para um amostrador até atingir um volume de $2 \mathrm{~cm}^{3}$. Após a separação deste volume, as amostras foram transferidas para cadinhos de porcelana enumeradas, onde também foram introduzidos $1 \mathrm{mg}$ do pólen de Kochia scoparia, que contém, aproximadamente, 60.543,88 grãos de pólen (Salgado-Labouriau and Rull 1986). A adição do pólen exótico logo no início da preparação é importante para que todo o processo, pelos quais passam os palinomorfos das amostras, seja avaliado, inclusive possibilitando a estimativa de possíveis perdas (Barberi 2001). As etapas seguintes consistiram na adição de $\mathrm{HCl}$ 10\% para eliminação de carbonatos e $\mathrm{HF} 40 \%$ para eliminação de silicatos (Faegri and Iversen 1950). Em seguida, cada amostra foi peneirada em tamis com malha de $106 \mu \mathrm{m}$, adequada para passagem dos palinomorfos de maiores dimensões (Salgado-Labouriau 1973) e outro com malha de $6 \mu \mathrm{m}$, permitindo a passagem de partículas menores que os palinomorfos. $\mathrm{Na}$ etapa final as amostras foram lavadas duas vezes com álcool etílico. Em seguida, foi adicionado um pouco de álcool isobutílico e duas gotas da mistura de glicerina e safranina, que confere uma tonalidade avermelhada para os palinomorfos. Por fim as amostras ficaram 24 horas na estufa à $60^{\circ} \mathrm{C}$ para retirada completa de água.

As lâminas foram montadas com duas gotas de amostra mais uma gota de glicerina pura, cobertas com a lamínula e seladas com base. Por convenção, preparamos duas lâminas de cada amostra que, após a leitura, foram seladas e estão depositadas no Laboratório de Paleoecologia da Pontifícia Universidade Católica de Goiás. A leitura foi realizada em microscópio óptico com câmera fotográfica acoplada (Leyca), onde foram contados todos os palinomorfos presentes, incluindo o marcador exótico. Por conta da ausência de referências de palinomorfos do Cretáceo do Grupo Bauru, foram utilizadas, como auxílio nas identificações, diversas bibliografias do 
Cretáceo ao Paleoceno de localidades no Brasil (Regali et al. 1974; Lima 1982; Coimbra et al. 2002; Ferreira et al. 2005; Arai and Duarte 2010; Premaor et al. 2010; Souza et al. 2010; Araújo et al. 2011; Ferreira et al. 2011, 2013; Oliveira 2011; Duarte et al. 2012; Portela et al. 2014), outros países da América da Sul (Van der Hammen and Wijmstra 1964; Vajda-Santivanez 1999; Prámparo et al. 2007; Ottone 2009; Vallati 2010, 2013; Garzon 2011; Povilauskas 2012, 2013) e do continente africano (McLachlan and Pieterse 1978; Morgan 1978; Kotova, 1978; Masure et al. 1998; AttaPetters and Salami 2006; Eisawi and Schrank 2008; Chiaghanam et al. 2012; Eisawi et al. 2012; Apaalse and Atta-Peters 2013; Atta-Peters et al. 2013; Oloto and Yikarebogha 2013; Oloto et al. 2013). A concentração de palinomorfos foi calculada para indicar o número de grãos por centímetro cúbico de amostra (Salgado-Labouriau and Rull 1986). Este cálculo é importante para evitar qualquer tipo de equívoco nas interpretações (Stockmarr 1971).

\section{Resultados e Discussões}

\subsection{Natureza e morfologia das amostras}

Recentemente, 16 amostras coletadas em Peirópolis foram consideradas pseudocoprólitos por apresentar morfologia irregular, ausência de marcas de adesão, sulcos e evidência de coprofagia, presença de grãos de minerais, ausência de fosfato na composição dos exemplares analisados e a tomografia não indicou sinais de conteúdo não digerido ou aberturas internas (Francischini et al. 2016). Contudo, testes de difração de raios-X e petrografia foram realizados em apenas duas amostras e uma foi submetida à tomografia computadorizada. Os autores extrapolaram os resultados para as demais amostras. Neste estudo observamos que, durante a

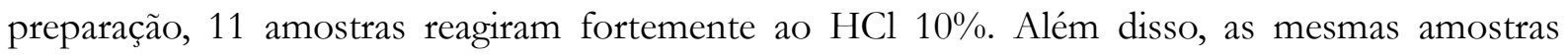
retornaram resultado negativo para a palinologia, matéria vegetal ou qualquer outro tipo de vestígio orgânico. Observamos também que, na maioria dos casos, a densidade dessas amostras foi consideravelmente mais elevada que das demais (Fig. 3). A difração de raios-X de algumas amostras com essas características citadas (FUP-000002, FUP-000005, FUP-000175 e FUP000333) revelaram composição carbonática. Estes resultados sugerem que, provavelmente, essas amostras são pseudocoprólitos. A amostra FUP-000195 reforça ainda mais estes critérios estabelecidos para determinar coprólitos e pseudocoprólitos. Esta amostra de formato cônico reagiu ao teste de $\mathrm{HCl} \mathrm{10 \% ,} \mathrm{indicando} \mathrm{presença} \mathrm{de} \mathrm{carbonatos,} \mathrm{mas} \mathrm{diferente} \mathrm{das} \mathrm{demais} \mathrm{possui}$ baixa densidade e retornou resultado positivo para palinologia. 


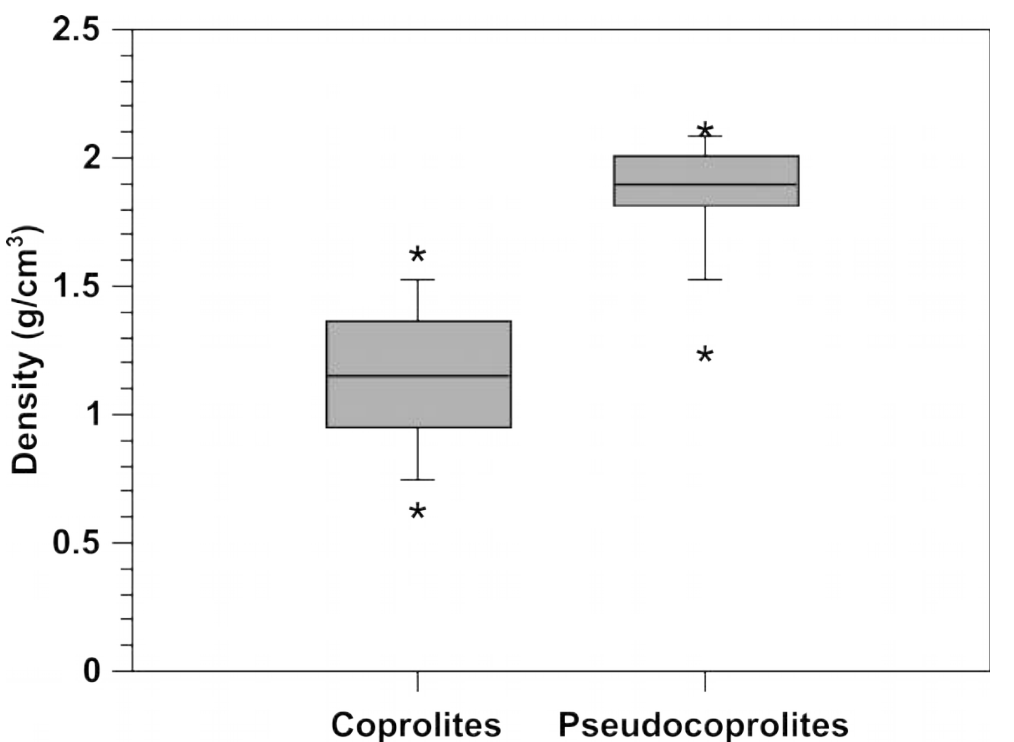

Figura 3. Boxplot da variação de densidade de coprólitos e pseudocoprólitos encontrados nos sítios Peirópolis e Serra da Galga, Município de Uberaba, Minas Gerais, Brasil. No eixo x estão representados os dois grupos de amostras (Coprólitos, $\mathrm{n}=17$; Pseudocoprólitos, $\mathrm{n}=13$ ). As linhas centrais indicam a mediana e divide a metade inferior e superior das amostragens, os retângulos indicam o quartil, as linhas verticais representam os valores mínimo e máximo (whisker) e, por fim, os asteriscos indicam os valores extremos (outliers).

As amostras consideradas aqui como coprólitos verdadeiros são constituídas por uma massa mais homogênea, apresentam rachaduras de ressecamento, marcas de adesão (grãos de areia, seixos ou moldes destes) e possuem baixa densidade, algumas vezes menor que a da água (Fig. 3). Na composição das amostras (FUP-000128, FUP-000144, FUP-000145, FUP-000154, FUP-000156, FUP-000159, FUP-000204, FUP-000282, FUP-000325 e FUP-000328) predominam minerais do grupo dos silicatos. Esses resultados são semelhantes aos encontrados em outros trabalhos (Souto 2003; Souto and Fernandes 2015). Ademais, muitas vezes os pseudocoprólitos apresentam uma superfície áspera e a maioria dos coprólitos apresenta superfície com textura bem suave, muitas vezes com uma espécie de "brilho gorduroso". A diferença na textura entre coprólitos e a rocha sedimentar pode ser usada na distinção de nódulos inorgânicos e concreções (Thulborn 1991). Este tipo de "brilho gorduroso" encontrado em coprólitos de vertebrados foi citado por outros autores (e.g. Friedman 2012). Das amostras referidas como coprólitos, quatro (FUP-000128, FUP-000154, FUP-000204 e FUP-000280) não retornaram resultado positivo para palinologia ou restos vegetais.

Após a avaliação das amostras, foi determinado que das 30 amostras, 17 são coprólitos verdadeiros e 13 são pseudocoprólitos. Dos coprólitos avaliados, um possui morfologia cilíndrica, três são cônicos, dois dômicos e 11 possuem morfologia indeterminada (Fig. 4), constituindo amostras em avançado estado de desgaste ou fragmentação. As amostras consideradas aqui como pseudocoprólitos possuem, no geral, morfologia bastante irregular (Fig. 5). A descrição dos parâmetros físicos de cada uma das amostras é apresentada na Tab. 1. 


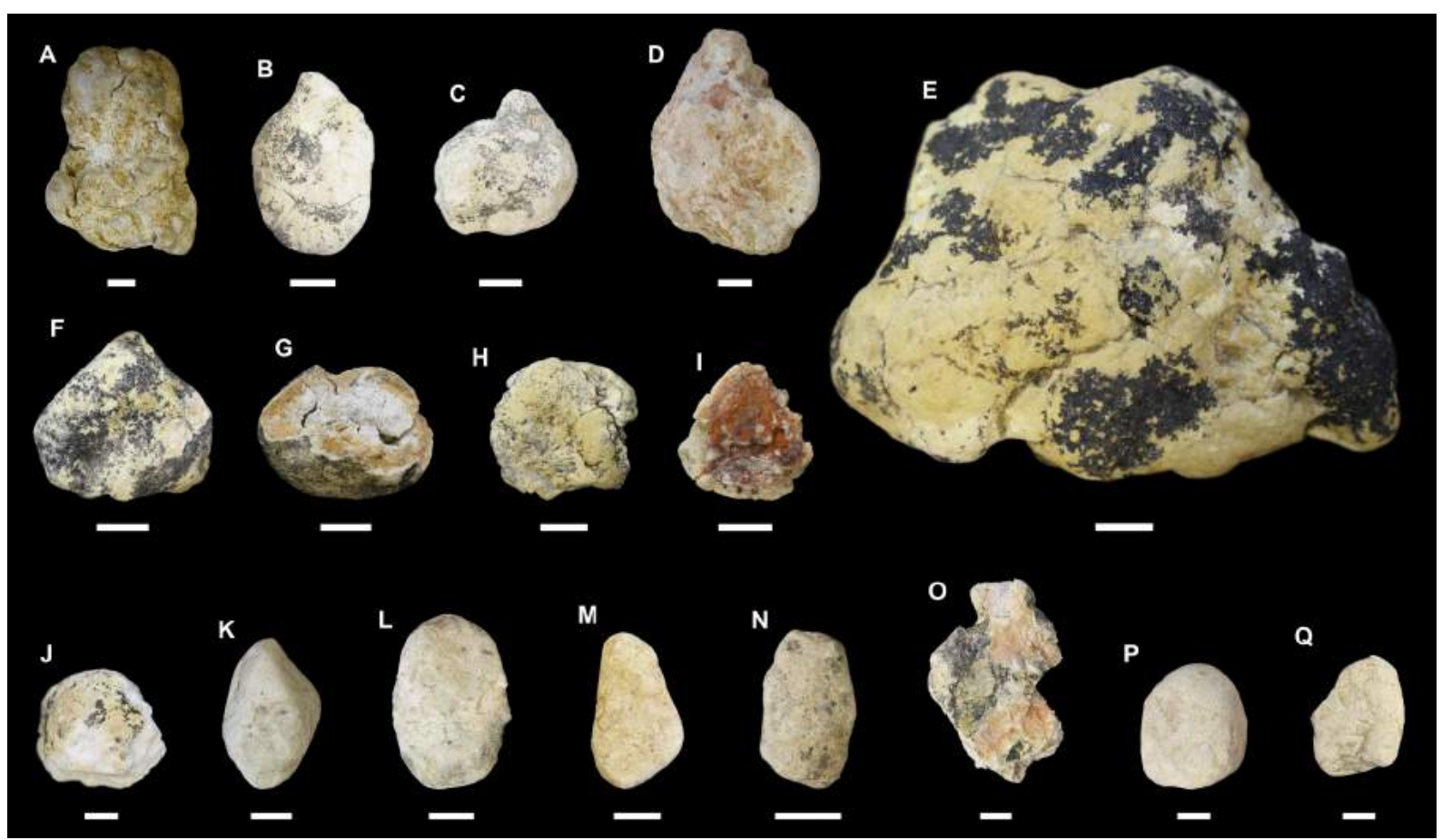

Figura 4. Coprólitos dos sítios paleontológicos Peirópolis e Serra da Galga, Uberaba, Minas Gerais, Brasil. Morfotipo cilíndrico: A) FUP-000154; Morfotipo cônico: B) FUP-000144, C) FUP-000195 e D) FUP-000280; Morfotipo dômico: E) FUP-000156 e F) FUP-000145; Indeterminados: G) FUP-000128, H) FUP-000130, I) FUP000134, J) FUP-000159, K) FUP-000204, L) FUP-000209, M) FUP-000217, N) FUP-000242, O) FUP-000282, P) FUP-000325 e Q) FUP-000328. Escala $=1 \mathrm{~cm}$.

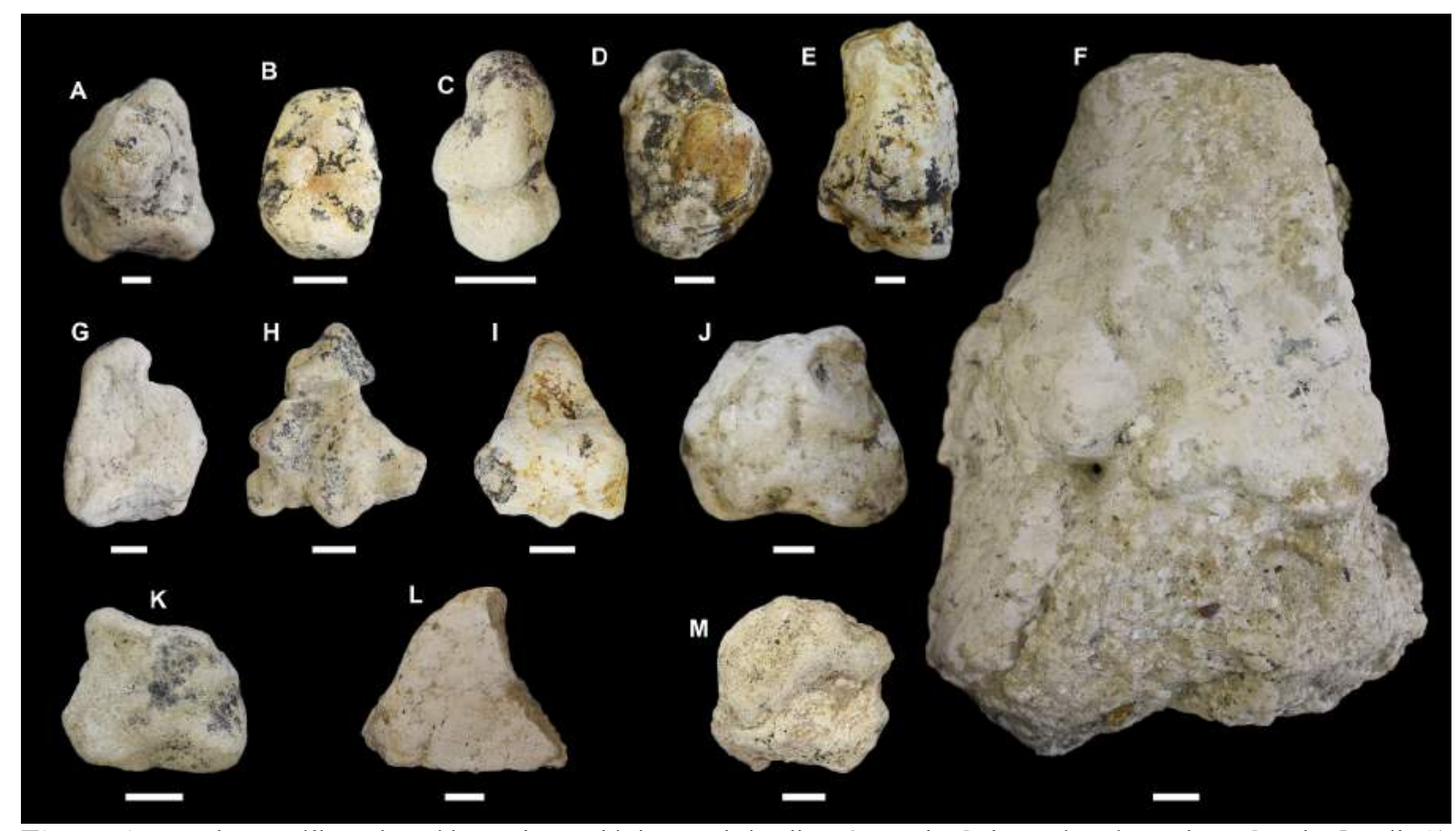

Figura 5. Pseudocoprólitos dos sítios paleontológicos Peirópolis e Serra da Galga, Uberaba, Minas Gerais, Brasil. A) FUP-000002, B) FUP-000005, C) FUP-000119, D) FUP-000137, E) FUP-000155, F) FUP-000263, G) FUP-000160, H) FUP-000175, I) FUP-000178, J) FUP-000185, K) FUP-000197, L) FUP-000322 e M) FUP-000333. Escala = 1 $\mathrm{cm}$. 
Tabela 1. Parâmetros físicos das amostras dos sítios paleontológicos Peirópolis e Serra da Galga, Uberaba, Minas Gerais, Brasil utilizadas na preparação palinológica.

\begin{tabular}{|c|c|c|c|c|c|c|c|c|}
\hline Code & Site & $\begin{array}{c}\text { Length } \\
(\mathrm{cm})\end{array}$ & $\begin{array}{c}\text { Width } \\
(\mathrm{cm})\end{array}$ & $\begin{array}{c}\text { Weight } \\
\text { (g) }\end{array}$ & $\begin{array}{c}\text { Volume } \\
\left(\mathrm{cm}^{3}\right)\end{array}$ & $\begin{array}{l}\text { Density } \\
\left(\mathrm{g} / \mathrm{cm}^{3}\right)\end{array}$ & Morphotype & Diagnosis \\
\hline FUP-000002 & Peirópolis & 5.2 & 4.38 & 82.2 & 39 & 2.1 & & Pseudocoprolite \\
\hline FUP-000005 & Peirópolis & 2.51 & 1.85 & 8.06 & 4 & 2.01 & & Pseudocoprolite \\
\hline FUP-000119 & Peirópolis & 2.7 & 1.74 & 5.41 & 3 & 1.8 & & Pseudocoprolite \\
\hline FUP-000128 & Peirópolis & 3.58 & 2.86 & 6.28 & 10 & 0.62 & Indeterminate & Coprolite \\
\hline FUP-000130 & Peirópolis & 3.05 & 3.05 & 8.64 & 8 & 1.08 & Indeterminate & Coprolite \\
\hline FUP-000134 & Peirópolis & 2.41 & 2.58 & 7.99 & 4.9 & 1.63 & Indeterminate & Coprolite \\
\hline FUP-000137 & Peirópolis & 5.43 & 4.43 & 67.4 & 37 & 1.82 & & Pseudocoprolite \\
\hline FUP-000144 & Peirópolis & 4.27 & 2.74 & 12.48 & 13 & 0.96 & Conical & Coprolite \\
\hline FUP-000145 & Peirópolis & 3.57 & 3.23 & 7.92 & 10 & 0.79 & Domical & Coprolite \\
\hline FUP-000154 & Peirópolis & 8.08 & 5.24 & 107.19 & 78 & 1.37 & Cylindrical & Coprolite \\
\hline FUP-000155 & Peirópolis & 7.89 & 4.63 & 169.41 & 82 & 2.06 & & Pseudocoprolite \\
\hline FUP-000156 & Peirópolis & 9.23 & 7.39 & 201 & 140 & 1.43 & Domical & Coprolite \\
\hline FUP-000159 & Peirópolis & 3.86 & 3.68 & 24.19 & 21 & 1.15 & Indeterminate & Coprolite \\
\hline FUP-000160 & Peirópolis & 5.23 & 3.87 & 37.92 & 20 & 1.89 & & Pseudocoprolite \\
\hline FUP-000175 & Peirópolis & 4.9 & 4.15 & 27.55 & 15 & 1.83 & & Pseudocoprolite \\
\hline FUP-000178 & Peirópolis & 4.45 & 3.48 & 35.04 & 18 & 1.94 & & Pseudocoprolite \\
\hline FUP-000185 & Peirópolis & 5.42 & 5.42 & 92.13 & 48 & 1.91 & & Pseudocoprolite \\
\hline FUP-000195 & Peirópolis & 3.41 & 3.14 & 23.82 & 17.5 & 1.36 & Conical & Coprolite \\
\hline FUP-000197 & Peirópolis & 3.25 & 2.77 & 14.61 & 8 & 1.82 & & Pseudocoprolite \\
\hline FUP-000204 & Peirópolis & 3.72 & 2.35 & 6.78 & 8.8 & 0.77 & Indeterminate & Coprolite \\
\hline FUP-000209 & Peirópolis & 3.98 & 2.72 & 11.19 & 9.5 & 1.17 & Indeterminate & Coprolite \\
\hline FUP-000217 & Peirópolis & 3.28 & 1.72 & 4.47 & 4.3 & 1.03 & Indeterminate & Coprolite \\
\hline FUP-000242 & Peirópolis & 2.34 & 1.51 & 2.61 & 2.1 & 1.24 & Indeterminate & Coprolite \\
\hline FUP-000263 & Peirópolis & 15.5 & 12.07 & 1295 & 751.5 & 1.72 & & Pseudocoprolite \\
\hline FUP-000280 & Peirópolis & 6.5 & 4.44 & 82.2 & 55 & 1.49 & Conical & Coprolite \\
\hline FUP-000282 & Peirópolis & 6.06 & 4.35 & 19.6 & 25 & 0.78 & Indeterminate & Coprolite \\
\hline FUP-000322 & Serra da Galga & 4.68 & 4.56 & 32.11 & 26 & 1.23 & & Pseudocoprolite \\
\hline FUP-000325 & Serra da Galga & 3.61 & 3.15 & 16.87 & 14 & 1.2 & Indeterminate & Coprolite \\
\hline FUP-000328 & Serra da Galga & 3.95 & 2.92 & 10.8 & 10 & 1.08 & Indeterminate & Coprolite \\
\hline FUP-000333 & Serra da Galga & 4.53 & 4.23 & 42.13 & 21 & 2 & & Pseudocoprolite \\
\hline
\end{tabular}

\subsection{Resultados palinológicos}

A copropalinologia pode ser uma importante ferramenta para interpretações bioestratigráficas e paleoecológicas (Vijaya and Singh 2009). Entretanto, a associação palinológica nos coprólitos avaliados neste estudo não se mostrou diversificada. Foram encontrados 34 palinomorfos em nove coprólitos (Tab. 2). Entre os componentes encontram-se alguns grãos de pólen de gimnospermas, esporos de fungos e matéria vegetal amorfa: cutículas ou fibras vegetais que não foram totalmente digeridas, além de dois tipos que não foram plenamente identificados, aparentemente pólen de angiospermas (Fig. 6 e 7). Adicionalmente, não foram encontrados esporos de pteridófitos. A taxonomia dos tipos polínicos e fungos é apresentada na sequência. 
Tabela 2. Palinomorfos encontrados em coprólitos dos sítios paleontológicos Peirópolis e Serra da Galga, Uberaba, Minas Gerais, Brasil.

\begin{tabular}{|c|c|c|c|c|c|c|c|c|c|c|}
\hline Number & Palynomorph types & 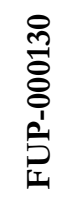 & 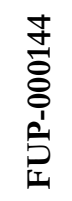 & 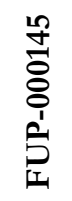 & 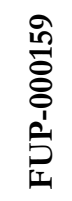 & 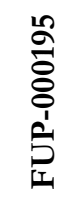 & 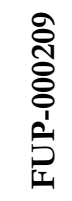 & 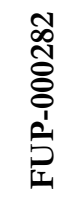 & 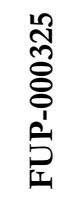 & 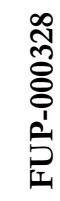 \\
\hline 5001 & Kochia scoparia (exotic pollen) & 680 & 698 & 749 & 825 & 941 & 823 & 786 & 883 & 912 \\
\hline 5002 & Equisetosporites sp.1 & & & & & 2 & & & & \\
\hline 5003 & Cycadopites sp. & & & & & 1 & & & & \\
\hline 5005 & Equisetosporites sp.2 & & & & 1 & 1 & & & & \\
\hline 5006 & Palynomorph 1 (Afropollis sp.?) & & 1 & 2 & & & & & & \\
\hline 5007 & Pluricellaesporites sp. & & & 4 & & & & & & \\
\hline 5008 & Classopollis sp.1 & & 2 & 2 & & & & & & \\
\hline 5010 & Podocarpidiites sp. & & 1 & & & & & & & \\
\hline 5011 & Equisetosporites sp.3 & & 1 & & & & & & & \\
\hline 5012 & Palynomorph 2 (Arecaceae?) & & & & & & & 1 & & \\
\hline 5013 & Gnetaceaepollenites sp. & & & & & & 1 & & & \\
\hline 5014 & Classopollis sp.2 & 2 & & & & & & & & \\
\hline 5015 & Classopollis sp.3 & 1 & & & & & & & 1 & 2 \\
\hline 5016 & Fungus unidentified & 1 & & 1 & & & & & & \\
\hline 5017 & Fungus unidentified & & 1 & & & & & & & \\
\hline 5018 & Fungus unidentified & & 1 & & & & & & & \\
\hline 5019 & Multicellites sp. & & 1 & & & & & & 1 & \\
\hline 5020 & Quilonia sp. & & & & & & & & 1 & \\
\hline 5021 & Fungus unidentified & & & & & & & 1 & & \\
\hline
\end{tabular}

\section{GRÃOS DE PÓLEN}

Divisão POLLENITES Potonié, 1893

Classe VESICULATAE Iversen and Troels-Smith, 1950

Gênero Podocarpidites (Cookson, 1947) ex Couper, 1953 emend. Potonié, 1958

Espécie-tipo: Podocarpidites ellipticus Cookson, 1947

Tipo Podocarpidites sp.

Fig. 6A1-2

Número de registro: 5010

Amostra: FUP-000144

Dimensões: vista polar $62,5 \mu \mathrm{m}$ e vista equatorial $40 \mu \mathrm{m}$ (medidas incluem os sacos aéreos)

Aberturas: inaperturado

Forma/âmbito: esferoidal bissacado

Ornamentação: psilado no grão e intrarreticulado nos sacos aéreos

Descrição: Grão de pólen bissacado, de corpo ovalado em vista polar e equatorial, com exina espessa. Os sacos aéreos estão inseridos lateralmente, apresentando uma superfície intrarreticulada de forma irregular e malha fina.

Afinidade botânica: Família Podocarpaceae (Povilauskas 2012). 
Ambiente: Atualmente são árvores de regiões temperadas (Joly 1993; Colinvaux et al. 1999; Lorenzi 2002; Nascimento 2013).

Classe POLYPLICATAE Erdtman, 1952

Gênero Equisetosporites Daugherty, 1941 emend. Singh, 1964

Espécie-tipo: Equisetosporites chinleana Daugherty, 1941

Tipo Equisetosporites sp.1

Fig. 6B

Número de registro: 5002

Amostra: FUP-000195

Dimensões: vista polar $25 \mu \mathrm{m}$ e vista equatorial $37,5 \mu \mathrm{m}$

Aberturas: inaperturado

Forma/âmbito: perprolato

Ornamentação: estriado (poliplicado)

Descrição: Grãos de pólen poliplicados de formato elíptico. Exina com duas camadas, uma interna lisa e uma externa ornamentada com "costelas" longitudinais e paralelas, em número de três a quatro por face do grão. As "costelas" não chegam a atingir as extremidades dos grãos de pólen, fundindo-se no final.

Afinidade botânica: Família Ephedraceae (Nascimento 2013).

Ambiente: Tropical (Portela 2008; Nascimento 2013). Os representantes atuais e fósseis do gênero Ephedra podem ser pequenas árvores, arbustos ou subarbustos (Yang et al. 2005). São plantas de hábito xeromórfico (Portela et al. 2014), que faz o gênero Ephedra ser comum na forma de arbusto em ambientes desérticos (Simpson 2006).

\section{Tipo Equisetosporites sp.2}

Fig. 6C

Número de registro: 5005

Amostras: FUP-000159 e FUP-000195

Dimensões: vista polar $25 \mu \mathrm{m}$ e vista equatorial $47,5 \mu \mathrm{m}$

Aberturas: inaperturado

Forma/âmbito: subprolato

Ornamentação: estriado (poliplicado)

Descrição: Grãos de pólen poliplicados de formato ovalado. Exina com duas camadas, uma interna lisa e uma externa ornamentada com "costelas" longitudinais e paralelas, separadas por 
depressões finas, em número de 15 a 18 por face do grão. As "costelas" não chegam a atingir as extremidades dos grãos de pólen, fundindo-se no final.

Afinidade botânica: Família Ephedraceae (Nascimento 2013).

Ambiente: Tropical (Portela 2008; Nascimento 2013). Os representantes atuais e fósseis do gênero Ephedra podem ser pequenas árvores, arbustos ou subarbustos (Yang et al. 2005). São plantas de hábito xeromórfico (Portela et al. 2014), que faz o gênero Ephedra ser comum na forma de arbusto em ambientes desérticos (Simpson 2006).

\section{Tipo Equisetosporites sp.3}

Fig. 6D

Número de registro: 5011

Amostra: FUP-000144

Dimensões: vista polar $10 \mu \mathrm{m}$ e vista equatorial $35 \mu \mathrm{m}$

Aberturas: inaperturado

Forma/âmbito: perprolato

Ornamentação: estriado (poliplicado)

Descrição: Grãos de pólen poliplicados de formato elipsoidal. Exina com duas camadas, uma interna lisa e uma externa ornamentada com "costelas" longitudinais e paralelas, separadas por depressões finas, com aproximadamente 10 por face do grão. As "costelas" não chegam a atingir as extremidades dos grãos de pólen, fundindo-se no final.

Afinidade botânica: Família Ephedraceae (Nascimento 2013).

Ambiente: Tropical (Portela 2008; Nascimento 2013). Os representantes atuais e fósseis do gênero Ephedra podem ser pequenas árvores, arbustos ou subarbustos (Yang et al. 2005). São plantas de hábito xeromórfico (Portela et al. 2014), que faz o gênero Ephedra ser comum na forma de arbusto em ambientes desérticos (Simpson 2006).

Gênero Gnetaceaepollenites (Thiergart, 1938) Jansonius, 1963

Espécie-tipo: Gnetaceaepollenites ellipticus Thiergart, 1938

Tipo Gnetaceapollenites sp.

Fig. 6E

Número de registro: 5013

Amostra: FUP-000209

Dimensões: vista polar 22,5 $\mu \mathrm{m}$ e vista equatorial $45 \mu \mathrm{m}$

Aberturas: inaperturado 
Forma/âmbito: subprolato

Ornamentação: estriado (poliplicado)

Descrição: Grão de pólen de formato elipsoidal com cristas e sulcos convergindo para os polos. As "costelas" e "canais" alcançam as extremidades do grão de pólen sem se fundirem.

Afinidade botânica: Ephedraceae/Gnetaceae/Welwitshiaceae (Nascimento 2013). As três famílias fazem parte do grupo das Gnetales ou Gnetophyta, cujos gêneros viventes são Ephedra, Gnetum e Welwitschia (Simpson 2006).

Ambiente: Tropical (Portela 2008; Nascimento 2013).

Classe MONOCOLPATAE Iversen and Troels-Smith, 1950

Gênero Cycadopites (Wodehouse, 1935) Wilson and Webster, 1946 emend. Herbst, 1965

Espécie-tipo: Cycadopites follicularis Wilson and Webster, 1946

Tipo Cycadopites sp.

Fig. 6F

Número de registro: 5003

Amostra: FUP-000195

Dimensões: vista polar $20 \mu \mathrm{m}$ e vista equatorial $32,5 \mu \mathrm{m}$

Aberturas: monocolpado

Forma/âmbito: subprolato

Ornamentação: reticulado

Descrição: Grão de pólen monocolpado de forma prolata e contorno equatorial elíptico. Exina grossa de ornamentação escabrada. Colpo ocupando todo o comprimento do grão, mais aberto nas extremidades que nas regiões próximas do centro.

Afinidade botânica: Cycadaceae (Portela 2008).

Ambiente: Tropical e subtropical (Portela 2008; Nascimento 2013).

Classe MONOPORATAE Iversen and Troels-Smith, 1950

Gênero Classopollis Pflug, 1953

Espécie-tipo: Classopollis classoides Pflug, 1953

Tipo Classopollis sp.1

Fig. 6G

Número de registro: 5008

Amostras: FUP-000144 e FUP000145

Dimensões: $25 \mu \mathrm{m}$ 
Aberturas: monoporado

Forma/âmbito: esferoidal

Ornamentação: rimulado

Descrição: Grãos de pólen rimulados de formato esférico em vista equatorial. Poro distal com formato circular, medindo entre 5 e $7 \mu \mathrm{m}$ de diâmetro, no qual a exina é mais fina.

Afinidade botânica: Família Cheirolepidiaceae (Povilauskas 2012).

Ambiente: Tropical e subtropical (Portela 2008; Nascimento 2013), indicativo de clima árido a semiárido e quente (Duarte et al. 2012; Coelho et al. 2014). Porte arbustivo ou arbóreo (GuerraSommer and Pires 2011).

\section{Tipo Classopollis sp.2}

Fig. $6 \mathrm{H}$

Número de registro: 5014

Amostra: FUP-000130

Dimensões: $27,5 \mu \mathrm{m}$

Aberturas: monoporado

Forma/âmbito: esferoidal

Ornamentação: rimulado

Descrição: Grãos de pólen rimulados de formato esférico em vista equatorial. Poro distal com formato circular e dificilmente observável, medindo aproximadamente $6 \mu \mathrm{m}$ de diâmetro, no qual a exina é mais fina.

Afinidade botânica: Família Cheirolepidiaceae (Povilauskas 2012).

Ambiente: Tropical e subtropical (Portela 2008; Nascimento 2013), indicativo de clima árido a semiárido e quente (Duarte et al. 2012; Coelho et al. 2014). Porte arbustivo ou arbóreo (GuerraSommer and Pires 2011).

Tipo Classopollis sp.3

Fig. 6I

Número de registro: 5015

Amostras: FUP-000130, FUP-000325 e FUP-000328

Dimensões: $32 \mu \mathrm{m}$

Aberturas: monoporado

Forma/âmbito: esferoidal

Ornamentação: rimulado 
Descrição: Grãos de pólen rimulados de formato ovoide em vista equatorial. Poro distal com formato circular, medindo entre 5 e $7 \mu \mathrm{m}$ de diâmetro, no qual a exina é mais fina.

Afinidade botânica: Família Cheirolepidiaceae (Povilauskas 2012).

Ambiente: Tropical e subtropical (Portela 2008; Nascimento 2013), indicativo de clima árido a semiárido e quente (Duarte et al. 2012; Coelho et al. 2014). Porte arbustivo ou arbóreo (GuerraSommer and Pires 2011).

\author{
Incertae sedis \\ Palinomorfo 1 - Tipo Afropollis?
}

Fig. 6J

Número de registro: 5006

Amostras: FUP-000144 e FUP-000145

Dimensões: total de $25 \mu \mathrm{m}$ com a escultura, célula central com aproximadamente 17,5 $\mu \mathrm{m}$

Abertura: inaperturado

Ornamentação: reticulada

Forma/âmbito: esferoidal

Descrição: Pólen inaperturado de pequenas dimensões, consistindo em um corpo central esférico, de exina escura. É circundada por um tipo de perispório. Entretanto, esta estrutura não se assemelha ao perispório finamente reticulado do tipo Afropollis.

Afinidade botânica: Gunneraceae?, representada por plantas arbustivas (Portela 2008).

Ambiente: Família associada a ambiente tropical e subtropical (Nascimento 2013) e pode também indicar aumento de aridez e temperatura (Lima 1978).

\title{
Palinomorfo 2 - Tipo Arecaceae?
}

Fig. 6K

Número de registro: 5012

Amostra: FUP-000282

Dimensões: $30 \mu \mathrm{m}$

Abertura: inaperturado

Ornamentação: gemado

Forma/âmbito: esferoidal

Descrição: Pólen aparentemente inaperturado de formato esférico e exina com ornamentação gemada. Não foi encontrado nenhum palinomorfo semelhante a este nas referências consultadas. Entretanto, tipos polínicos de ornamentação gemada (além de equinada e clavada) de afinidade 
com as arecáceas podem ocorrer no Cretáceo Superior em regiões da África e América do Sul (Friis et al. 2011).

Afinidade botânica: Arecaceae? (Friis et al. 2011).

\section{ESPOROS DE FUNGOS}

Reino FUNGI Whittaker, 1969

Divisão EUMYCOTA Whittaker, 1969

Gênero Pluricellaesporites Van der Hammen, 1954 emend. Elsik and Jansonius, 1974

Tipo Pluricellaesporites sp.

Fig. 6L

Número de registro: 5007

Amostra: FUP-000145

Dimensões: $50 \mu \mathrm{m}$ de comprimento

Descrição: Esporo de formato cilíndrico, multicelado, multiseptado transversalmente e monoporado.

Gênero Multicellites Kalgutkar and Jansonius, 2000

Tipo Multicellites sp.

Fig. 6M

Número de registro: 5019

Amostras: FUP-000144 e FUP-000325

Dimensões: $42,5 \mu \mathrm{m}$ de comprimento

Descrição: Esporo de formato cilíndrico, inaperturado, parede lisa e com quatro células. As duas

células da extremidade são menores e de tamanho igual, enquanto as duas células centrais são maiores.

Gênero Quilonia Jain and Gupta, 1970 emend. Kalgutkar and Jansonius, 2000

\section{Tipo Quilonia sp.}

Fig. $6 \mathrm{~N}$

Número de registro: 5020

Amostra: FUP-000325

Dimensões: $57,5 \mu \mathrm{m}$ de comprimento 
Descrição: Esporo multicelado, piriforme e inaperturado com parede lisa. A extremidade proximal é arredondada e a distal afilada, sendo a última célula apresentando-se mais alongada que as demais.

Outros fungos

Fungo 1

Fig. $6 \mathrm{O}$

Número de registro: 5016

Amostra: FUP-000130

Dimensões: $45 \mu \mathrm{m}$ de comprimento

Fungo 2

Fig. 6P

Número de registro: 5017

Amostra: FUP-000144

Dimensões: $90 \mu \mathrm{m}$ de comprimento

Fungo 3

Fig. 6Q

Número de registro: 5018

Amostra: FUP-000144

Dimensões: $60 \mu \mathrm{m}$ de comprimento

Fungo 4

Fig. 6R

Número de registro: 5021

Amostra: FUP-000282

Dimensões: $90 \mu \mathrm{m}$ de comprimento 


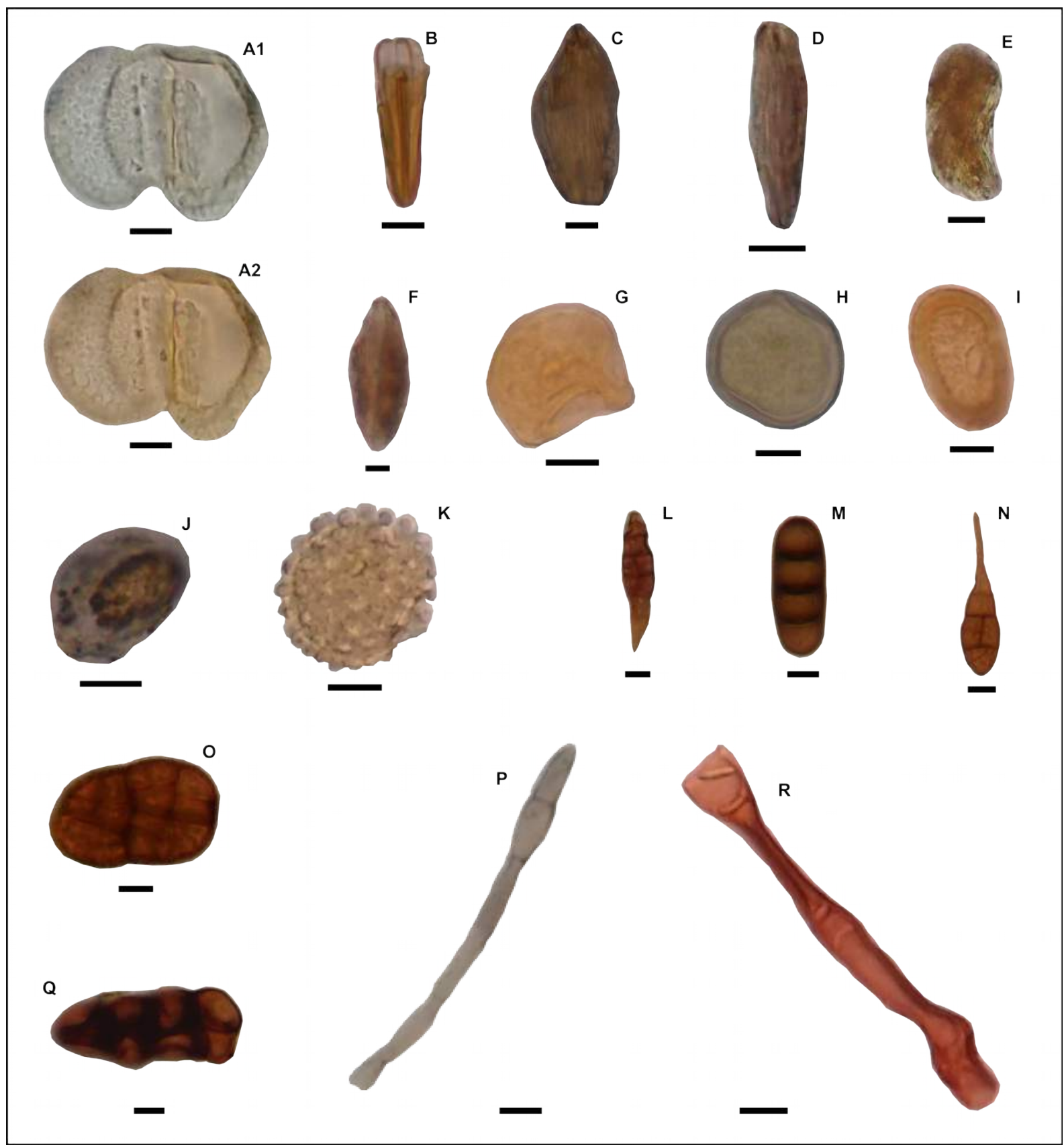

Figura 6. Palinomorfos encontrados em coprólitos dos sítios Peirópolis e Serra da Galga, Uberaba, Minas Gerais, Brasil. Grãos de pólen: A1-2) Podocarpidites sp., amostra FUP-000144 - lâmina C144/1; B) Equisetosporites sp.1, amostra FUP-000195 - lâmina C195/1; C) Equisetosporites sp.2, amostra FUP-000159 - lâmina C159/2; D) Equisetosporites sp.3, amostra FUP-000144 - lâmina C144/2; E); Gnetaceaepollenites sp., amostra FUP-000209 - lâmina C209/1; F) Cycadopites sp., amostra FUP-000195 - lâmina C195/1; G) Classopollis sp.1, amostra FUP-000145 - lâmina C145/1; H) Classopollis sp.2, amostra FUP-000130 - lâmina C130/1; I) Classopollis sp.3, amostra FUP-000328 lâmina C328/2; J) Palinomorfo 1 - Afropollis?, amostra FUP-000145 - lâmina C145/1; K) Palinomorfo 2 Arecaceae?, amostra FUP-000282 - lâmina C282/1. Fungos: L) Pluricellaesporites sp., amostra FUP-000145 - lâmina C145/1; M) Multicellites sp., amostra FUP-000325 - lâmina C325/1; N) Quilonia sp., amostra FUP-000325 - lâmina C325/2; O) Fungo 1, amostra FUP-000130 - lâmina C130/1; P) Fungo 2, amostra FUP-000144 - lâmina C144/1; Q) Fungo 3, amostra FUP-000144 - lâmina C144/2; R) Fungo 4, amostra FUP-000282 - lâmina C282/2. Escala = $10 \mu \mathrm{m}$. 


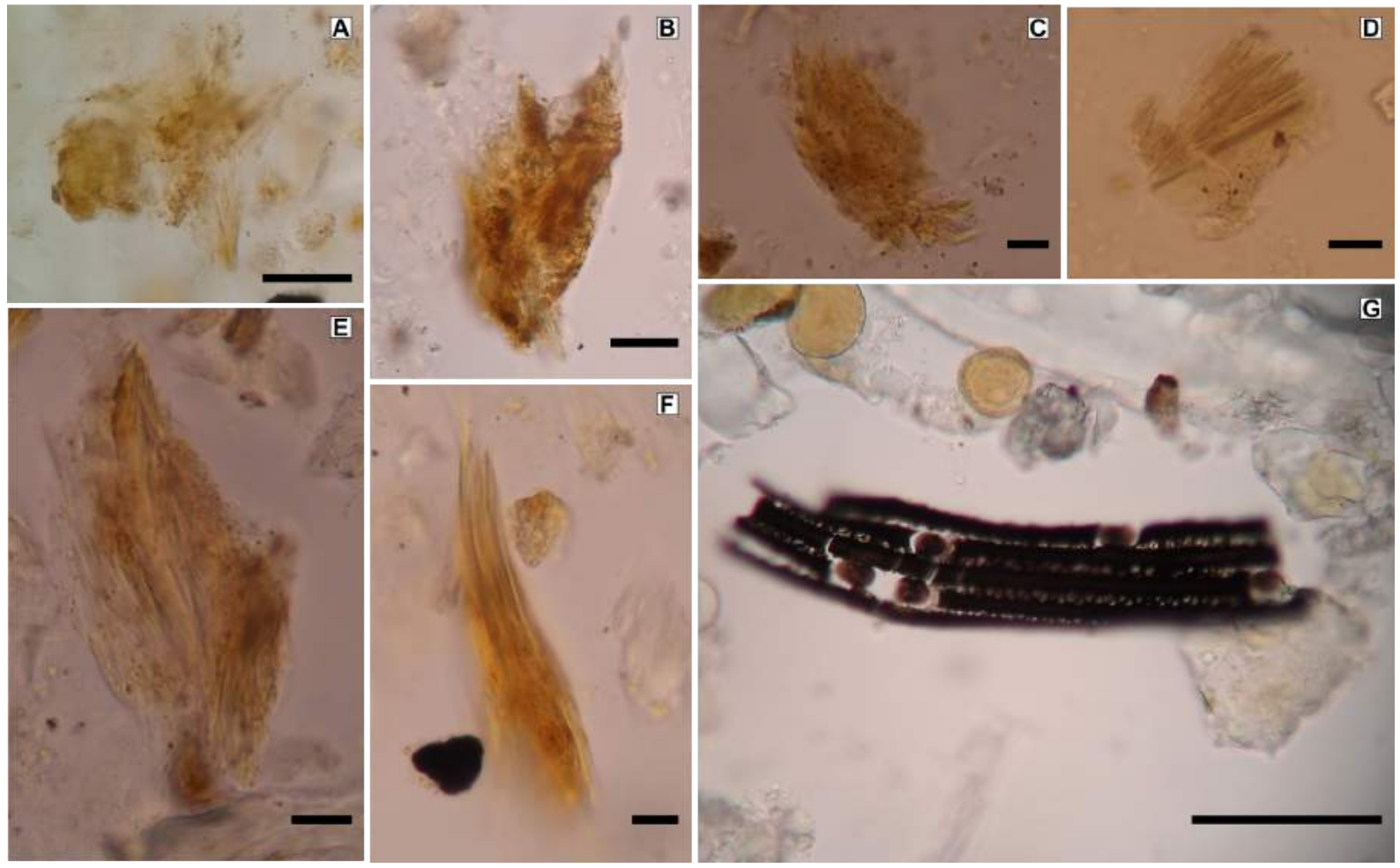

Figura 7. Prováveis fragmentos vegetais encontrados em coprólitos dos sítios paleontológicos Peirópolis e Serra da Galga, Uberaba, Minas Gerais, Brasil. A-F) Matéria vegetal não digerida nas amostras FUP-000134 - lâmina C134/2 (A), FUP-000144 - lâmina C144/1 (B), FUP-000145 - lâmina C145/2 (C), FUP-000156 - lâmina C156/2 (D), FUP000217 - lâmina C217/1 (E) e FUP-000242 - lâmina C242/1 (F); G) Provável cutícula vegetal com estômatos da amostra FUP-000195 - lâmina C195/1. Escala $=100 \mu \mathrm{m}$.

Coprólitos de idade maastrichtiana da Formação Lameta, Índia, revelaram conteúdo palinológico composto por pteridófitos, angiospermas, gimnospermas, fungos, algas, diatomáceas e restos vegetais não digeridos (Samant and Mohabey 2014), incluindo tipos encontrados nos coprólitos de Peirópolis e Serra da Galga como os tipos polínicos Podocarpidites e Cycadopites e esporos de fungos dos tipos Pluricellaesporites e Quilonia. Restos de fungos já foram relatados em uma variedade de coprólitos, especialmente do Quaternário (Davis 2006). Adicionalmente, Samant and Mohabey (2014) também encontraram nos coprólitos cutículas com estômatos, muito semelhante às encontradas nos coprólitos deste estudo (Fig. 7G).

\subsection{Avaliação paleoecológica e paleoambiental}

Entre os coprólitos, 11 amostras apresentam morfologia indeterminada por estarem muito fragmentadas ou desgastadas por transporte. O único coprólito de morfologia cilíndrica analisado não apresentou indícios de palinomorfos ou restos vegetais. Este coprólito também apresenta calcita na sua constituição, que pode estar relacionado com a substituição do fosfato de cálcio (Souto 2003) ou ter sofrido efeito da fossildiagênese. Este resultado sugere que o coprólito 
em questão pode ter sido produzido por um animal de dieta carnívora. De fato, coprólitos cilíndricos do Grupo Bauru têm sido associados a animais carnívoros, como os crocodilomorfos (Souto 2003). Somente na região de Uberaba foram encontrados os crocodilomorfos Itasuchus jesuinoi (Price 1955), Peirosaurus tormini (Price 1955) e Uberabasuchus terrificus (Carvalho et al. 2004). Por outro lado, os demais coprólitos apresentam material silicático em sua composição. Neste estudo os morfotipos cônicos e dômicos revelaram presença de palinomorfos e restos vegetais. Morfotipos ovoides, cônicos e dômicos podem ter sido produzidos por herbívoros ou onívoros (Souto 2003) de diversos grupos como anfíbios, quelônios, dinossauros, répteis, aves e mamíferos (Murie 1974; Halfpenny and Biesiot 1986; Souto 2003). Os resultados aqui encontrados também reforçam esta hipótese. A presença de sílica nos coprólitos pode estar relacionada com a substituição de material vegetal por este mineral. No Grupo Bauru, esta hipótese já havia sido levantada por outros autores (Souto 2003; Souto and Fernandes 2015).

Quanto ao conteúdo palinológico dos coprólitos, dos 34 palinomorfos presentes foram encontrados 18 tipos polínicos de Equisetosporites, Cycadopites, Classopollis, Podocarpidites e Gnetaceaepollenites, quatro não identificados (incertae sedis) e os 12 restantes são esporos de fungos. Nos dois coprólitos do afloramento da BR-050 (FUP-000325 e FUP-000328) foram observados apenas exemplares de Classopollis. Os resultados indicam baixa diversidade e concentração de palinomorfos por centímetro cúbico de amostra (Fig. 8), que somado a inexistência de trabalhos de cunho palinológico na região impede a confecção de interpretações bioestratigráficas precisas, mas os tipos polínicos encontrados são condizentes com a idade campaniana/maastrichtiana. Por outro lado, a presença destes palinomorfos revela importantes informações sobre a paleovegetação e o paleoclima da área durante a época em que os coprólitos foram produzidos.

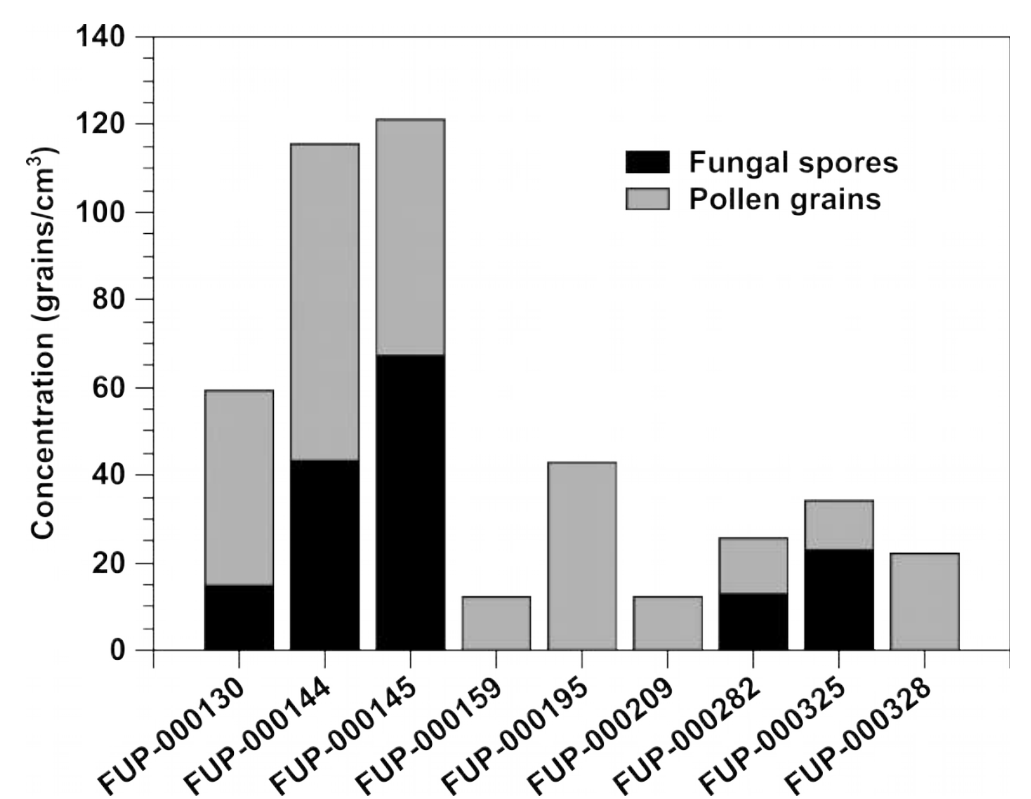

Figura 8. Concentração estimada de palinomorfos presentes em um centímetro cúbico de amostra. 
Resultados palinológicos de coprólitos humanos e animais têm sido utilizados para interpretações paleoambientais e composição da vegetação na época e local onde seus produtores viveram (Waldman and Hopkins 1970; Chaves and Renault-Miskovsky 1996; Carrión 2001; Carrión et al. 2001; Chaves 2001; Vijaya and Singh 2009). Entretanto, esses resultados devem ser interpretados com parcimônia pois representam um conteúdo ingerido e não deve representar a totalidade do ambiente. Na região dos sítios Peirópolis e Serra da Galga, os dados indicam que o paleoclima denota condições semiáridas a áridas (Fernandes and Coimbra 2000; Carvalho 2001; Fernandes 2004). De fato, a ocorrência dos tipos polínicos Classopollis, Equisetosporites e Gnetaceaepollenites sugerem a presença de um clima árido e quente (Lima et al. 1986; Castro et al. 2002; Duarte et al. 2012; Coelho et al. 2014; Portela et al. 2014; Arai et al. 2015). Apesar da baixa concentração polínica, os resultados sugerem um conjunto onde predominaram as plantas arbustivas (gnetófitas), com presença de elementos arbóreos (coníferas) e cicadáceas resistentes a condições mais áridas. Esta interpretação é reforçada pela completa ausência de esporos pteridófitos, que poderiam indicar maior umidade (Duarte et al. 2012), associado ao fato que alguns dos elementos vegetais encontrados apresentam hábito xeromórfico (Portela et al. 2014).

Na Formação São Carlos, o aumento do pólen de angiospermas em alguns níveis foi interpretado como redução das condições de aridez (Lima et al. 1986; Castro et al. 2002). Estes tipos polínicos foram muito pouco representados nos coprólitos de Peirópolis e Serra da Galga. Aparentemente, o registro palinológico sugere que o paleoclima da região, durante a época de produção dos coprólitos, parece ter sido mais seco e árido que as condições encontradas nos níveis da Formação São Carlos. Por outro lado, a presença do tipo Podocarpidites (Podocarpaceae), que em princípio pode indicar condições não tropicais, deve ser interpretado com parcimônia. É possível que seja uma planta adaptada ao deficit hídrico na região. Cabe destacar também que a estrutura bissacada deste palinomorfo permite que seja transportado por grandes distâncias (Salgado-Labouriau 1973, 1994) e poderia ser originário de regiões mais altas (Lima et al. 1986), já que o coprólito onde este palinomorfo foi encontrado (FUP-000144) estava depositado em leque aluvial.

Quanto à presença dos esporos de fungos nos coprólitos, é possível que sejam resultantes de emboloramento das próprias fezes, assim que foram produzidas e ficaram em exposição. Ou até mesmo ingeridos junto com o alimento. A presença de um tipo de fungo micorriza (Glomus) em coprólitos da Formação Lameta, Índia foi interpretada como contaminação após ter sido excretado no solo (Sharma et al. 2005). Por outro lado, neste mesmo trabalho (Sharma et al. 2005) a presença de fungos de plantas foi utilizada para inferir uma dieta herbívora, provavelmente do saurópode Isisaurus (Titanosaurus). Um estudo interessante (Chin 2007) demonstra que coprólitos 
do dinossauro ornitísquio Maiasaura da Formação Two Medicine, Montana apresentam indícios do consumo de madeira degradada por fungos, comportamento que pode ter ocorrido em momentos de baixa oferta de alimento.

Em campo, nossa análise sedimentológica do afloramento em Peirópolis mostra que os coprólitos estão contidos essencialmente em arenitos conglomeráticos, com estratificação cruzada tabular a acanalada e com seixos dispostos de forma caótica na matriz, indicando que se trata de depósitos de leques aluviais. Por outro lado, no sítio Serra da Galga os níveis que contêm coprólitos apresentam seixos dispostos horizontalmente, indicando deposição fluvial. Adicionalmente, diversos coprólitos apresentam seixos ou moldes destes, o que ilustra um contexto deposicional diferente do observado nos afloramentos. Isso demonstra que, provavelmente, os coprólitos foram produzidos em local com presença de seixos e passaram por um longo período de seca. Souto (2003) relaciona as rachaduras de ressecamento nos coprólitos com condições de elevada temperatura e baixa umidade. De fato, quando não estão muito desgastados por transporte os coprólitos aqui estudados podem apresentar grandes rachaduras de ressecamento. É provável que, após um longo período de seca, repentinas inundações transportaram os coprólitos até a área fonte nos afloramentos.

\section{Conclusão}

$\mathrm{Na}$ região dos sítios Peirópolis e Serra da Galga ocorrem coprólitos em relativa abundância, junto a nódulos inorgânicos carbonáticos (pseudocoprólitos). Isso demonstra a variedade de organismos que habitaram os paleoambientes em questão. A metodologia empregada na preparação palinológica dos coprólitos foi positiva e apresentou os primeiros registros polínicos da Formação Marília. Entretanto, a associação palinológica encontrada nos coprólitos não se mostrou muito diversificada, ocorrendo também em baixas concentrações. Devido à baixa diversidade, associado à ausência de dados palinológicos, não foi possível realizar qualquer inferência bioestratigráfica. De toda forma, os palinomorfos encontrados são condizentes com a idade campaniana/maastrichtiana classicamente reportada para o Membro Serra da Galga na literatura. O conjunto polínico encontrado sugere a presença de um clima árido e quente, resultado que condiz com dados sedimentológicos. Os palinomorfos indicam a presença de plantas arbustivas e arbóreas, representadas por gnetófitas, coníferas e cicadáceas. Entretanto, o conjunto polínico dos coprólitos deve ser mais específico, representando apenas parte do conjunto vegetacional. A presença do tipo Podocarpidites entre os tipos polínicos pode 
não ter relação apenas com a capacidade de dispersão destes palinomorfos, mas pode também representar uma adaptação as condições ambientais da região. A presença de palinomorfos e restos vegetais em parte das amostras analisadas sugerem que os vertebrados produtores desses coprólitos eram herbívoros e, com base no tamanho desses coprólitos e o registro fóssil desses afloramentos, infere-se que esse material tenha sido produzido por dinossauros saurópodes, no caso, titanossauros. Pela primeira vez, registra-se a presença de fungos no Grupo Bauru. A presença de fungos associados aos coprólitos pode estar relacionada com o processo de decomposição e ressecamento desses coprólitos.

Agradecimentos: os autores agradecem a Luiz Carlos Borges Ribeiro (Museu dos Dinossauros/CPP L. I. Price) por todo apoio durante o desenvolvimento do trabalho. Agradecemos também ao Laboratório de Difração de Raios-X do Instituto de Geociências da UnB, pela análise das amostras e ao Laboratório de Paleoecologia da PUC-GO, onde as amostras palinológicas foram processadas e analisadas.

\section{Referências}

AMSTUTZ, G. C. 1958. Coprolites: a review of the literature and a study of specimens from Southern Washington. Journal of Sedimentary Petrology, 28, 498-508.

APAALSE, L. A. and ATTA-PETERS, D. 2013. Cretaceous-Palaeogene Palynology of the Keta1 Well Offshore Keta Basin, Southeastern Ghana. World Applied Sciences Journal, 23, 15761583.

ARAI, M., DIAS-BRITO, D., CASTRO, J. C. and ASSINE, M. L. 2015. Palinologia da Formação São Carlos (Grupo Bauru, Cretáceo Superior): implicações cronoestratigráficas e paleoambientais. $8^{\text {th }}$ Simpósio do Cretáceo do Brasil, Campos do Jordão, p. 1.

ARAI, M. and DUARTE, S. G. 2010. Tricomas fósseis como nova categoria de palinomorfos lato sensu: sua classificação preliminar e aplicabilidade na Bioestratigrafia. Boletim do Museu Paraense Emílio Goeldi, 5, 175-188.

ARAujO, M. N., FERrEirA, E. P., CARVAlHO, I. S. and CARVALHO, M. A. 2011. Análise sedimentar e palinológica em afloramento da Formação Periá, Bacia de São Luís (Brasil). 8192. In CARVALHO, I. S., SRIVASTAVA, N. K., STROHSCHOEN, JR., O. and LANA, C. C. (eds). Paleontologia: cenários de vida. Editora Interciência, Rio de Janeiro, v. 3, 476 pp. 
ARCHANGELSKY, A. and LLORENS, M. 2009. Palinología de la Formación Kachaike, Cretácico Inferior de la Cuenca Austral, provincia de Santa Cruz. Granos de polen de Gimnospermas. Ameghiniana, 46, 225-234.

ATTA-PETERS, D. and SALAMI, M. B. 2006. Aptian-Maastrichtian palynomorphs from the offshore Tano Basin, western Ghana. Journal of African Earth Sciences, 46, 379-394.

ATTA-PETERS, D., AGAMA, C. I., ASIEDU, D. K. and APESEGAH, E. 2013. Palynology, palynofacies and palaeoenvironments of sedimentary organic matter from Bonyere -1 Well, Tano basin, western Ghana. International Letters of Natural Sciences, 5, 27-45.

BARBERI, M. 2001. Mudanças paleoambientais na região dos cerrados do Planalto Central durante o Quaternário Tardio: o estudo da lagoa Bonita, DF. PhD Thesis, Programa de Pósgraduação em Geologia Sedimentar, Instituto de Geociências, Universidade de São Paulo, 210 pp.

BON, C., BERTHONAUD, V., MAKSUD, F., LABADIE, K., POULAIN, J., ARTIGUENAVE, F., WINCKER, P., AURY, J. M. AND ELALOUF, J. M. 2012. Coprolites as a source of information on the genome and diet of the cave hyena. Proceedings of the Royal Society B, 279, 2825-2830.

BRYANT, V. M. 2003. Invisible clues to New World plant domestication. Science, 299, 1029-1030.

CARrión, J. S., GIL, G., RODRÍGUEZ, E., FUENTES, N., GARCÍA-ANTÓN, M. and ARRIBAS, A. 2005. Palynology of badger coprolites from central Spain. Palaeogeography, Palaeoclimatology, Palaeoecology, 226, 259-271.

CARRIÓN, J. S., RIQUELME, J. A., NAVARRO, C. and MUNUERA, M. 2001. Pollen in hyena coprolites reflects Late Glacial landscape in southern Spain. Palaeogeography, Palaeoclimatology, Palaeoecology, 176, 193-205.

CARVALHO, I. S. 2001. A bacia Bauru. 167-177. In BRITO I. M. (ed). Geologia histórica. Edufu, Uberlândia, 413 pp.

CARVALHO, I. S., RIBEIRO, L. C. B. and AVILLA, L. S. 2004. Uberabasuchus terrificus sp. nov., a new Crocodylomorpha from the Bauru Basin (Upper Cretaceous), Brazil. Gondwana Research, 7, 975-1002.

CASTRO, J. C., DIAS-BRITO, D., ARAI, M., RODRIGUES, R. and MUSACCHIO, E. A. 2002. Formação São Carlos: uma nova unidade para o Grupo Bauru (Cretáceo continental do Brasil). $\sigma^{\text {th }}$ Simpósio sobre o Cretáceo do Brasil / $2^{\text {nd }}$ Simposio sobre el Cretácico de América del Sur, São Pedro, pp. 351-357. 
CHAVES, S. A. M. 2000. New paleovegetational and paleoethnobotanical perspectives on Brazil's Central Plateau: a palynological proposal. Revista da Universidade de Guarulhos (Geociências V), Special Issue, $164-167$.

CHAVES, S. A. M. 2001. Análise palinológica de coprólitos pré-históricos holocênicos coletados na Toca do Boqueirão do sítio da Pedra Furada. Contribuições paleoetnológicas, paleoclimáticas e paleoambientais para a região sudeste do Piauí, Brasil. Revista do Museu de Arqueologia e Etnologia, 10, 103-120.

CHAVES, S. A. M. and REINHARD, K. J. 2006. Critical Analysis of Coprolite Evidence of Medicinal Plant Use, Piauí, Brazil. Palaeogeography, Palaeoclimatology, Palaeoecology, 237, 110-118.

CHAVES, S. A. M. and RENAULT-MISKOVSKY, J. 1996. Paléoethnologie, paléoenvironnement et paléoclimatologie au Piauí, Brésil: apport de l'étude pollinique de coprolithes humains recueills dans le gisement préhistorique Pléistocène de "Pedra Furada". Comptes Rendus de l'Académie des Sciences, 322, 1053-1060.

CHIAghanAm, O. I., IKEGWUONU, O. N., CHIADIKOBI, K. C., NWOZOR, K. K., OFOMA, A. E. and OMOBORIOWO, A. O. 2012. Sequence Stratigraphy and Palynological Analysis of late Campanian to Maastrichtian Sediments in the Upper-Cretaceous, Anambra Basin. A Case Study of Okigwe and its Environs, South-Eastern, Nigeria. Advances in Applied Science Research, 3, 962-979.

CHIN, K. 2002. Analyses of coprolites produced by carnivorous vertebrates. Paleontological Society Press, 8, 43-50.

CHIN, K. 2007. The paleobiological implications of herbivorous dinosaur coprolites from the Upper Cretaceous Two Medicine Formation of Montana: why eat wood? Palaios, 22, 554566.

CHIN, K., HARTMAN, J. H. and ROTH, B. 2009. Opportunistic exploitation of dinosaur dung: fossil snails in coprolites from the Upper Cretaceous Two Medicine Formation of Montana. Lethaia, 42, 185-198.

COELHO, A. C. M. Q., ANTONIOLI, L., DINO, R. and PORTELA, H. A. 2014. Avaliação do potencial gerador de petróleo da seção Aptiana-Albiana da Bacia de Sergipe, integrando análises palinofaciológicas e dados de geoquímica orgânica. Brazilian Journal of Geology, 44, 579-595.

COIMBRA, J. C., ARAI, M. and CARREÑO, A. L. 2002. Biostratigraphy of Lower Cretaceous microfossils from the Araripe Basin, northeastern Brazil. Geobios, 35, 687-698. 
COLINVAUX, P. A., DE OLIVEIRA, P. E. and PATINO, E. M. 1999. Amazon pollen manual and atlas / Manual e atlas palinológico da Amazônia. Harwood Academic Publishers, Amsterdan, 332 pp.

DAVIS, O. K. (ed). 2006. Advances in the interpretation of pollen and spores in coprolites. Palaeogeography, Palaeoclimatology, Palaeoecology, 237, 1-118.

DIAS-BRITO, D., MUSACCHIO, E. A., CASTRO, J. C., MARANHÃO, M. S. A. S., SUÁREZ, J. M. and RODRIGUES, R. 2001. Grupo Bauru: uma unidade continental do Cretáceo no Brasil - concepções baseadas em dados micropaleontológicos, isotópicos e estratigráficos. Revue de Paléobiologie, 20, 245-304.

DUARTE, S. G., ARAI, M. and WANDERLEY, M. D. 2012. Significado paleoambiental da família Anemiaceae no Cretáceo do Brasil: inferências a partir de dados palinológicos. Revista do Instituto Geológico, 33, 1-12.

EISAWI, A. A. M., IBRAHIM, A. B., RAHIM, O. B. A. and SCHRANK, E. 2012. Palynozonation of the Cretaceous to Lower Paleogene strata of the Muglad Basin, Sudan. Palynology, 36, 191-207.

EISAWI, A. and SCHRANK, E. 2008. Upper Cretaceous to Neogene palynology of the Melut Basin, Southeast Sudan. Palynology, 32, 101-129.

ERIKSSON, M. E., LINDGREN, J., CHIN, K. and MÅNSBY, U. 2011. Coprolite morphotypes from the Upper Cretaceous of Sweden: novel views on an ancient ecosystem and implications for coprolite taphonomy. Lethaia, 44, 455-468.

FAEGRI, K. and IVERSEN, P. 1950. Text-book of modern pollen analysis. Ejnar Munksgaard, Copenhagen, $168 \mathrm{pp}$.

FERNANDES, L. A. 1998. Estratigrafia e evolução geológica da parte Oriental da Bacia Bauru (Ks, Brasil). PhD Thesis, Programa de Pós-graduação em Geociências, Universidade de São Paulo, São Paulo, 216 pp.

FERNANDES, L. A. 2004. Mapa litoestratigráfico da parte oriental da Bacia Bauru (PR, SP, MG), escala 1:1.000.000. Boletim Paranaense de Geociências, 55, 53-66.

FERNANDES, L. A. 2010. Calcretes e registros de paleossolos em depósitos continentais neocretáceos (Bacia Bauru, Formação Marília). Revista Brasileira de Geociências, 40, 19-35.

FERNANDES, L. A. and COIMBRA, A. M. 1996. A Bacia Bauru (Cretáceo Superior, Brasil). Anais da Academia Brasileira de Ciências, 68, 195-205.

FERreirA, E. P., CARVALHO, M. A. and VIVIERS, M. C. Palinologia (fungos) da Formação Calumbi, Paleoceno da Bacia de Sergipe, Brasil. Arquivos do Musen Nacional, 63, 395-410. 
FERREIRA, N. N., FERREIRA, E. P. and CARVALHO, I. S. 2013. Registro de Cutículas com Estômatos em Associação Palinológica da Formação Itapecuru (Albiano), Bacia do Parnaíba, Brasil. Anuário do Instituto de Geociências, 36, 16-24.

FERREIRA, N. N., FERREIRA, E. P., CARVALHO, I. S. and CARVALHO, M. A. 2011. Análise sedimentológica e palinológica dos depósitos do Afloramento Querru, Formação Itapecuru, Bacia do Parnaíba. 93-103. In CARVALHO, I. S., SRIVASTAVA, N. K., STROHSCHOEN, JR., O. and LANA, C. C. (eds). Paleontologia: cenários de vida. Editora Interciência, Rio de Janeiro, v. 3, 476 pp.

FRANCISCHINI, H., PAES-NETO, V. D., MARTINELli, A. G., PEREIRA, V. P., MARINHO, T. S., TEIXEIRA, V. P. A., FERRAZ, M. L. F., SOARES, M. B. and SCHULTZ, C. L. 2016. Invertebrate traces in pseudo-coprolites from the Upper Cretaceous Marília Formation (Bauru Group), Minas Gerais State, Brazil. Cretaceous Research, 57, 29-39.

FRANCISCHINI, H., PAES-NETO, V. D., MARTINELLI, A. G., SOARES, M. B., SCHULTZ, C. L., MARINHO, T. S., FERRAZ, M. L. F. and TEIXEIRA, V. P. A. 2014. Invertebrate trace fossils on vertebrate coprolites from the Upper Cretaceous Marilia Formation (Bauru Group) of Uberaba (Minas Gerais State, Brazil). $4^{\text {th }}$ International Palaeontological Congress, Mendoza, pp. 239.

FRIEDMAN, V. 2012. Vertebrate coprolites from the lower Eagle Ford Group of north central Texas and their paleoecological significance. New Mexico Museum of Natural History, 57, 221228.

FRIIS, E. M., CRANE, P. R. and PEDERSEN, K. R. Early Flowers and Angiosperm Evolution. Cambridge University Press, Cambridge, 596 pp.

GHILARDi, R. P., D’ÁGOSTA, F. C. P., ALVES, K. and CAMPOS, A. C. A. 2011. Tafonomia de moluscos fósseis do Grupo Bauru (Cretáceo Superior, Bacia Bauru), na região do município de Monte Alto, São Paulo, Brasil. Boletim do Musen Paraense Emílio Goeldi, 6, $197-$ 206.

GOBBO-RODRIGUES, S. R. 2002. Caulóides de Charophyta maastrichtianos na Formação Marília (Grupo Bauru) na região de Uberaba (MG), Brasil. $6^{\text {th }}$ Simpósio sobre o Cretáceo do Brasil / $2^{\text {nd }}$ Simposio sobre el Cretácico de América del Sur, São Pedro, pp. 395-399.

GODFREY, S. J. and SMITH, J. B. 2010. Shark-bitten vertebrate coprolites from the Miocene of Maryland. Naturwissenschaften, 97, 461-467.

GONZÁLEZ-SAMPÉRIZ, P., MONTES, L. and UTRILLA, P. 2003. Pollen in hyena coprolites from Gabasa Cave (northern Spain). Review of Palaeobotany and Palynology, 126, 7-15. 
GUERRA-SOMMER, M. and PIRES, E. F. 2011. Gimnospermas. 271-331. In CARVALHO, I. S. (ed). Paleontologia: paleovertebrados, paleobotânica. $3^{\text {rd }}$ edn. Editora Interciência, Rio de Janeiro, v. 3, 429 pp.

HALFPENNY, J. C. and BIESIOT, E. A. 1986. A field guide to mammal tracking in North America. $2^{\text {nd }}$ edn. Johnson Books, Boulder, 161 pp.

HÄNTZSCHEL, W, EL-BAZ, F. and AMSTUTZ, G. C. 1968. Coprolites: an annotated bibliography. Memoir Geological Society of America, 108, 1-132.

HUNT, A. P., CHIN, K. and LOCKLEY, M. G. 1994. The palaeobiology of vertebrate coprolites. 221-240. In DONOVAN, S. K. (ed). The palaeobiology of trace fossils. John Hopkins University Press, Baltimore, 308 pp.

JEPSEN, G. L. 1963. Eocene vertebrates coprolites and plants in the Golden Valley Formation of Western North Dakota. Bulletin of Geological Society America, 74, 673-684.

JOLY, A. B. 1993. Botânica: introdução à taxonomia vegetal. $11^{\text {th }}$ edn. Companhia Editora Nacional, São Paulo, 777 pp.

KOTOVA, I. Z. 1978. Spores and Pollen from Cretaceous Deposits of the Eastern North Atlantic Ocean, Deep Sea Drilling Project, Leg 41, Sites 367 and 370. 841-881. In LANCELOT, Y., SEIBOLD, E., DEAN, W. E., JANSA, L. F., EREMEEV, V., GARDNER, J., CEPEK, P., KRASHENINNIKOV, V. A., PFLAUMANN, U., JOHNSON, D., RANKIN, J. G. and TRABANT, P. (eds). Initial Reports of the Deep Sea Drilling Project. U. S. Government Printing Office, Washington, v. 41, 1259 pp.

LIMA, M. R. 1978. Palinologia da Formação Santana (Cretáceo do Nordeste do Brasil). PhD Thesis, Instituto de Geociências, Universidade de São Paulo, São Paulo, 334 pp.

LIMA, M. R. 1982. Palinologia da Formação Codó na região de Codó, Maranhão. Boletim do Instituto de Geociências, 13, 116-128.

LIMA, M. R., MEZZALIRA, S., DINO, R. and SAAD, A. R. 1986. Descoberta de microflora em sedimentos do Grupo Bauru, Cretáceo do Estado de São Paulo. Revista IG, 7, 5-9.

LORENZI, H. 2002. Árvores brasileiras: manual de identificação e cultivo de plantas arbóreas nativas do Brasil. $4^{\text {th }}$ edn. Plantarum, Nova Odessa, v. 1, 368 pp.

MASURE, E., RAUSCHER, R., DEJAX, J., SCHULER, M. and FERRÉ, B. 1998. CretaceousPaleocene palynology from the Côte D'Ivoire-Ghana transform margin, sites 959, 960, 961, and 962. 253-276. In MASClE, J., LOHMANN, G. P. and MOULLADE, M. (eds). Proceedings of the Ocean Drilling Program, Scientific Results. Ocean Drilling Program / Texas A\&M University, College Station, v. 159, 613 pp. 
MCLACHLAN, I. R. and PIETERSE, E. 1978. Preliminary Palynological Results: Site 361, Leg 40, Deep Sea Drilling Project. 857-881. In BOLLI, H. M., RYAN, W. B. F., MCKNIGHT, B. K., KAGAMI, H., MELGUEN, M., SIESSER, W. G., NATLAND, J. H., LONGORIA, J. F., DECIMA, F. P., FORESMAN, J. B. and HOTTMAN, W. E. (eds). Initial Reports of the Deep Sea Drilling Project. U. S. Government Printing Office, Washington, v. 40, 1079 pp.

MILANI, E. J. 1997. Evolução tectono-estratigráfica da bacia do Paraná e seu relacionamento com a geodinâmica Fanerozóica do Gondwana Sul-Ocidental. PhD Thesis, Programa de Pós-graduação em Geociências, Universidade Federal do Rio Grande do Sul, Porto Alegre, 255 pp.

MILANI, E. J., FRANÇA, A. B. and Schneider, R. L. 1994. Bacia do Paraná. Boletim de Geociências da Petrobras, 8, 69-82.

MILANI, E. J., MELO, J. H. G, SOUZA, P. A., FERNANDES, L. A. and FRANÇA, A. B. 2007. Bacia do Paraná. Boletim de Geociências da Petrobras, 15, 265-287.

MORGAN, R. 1978. Albian to Senonian Palynology of Site 364, Angola Basin. 915-951. In BOLLI, H. M., RYAN, W. B. F., MCKNIGHT, B. K., KAGAMI, H., MELGUEN, M., SIESSER, W. G., NATLAND, J. H., LONGORIA, J. F., DECIMA, F. P., FORESMAN, J. B. and HOTTMAN, W. E. (eds). Initial Reports of the Deep Sea Drilling Project. U. S. Government Printing Office, Washington, v. 40, 1079 pp.

MURIE, O. J. 1974. A field guide to animal tracks. $2^{\text {nd }}$ edn. Houghton Mifflin, Boston, 374 pp.

NARVÁEZ, P. L., PRÁMPARO, M. B. and SABINO, I. F. 2014. First palynologic record of the Cretaceous la Yesera Formation (Salta Group), Northwestern Argentina. Revista Brasileira de Paleontologia, 17, 141-156.

NASCIMENTO, L. R. S. L. 2013. Palinoestratigrafia e paleoecologia da sequência lacustre do Cretáceo Inferior, em Serra Negra-PE, Bacia Sedimentar do Jatobá, NE do Brasil. PhD Thesis, Programa de Pós-graduação em Geociências, Universidade Federal de Pernambuco, 146 pp.

OLIVEIRA, F. A., CAPUZZO, J. P., BARBERI, M., HOVIKOSKI, J. and RÄSÄNEN, M. 2007. Caracterização da vegetação do Distrito de Madre de Dios (Amazônia Peruana) durante o Mioceno Superior com base em análise palinológica e paleoecológica. $8^{\text {th }}$ Congresso de Ecologia do Brasil, Caxambu, pp. 1-2. Published in: www.sbe-ecologia.org.br/viiiceb/pdf/671.pdf.

OLIVEIRA, M. A. 2011. Análise palinológica, bioestratigráfica e paleoambiental dos sedimentos maastrichtianos/paleocenos da Bacia da Paraíba. MS Dissertation, Programa de Pósgraduação em Geociências, Universidade Federal de Pernambuco, 121 pp. 
OLOTO, I. N. and YIKAREBOGHA, Y. 2013. High Resolution Palynological Studies Of Upper Cretaceous Succession Of Mushe-1 Well, Central Chad Basin, Nigeria. International Journal of Scientific \& Technology Research, 2, 204-211.

OLOTO, I. N., YIKAREBOGHA, Y. and OMOBORIOWO, A. O. 2013. Palynological studies of Upper Cretaceous succession of Herwa-1 Well, Central Chad Basin, Nigeria. International Journal of Innovative Research in Science, Engineering and Technology, 2, 880-889.

OTTONE, E. G. 2009. La flora Cretácica de Cuenca Neuquina, su significado paleoambiental y paleoclimático. Revista de la Asociación Geológica Argentina, 65, 373-386.

OWOCKI, K., NIEDŹWIEDZKI, G., SENNIKOV, A. G., GOLUBEV, V. K., JANISZEWSKA, K. and SULEJ, T. 2012. Upper Permian vertebrate coprolites from Vyazniki and Gorokhovets, Vyatkian regional stage, Russian Plataform. Palaios, 27, 867-877.

POINAR, JR., G, and BOUCOT, A. J. 2006. Evidence of intestinal parasites of dinosaurs. Parasitology, 133, 245-249.

PORTELA, H. A. 2008. Estudo palinológico e palinofaciológico da Formação Santana, Bacia do Araripe, nordeste do Brasil. MS Dissertation, Programa de Pós-graduação em Análise de Bacias e Faixas Móveis, Universidade do Estado do Rio de Janeiro, 133 pp.

PORTELA, H. A., ANTONIOLI, L., DINO, R. and GARCIA, M. J. 2014. Caracterização palinoflorística e paleoambiental da Formação Santana (Cretáceo Inferior), Poço 4-BO-1-PE, Bacia do Araripe, Nordeste do Brasil. Revista Brasileira de Paleontologia, 17, 363-372.

POVILAUSKAS, L. 2012. Palinología de la Formación Monte Chico (Cretácico Tardío) de la Provincia de Santa Cruz, Argentina: gimnospermas. Revista Brasileira de Paleontologia, 15, 85-94. POVILAUSKAS, L. 2013. Palinología de angiospermas de la Formación Monte Chico (Cretácico Superior) de la Provincia De Santa Cruz, Argentina. Revista Brasileira de Paleontologia, 16, 115 126.

PREMAOR, E., SOUZA, P. A., ARAI, M. and HELENES, J. 2010. Palinomorfos do Campaniano (Cretáceo Superior) da Bacia de Pelotas, Rio Grande do Sul: implicações bioestratigráficas e paleoambientais. Pesquisas em Geociências, 37, 63-79.

PRICE, L. I. 1955. Novos crocodilídeos dos arenitos da Série Bauru, Cretáceo do Estado de Minas Gerais. Anais da Academia Brasileira de Ciências, 27, 487-498.

REGALI, M. S. P., UESUGUI, N and SANTOS, A. S. 1974a. Palinologia dos sedimentos mesocenozóicos do Brasil (I). Boletim Técnico da Petrobras, 17, 177-191.

REGALI, M. S. P., UESUGUI, N and SANTOS, A. S. 1974b. Palinologia dos sedimentos mesocenozóicos do Brasil (II). Boletim Técnico da Petrobras, 17, 263-301. 
RIBEIRO, L. C. B. 2014. Geoparque Uberaba - terra dos dinossauros do Brasil. PhD Thesis, Programa de Pós-graduação em Geologia, Universidade Federal do Rio de Janeiro, Rio de Janeiro, 123 pp.

RIBEIRO, L. C. B. and CARVALHO, I. S. 2009. Peirópolis e Serra da Galga, Uberaba, MG. 389402. In WINGE, M., SCHOBBENHAUS, C., SOUZA, C. R. G., FERNANDES, A. C. S., QUEIROZ, E. T., BERBERT-BORN, M. and CAMPOS, D. A. (eds). Sítios geológicos e paleontológicos do Brasil. CPRM, Brasília, v. 2, 515 pp.

RIBEIRO, L. C. B., CARVALHO, I. S. and NETO, F. M. 2015. Geopark Uberaba: Relevance of the Geological Heritage. Geoheritage, 7, 261-273.

RIBEIRO, L. C. B., TREVISOL, A., CARVALHO, I. S., NETO, F. M., MARTINS, L. A. and TEIXEIRA, V. P. A. 2012. Geoparque Uberaba - terra dos dinossauros do Brasil (MG). 583616. In SCHOBBENHAUS, C. and SILVA, C. R. (orgs). Geoparques do Brasil - propostas. CPRM, Rio de Janeiro, v. 1, 748 pp.

SALGADO-LABOURIAU, M. L. 1973. Contribuição a palinologia dos cerrados. Academia Brasileira de Ciências, Rio de Janeiro, 291 pp.

SALGADO-LABOURIAU, M. L. 1994. História ecológica da Terra. $2^{\text {nd }}$ edn. Editora Edgard Blücher, São Paulo, 307 pp.

SALGADO-LABOURIAU, M. L. and RULL, V. 1986. A method of introducing exotic pollen for palaeoecological analysis of sediments. Review of Palaeobotany and Palynology, 47, 97-103.

SALGADO, L. and CARVALHO, I. S. 2008. Uberabatitan ribeiroi, a new titanosaur from the Marília Formation (Bauru Group, Upper Cretaceous), Minas Gerais, Brazil. Palaeontology, 51, 881-901.

SAMANT, B. and MOHABEY, D. M. 2014. Deccan volcanic eruptions and their impact on flora: Palynological evidence. Geological Society of America Special Papers, 505, published online. http://specialpapers.gsapubs.org/.

SANTUCCI, R. M. and BERTINI, R. J. 2001. Distribuição paleogeográfica e biocronológica dos titanossauros (Saurischia, Sauropoda) do Grupo Bauru, Cretáceo Superior do sudeste brasileiro. Revista Brasileira de Geociências, 31, 307-314.

SCOTT, L. 1987. Pollen analysis of hyena coprolites and sediments from Equus Cave, Taung, southern Kalahari (South Africa). Quaternary Research, 28, 144-156.

SCOTT, L., FERNANDÉZ-JALVO, Y., CARRIÓN, J. and BRINK, J. 2003. Preservation and interpretation of pollen in hyaena coprolites: taphonomic observations from Spain and southern Africa. Palaeontologia Africana, 39, 83-91. 
SHARMA, N., KAR, R. K., AGARWAL, A. and KAR, R. 2005. Fungi in dinosaurian (Isisaurus) coprolites from the Lameta Formation (Maastrichtian) and its reflection on food habit and environment. Micropaleontology, 51, 73-82.

SIMPSON, M. G. 2006. Plant systematics. Elsevier Academic Press, Amsterdam, 590 pp.

SOUTO, P. R. F. 2003. Coprólitos do Cretáceo do Brasil. PhD Thesis, Instituto de Geociências, Universidade Federal do Rio de Janeiro, Rio de Janeiro, 237 pp.

SOUTO, P. R. F. and FERNANDES, M. A. 2015. Fossilized excreta associated to dinosaurs in Brazil. Journal of South American Earth Sciences, 57, 32-38.

SOUZA, P. A., MATZEMBACHER, L. T., ABELHA, M. and BORGHI, L. 2010. Palinologia da Formação Piauí, Pensilvaniano da Bacia do Parnaíba: biocronoestratigrafia de intervalo selecionado do poço 1-UN-09-PI (Caxias, MA, Brasil). Revista Brasileira de Paleontologia, 13, 57 66.

STOCKMARR, J. 1971. Tablets with spores used in absolute pollen analysis. Pollen et Spores, 13, 615-621.

THULBORN, R. A. 1991. Morphology, preservation and palaeobiological significance of dinosaur coprolites. Palaeogeography, Palaeoclimatology, Palaeoecology, 83, 341-366.

TRAVERSE, A. Paleopalynology. $2^{\text {nd }}$ edn. Springer, Dordrecht, 813 pp.

VAJDA-SANTIVANEZ, V. 1999. Miospores from Upper Cretaceous-Paleocene Strata in Northwestern Bolivia. Palynology, 23, 181-196.

VALLATI, P. 2010. Asociaciones palinológicas con angiospermas en el Cretácico Superior de la Cuenca Neuquina, Argentina. Revista Brasileira de Paleontologia, 13, 143-158.

VALLATI, P. 2013. Paleotropical pollen grains from the Neuquén Group, Patagonia, Argentina. Carnets de Géologie, 2013/05, 273-279.

VAN DER HAMMEN, T. and WIJMSTRA, T. A. 1964. A palynological study on the Tertiary and Upper Cretaceous of British Guiana. Leidse Geologische Mededelingen, 30, 183-241.

VASCONCELLOS, F. M. and CARVALHO, I. S. 2006. Condicionante etológico na tafonomia de Uberabasuchus terrificus (Crocodyliformes, Peirosauridae) da Bacia Bauru (Cretáceo Superior). Geociências, 25, 225-230.

VASILIEF, I. 2011. QtiPlot - Data Analysis and Scientific Visualisation. Version 0.9.8.9 svn 2288 copyright (C) 2004-2011. www.qtiplot.com.

VIJAYA, PRASAD, G. V. R. and SINGH, K. 2009. Late Triassic palynoflora from the PranhitaGodavari Valley, India: evidence from vertebrate coprolites. Alcheringa, 33, 91-111. 
WALDMAN, M. and HOPKINS, JR., W. S. 1970. Coprolites from the Upper Cretaceous of Alberta, Canada, with a description of their microflora. Canadian Journal of Earth Sciences, 7, 1295-1303.

WOOD, J. R., WILMSHURST, J. M., WORTHY, T. H., HOLZAPFEL, A. S. and COOPER, A. A Lost Link between a Flightless Parrot and a Parasitic Plant and the Potential Role of Coprolites in Conservation Paleobiology. Conservation Biology, 26, 1091-1099.

YANG, Y., GENG, B. Y., DILCHER, D. L., CHEN, Z. D. and LOTT, T. A. 2005. Morphology and affinities of an Early Cretaceous Ephedra (Ephedraceae) from China. American Journal of Botany, 92, 231-241.

YBERT, J. P., SALGADO-LABOURIAU, M. L., BARTH, O. M., LORSCHEITTER, M. L., BArros, M. A., CHAVES, S. A. M., LUZ, C. F. P., RIBEIRO, M., SCHEEL, R. and VICENTINI, K. F. 1992. Sugestões para padronização da metodologia empregada em estudos palinológicos do Quaternário. Revista IG, 13, 47-49.

YLL, R., CARRIÓN, J. S., MARRA, A. C. and BONFIGLIO, L. 2006. Vegetation reconstruction on the basis of pollen in Late Pleistocene hyena coprolites from San Teodoro Cave (Sicily, Italy). Palaeogeography, Palaeoclimatology, Palaeoecology, 237, 32-39. 


\section{Capítulo 4}

\section{Conclusões}

$\mathrm{Na}$ região dos sítios Peirópolis e Serra da Galga ocorrem coprólitos em relativa abundância. Entretanto, nódulos inorgânicos carbonáticos (pseudocoprólitos) também são encontrados nos mesmos níveis estratigráficos. Coprólitos e pseudocoprólitos puderam ser diferenciados com algumas técnicas empregadas, sobretudo quando se considera as amostras com alta e baixa densidade.

A grande quantidade de coprólitos encontrada nos afloramentos sugere relação com um efeito tafonômico. A análise dos coprólitos indica que houve mistura temporal e espacial. Poucos exemplares foram considerados parautóctones. A maioria das amostras foi considerada como alóctone, devido à presença de desgaste e de seixos aderidos ao material ou marcas dos mesmos.

A metodologia empregada na preparação palinológica dos coprólitos foi positiva e apresentou os primeiros registros polínicos da Formação Marília. Entretanto, a associação palinológica encontrada nos coprólitos não se mostrou muito diversificada, ocorrendo também em baixas concentrações. Devido à baixa diversidade, associado à ausência de dados palinológicos, não foi possível realizar qualquer inferência bioestratigráfica mais detalhada. De toda forma, os palinomorfos encontrados são condizentes com a idade campaniana/maastrichtiana classicamente reportada para o Membro Serra da Galga na literatura.

A ocorrência de diferentes morfotipos e quantidade de material presente na área de estudo são indicadores da variedade de organismos que habitaram os paleoambientes em questão. Ademais, os morfotipos estão em concordância com outras ocorrências na literatura paleontológica, e podem ser associados a animais com diversas formas e tamanhos, de dieta carnívora, herbívora e onívora. De fato, a presença de palinomorfos e restos vegetais em parte das amostras analisadas sugerem que os vertebrados produtores desses coprólitos eram herbívoros e, com base no tamanho desses coprólitos e o registro fóssil desses afloramentos, infere-se que esse material tenha sido produzido por dinossauros saurópodes, no caso, titanossauros.

O conjunto polínico encontrado sugere a presença de um clima árido e quente, resultado que condiz com dados sedimentológicos. Os palinomorfos indicam a presença de plantas arbustivas e arbóreas, representadas por gnetófitas, coníferas e cicadáceas. Entretanto, o conjunto polínico dos coprólitos deve ser mais específico, representando apenas parte do conjunto vegetacional. A presença do tipo Podocarpidites entre os tipos polínicos pode não ter relação 
apenas com a capacidade de dispersão destes palinomorfos, mas pode também representar uma adaptação as condições ambientais da região. Pela primeira vez, registra-se a presença de fungos no Grupo Bauru. A presença de fungos associados aos coprólitos pode estar relacionada com o processo de decomposição e ressecamento desses coprólitos. Aparentemente, pela presença de seixos ou marcas de seixos observados, esses coprólitos foram produzidos em local com substrato mais cascalhento e menos arenoso, bem diferente da matriz arenosa onde foram encontrados. Após passar por um longo período de seca, por conta do clima árido e quente, os coprólitos podem ter sido transportados e soterrados após nos períodos de maior umidade.

O padrão tafonômico que ocorreu com os coprólitos sugere que os demais fósseis encontrados na região podem ter sofrido o mesmo efeito. Tal fato fica mais relevante com a grande quantidade de material fragmentado citado na literatura, tão abundantes na região, somado a um local de condições mais severas de um ambiente árido, como demonstrado nos registros palinológicos. A possibilidade de mistura temporal e espacial fornece novas informações para a reconstituição paleoambiental da região, comumente retratada com todos os indivíduos dividindo o mesmo ambiente. 


\section{Apêndices}

Neste tópico é apresentada uma tabela com os dados físicos das 340 amostras avaliadas neste estudo. São apresentados os seguintes dados: código de tombo, sítio paleontológico, comprimento, largura, peso, volume e densidade. Em seguida é apresentado um registro fotográfico completo das amostras, dividido em dez estampas: Estampa I - morfotipos cilíndricos; Estampa II - morfotipos ovoides; Estampa III - morfotipos cônicos e dômicos; Estampas IV, V e VI - morfotipos indeterminados; e Estampas VII, VIII, IX e X pseudocoprólitos. 
Apêndice 1. Tabela de dados físicos dos coprólitos e pseudocoprólitos dos sítios paleontológicos Peirópolis e Serra da Galga, região de Uberaba, Minas Gerais, Brasil.

\begin{tabular}{|c|c|c|c|c|c|c|c|c|}
\hline Code & Site & $\begin{array}{c}\text { Length } \\
(\mathrm{cm})\end{array}$ & $\begin{array}{l}\text { Width } \\
\text { (cm) }\end{array}$ & $\begin{array}{l}\text { Weight } \\
\text { (g) }\end{array}$ & $\begin{array}{c}\text { Volume } \\
\left(\mathrm{cm}^{3}\right)\end{array}$ & $\begin{array}{l}\text { Density } \\
\left(\mathrm{g} / \mathrm{cm}^{3}\right)\end{array}$ & Morphotype & Diagnosis \\
\hline FUP-000001 & Peirópolis & 1.93 & 1.32 & 3.26 & 1.9 & 1.71 & Ovoid & Coprolite \\
\hline FUP-000002 & Peirópolis & 5.2 & 4.38 & 82.2 & 39 & 2.1 & & Pseudocoprolite \\
\hline FUP-000003 & Peirópolis & 2.38 & 1.86 & 5.35 & 3.5 & 1.52 & Ovoid & Coprolite \\
\hline FUP-000004 & Peirópolis & 1.64 & 1.12 & 1.48 & 1 & 1.48 & Cylindrical & Coprolite \\
\hline FUP-000005 & Peirópolis & 2.51 & 1.85 & 8.06 & 4 & 2.01 & & Pseudocoprolite \\
\hline FUP-000006 & Peirópolis & 2.38 & 2.04 & 4.96 & 3.5 & 1.41 & Indeterminate & Coprolite \\
\hline FUP-000007 & Peirópolis & 3.27 & 1.9 & 11.2 & 5.9 & 1.89 & & Pseudocoprolite \\
\hline FUP-000008 & Peirópolis & 2.55 & 2.02 & 8.13 & 4.2 & 1.93 & & Pseudocoprolite \\
\hline FUP-000009 & Peirópolis & 3.92 & 3.02 & 23.98 & 13 & 1.84 & & Pseudocoprolite \\
\hline FUP-000010 & Peirópolis & 3.85 & 2.78 & 26.56 & 13.5 & 1.96 & & Pseudocoprolite \\
\hline FUP-000011 & Peirópolis & 1.46 & 1.23 & 1.06 & 0.9 & 1.17 & Indeterminate & Coprolite \\
\hline FUP-000012 & Peirópolis & 2.41 & 1.67 & 2.78 & 2 & 1.39 & Ovoid & Coprolite \\
\hline FUP-000013 & Peirópolis & 5.2 & 4.95 & 62.67 & 42 & 1.49 & & Pseudocoprolite \\
\hline FUP-000014 & Peirópolis & 3.13 & 2.47 & 14.72 & 7.8 & 1.88 & & Pseudocoprolite \\
\hline FUP-000015 & Peirópolis & 2.7 & 1.97 & 6.7 & 4.7 & 1.42 & & Pseudocoprolite \\
\hline FUP-000016 & Peirópolis & 1.28 & 1.08 & 0.63 & 0.8 & 0.78 & Conical & Coprolite \\
\hline FUP-000017 & Peirópolis & 2.18 & 1.54 & 3.28 & 2.1 & 1.56 & & Pseudocoprolite \\
\hline FUP-000018 & Peirópolis & 1.28 & 1.17 & 1.3 & 0.9 & 1.44 & Indeterminate & Coprolite \\
\hline FUP-000019 & Peirópolis & 1.6 & 1.24 & 1.82 & 1.6 & 1.13 & Ovoid & Coprolite \\
\hline FUP-000020 & Peirópolis & 1.89 & 1.63 & 1.64 & 1.9 & 0.86 & Ovoid & Coprolite \\
\hline FUP-000021 & Peirópolis & 2.05 & 1.51 & 3.74 & 2.3 & 1.62 & & Pseudocoprolite \\
\hline FUP-000022 & Peirópolis & 2.09 & 1.36 & 3.37 & 2 & 1.68 & & Pseudocoprolite \\
\hline FUP-000023 & Peirópolis & 1.46 & 1.23 & 1.62 & 1.1 & 1.47 & Domical & Coprolite \\
\hline FUP-000024 & Peirópolis & 2.24 & 1.88 & 5.74 & 3.5 & 1.64 & Conical & Coprolite \\
\hline FUP-000025 & Peirópolis & 2.21 & 1.89 & 3.26 & 2.8 & 1.16 & Conical & Coprolite \\
\hline FUP-000026 & Peirópolis & 2.14 & 1.48 & 2.57 & 2 & 1.28 & Ovoid & Coprolite \\
\hline FUP-000027 & Peirópolis & 1.85 & 1.71 & 3.24 & 2.1 & 1.54 & Cylindrical & Coprolite \\
\hline FUP-000028 & Peirópolis & 1.57 & 1.2 & 1.66 & 1.1 & 1.5 & & Pseudocoprolite \\
\hline FUP-000029 & Peirópolis & 2.7 & 1.92 & 6.18 & 3.2 & 1.93 & & Pseudocoprolite \\
\hline FUP-000030 & Peirópolis & 1.62 & 1.39 & 1.79 & 1.1 & 1.62 & Indeterminate & Coprolite \\
\hline FUP-000031 & Peirópolis & 1.18 & 1.08 & 0.67 & 0.5 & 1.34 & Ovoid & Coprolite \\
\hline FUP-000032 & Peirópolis & 2.87 & 1.46 & 3.44 & 3 & 1.14 & Conical & Coprolite \\
\hline FUP-000033 & Peirópolis & 1.48 & 1.31 & 1.57 & 1 & 1.57 & & Pseudocoprolite \\
\hline FUP-000034 & Peirópolis & 2.6 & 1.21 & 3.69 & 2.1 & 1.75 & & Pseudocoprolite \\
\hline FUP-000035 & Peirópolis & 1.73 & 1.12 & 1.43 & 1 & 1.43 & & Pseudocoprolite \\
\hline FUP-000036 & Peirópolis & 2.88 & 1.91 & 5.43 & 3.5 & 1.55 & Ovoid & Coprolite \\
\hline FUP-000037 & Peirópolis & 1.78 & 1.04 & 1.62 & 1 & 1.62 & & Pseudocoprolite \\
\hline FUP-000038 & Peirópolis & 2.75 & 1.77 & 6.16 & 3.5 & 1.76 & & Pseudocoprolite \\
\hline FUP-000039 & Peirópolis & 1.88 & 1.58 & 3.28 & 2 & 1.64 & & Pseudocoprolite \\
\hline FUP-000040 & Peirópolis & 1.69 & 1.41 & 1.9 & 1.3 & 1.46 & & Pseudocoprolite \\
\hline FUP-000041 & Peirópolis & 1.45 & 0.92 & 0.69 & 0.5 & 1.38 & Cylindrical & Coprolite \\
\hline FUP-000042 & Peirópolis & 1.74 & 1.06 & 1.12 & 0.9 & 1.24 & Indeterminate & Coprolite \\
\hline FUP-000043 & Peirópolis & 1.24 & 1.06 & 0.66 & 0.5 & 1.32 & Indeterminate & Coprolite \\
\hline FUP-000044 & Peirópolis & 1.63 & 1.41 & 1.86 & 1.5 & 1.24 & Conical & Coprolite \\
\hline FUP-000045 & Peirópolis & 2.46 & 1.55 & 4.69 & 2.9 & 1.61 & Cylindrical & Coprolite \\
\hline FUP-000046 & Peirópolis & 2.33 & 1.75 & 3.63 & 2.3 & 1.57 & & Pseudocoprolite \\
\hline FUP-000047 & Peirópolis & 3.16 & 2.29 & 5.55 & 5 & 1.11 & Conical & Coprolite \\
\hline
\end{tabular}




\begin{tabular}{|c|c|c|c|c|c|c|c|c|}
\hline Code & Site & $\begin{array}{c}\text { Length } \\
(\mathrm{cm})\end{array}$ & $\begin{array}{l}\text { Width } \\
(\mathrm{cm})\end{array}$ & $\begin{array}{l}\text { Weight } \\
\text { (g) }\end{array}$ & $\begin{array}{c}\text { Volume } \\
\left(\mathrm{cm}^{3}\right)\end{array}$ & $\begin{array}{l}\text { Density } \\
\left(\mathrm{g} / \mathrm{cm}^{3}\right)\end{array}$ & Morphotype & Diagnosis \\
\hline FUP-000048 & Peirópolis & 2.03 & 1.69 & 3.71 & 2 & 1.85 & & Pseudocoprolite \\
\hline FUP-000049 & Peirópolis & 1.35 & 1.33 & 1.86 & 1.5 & 1.24 & Ovoid & Coprolite \\
\hline FUP-000050 & Peirópolis & 2.89 & 2.3 & 11.65 & 6.8 & 1.71 & & Pseudocoprolite \\
\hline FUP-000051 & Peirópolis & 1.41 & 1.09 & 1.06 & 0.8 & 1.32 & Ovoid & Coprolite \\
\hline FUP-000052 & Peirópolis & 1.26 & 1.26 & 0.92 & 1.1 & 0.83 & Ovoid & Coprolite \\
\hline FUP-000053 & Peirópolis & 2.71 & 1.88 & 6.65 & 3.9 & 1.7 & & Pseudocoprolite \\
\hline FUP-000054 & Peirópolis & 1.88 & 1.96 & 3.11 & 2.2 & 1.41 & Indeterminate & Coprolite \\
\hline FUP-000055 & Peirópolis & 1.68 & 1.52 & 1.79 & 1.9 & 0.94 & Ovoid & Coprolite \\
\hline FUP-000056 & Peirópolis & 2.32 & 2.31 & 6.66 & 4.8 & 1.38 & & Pseudocoprolite \\
\hline FUP-000057 & Peirópolis & 1.78 & 1.22 & 0.98 & 1.2 & 0.81 & Cylindrical & Coprolite \\
\hline FUP-000058 & Peirópolis & 1.52 & 1.18 & 1.03 & 0.9 & 1.14 & & Pseudocoprolite \\
\hline FUP-000059 & Peirópolis & 2.73 & 2.03 & 6.13 & 4 & 1.53 & Indeterminate & Coprolite \\
\hline FUP-000060 & Peirópolis & 3.04 & 2.26 & 7.84 & 4.1 & 1.91 & & Pseudocoprolite \\
\hline FUP-000061 & Peirópolis & 2.31 & 1.95 & 6.1 & 3.5 & 1.74 & & Pseudocoprolite \\
\hline FUP-000062 & Peirópolis & 1.98 & 1.42 & 1.77 & 1.2 & 1.47 & Indeterminate & Coprolite \\
\hline FUP-000063 & Peirópolis & 2.71 & 1.95 & 4.91 & 3.3 & 1.48 & Ovoid & Coprolite \\
\hline FUP-000064 & Peirópolis & 2.98 & 2.4 & 5.36 & 4.1 & 1.3 & Cylindrical & Coprolite \\
\hline FUP-000065 & Peirópolis & 1.6 & 1.29 & 0.68 & 1 & 0.68 & Indeterminate & Coprolite \\
\hline FUP-000066 & Peirópolis & 2.64 & 1.76 & 4.85 & 4.2 & 1.15 & Indeterminate & Coprolite \\
\hline FUP-000067 & Peirópolis & 2.62 & 2.15 & 8.35 & 4.3 & 1.94 & & Pseudocoprolite \\
\hline FUP-000068 & Peirópolis & 2.82 & 1.75 & 5.18 & 3.1 & 1.67 & & Pseudocoprolite \\
\hline FUP-000069 & Peirópolis & 1.35 & 1.13 & 0.73 & 1 & 0.73 & Indeterminate & Coprolite \\
\hline FUP-000070 & Peirópolis & 1.66 & 1.33 & 0.72 & 1.3 & 0.55 & Indeterminate & Coprolite \\
\hline FUP-000071 & Peirópolis & 1.6 & 1.29 & 1.35 & 1.1 & 1.22 & Indeterminate & Coprolite \\
\hline FUP-000072 & Peirópolis & 1.74 & 1.45 & 3.33 & 2.1 & 1.58 & Indeterminate & Coprolite \\
\hline FUP-000073 & Peirópolis & 1.68 & 1.46 & 1.13 & 1.4 & 0.8 & Conical & Coprolite \\
\hline FUP-000074 & Peirópolis & 1.39 & 0.96 & 0.61 & 0.6 & 1.01 & Indeterminate & Coprolite \\
\hline FUP-000075 & Peirópolis & 1.23 & 1.12 & 0.58 & 0.7 & 0.82 & Indeterminate & Coprolite \\
\hline FUP-000076 & Peirópolis & 1.51 & 1.06 & 1 & 1.2 & 0.83 & Indeterminate & Coprolite \\
\hline FUP-000077 & Peirópolis & 1.75 & 1.19 & 1.69 & 1.3 & 1.3 & Indeterminate & Coprolite \\
\hline FUP-000078 & Peirópolis & 2.13 & 1.48 & 2.47 & 1.7 & 1.45 & & Pseudocoprolite \\
\hline FUP-000079 & Peirópolis & 1.78 & 1.39 & 1.33 & 1.5 & 0.88 & Indeterminate & Coprolite \\
\hline FUP-000080 & Peirópolis & 2.19 & 1.45 & 1.88 & 1.8 & 1.04 & Conical & Coprolite \\
\hline FUP-000081 & Peirópolis & 1.8 & 1.52 & 1.88 & 1.6 & 1.17 & Conical & Coprolite \\
\hline FUP-000082 & Peirópolis & 1.51 & 0.99 & 0.83 & 0.8 & 1.03 & Indeterminate & Coprolite \\
\hline FUP-000083 & Peirópolis & 2.02 & 1.58 & 1.96 & 1.7 & 1.15 & Indeterminate & Coprolite \\
\hline FUP-000084 & Peirópolis & 1.83 & 1.68 & 3.62 & 1.9 & 1.9 & & Pseudocoprolite \\
\hline FUP-000085 & Peirópolis & 1.21 & 1.11 & 0.74 & 0.8 & 0.92 & Indeterminate & Coprolite \\
\hline FUP-000086 & Peirópolis & 1.56 & 1.13 & 1.18 & 0.9 & 1.31 & Indeterminate & Coprolite \\
\hline FUP-000087 & Peirópolis & 1.14 & 0.86 & 0.39 & 0.3 & 1.3 & Indeterminate & Coprolite \\
\hline FUP-000088 & Peirópolis & 1.08 & 0.79 & 0.47 & 0.3 & 1.56 & & Pseudocoprolite \\
\hline FUP-000089 & Peirópolis & 1.46 & 1.4 & 1.55 & 1.3 & 1.19 & Indeterminate & Coprolite \\
\hline FUP-000090 & Peirópolis & 1 & 1.21 & 0.59 & 0.7 & 0.84 & Indeterminate & Coprolite \\
\hline FUP-000091 & Peirópolis & 1.13 & 0.99 & 0.84 & 0.5 & 1.68 & Indeterminate & Coprolite \\
\hline FUP-000092 & Peirópolis & 2.86 & 1.46 & 3.89 & 3.3 & 1.17 & Cylindrical & Coprolite \\
\hline FUP-000093 & Peirópolis & 2.44 & 2.28 & 5.86 & 3.9 & 1.5 & Indeterminate & Coprolite \\
\hline FUP-000094 & Peirópolis & 2.43 & 1.93 & 5.38 & 2.9 & 1.85 & & Pseudocoprolite \\
\hline FUP-000095 & Peirópolis & 2.22 & 2.07 & 7 & 3.9 & 1.79 & Indeterminate & Coprolite \\
\hline FUP-000096 & Peirópolis & 3.11 & 2.64 & 7.85 & 5.6 & 1.4 & Conical & Coprolite \\
\hline FUP-000097 & Peirópolis & 2.46 & 1.33 & 1.54 & 1.9 & 0.81 & Ovoid & Coprolite \\
\hline FUP-000098 & Peirópolis & 3.06 & 1.94 & 8.38 & 4 & 2.09 & & Pseudocoprolite \\
\hline
\end{tabular}




\begin{tabular}{|c|c|c|c|c|c|c|c|c|}
\hline Code & Site & $\begin{array}{c}\text { Length } \\
(\mathrm{cm})\end{array}$ & $\begin{array}{l}\text { Width } \\
(\mathrm{cm})\end{array}$ & $\begin{array}{l}\text { Weight } \\
\text { (g) }\end{array}$ & $\begin{array}{c}\text { Volume } \\
\left(\mathrm{cm}^{3}\right)\end{array}$ & $\begin{array}{l}\text { Density } \\
\left(\mathrm{g} / \mathrm{cm}^{3}\right)\end{array}$ & Morphotype & Diagnosis \\
\hline FUP-000099 & Peirópolis & 2.46 & 1.81 & 4.69 & 4 & 1.17 & Conical & Coprolite \\
\hline FUP-000100 & Peirópolis & 2.12 & 1.91 & 1.27 & 2 & 0.63 & Domical & Coprolite \\
\hline FUP-000101 & Peirópolis & 2.6 & 1.95 & 8.02 & 4 & 2 & & Pseudocoprolite \\
\hline FUP-000102 & Peirópolis & 2.03 & 1.76 & 3.3 & 2.2 & 1.5 & & Pseudocoprolite \\
\hline FUP-000103 & Peirópolis & 2.52 & 2.33 & 7.49 & 4.2 & 1.78 & Ovoid & Coprolite \\
\hline FUP-000104 & Peirópolis & 2.53 & 1.52 & 5.53 & 3 & 1.84 & & Pseudocoprolite \\
\hline FUP-000105 & Peirópolis & 2.53 & 2.07 & 10.57 & 5.5 & 1.92 & & Pseudocoprolite \\
\hline FUP-000106 & Peirópolis & 2.74 & 2.53 & 9.35 & 4.7 & 1.98 & & Pseudocoprolite \\
\hline FUP-000107 & Peirópolis & 2.77 & 1.79 & 6.97 & 4.3 & 1.62 & Cylindrical & Coprolite \\
\hline FUP-000108 & Peirópolis & 2.52 & 1.92 & 5.83 & 3 & 1.94 & & Pseudocoprolite \\
\hline FUP-000109 & Peirópolis & 3.95 & 1.94 & 9.4 & 6 & 1.56 & & Pseudocoprolite \\
\hline FUP-000110 & Peirópolis & 2.02 & 1.41 & 1.66 & 1.2 & 1.38 & Indeterminate & Coprolite \\
\hline FUP-000111 & Peirópolis & 1.48 & 1.25 & 1.21 & 0.9 & 1.34 & Indeterminate & Coprolite \\
\hline FUP-000112 & Peirópolis & 1.68 & 1.26 & 2.03 & 1.1 & 1.84 & & Pseudocoprolite \\
\hline FUP-000113 & Peirópolis & 1.51 & 1.32 & 1.88 & 1.2 & 1.56 & Indeterminate & Coprolite \\
\hline FUP-000114 & Peirópolis & 2.12 & 1.91 & 7.02 & 3.3 & 2.12 & & Pseudocoprolite \\
\hline FUP-000115 & Peirópolis & 2.83 & 2.05 & 7.95 & 4.5 & 1.76 & & Pseudocoprolite \\
\hline FUP-000116 & Peirópolis & 2.51 & 2.04 & 6.07 & 4 & 1.51 & & Pseudocoprolite \\
\hline FUP-000117 & Peirópolis & 2.59 & 1.97 & 7.75 & 4 & 1.93 & & Pseudocoprolite \\
\hline FUP-000118 & Peirópolis & 2.77 & 2.26 & 8.4 & 4.9 & 1.71 & & Pseudocoprolite \\
\hline FUP-000119 & Peirópolis & 2.7 & 1.74 & 5.41 & 3 & 1.8 & & Pseudocoprolite \\
\hline FUP-000120 & Peirópolis & 2.2 & 1.5 & 3.77 & 2.2 & 1.71 & & Pseudocoprolite \\
\hline FUP-000121 & Peirópolis & 2.57 & 1.83 & 8.14 & 4 & 2.03 & & Pseudocoprolite \\
\hline FUP-000122 & Peirópolis & 1.74 & 1.53 & 2.02 & 1.5 & 1.34 & Ovoid & Coprolite \\
\hline FUP-000123 & Peirópolis & 2.07 & 2.56 & 2.55 & 1.9 & 1.34 & & Pseudocoprolite \\
\hline FUP-000124 & Peirópolis & 2.91 & 1.96 & 5.31 & 3.9 & 1.36 & Indeterminate & Coprolite \\
\hline FUP-000125 & Peirópolis & 4.29 & 3.51 & 28.2 & 22 & 1.28 & Conical & Coprolite \\
\hline FUP-000126 & Peirópolis & 3.12 & 2.78 & 14.49 & 10 & 1.44 & Indeterminate & Coprolite \\
\hline FUP-000127 & Peirópolis & 3.48 & 2.99 & 20.92 & 12 & 1.74 & & Pseudocoprolite \\
\hline FUP-000128 & Peirópolis & 3.58 & 2.86 & 6.28 & 10 & 0.62 & Indeterminate & Coprolite \\
\hline FUP-000129 & Peirópolis & 3.98 & 3.24 & 31.33 & 18 & 1.74 & & Pseudocoprolite \\
\hline FUP-000130 & Peirópolis & 3.05 & 3.05 & 8.64 & 8 & 1.08 & Indeterminate & Coprolite \\
\hline FUP-000131 & Peirópolis & 2.84 & 2.57 & 25.09 & 15 & 1.67 & Conical & Coprolite \\
\hline FUP-000132 & Peirópolis & 3.27 & 2.77 & 14.39 & 7.5 & 1.91 & & Pseudocoprolite \\
\hline FUP-000133 & Peirópolis & 3.81 & 2.31 & 19.59 & 9.1 & 2.15 & & Pseudocoprolite \\
\hline FUP-000134 & Peirópolis & 2.41 & 2.58 & 7.99 & 4.9 & 1.63 & Indeterminate & Coprolite \\
\hline FUP-000135 & Peirópolis & 4.01 & 3.72 & 21.36 & 13 & 1.64 & Ovoid & Coprolite \\
\hline FUP-000136 & Peirópolis & 2.77 & 2.38 & 9.06 & 6 & 1.51 & & Pseudocoprolite \\
\hline FUP-000137 & Peirópolis & 5.43 & 4.43 & 67.4 & 37 & 1.82 & & Pseudocoprolite \\
\hline FUP-000138 & Peirópolis & 3.6 & 4.19 & 46.03 & 21 & 2.19 & & Pseudocoprolite \\
\hline FUP-000139 & Peirópolis & 5.81 & 4.41 & 68.02 & 39 & 1.74 & & Pseudocoprolite \\
\hline FUP-000140 & Peirópolis & 3.58 & 2.56 & 18.71 & 10 & 1.87 & & Pseudocoprolite \\
\hline FUP-000141 & Peirópolis & 3.67 & 3.42 & 20.78 & 17 & 1.22 & Indeterminate & Coprolite \\
\hline FUP-000142 & Peirópolis & 3.12 & 2.97 & 18.56 & 11 & 1.68 & Indeterminate & Coprolite \\
\hline FUP-000143 & Peirópolis & 4.05 & 3.03 & 28.73 & 16 & 1.79 & Indeterminate & Coprolite \\
\hline FUP-000144 & Peirópolis & 4.27 & 2.74 & 12.48 & 13 & 0.96 & Conical & Coprolite \\
\hline FUP-000145 & Peirópolis & 3.57 & 3.23 & 7.92 & 10 & 0.79 & Domical & Coprolite \\
\hline FUP-000146 & Peirópolis & 2.82 & 2.22 & 11.51 & 7.5 & 1.53 & & Pseudocoprolite \\
\hline FUP-000147 & Peirópolis & 3.93 & 2.75 & 23.21 & 12 & 1.93 & & Pseudocoprolite \\
\hline FUP-000148 & Peirópolis & 3.94 & 3.88 & 21.21 & 14 & 1.51 & & Pseudocoprolite \\
\hline
\end{tabular}




\begin{tabular}{|c|c|c|c|c|c|c|c|c|}
\hline Code & Site & $\begin{array}{l}\text { Length } \\
\text { (cm) }\end{array}$ & $\begin{array}{l}\text { Width } \\
\text { (cm) }\end{array}$ & $\begin{array}{l}\text { Weight } \\
\text { (g) }\end{array}$ & $\begin{array}{c}\text { Volume } \\
\left(\mathrm{cm}^{3}\right)\end{array}$ & $\begin{array}{l}\text { Density } \\
\left(\mathrm{g} / \mathrm{cm}^{3}\right)\end{array}$ & Morphotype & Diagnosis \\
\hline FUP-000149 & Peirópolis & 3.58 & 2.36 & 10.02 & 5.5 & 1.82 & & Pseudocoprolite \\
\hline FUP-000150 & Peirópolis & 5.29 & 3.08 & 29.86 & 16 & 1.86 & & Pseudocoprolite \\
\hline FUP-000151 & Peirópolis & 3.58 & 3.19 & 21.94 & 11 & 1.99 & & Pseudocoprolite \\
\hline FUP-000152 & Peirópolis & 4.82 & 4.4 & 58.93 & 28 & 2.1 & & Pseudocoprolite \\
\hline FUP-000153 & Peirópolis & 4.12 & 3.34 & 23 & 14 & 1.64 & & Pseudocoprolite \\
\hline FUP-000154 & Peirópolis & 8.08 & 5.24 & 107.19 & 78 & 1.37 & Cylindrical & Coprolite \\
\hline FUP-000155 & Peirópolis & 7.89 & 4.63 & 169.41 & 82 & 2.06 & & Pseudocoprolite \\
\hline FUP-000156 & Peirópolis & 9.23 & 7.39 & 201 & 140 & 1.43 & Domical & Coprolite \\
\hline FUP-000157 & Peirópolis & 5.81 & 5.35 & 86.93 & 50 & 1.73 & Ovoid & Coprolite \\
\hline FUP-000158 & Peirópolis & 4.48 & 3.23 & 25.21 & 19 & 1.32 & Ovoid & Coprolite \\
\hline FUP-000159 & Peirópolis & 3.86 & 3.68 & 24.19 & 21 & 1.15 & Indeterminate & Coprolite \\
\hline FUP-000160 & Peirópolis & 5.23 & 3.87 & 37.92 & 20 & 1.89 & & Pseudocoprolite \\
\hline FUP-000161 & Peirópolis & 4.55 & 2.43 & 15.24 & 10.7 & 1.42 & Cylindrical & Coprolite \\
\hline FUP-000162 & Peirópolis & 4.69 & 2.69 & 21 & 11 & 1.9 & & Pseudocoprolite \\
\hline FUP-000163 & Peirópolis & 4.02 & 3.12 & 23.53 & 17.5 & 1.34 & Ovoid & Coprolite \\
\hline FUP-000164 & Peirópolis & 3.49 & 3.17 & 10.06 & 8.5 & 1.18 & Indeterminate & Coprolite \\
\hline FUP-000165 & Peirópolis & 2.59 & 2.36 & 11.46 & 6 & 1.91 & & Pseudocoprolite \\
\hline FUP-000166 & Peirópolis & 2.81 & 2.53 & 11.91 & 7 & 1.7 & & Pseudocoprolite \\
\hline FUP-000167 & Peirópolis & 6.5 & 4.8 & 91.26 & 42 & 2.17 & & Pseudocoprolite \\
\hline FUP-000168 & Peirópolis & 6.76 & 6.4 & 133.87 & 60 & 2.23 & & Pseudocoprolite \\
\hline FUP-000169 & Peirópolis & 6.19 & 3.8 & 73.53 & 36 & 2.04 & & Pseudocoprolite \\
\hline FUP-000170 & Peirópolis & 6.47 & 4.6 & 124.6 & 65.5 & 1.9 & & Pseudocoprolite \\
\hline FUP-000171 & Peirópolis & 8.13 & 5.59 & 98.07 & 41 & 2.39 & & Pseudocoprolite \\
\hline FUP-000172 & Peirópolis & 4.65 & 3.33 & 21 & 11 & 1.9 & & Pseudocoprolite \\
\hline FUP-000173 & Peirópolis & 3.22 & 2.57 & 10.91 & 6 & 1.81 & & Pseudocoprolite \\
\hline FUP-000174 & Peirópolis & 3.58 & 3.42 & 24.77 & 16 & 1.54 & & Pseudocoprolite \\
\hline FUP-000175 & Peirópolis & 4.9 & 4.15 & 27.55 & 15 & 1.83 & & Pseudocoprolite \\
\hline FUP-000176 & Peirópolis & 7.77 & 5.6 & 190.29 & 100 & 1.9 & & Pseudocoprolite \\
\hline FUP-000177 & Peirópolis & 3.79 & 2.87 & 17.68 & 10 & 1.76 & & Pseudocoprolite \\
\hline FUP-000178 & Peirópolis & 4.45 & 3.48 & 35.04 & 18 & 1.94 & & Pseudocoprolite \\
\hline FUP-000179 & Peirópolis & 5.59 & 4.45 & 74.73 & 38 & 1.96 & & Pseudocoprolite \\
\hline FUP-000180 & Peirópolis & 2.65 & 2.53 & 12.28 & 7 & 1.75 & & Pseudocoprolite \\
\hline FUP-000181 & Peirópolis & 3.36 & 3.04 & 26.93 & 14 & 1.92 & & Pseudocoprolite \\
\hline FUP-000182 & Peirópolis & 4.07 & 3.52 & 32.45 & 16 & 2.02 & & Pseudocoprolite \\
\hline FUP-000183 & Peirópolis & 4.23 & 3.95 & 43.47 & 24 & 1.81 & & Pseudocoprolite \\
\hline FUP-000184 & Peirópolis & 3.17 & 2.94 & 14.31 & 7.5 & 1.9 & & Pseudocoprolite \\
\hline FUP-000185 & Peirópolis & 5.42 & 5.42 & 92.13 & 48 & 1.91 & & Pseudocoprolite \\
\hline FUP-000186 & Peirópolis & 2.54 & 2.5 & 9.94 & 5.5 & 1.8 & & Pseudocoprolite \\
\hline FUP-000187 & Peirópolis & 3.5 & 3.5 & 33.5 & 16 & 2.09 & & Pseudocoprolite \\
\hline FUP-000188 & Peirópolis & 3.38 & 2.87 & 21.2 & 11 & 1.92 & & Pseudocoprolite \\
\hline FUP-000189 & Peirópolis & 3.39 & 2.96 & 16.22 & 8.5 & 1.9 & & Pseudocoprolite \\
\hline FUP-000190 & Peirópolis & 2.78 & 2.08 & 6.35 & 3.2 & 1.98 & & Pseudocoprolite \\
\hline FUP-000191 & Peirópolis & 2.94 & 2.08 & 6.39 & 3.2 & 1.99 & & Pseudocoprolite \\
\hline FUP-000192 & Peirópolis & 2.34 & 2.01 & 6.94 & 3.6 & 1.92 & & Pseudocoprolite \\
\hline FUP-000193 & Peirópolis & 4.05 & 3.05 & 20.08 & 10 & 2 & & Pseudocoprolite \\
\hline FUP-000194 & Peirópolis & 4.67 & 4.01 & 51.64 & 26 & 1.98 & & Pseudocoprolite \\
\hline FUP-000195 & Peirópolis & 3.41 & 3.14 & 23.82 & 17.5 & 1.36 & Conical & Coprolite \\
\hline FUP-000196 & Peirópolis & 3.77 & 3.06 & 19.44 & 10 & 1.94 & & Pseudocoprolite \\
\hline FUP-000197 & Peirópolis & 3.25 & 2.77 & 14.61 & 8 & 1.82 & & Pseudocoprolite \\
\hline
\end{tabular}




\begin{tabular}{|c|c|c|c|c|c|c|c|c|}
\hline Code & Site & $\begin{array}{l}\text { Length } \\
\text { (cm) }\end{array}$ & $\begin{array}{l}\text { Width } \\
\text { (cm) }\end{array}$ & $\begin{array}{l}\text { Weight } \\
\text { (g) }\end{array}$ & $\begin{array}{c}\text { Volume } \\
\left(\mathrm{cm}^{3}\right)\end{array}$ & $\begin{array}{l}\text { Density } \\
\left(\mathrm{g} / \mathrm{cm}^{3}\right)\end{array}$ & Morphotype & Diagnosis \\
\hline FUP-000198 & Peirópolis & 2.95 & 2.02 & 8.73 & 5 & 1.74 & Ovoid & Coprolite \\
\hline FUP-000199 & Peirópolis & 2.24 & 1.97 & 6.47 & 4.3 & 1.5 & Conical & Coprolite \\
\hline FUP-000200 & Peirópolis & 3.33 & 3.06 & 23.29 & 12.5 & 1.86 & & Pseudocoprolite \\
\hline FUP-000201 & Peirópolis & 2.11 & 1.72 & 3.18 & 1.8 & 1.76 & & Pseudocoprolite \\
\hline $\begin{array}{l}\text { FUP-000202 } \\
\end{array}$ & Peirópolis & 1.16 & 1.09 & 0.93 & 0.7 & 1.32 & Ovoid & Coprolite \\
\hline FUP-000203 & Peirópolis & 1.31 & 0.93 & 0.58 & 0.5 & 1.16 & Ovoid & Coprolite \\
\hline FUP-000204 & Peirópolis & 3.72 & 2.35 & 6.78 & 8.8 & 0.77 & Indeterminate & Coprolite \\
\hline FUP-000205 & Peirópolis & 2.98 & 2.22 & 4.37 & 4.9 & 0.89 & Indeterminate & Coprolite \\
\hline FUP-000206 & Peirópolis & 3.25 & 2.68 & 4.02 & 7 & 0.57 & Ovoid & Coprolite \\
\hline FUP-000207 & Peirópolis & 2.5 & 1.78 & 2.48 & 4 & 0.62 & Indeterminate & Coprolite \\
\hline FUP-000208 & Peirópolis & 2.54 & 1.58 & 1.65 & 2.3 & 0.71 & Indeterminate & \\
\hline FUP-000209 & Peirópolis & 3.98 & 2.72 & 11.19 & 9.5 & 1.17 & Indeterminate & \\
\hline FUP-000210 & Peirópolis & 3.12 & 2.7 & 5.2 & 7 & 0.74 & Indeterminate & \\
\hline FUP-000211 & Peirópolis & 2.05 & 1.53 & 1.85 & 1.8 & 1.02 & Indeterminate & \\
\hline FUP-000212 & Peirópolis & 3.19 & 1.99 & 3.73 & 3.5 & 1.06 & determ & \\
\hline FUP-000213 & Peirópolis & 2.49 & 1.48 & 0.48 & 0.6 & 0.8 & determinate & \\
\hline FUP-000214 & Peirópolis & 3.07 & 2.13 & 6.5 & 5.5 & 1.18 & determinate & \\
\hline FUP-000215 & Peirópolis & 2.53 & 2.1 & 1.5 & 1.9 & & ideterminate & \\
\hline FUP-000216 & rópolis & 2.01 & 1.97 & 4.4 & 4 & & ate & \\
\hline FUP-000217 & Peirópolis & 3.28 & 1.72 & 4.47 & 4.3 & 1.03 & ate & \\
\hline FUP-000218 & Peirópolis & 2.72 & 2.09 & 3.44 & 4 & 0.86 & Indeterminate & Coprolite \\
\hline FUP-000219 & Peirópolis & 3.25 & 1.99 & 4.79 & 2.6 & 1.84 & & Pseudocoprolite \\
\hline FUP-000220 & Peirópolis & 1.71 & 1.31 & 0.61 & 1 & 0.61 & Indeterminate & Coprolite \\
\hline FUP-000221 & Peirópolis & 2.89 & 1.64 & 3.5 & 3.5 & 1 & Indeterminate & Coprolite \\
\hline FUP-000222 & Peirópolis & 4.04 & 3.13 & 14.28 & 10 & 1.42 & Conical & Coprolite \\
\hline FUP-000223 & Peirópolis & 2.81 & 2.02 & 4.4 & 4.1 & 1.07 & Indeterminate & Coprolite \\
\hline FUP-000224 & Peirópolis & 2.05 & 1.59 & 2.22 & 2.2 & 1 & Indeterminate & Coprolite \\
\hline FUP-000225 & Peirópolis & 2.42 & 1.51 & 3.44 & 3 & 1.14 & Indeterminate & Coprolite \\
\hline FUP-000226 & Peirópolis & 2.79 & 2.02 & 3.07 & 2.9 & 1.05 & Indeterminate & Coprolite \\
\hline FUP-000227 & Peirópolis & 2.71 & 1.98 & 3.53 & 4 & 0.88 & Indeterminate & Coprolite \\
\hline FUP-000228 & Peirópolis & 1.64 & 1.42 & 1.37 & 1.1 & 1.24 & Ovoid & Coprolite \\
\hline FUP-000229 & Peirópolis & 1.83 & 1.18 & 0.68 & 0.9 & 0.75 & Indeterminate & Coprolite \\
\hline FUP-000230 & Peirópolis & 2.71 & 1.95 & 5.54 & 3.5 & 1.58 & Indeterminate & Coprolite \\
\hline FUP-000231 & Peirópolis & 2.07 & 1.63 & 1.82 & 2 & 0.91 & Indeterminate & Coprolite \\
\hline FUP-000232 & Peirópolis & 1.76 & 1.34 & 1.34 & 1.1 & 1.21 & Indeterminate & Coprolite \\
\hline FUP-000233 & Peirópolis & 2.39 & 1.64 & 1.36 & 1.8 & 0.75 & Indeterminate & Coprolite \\
\hline FUP-000234 & Peirópolis & 2 & 1.59 & 1.84 & 1.8 & 1.02 & Indeterminate & Coprolite \\
\hline FUP-000235 & Peirópolis & 2.65 & 2.35 & 5.01 & 3.8 & 1.31 & Indeterminate & Coprolite \\
\hline FUP-000236 & Peirópolis & 1.75 & 1.3 & 1.79 & 1 & 1.79 & & Pseudocoprolite \\
\hline FUP-000237 & Peirópolis & & 1.47 & 1.9 & 1.8 & 1.0 & & \\
\hline FUP-000238 & Peirópolis & 2.31 & 1.55 & 1.27 & 1.1 & 1.1 & Indeterminate & Coprolite \\
\hline FUP-000239 & Peirópolis & 1.93 & 1.57 & 2.65 & 2.1 & 1.26 & Indeterminate & Coprolite \\
\hline FUP-000240 & Peirópolis & 1.9 & 1.36 & 1.48 & 1.1 & 1.34 & Indeterminate & Coprolite \\
\hline FUP-000241 & Peirópolis & 1.98 & 1.61 & 1.76 & 1.2 & 1.46 & Indeterminate & Coprolite \\
\hline FUP-000242 & Peirópolis & 2.34 & 1.51 & 2.61 & 2.1 & 1.24 & Indeterminate & Coprolite \\
\hline FUP-000243 & Peirópolis & 2.52 & 2 & 2.28 & 2 & 1.14 & Indeterminate & Coprolite \\
\hline FUP-000244 & Peirópolis & 3.28 & 1.91 & 14.36 & 7 & 2.05 & & Pseudocoprolite \\
\hline FUP-000245 & Peirópolis & 3.2 & 2.18 & 8.75 & 5.3 & 1.65 & & Pseudocoprolite \\
\hline FUP-000246 & Peirópolis & 2.77 & 2.23 & 10.02 & 5.1 & 1.96 & & Pseudocoprolite \\
\hline FUP-000247 & Peirópolis & 3.28 & 2.7 & 4.72 & 4.1 & 1.15 & Indeterminate & Coprolite \\
\hline FUP-000248 & Peirópolis & 1.81 & 1.5 & 2.46 & 1.5 & 1.64 & & Pseudocoprolite \\
\hline FUP-000249 & Peirópolis & 1.45 & 1.24 & 0.95 & 0.6 & 1.58 & Indeterminate & Coprolite \\
\hline
\end{tabular}




\begin{tabular}{|c|c|c|c|c|c|c|c|c|}
\hline Code & Site & $\begin{array}{c}\text { Length } \\
(\mathrm{cm})\end{array}$ & $\begin{array}{l}\text { Width } \\
\text { (cm) }\end{array}$ & $\begin{array}{l}\text { Weight } \\
\text { (g) }\end{array}$ & $\begin{array}{c}\text { Volume } \\
\left(\mathrm{cm}^{3}\right)\end{array}$ & $\begin{array}{l}\text { Density } \\
\left(\mathrm{g} / \mathrm{cm}^{3}\right)\end{array}$ & Morphotype & Diagnosis \\
\hline FUP-000250 & Peirópolis & 2.16 & 1.58 & 4.29 & 2.7 & 1.58 & & Pseudocoprolite \\
\hline FUP-000251 & Peirópolis & 2.39 & 2.39 & 8.9 & 4.9 & 1.81 & & Pseudocoprolite \\
\hline FUP-000252 & Peirópolis & 2.76 & 2.53 & 10.41 & 5.5 & 1.89 & & Pseudocoprolite \\
\hline FUP-000253 & Peirópolis & 2.47 & 1.86 & 6.81 & 3.3 & 2.06 & & Pseudocoprolite \\
\hline FUP-000254 & Peirópolis & 3.14 & 1.55 & 4.96 & 3 & 1.65 & Cylindrical & Coprolite \\
\hline FUP-000255 & Peirópolis & 1.94 & 1.45 & 1.88 & 1.5 & 1.25 & Indeterminate & Coprolite \\
\hline FUP-000256 & Peirópolis & 2.63 & 2.43 & 3.96 & 5.9 & 0.67 & Indeterminate & Coprolite \\
\hline FUP-000257 & Peirópolis & 2.72 & 1.95 & 5.45 & 3.2 & 1.7 & Ovoid & Coprolite \\
\hline FUP-000258 & Peirópolis & 3.72 & 2.91 & 19.74 & 9.5 & 2.07 & & Pseudocoprolite \\
\hline FUP-000259 & Peirópolis & 3.58 & 2.82 & 13.96 & 7.5 & 1.86 & & Pseudocoprolite \\
\hline FUP-000260 & Peirópolis & 6.33 & 4.09 & 68.68 & 35 & 1.96 & & Pseudocoprolite \\
\hline FUP-000261 & Peirópolis & 6.17 & 5.61 & 118.88 & 67 & 1.77 & & Pseudocoprolite \\
\hline FUP-000262 & Peirópolis & 7.33 & 4.29 & 116.42 & 57 & 2.04 & & Pseudocoprolite \\
\hline FUP-000263 & Peirópolis & 15.5 & 12.07 & 1295 & 751.5 & 1.72 & & Pseudocoprolite \\
\hline FUP-000264 & Peirópolis & 2.22 & 1.76 & 3.34 & 2.2 & 1.51 & Indeterminate & Coprolite \\
\hline FUP-000265 & Peirópolis & 1.81 & 1.34 & 1.79 & 1.18 & 1.51 & Indeterminate & Coprolite \\
\hline FUP-000266 & Peirópolis & 1.93 & 1.27 & 1.56 & 1.1 & 1.41 & Ovoid & Coprolite \\
\hline FUP-000267 & Peirópolis & 1.32 & 1 & 0.48 & 0.7 & 0.68 & Ovoid & Coprolite \\
\hline FUP-000268 & Peirópolis & 2.72 & 1.76 & 3.95 & 2.7 & 1.46 & Indeterminate & Coprolite \\
\hline FUP-000269 & Peirópolis & 1.83 & 1.38 & 1.85 & 1.4 & 1.32 & Indeterminate & Coprolite \\
\hline FUP-000270 & Peirópolis & 0.92 & 0.83 & 0.41 & 0.3 & 1.36 & Indeterminate & Coprolite \\
\hline FUP-000271 & Peirópolis & 1.25 & 1.02 & 0.58 & 0.4 & 1.45 & Indeterminate & Coprolite \\
\hline FUP-000272 & Peirópolis & 1.09 & 0.94 & 0.49 & 0.3 & 1.63 & Indeterminate & Coprolite \\
\hline FUP-000273 & Peirópolis & 1.61 & 0.95 & 0.92 & 0.5 & 1.84 & & Pseudocoprolite \\
\hline FUP-000274 & Peirópolis & 2.79 & 1.8 & 3.28 & 3.8 & 0.86 & Indeterminate & Coprolite \\
\hline FUP-000275 & Peirópolis & 1.83 & 1.54 & 2.67 & 2 & 1.33 & Indeterminate & Coprolite \\
\hline FUP-000276 & Peirópolis & 3.03 & 2.03 & 7.01 & 5 & 1.4 & Indeterminate & Coprolite \\
\hline FUP-000277 & Peirópolis & 3.07 & 2.35 & 12.86 & 7.2 & 1.78 & Conical & Coprolite \\
\hline FUP-000278 & Peirópolis & 3 & 1.93 & 4.22 & 3.1 & 1.36 & Ovoid & Coprolite \\
\hline FUP-000279 & Peirópolis & 2.56 & 2.09 & 4.63 & 3.1 & 1.49 & Ovoid & Coprolite \\
\hline FUP-000280 & Peirópolis & 6.5 & 4.44 & 82.2 & 55 & 1.49 & Conical & Coprolite \\
\hline FUP-000281 & Peirópolis & 5.69 & 5.69 & 58.45 & 42 & 1.39 & & Pseudocoprolite \\
\hline FUP-000282 & Peirópolis & 6.06 & 4.35 & 19.6 & 25 & 0.78 & Indeterminate & Coprolite \\
\hline FUP-000283 & Peirópolis & 5.2 & 3.98 & 27.46 & 27 & 1.01 & Indeterminate & Coprolite \\
\hline FUP-000284 & Peirópolis & 3.42 & 3.32 & 18.58 & 17 & 1.09 & Indeterminate & Coprolite \\
\hline FUP-000285 & Peirópolis & 4.93 & 3.41 & 54.84 & 26 & 2.1 & & Pseudocoprolite \\
\hline FUP-000286 & Peirópolis & 2.9 & 2.22 & 7.99 & 6.8 & 1.17 & Indeterminate & Coprolite \\
\hline FUP-000287 & Peirópolis & 3.45 & 2.37 & 14.16 & 8 & 1.77 & Cylindrical & Coprolite \\
\hline FUP-000288 & Peirópolis & 3.12 & 2.47 & 15.08 & 8.5 & 1.77 & Conical & Coprolite \\
\hline FUP-000289 & Peirópolis & 3.06 & 2.14 & 7.41 & 7.2 & 1.02 & Cylindrical & Coprolite \\
\hline FUP-000290 & Peirópolis & 3.71 & 2.86 & 16.81 & 10 & 1.68 & & Pseudocoprolite \\
\hline FUP-000291 & Peirópolis & 3.1 & 2.8 & 13.5 & 7.5 & 1.8 & & Pseudocoprolite \\
\hline FUP-000292 & Peirópolis & 2.99 & 2.24 & 14.58 & 7 & 2.08 & & Pseudocoprolite \\
\hline FUP-000293 & Peirópolis & 3.49 & 3.1 & 34.13 & 16 & 2.13 & & Pseudocoprolite \\
\hline FUP-000294 & Peirópolis & 3.8 & 3.2 & 25.38 & 13 & 1.95 & & Pseudocoprolite \\
\hline FUP-000295 & Peirópolis & 3.4 & 2.65 & 25.09 & 18.5 & 1.35 & Cylindrical & Coprolite \\
\hline FUP-000296 & Serra da Galga & 1.66 & 1.61 & 0.86 & 1.1 & 0.78 & Indeterminate & Coprolite \\
\hline FUP-000297 & Serra da Galga & 0.85 & 0.66 & 0.11 & 0.15 & 0.73 & Indeterminate & Coprolite \\
\hline FUP-000298 & Serra da Galga & 1.11 & 0.91 & 0.33 & 0.3 & 1.1 & Indeterminate & Coprolite \\
\hline FUP-000299 & Serra da Galga & 1.19 & 0.96 & 1.13 & 0.9 & 1.25 & Indeterminate & Coprolite \\
\hline FUP-000300 & Serra da Galga & 1.64 & 0.99 & 0.35 & 0.4 & 0.87 & Indeterminate & Coprolite \\
\hline
\end{tabular}




\begin{tabular}{|c|c|c|c|c|c|c|c|c|}
\hline Code & Site & $\begin{array}{l}\text { Length } \\
(\mathrm{cm})\end{array}$ & $\begin{array}{l}\text { Width } \\
\text { (cm) }\end{array}$ & $\begin{array}{l}\text { Weight } \\
\text { (g) }\end{array}$ & $\begin{array}{c}\text { Volume } \\
\left(\mathrm{cm}^{3}\right)\end{array}$ & $\begin{array}{l}\text { Density } \\
\left(\mathrm{g} / \mathrm{cm}^{3}\right)\end{array}$ & Morphotype & Diagnosis \\
\hline FUP-000301 & Serra da Galga & 1.27 & 1.08 & 0.48 & 0.5 & 0.96 & Indeterminate & Coprolite \\
\hline FUP-000302 & Serra da Galga & 1.56 & 1.45 & 0.96 & 0.9 & 1.06 & Indeterminate & Coprolite \\
\hline FUP-000303 & Serra da Galga & 2.13 & 1.31 & 0.71 & 0.7 & 1.01 & Indeterminate & Coprolite \\
\hline FUP-000304 & Serra da Galga & 1.58 & 1.32 & 1.42 & 1.1 & 1.29 & Indeterminate & Coprolite \\
\hline FUP-000305 & Serra da Galga & 1.97 & 1.57 & 1.04 & 0.9 & 1.15 & Indeterminate & Coprolite \\
\hline FUP-000306 & Serra da Galga & 1.69 & 1.44 & 1.07 & 0.95 & 1.12 & Indeterminate & Coprolite \\
\hline FUP-000307 & Serra da Galga & 2.51 & 1.48 & 2.46 & 1.6 & 1.53 & Indeterminate & Coprolite \\
\hline FUP-000308 & Serra da Galga & 1.59 & 1.66 & 2.99 & 1.6 & 1.86 & & Pseudocoprolite \\
\hline FUP-000309 & Serra da Galga & 1.53 & 1.51 & 0.97 & 1.1 & 0.88 & Indeterminate & Coprolite \\
\hline FUP-000310 & Serra da Galga & 1.93 & 1.39 & 2.29 & 1.9 & 1.2 & Indeterminate & Coprolite \\
\hline FUP-000311 & Serra da Galga & 2.21 & 1.43 & 2.79 & 1.2 & 2.32 & & Pseudocoprolite \\
\hline FUP-000312 & Serra da Galga & 1.92 & 1.58 & 1.17 & 1.4 & 0.83 & Indeterminate & Coprolite \\
\hline FUP-000313 & Serra da Galga & 1.94 & 1.78 & 5.12 & 2.3 & 2.22 & & Pseudocoprolite \\
\hline FUP-000314 & Serra da Galga & 2.64 & 1.97 & 4.31 & 4 & 1.07 & Indeterminate & Coprolite \\
\hline FUP-000315 & Serra da Galga & 2.92 & 2.04 & 2.2 & 2.9 & 0.75 & Indeterminate & Coprolite \\
\hline FUP-000316 & Serra da Galga & 2.53 & 2.02 & 4.88 & 3.1 & 1.57 & Indeterminate & Coprolite \\
\hline FUP-000317 & Serra da Galga & 2.37 & 1.71 & 2.14 & 2.5 & 0.85 & Indeterminate & Coprolite \\
\hline FUP-000318 & Serra da Galga & 2.54 & 1.79 & 3.81 & 2.7 & 1.41 & Indeterminate & Coprolite \\
\hline FUP-000319 & Serra da Galga & 2.65 & 2.28 & 4.72 & 4.3 & 1.09 & Indeterminate & Coprolite \\
\hline FUP-000320 & Serra da Galga & 2.84 & 2.08 & 4.41 & 3.5 & 1.26 & Indeterminate & Coprolite \\
\hline FUP-000321 & Serra da Galga & 2.86 & 2.56 & 4.73 & 4.8 & 0.98 & Indeterminate & Coprolite \\
\hline FUP-000322 & Serra da Galga & 4.68 & 4.56 & 32.11 & 26 & 1.23 & & Pseudocoprolite \\
\hline FUP-000323 & Serra da Galga & 4.28 & 3.62 & 22.72 & 20 & 1.13 & Cylindrical & Coprolite \\
\hline FUP-000324 & Serra da Galga & 3.98 & 3.57 & 17.67 & 15 & 1.17 & Conical & Coprolite \\
\hline FUP-000325 & Serra da Galga & 3.61 & 3.15 & 16.87 & 14 & 1.2 & Indeterminate & Coprolite \\
\hline FUP-000326 & Serra da Galga & 3.56 & 2.37 & 3.94 & 4 & 0.98 & Indeterminate & Coprolite \\
\hline FUP-000327 & Serra da Galga & 3.44 & 2.34 & 12.67 & 9 & 1.4 & Cylindrical & Coprolite \\
\hline FUP-000328 & Serra da Galga & 3.95 & 2.92 & 10.8 & 10 & 1.08 & Indeterminate & Coprolite \\
\hline FUP-000329 & Serra da Galga & 2.79 & 2.29 & 6.36 & 6 & 1.06 & Indeterminate & Coprolite \\
\hline FUP-000330 & Serra da Galga & 3.02 & 2.5 & 3.71 & 4.5 & 0.82 & Indeterminate & Coprolite \\
\hline FUP-000331 & Serra da Galga & 4.24 & 3.41 & 29.7 & 16 & 1.85 & & Pseudocoprolite \\
\hline FUP-000332 & Serra da Galga & 2.94 & 1.99 & 8.78 & 4.5 & 1.95 & & Pseudocoprolite \\
\hline FUP-000333 & Serra da Galga & 4.53 & 4.23 & 42.13 & 21 & 2 & & Pseudocoprolite \\
\hline FUP-000334 & Serra da Galga & 4.21 & 4.05 & 60.6 & 26 & 2.33 & & Pseudocoprolite \\
\hline FUP-000335 & Serra da Galga & 6.25 & 4.38 & 125.72 & 57 & 2.2 & & Pseudocoprolite \\
\hline FUP-000336 & Peirópolis & 1.64 & 1.36 & 1.48 & 0.95 & 1.55 & Indeterminate & Coprolite \\
\hline FUP-000337 & Peirópolis & 3.31 & 2.47 & 9.05 & 6 & 1.5 & Indeterminate & Coprolite \\
\hline FUP-000338 & Peirópolis & 3.15 & 2.91 & 15.3 & 11 & 1.39 & Ovoid & Coprolite \\
\hline FUP-000339 & Peirópolis & 5.74 & 4.16 & 56.58 & 31 & 1.82 & & Pseudocoprolite \\
\hline FUP-000340 & Peirópolis & 3.4 & 2.69 & 15.3 & 10 & 1.53 & Ovoid & Coprolite \\
\hline
\end{tabular}


Apêndice 2. Registro fotográfico dos coprólitos e pseudocoprólitos dos sítios paleontológicos Peirópolis e Serra da Galga, região de Uberaba, Minas Gerais, Brasil.

\section{Estampa I}

Morfotipo 1 - coprólitos cilíndricos:

1. FUP-000004

2. FUP-000027

3. FUP-000041

4. FUP-000045

5. FUP-000057

6. FUP-000064

7. FUP-000092

8. FUP-000107

9. FUP-000154

10. FUP-000161

11. FUP-000254

12. FUP-000287

13. FUP-000289

14. FUP-000295

15. FUP-000323

16. FUP-000327

Escala $=1 \mathrm{~cm}$ 


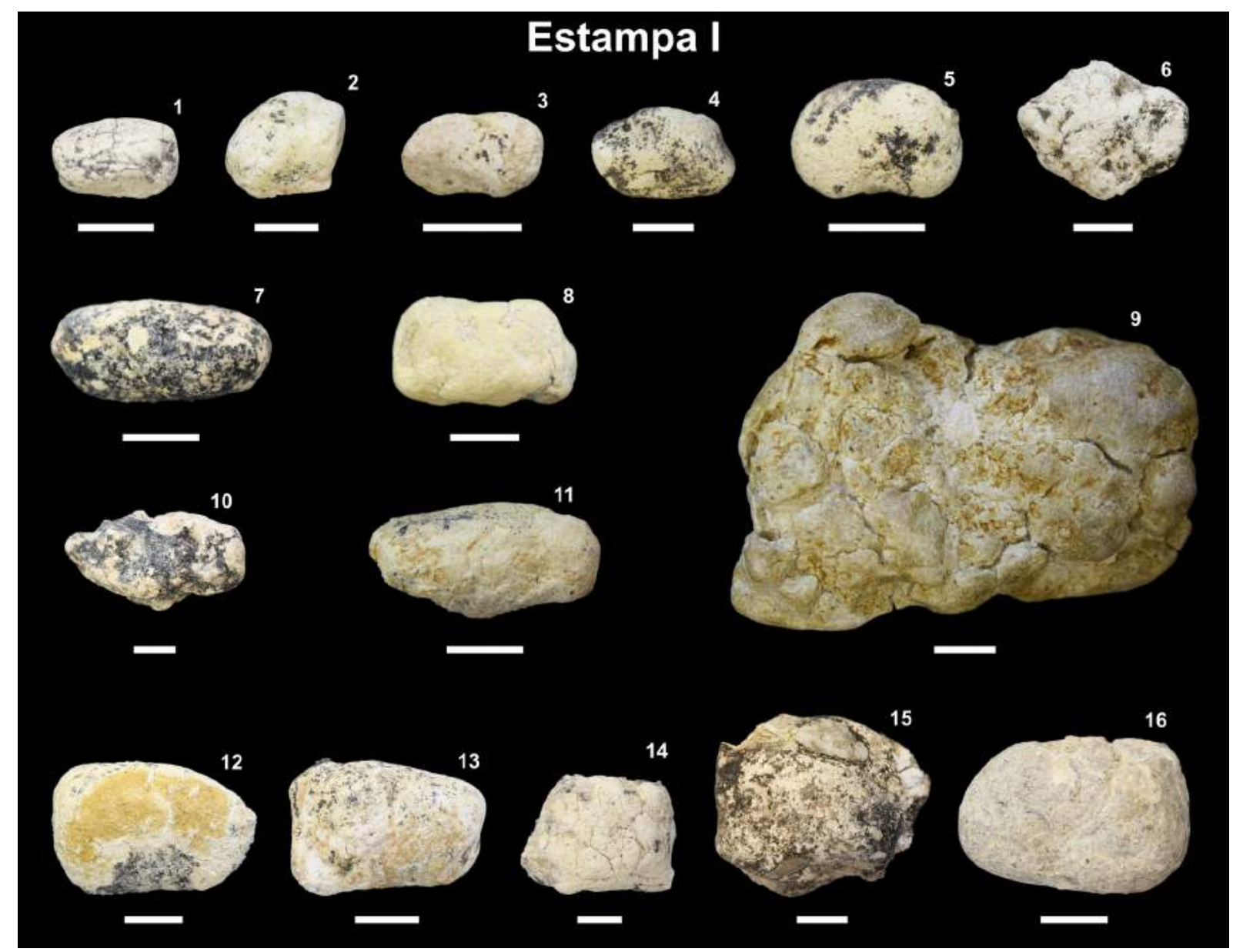




\section{Estampa II}

Morfotipo 2 - coprólitos ovoides:

1. FUP-000001

2. FUP-000003

3. FUP-000012

4. FUP-000019

5. FUP-000020

6. FUP-000026

7. FUP-000031

8. FUP-000036

9. FUP-000049

10. FUP-000051

11. FUP-000052

12. FUP-000055

13. FUP-000063

14. FUP-000097

15. FUP-000103

16. FUP-000122
17. FUP-000135

18. FUP-000157

19. FUP-000158

20. FUP-000163

21. FUP-000198

22. FUP-000202

23. FUP-000203

24. FUP-000206

25. FUP-000228

26. FUP-000257

27. FUP-000266

28. FUP-000267

29. FUP-000278

30. FUP-000279

31. FUP-000338

32. FUP-000340

Escala $=1 \mathrm{~cm}$ 


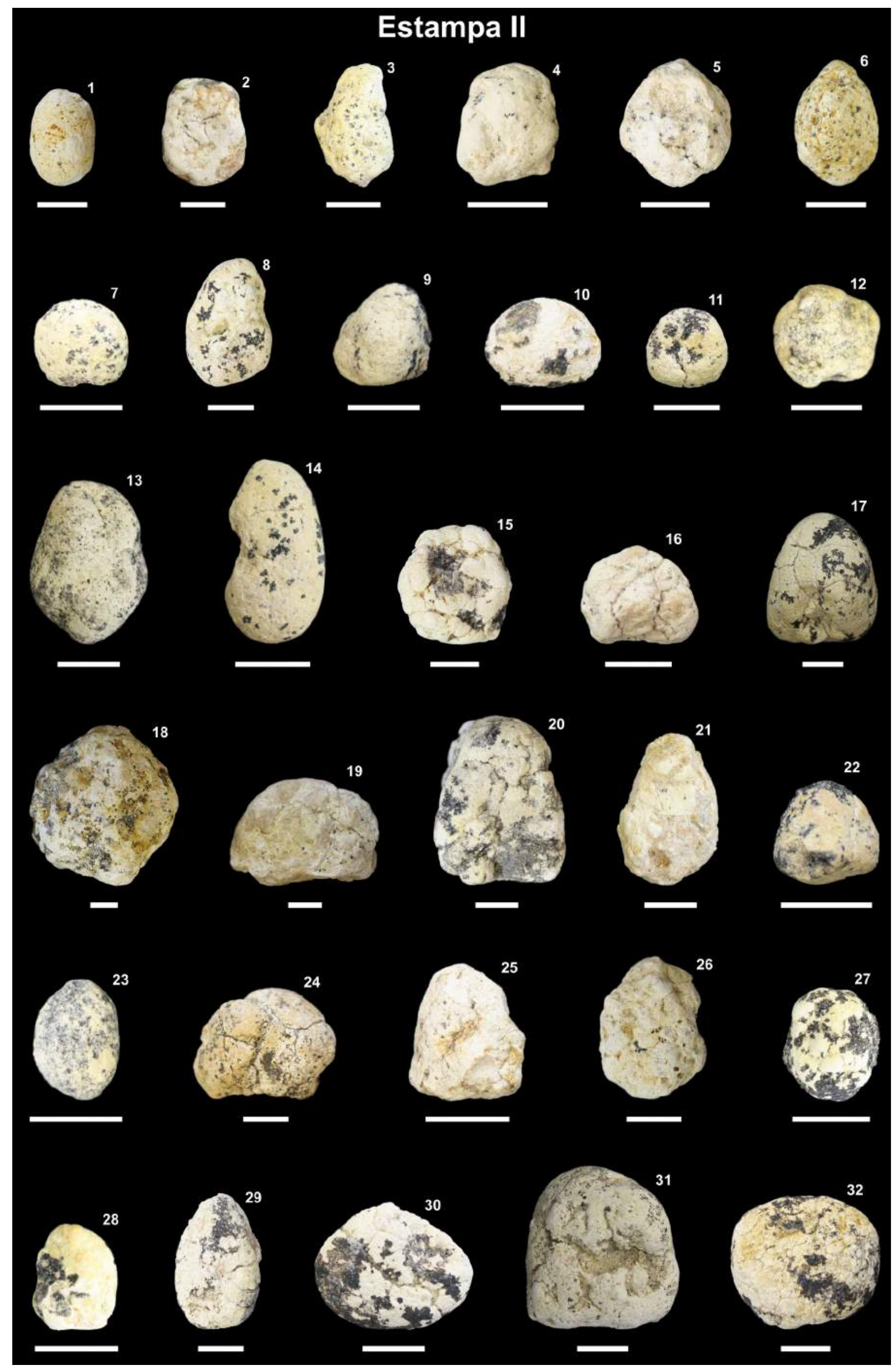




\section{Estampa III}

Morfotipo 3-coprólitos cônicos:

1. FUP-000016

2. FUP-000024

3. FUP-000025

4. FUP-000032

5. FUP-000044

6. FUP-000047

7. FUP-000073

8. FUP-000080

9. FUP-000081

10. FUP-000096

11. FUP-000099
12. FUP-000125

13. FUP-000131

14. FUP-000144

15. FUP-000195

16. FUP-000199

17. FUP-000222

18. FUP-000277

19. FUP-000280

20. FUP-000288

21. FUP-000324

Morfotipo 4 - coprólitos dômicos:

22. FUP-000023

24. FUP-000145

23. FUP-000100

25. FUP-000156

Escala $=1 \mathrm{~cm}$ 


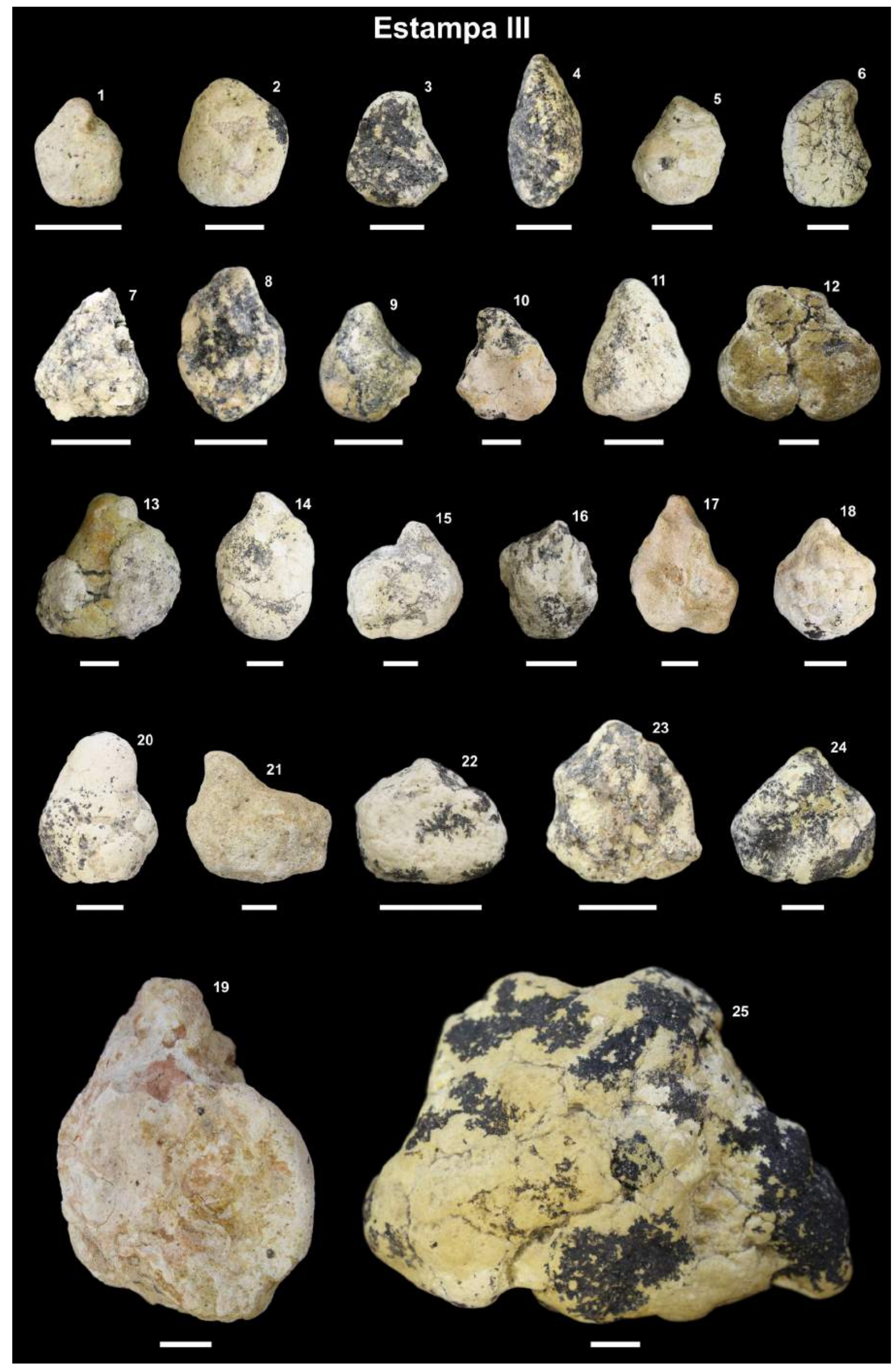




\section{Estampa IV}

Coprólitos de morfologia indeterminada:

1. FUP-000006

2. FUP-000011

3. FUP-000018

4. FUP-000030

5. FUP-000042

6. FUP-000043

7. FUP-000054

8. FUP-000059

9. FUP-000062

10. FUP-000065

11. FUP-000066

12. FUP-000069

13. FUP-000070

14. FUP-000071

15. FUP-000072

16. FUP-000074

17. FUP-000075

18. FUP-000076

19. FUP-000077

20. FUP-000079

21. FUP-000082

22. FUP-000083

23. FUP-000085

24. FUP-000086
25. FUP-000087

26. FUP-000089

27. FUP-000090

28. FUP-000091

29. FUP-000093

30. FUP-000095

31. FUP-000110

32. FUP-000111

33. FUP-000113

34. FUP-000124

35. FUP-000126

36. FUP-000128

37. FUP-000130

38. FUP-000134

39. FUP-000141

40. FUP-000142

41. FUP-000143

42. FUP-000159

43. FUP-000164

44. FUP-000204

45. FUP-000205

46. FUP-000207

47. FUP-000208

48. FUP-000209

Escala $=1 \mathrm{~cm}$ 


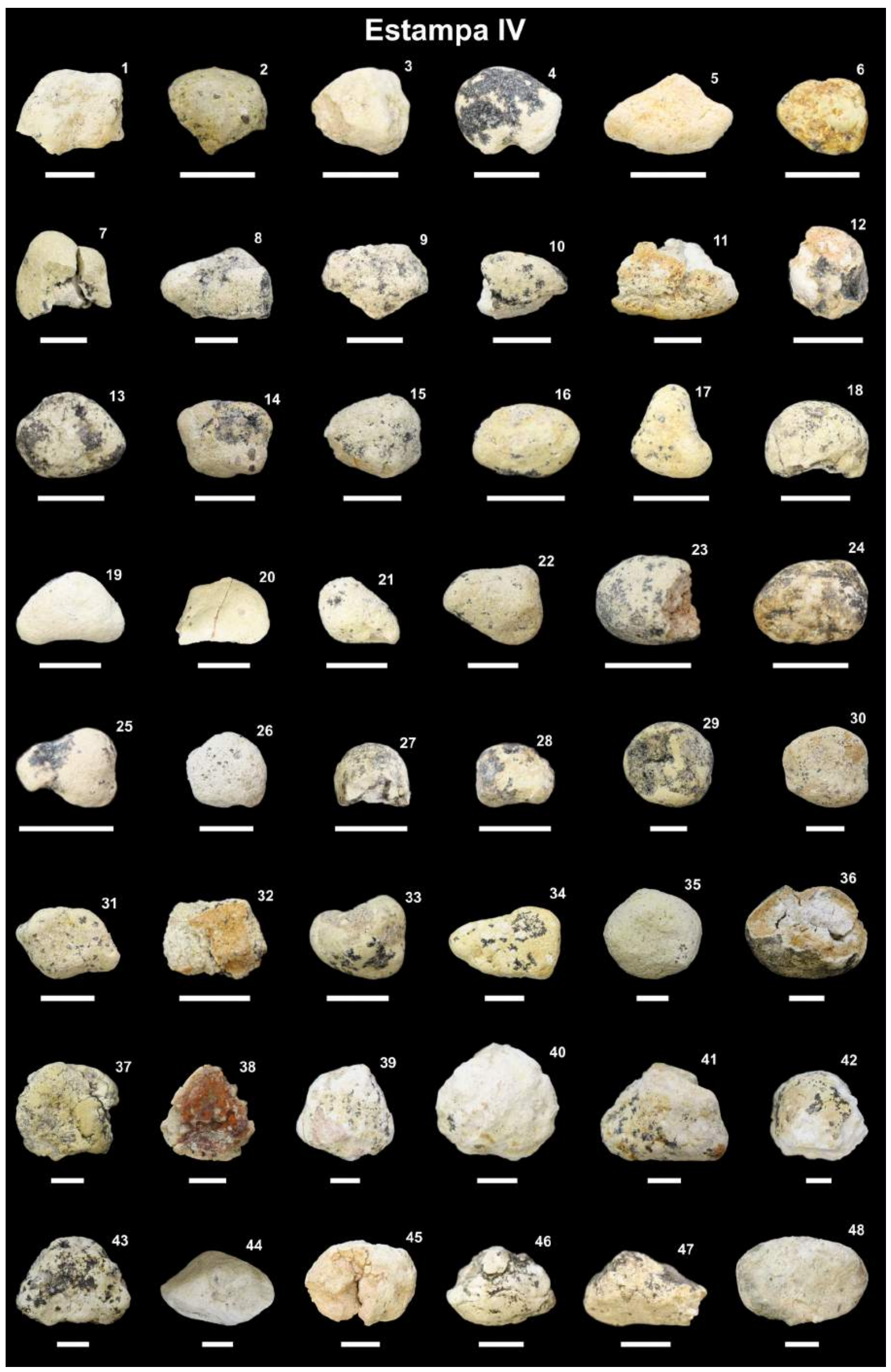




\section{Estampa V}

Coprólitos de morfologia indeterminada:

1. FUP-000210

2. FUP-000211

3. FUP-000212

4. FUP-000213

5. FUP-000214

6. FUP-000215

7. FUP-000216

8. FUP-000217

9. FUP-000218

10. FUP-000220

11. FUP-000221

12. FUP-000223

13. FUP-000224

14. FUP-000225

15. FUP-000226

16. FUP-000227

17. FUP-000229

18. FUP-000230

19. FUP-000231

20. FUP-000232

21. FUP-000233

22. FUP-000234

23. FUP-000235

24. FUP-000237
25. FUP-000238

26. FUP-000239

27. FUP-000240

28. FUP-000241

29. FUP-000242

30. FUP-000243

31. FUP-000247

32. FUP-000249

33. FUP-000255

34. FUP-000256

35. FUP-000264

36. FUP-000265

37. FUP-000268

38. FUP-000269

39. FUP-000270

40. FUP-000271

41. FUP-000272

42. FUP-000274

43. FUP-000275

44. FUP-000276

45. FUP-000282

46. FUP-000283

47. FUP-000284

48. FUP-000286

Escala $=1 \mathrm{~cm}$ 


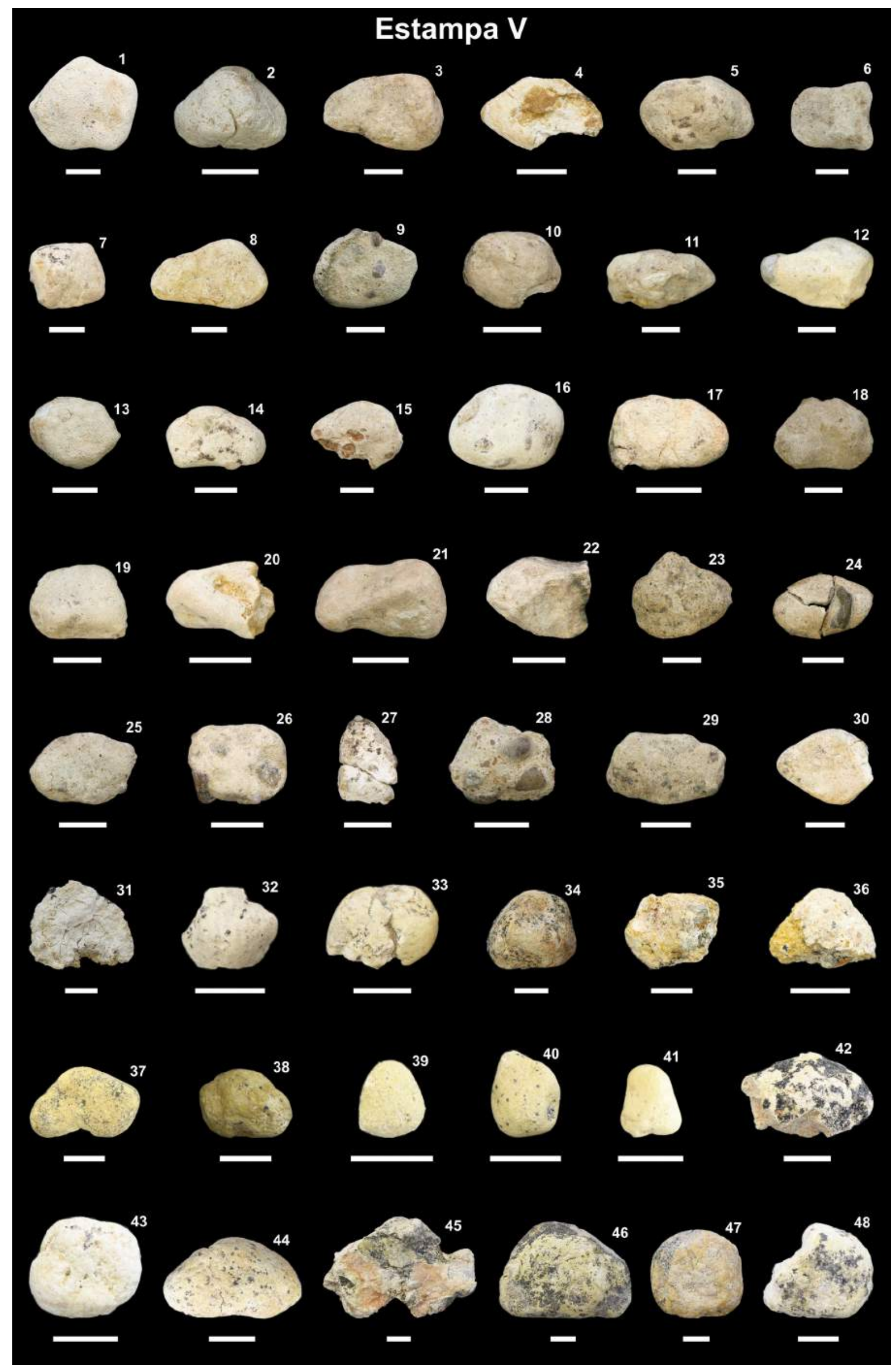




\section{Estampa VI}

Coprólitos de morfologia indeterminada:

1. FUP-000296

2. FUP-000297

3. FUP-000298

4. FUP-000299

5. FUP-000300

6. FUP-000301

7. FUP-000302

8. FUP-000303

9. FUP-000304

10. FUP-000305

11. FUP-000306

12. FUP-000307

13. FUP-000309

14. FUP-000310

15. FUP-000312
16. FUP-000314

17. FUP-000315

18. FUP-000316

19. FUP-000317

20. FUP-000318

21. FUP-000319

22. FUP-000320

23. FUP-000321

24. FUP-000325

25. FUP-000326

26. FUP-000328

27. FUP-000329

28. FUP-000330

29. FUP-000336

30. FUP-000337

Escala $=1 \mathrm{~cm}$ 


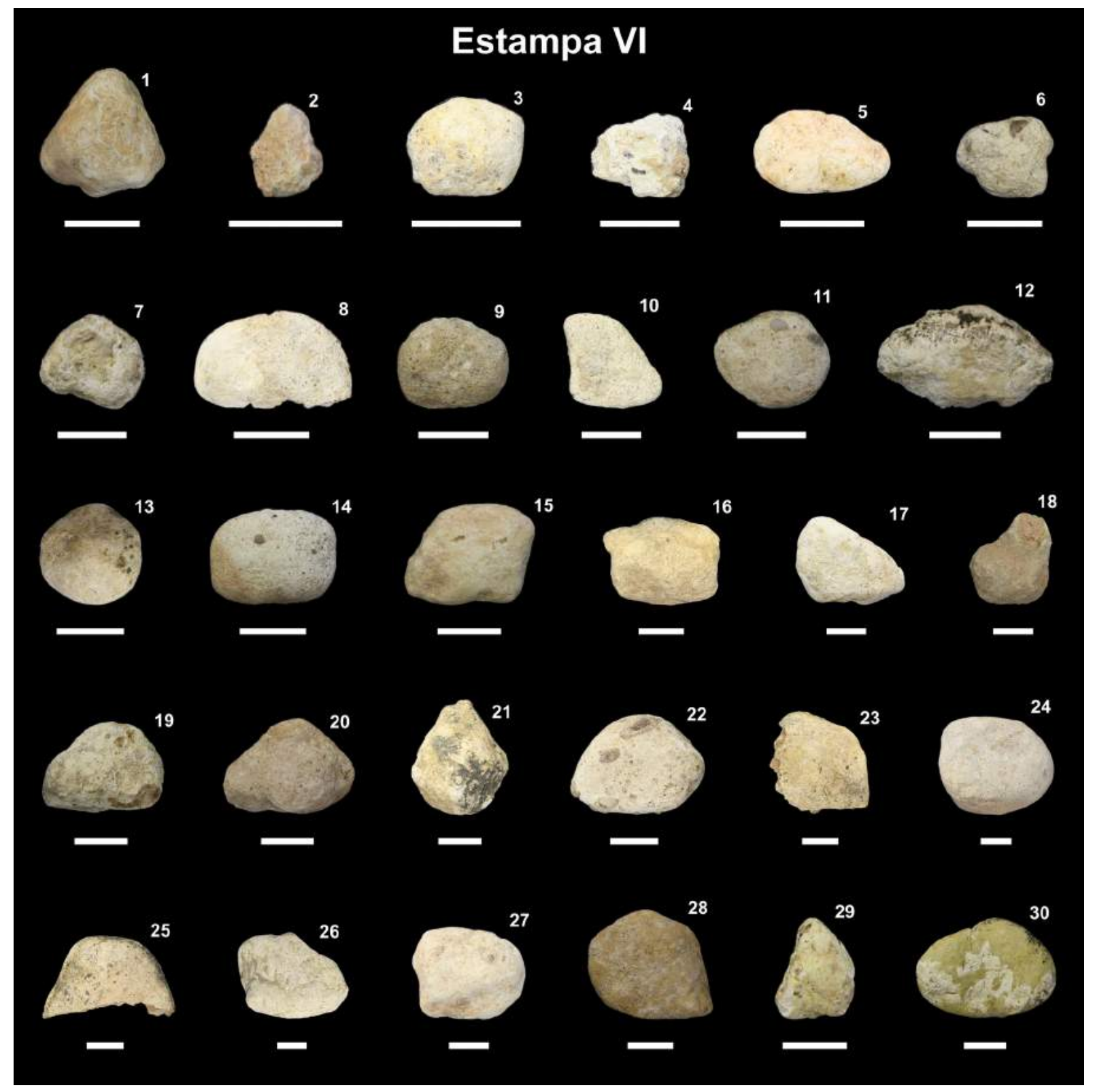




\section{Estampa VII}

Pseudocoprólitos:

1. FUP-000002

2. FUP-000005

3. FUP-000007

4. FUP-000008

5. FUP-000009

6. FUP-000010

7. FUP-000013

8. FUP-000014

9. FUP-000015

10. FUP-000017

11. FUP-000021

12. FUP-000022

13. FUP-000028

14. FUP-000029

15. FUP-000033

16. FUP-000034

17. FUP-000035

18. FUP-000037

19. FUP-000038

20. FUP-000039

21. FUP-000040

22. FUP-000046

23. FUP-000048

24. FUP-000050
25. FUP-000053

26. FUP-000056

27. FUP-000058

28. FUP-000060

29. FUP-000061

30. FUP-000067

31. FUP-000068

32. FUP-000078

33. FUP-000084

34. FUP-000088

35. FUP-000094

36. FUP-000098

37. FUP-000101

38. FUP-000102

39. FUP-000104

40. FUP-000105

41. FUP-000106

42. FUP-000108

43. FUP-000109

44. FUP-000112

45. FUP-000114

46. FUP-000115

47. FUP-000116

48. FUP-000117

Escala $=1 \mathrm{~cm}$ 


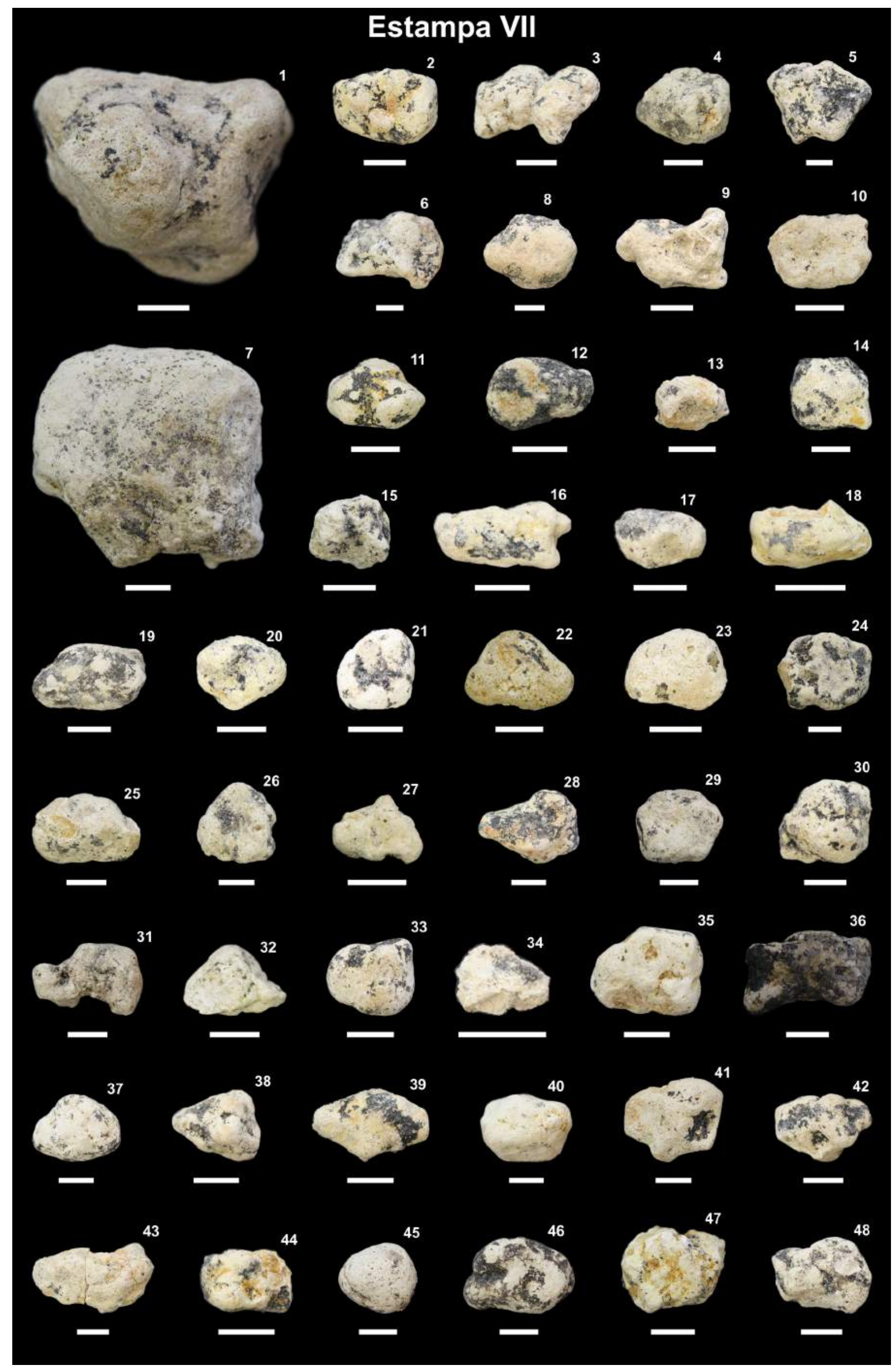




\section{Estampa VIII}

Pseudocoprólitos:

1. FUP-000118

2. FUP-000119

3. FUP-000120

4. FUP-000121

5. FUP-000123

6. FUP-000127

7. FUP-000129

8. FUP-000132

9. FUP-000133

10. FUP-000136

11. FUP-000137

12. FUP-000138

13. FUP-000139

14. FUP-000140

15. FUP-000146
16. FUP-000147

17. FUP-000148

18. FUP-000149

19. FUP-000150

20. FUP-000151

21. FUP-000152

22. FUP-000153

23. FUP-000155

24. FUP-000160

25. FUP-000162

26. FUP-000165

27. FUP-000166

28. FUP-000167

29. FUP-000168

30. FUP-000169

Escala $=1 \mathrm{~cm}$ 


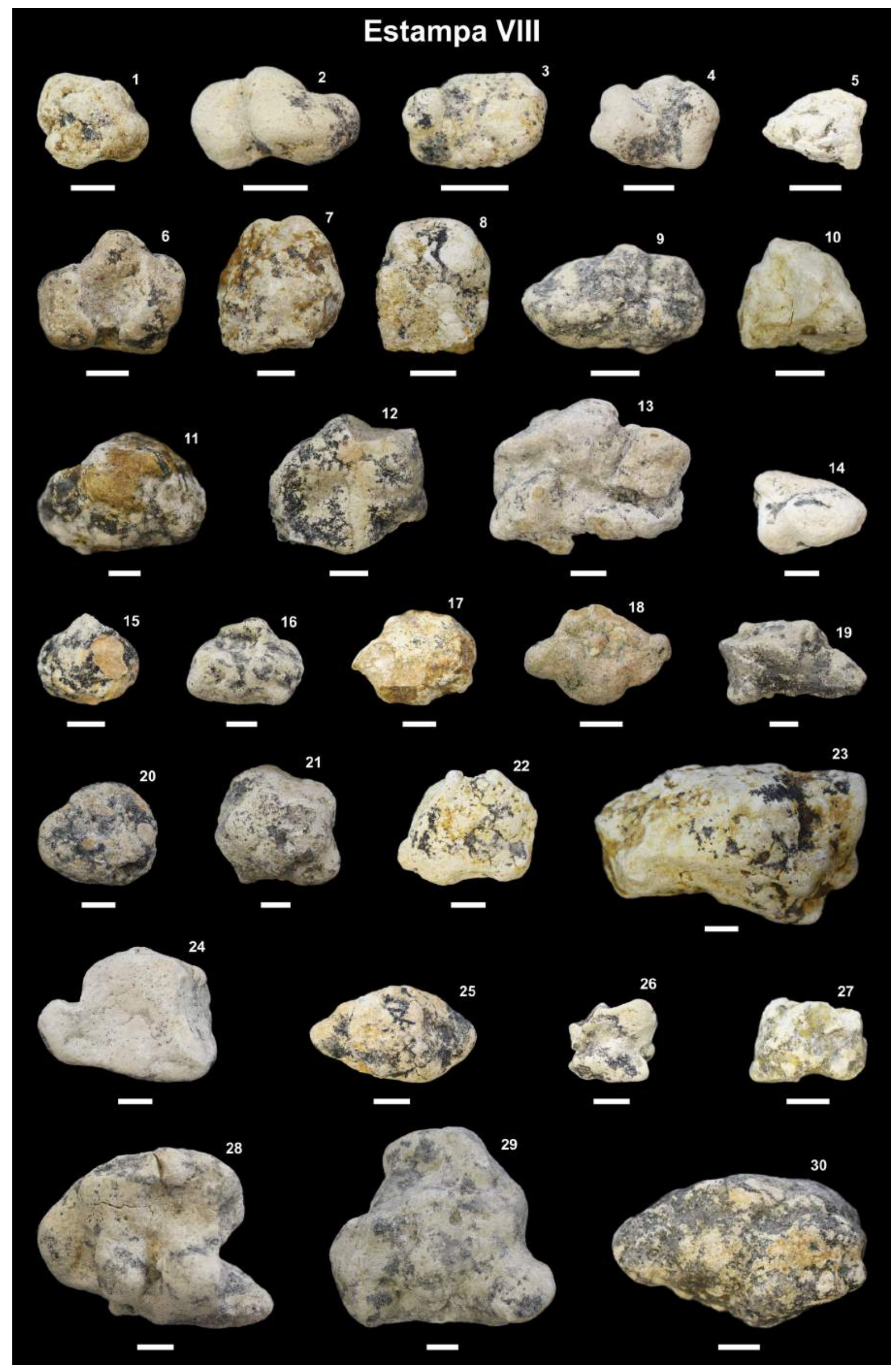




\section{Estampa IX}

Pseudocoprólitos:

1. FUP-000170

2. FUP-000171

3. FUP-000172

4. FUP-000173

5. FUP-000174

6. FUP-000175

7. FUP-000176

8. FUP-000177

9. FUP-000178

10. FUP-000179

11. FUP-000180

12. FUP-000181

13. FUP-000182

14. FUP-000183

15. FUP-000184
16. FUP-000185

17. FUP-000186

18. FUP-000187

19. FUP-000188

20. FUP-000189

21. FUP-000190

22. FUP-000191

23. FUP-000192

24. FUP-000193

25. FUP-000194

26. FUP-000196

27. FUP-000197

28. FUP-000200

29. FUP-000201

30. FUP-000219

Escala $=1 \mathrm{~cm}$ 


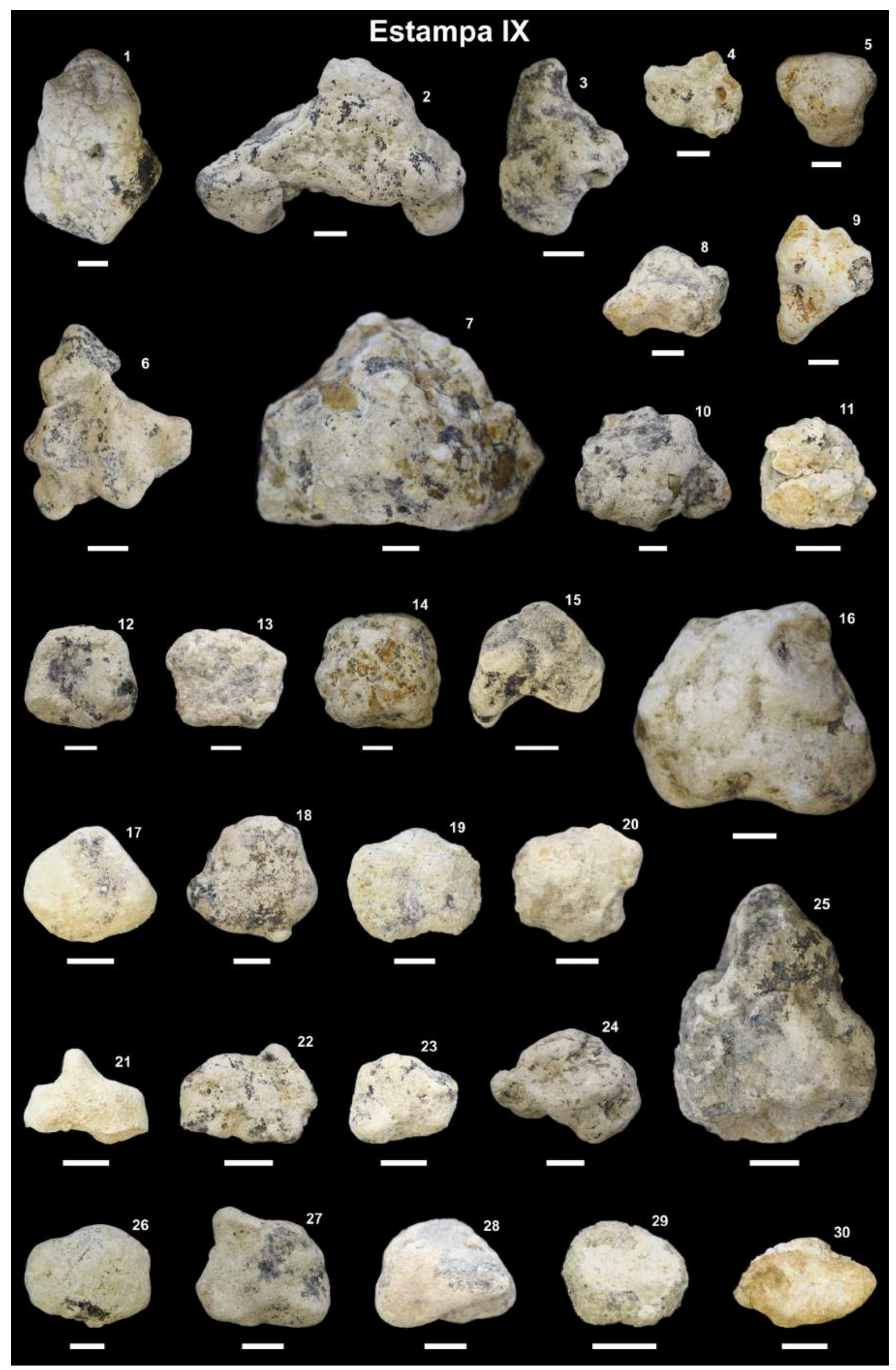




\section{Estampa X}

Pseudocoprólitos

1. FUP-000236

2. FUP-000244

3. FUP-000245

4. FUP-000246

5. FUP-000248

6. FUP-000250

7. FUP-000251

8. FUP-000252

9. FUP-000253

10. FUP-000258

11. FUP-000259

12. FUP-000260

13. FUP-000261

14. FUP-000262

15. FUP-000263

16. FUP-000273

17. FUP-000281
18. FUP-000285

19. FUP-000290

20. FUP-000291

21. FUP-000292

22. FUP-000293

23. FUP-000294

24. FUP-000308

25. FUP-000311

26. FUP-000313

27. FUP-000322

28. FUP-000331

29. FUP-000332

30. FUP-000333

31. FUP-000334

32. FUP-000335

33. FUP-000339

Escala $=1 \mathrm{~cm}$ 


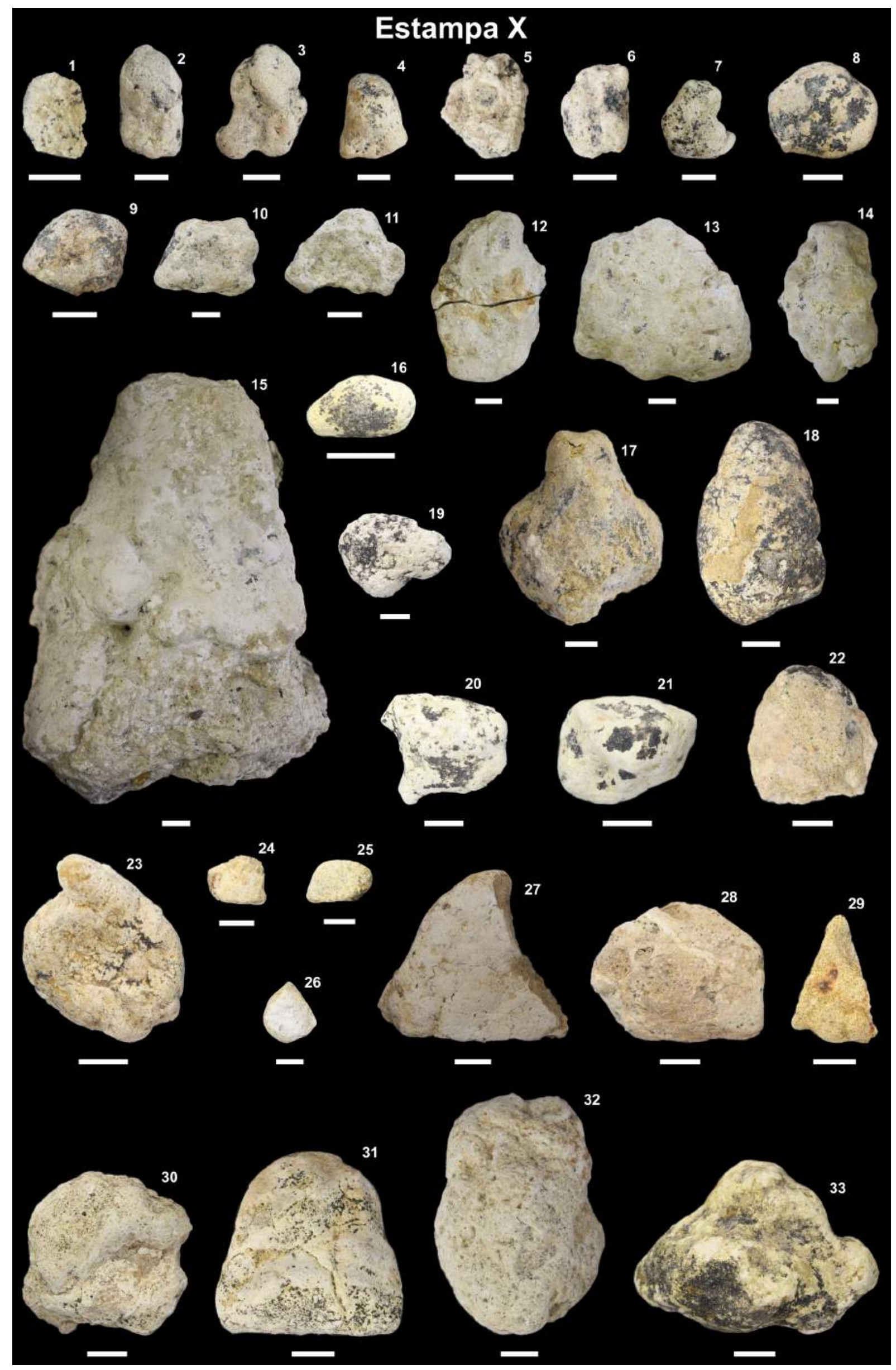




\section{Anexos}

Neste tópico são apresentados os resultados da difratometria de raios-X dos coprólitos e pseudocoprólitos dos sítios paleontológicos Peirópolis e Serra da Galga, região de Uberaba, Minas Gerais, Brasil. As análises foram realizadas pelo Laboratório de Difração de Raios-X do Instituto de Geociências (IG) da Universidade de Brasília (UnB).

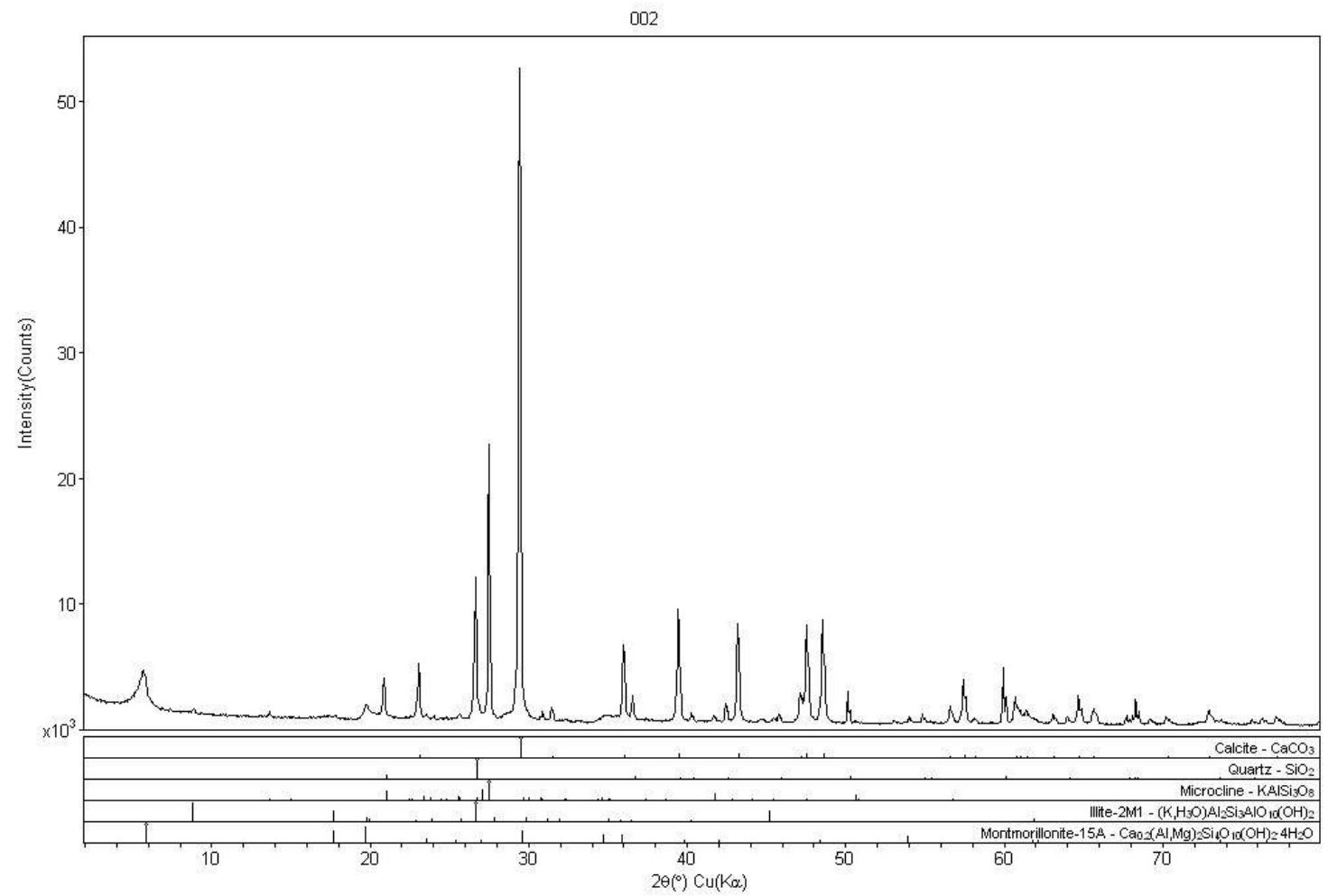

Campus Univ Darby Ribeiro [RAI0-X||G] Wednesday, December 09, 2015 10:17a (MDIJJADE9)

Anexo 1. Espectro de difração de raios-X da amostra FUP-000002. 


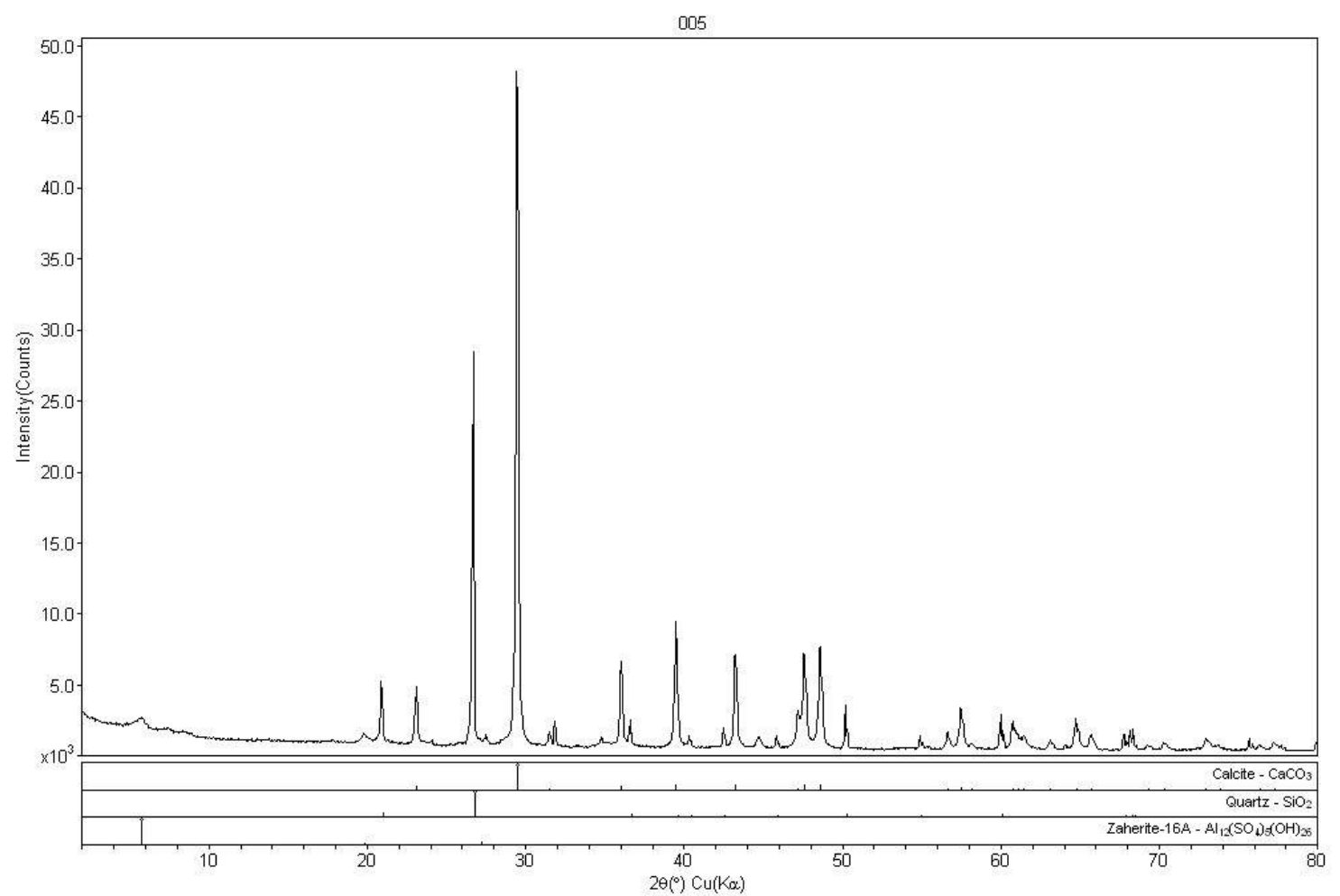

Campus Univ Darby Ribeiro

[RAOO-X||G] Wednesday, December 09, 2015 10:12a (MDIJJADEQ)

Anexo 2. Espectro de difração de raios-X da amostra FUP-000005.

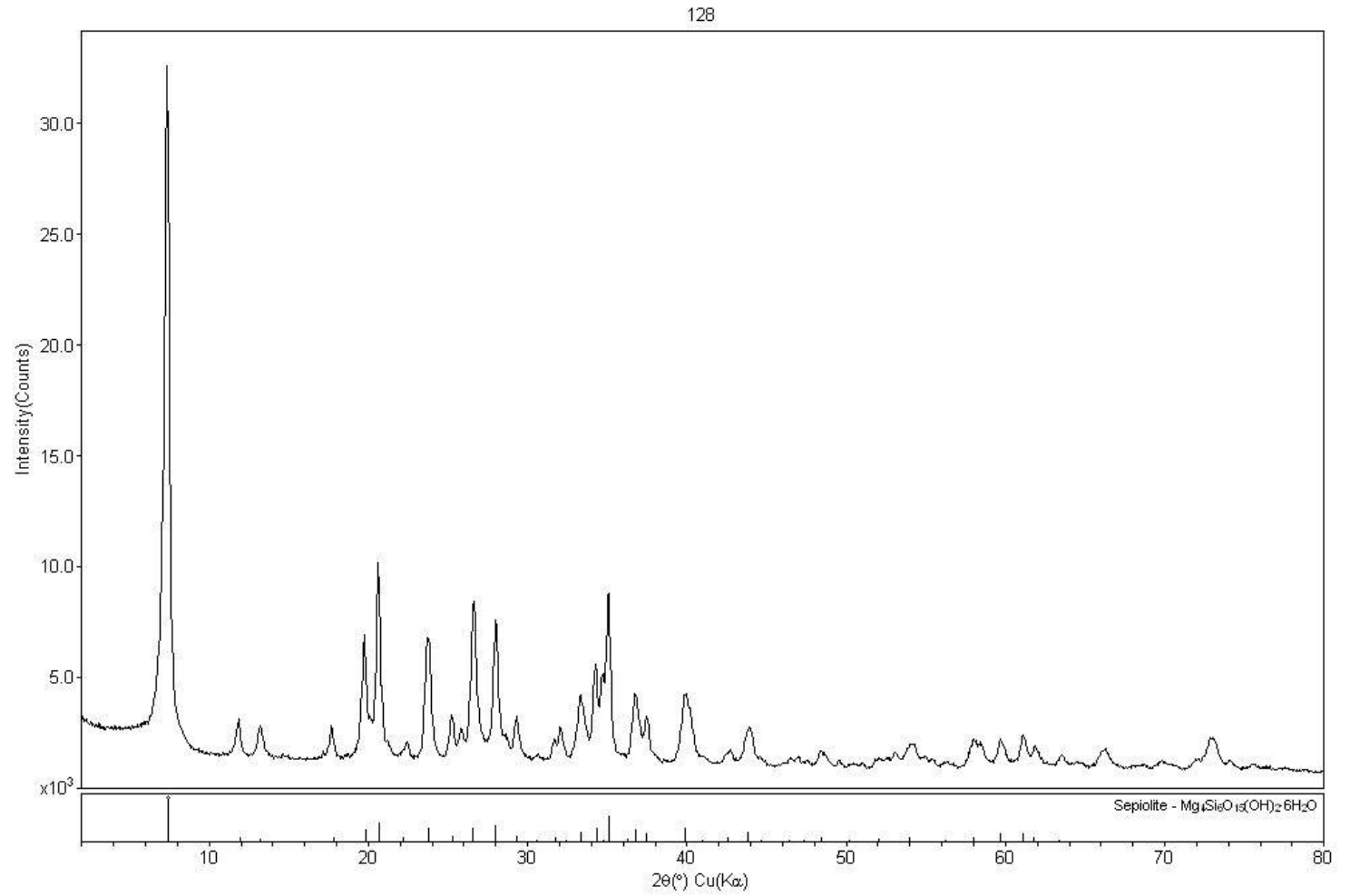

Campus Univ Darby Ribeiro [RA0-X||G] Wiednesday, December 09, 2015 10:12a MDI/JADEg)

Anexo 3. Espectro de difração de raios-X da amostra FUP-000128. 


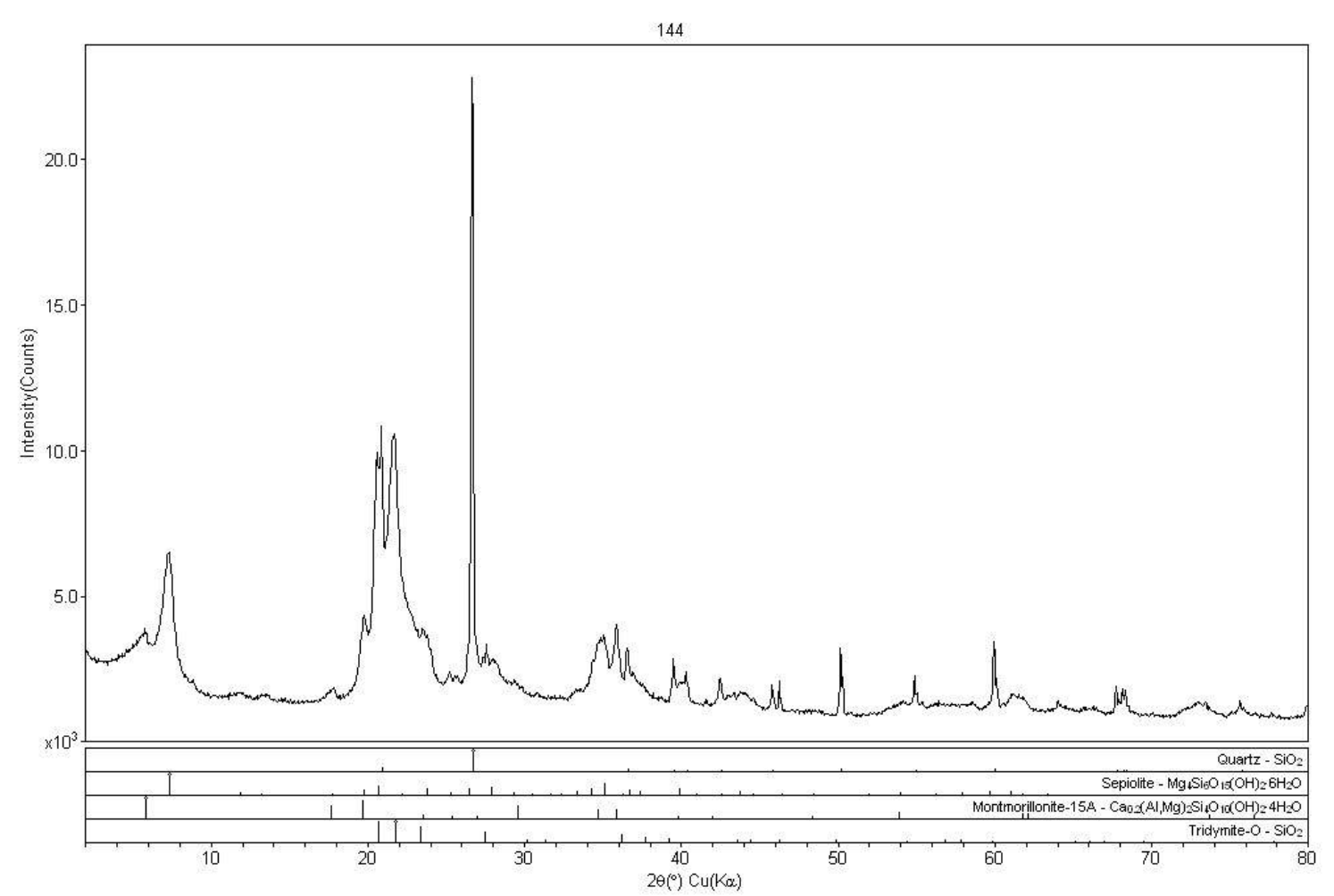

Campus Univ Darby Ribeiro

Anexo 4. Espectro de difração de raios-X da amostra FUP-000144.

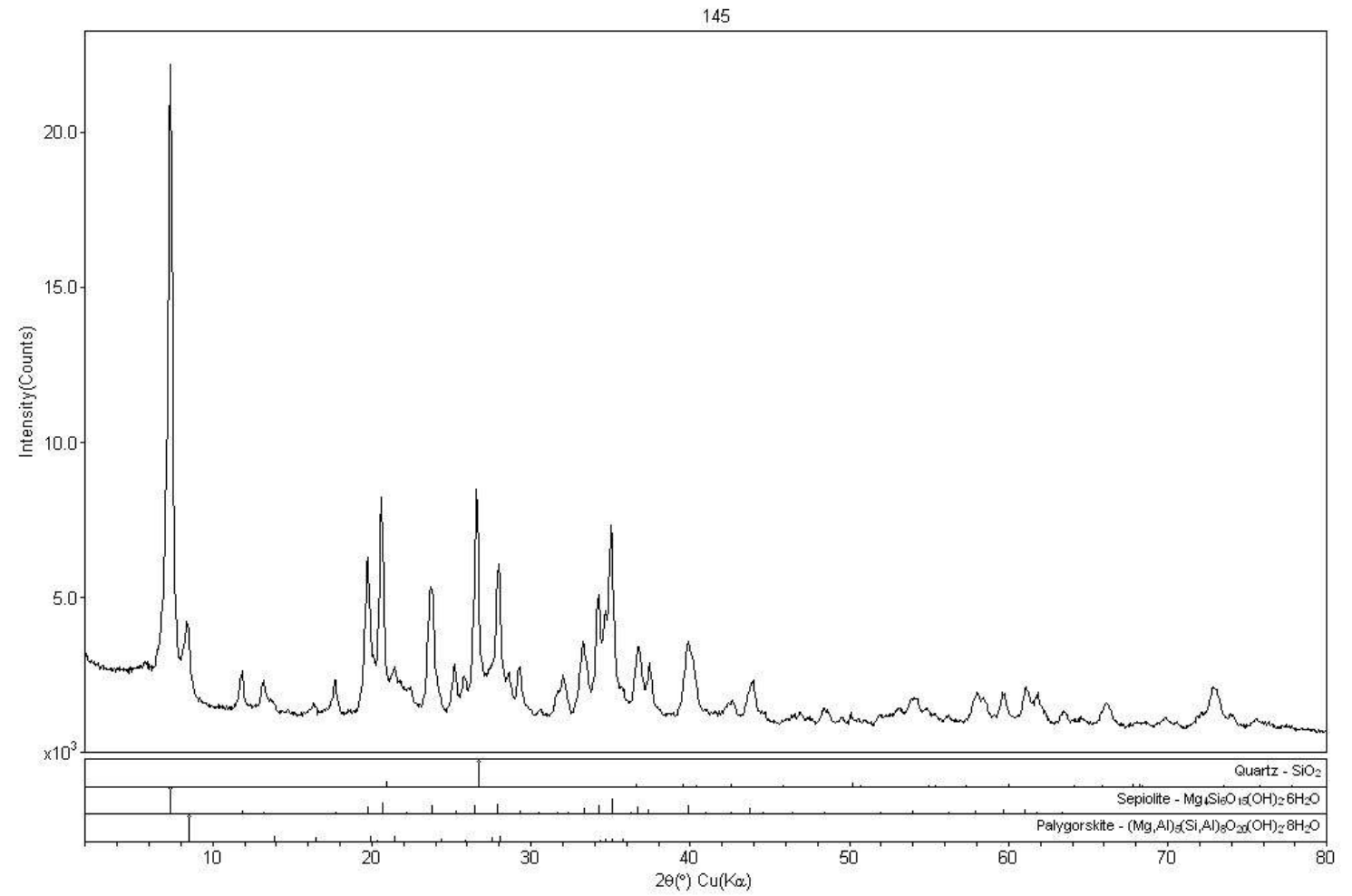

Campus Univ Darby Ribeiro [RAOO-X||G] Wednesday, December 09, 2015 10:13a (MDIIJADE9)

Anexo 5. Espectro de difração de raios-X da amostra FUP-000145. 


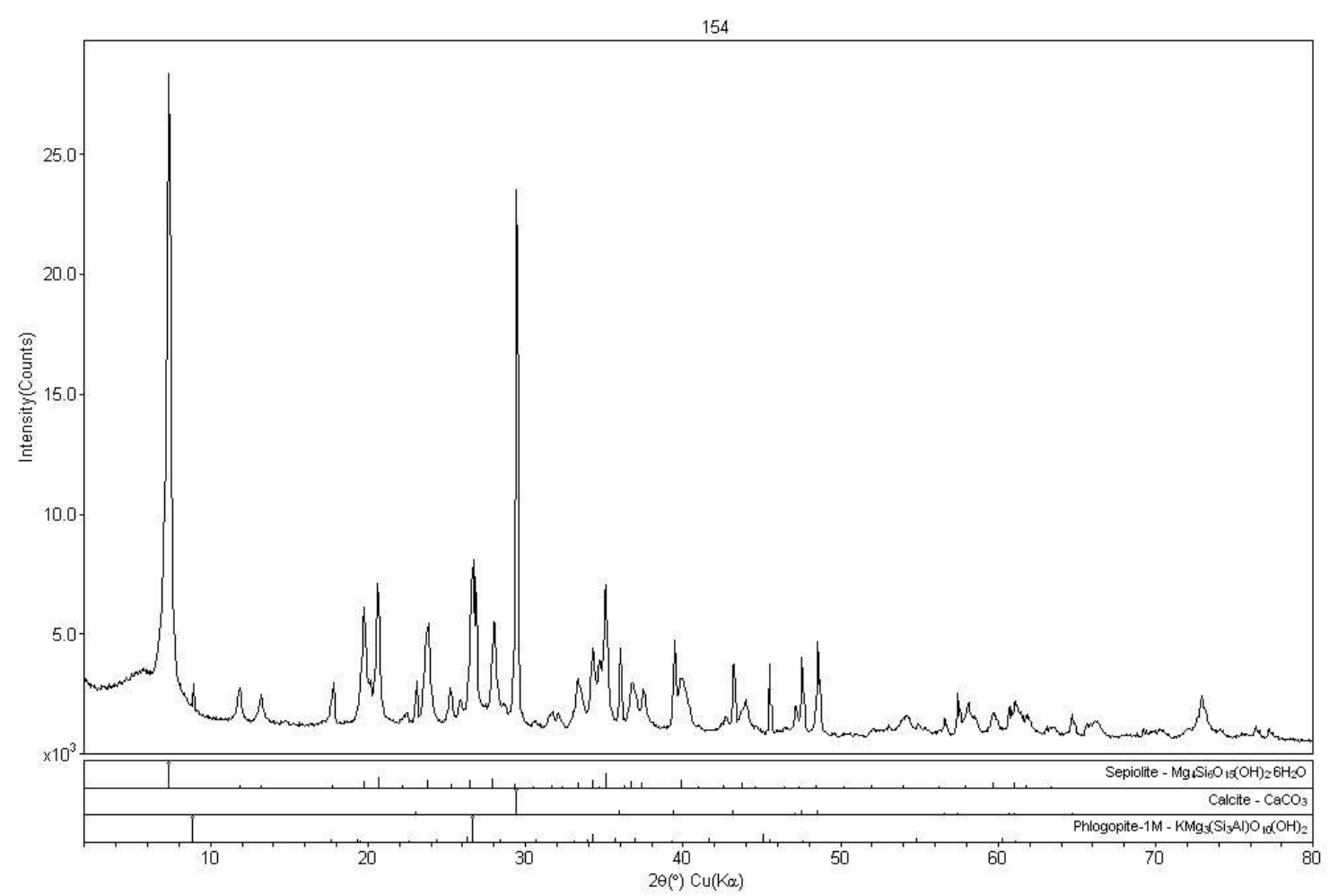

Campus Univ Darby Ribeiro

Anexo 6. Espectro de difração de raios-X da amostra FUP-000154.

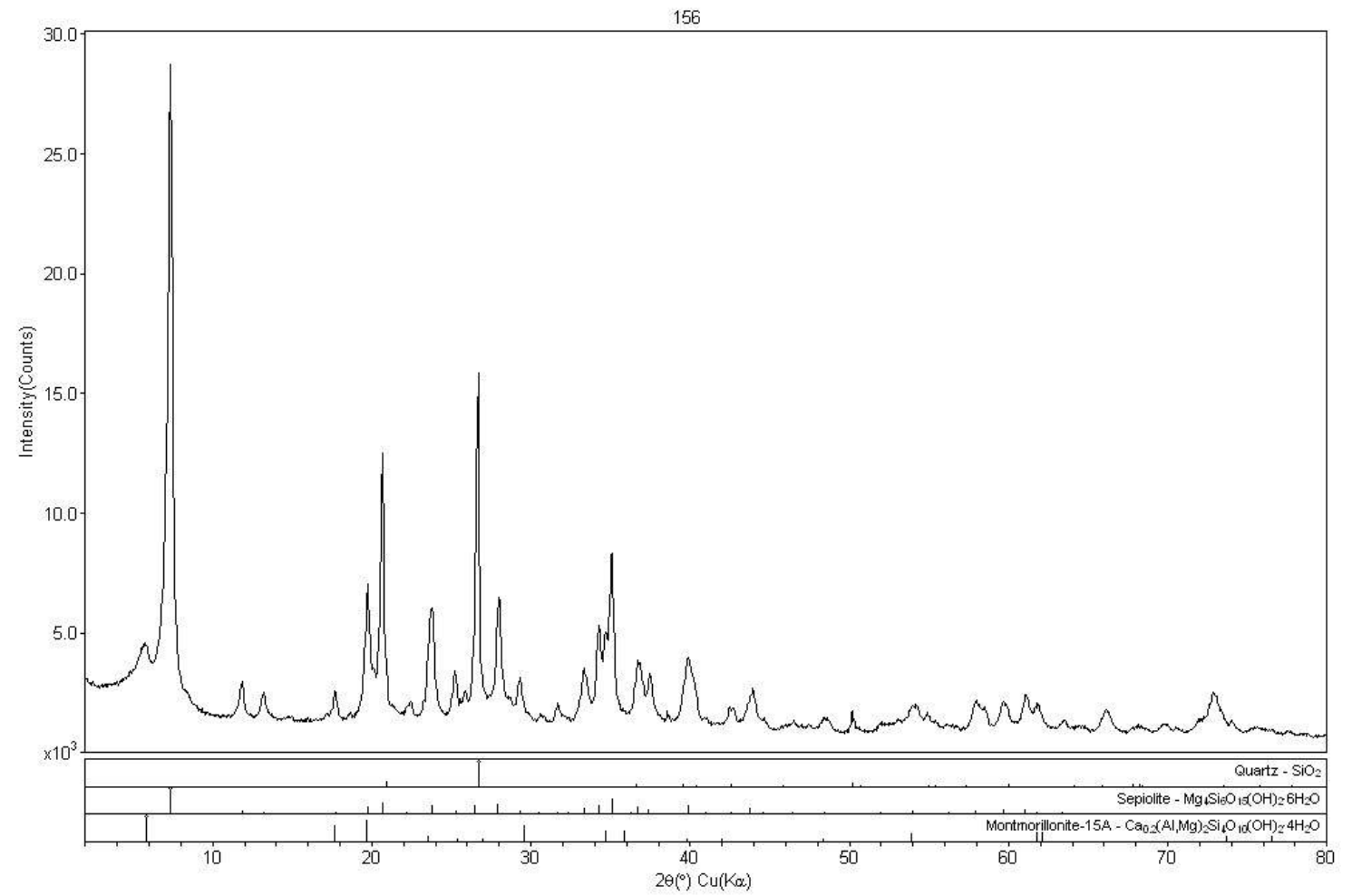

Campus Univ Darby Ribeiro [RA|O-X||G] Mbnday, January 18, 2016 02:33P (MDI/JADE9)

Anexo 7. Espectro de difração de raios-X da amostra FUP-000156. 


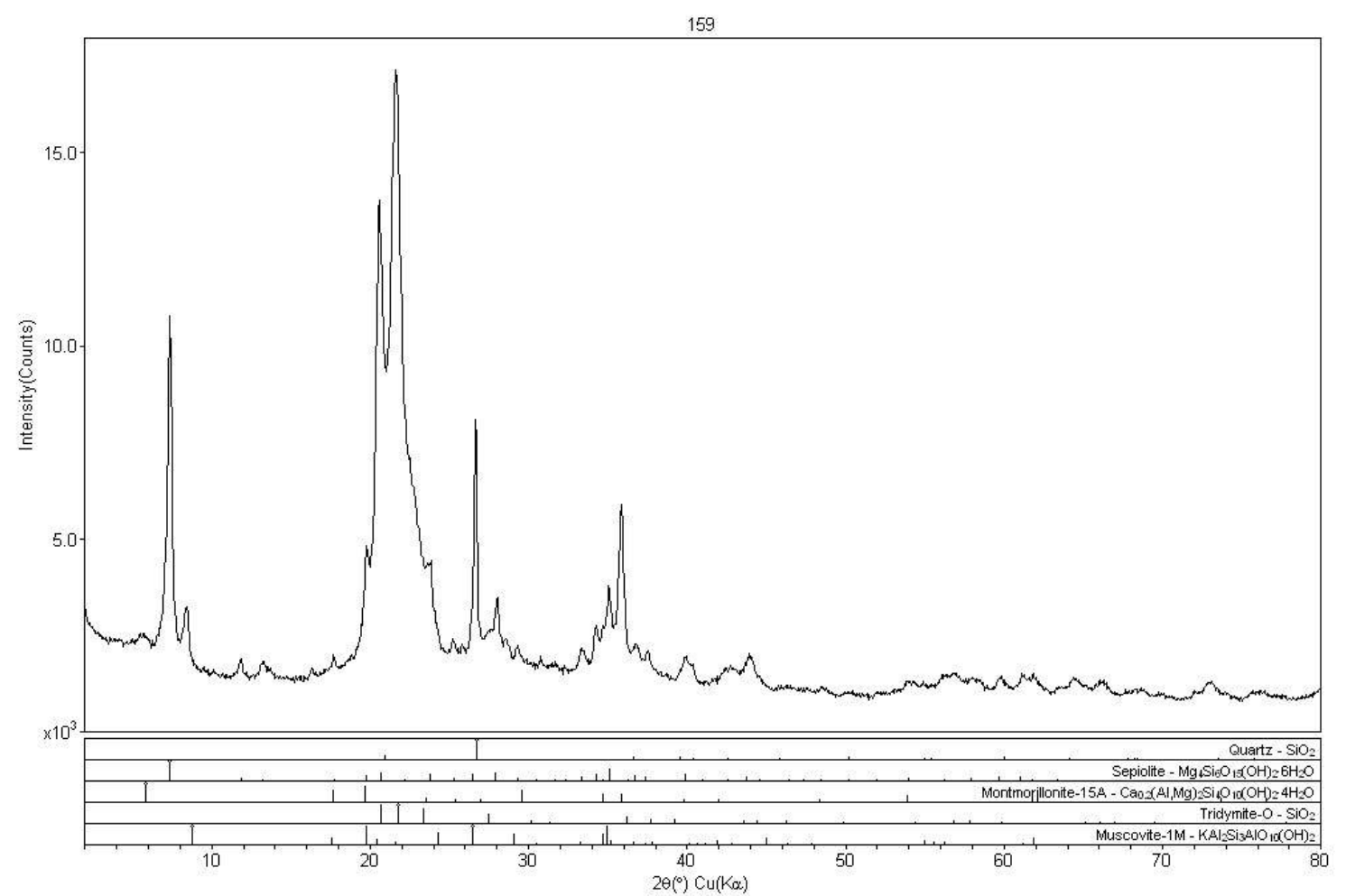

Campus Univ Darby Ribeiro

[RAOO-X||G] Wiednesday, December 09, 2015 10:13a (MOIJADE9)

Anexo 8. Espectro de difração de raios-X da amostra FUP-000159.

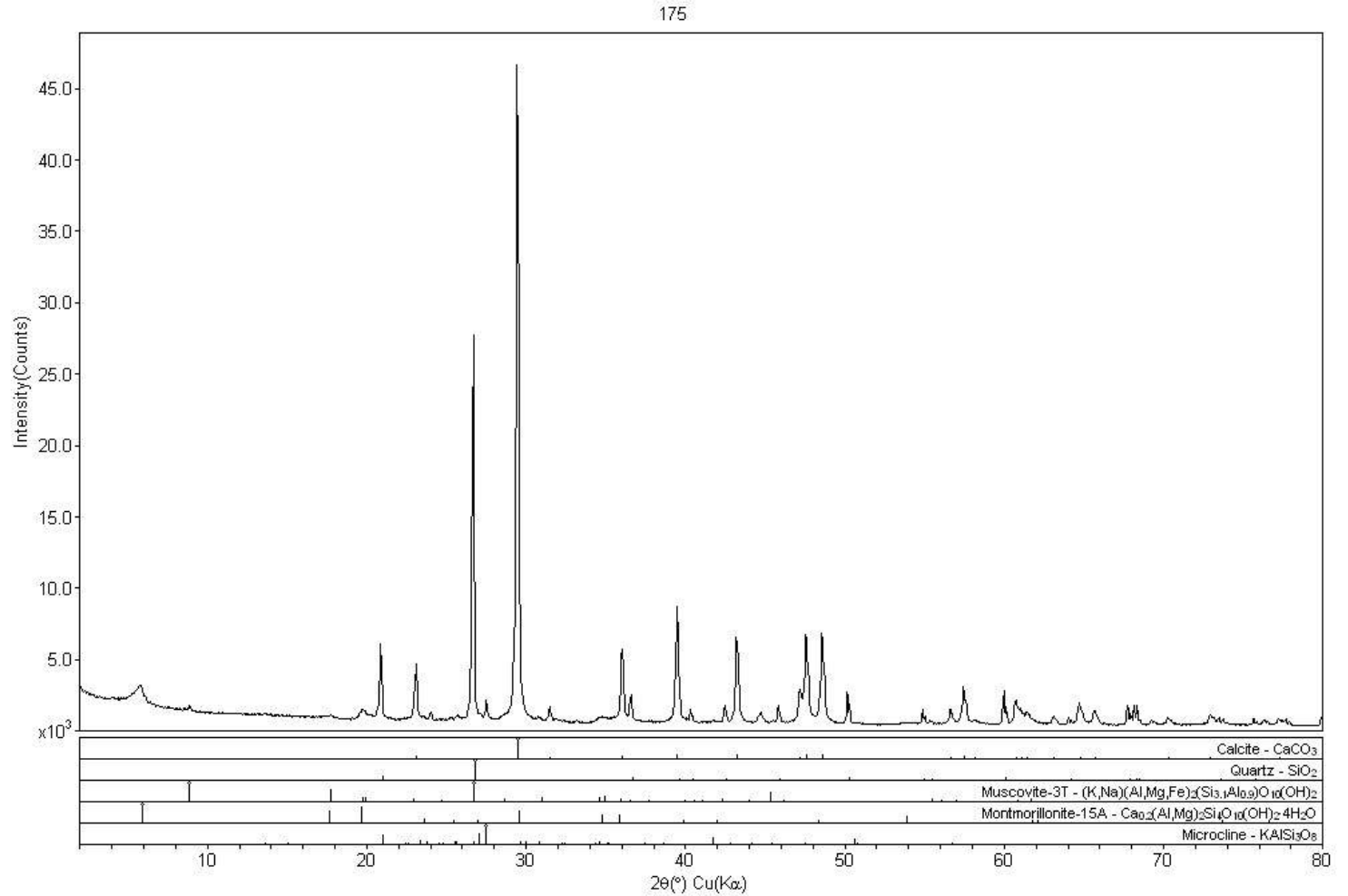

Campus Univ Darby Ribeiro [RAO-X||G] Wednesday, December 09, 2015 10:16a (MDIJJADE9)

Anexo 9. Espectro de difração de raios-X da amostra FUP-000175. 


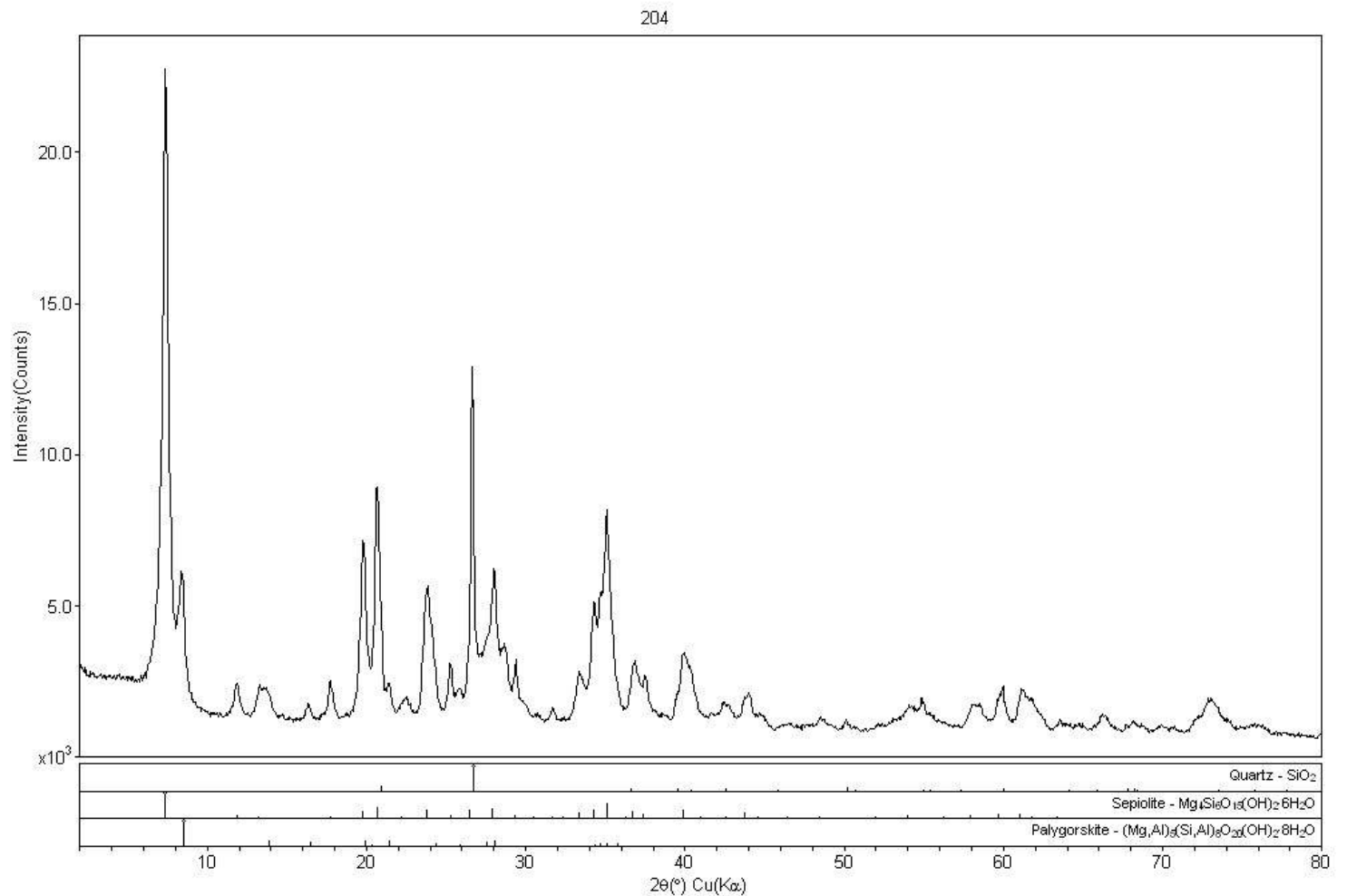

Campus Univ Darby Ribeiro

Anexo 10. Espectro de difração de raios-X da amostra FUP-000204.

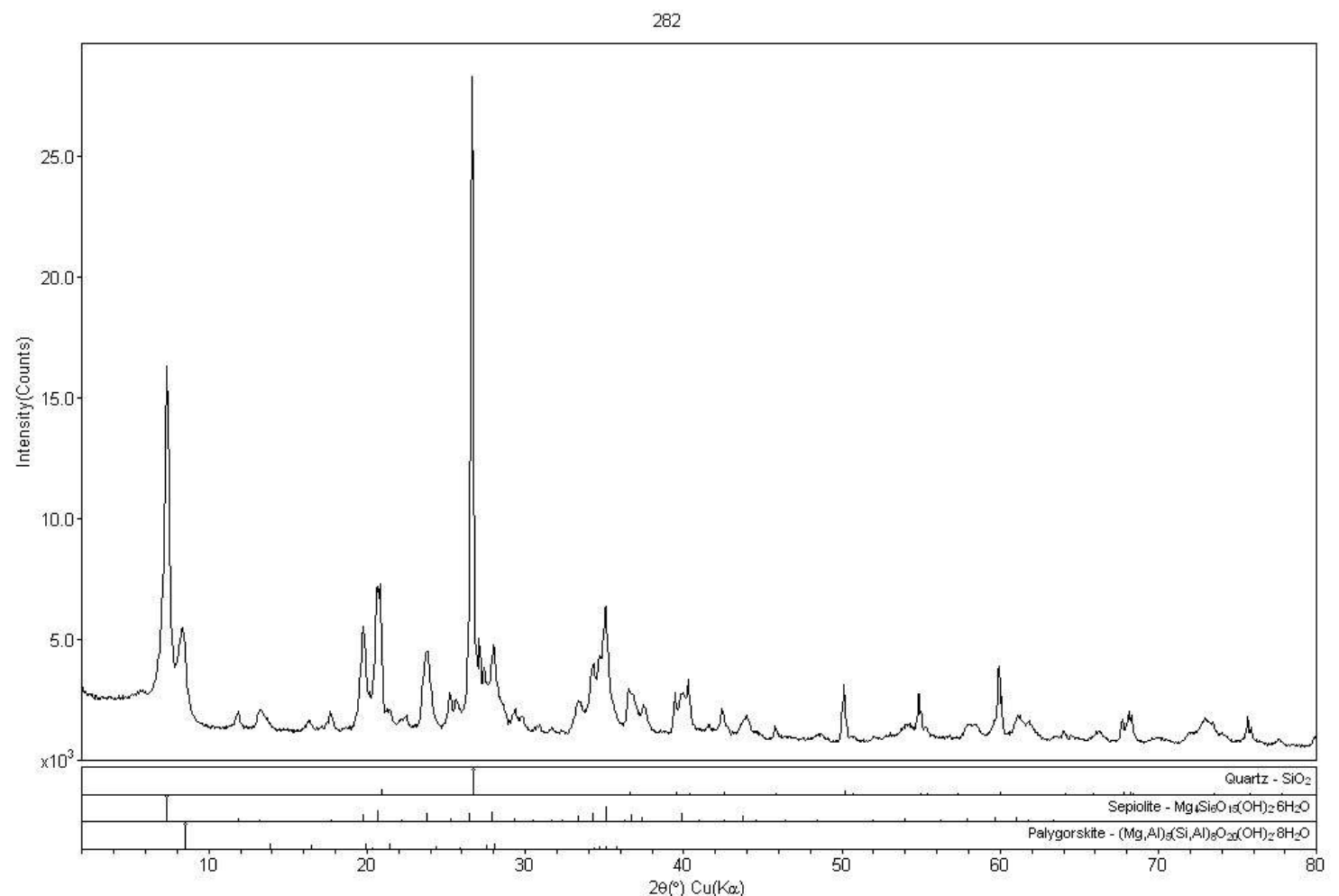

Campus Univ Darby Ribeiro
Anexo 11. Espectro de difração de raios-X da amostra FUP-000282. [RA0-X||G] WWednesday, December 09, 2015 10:15a MDIJJADE9) 


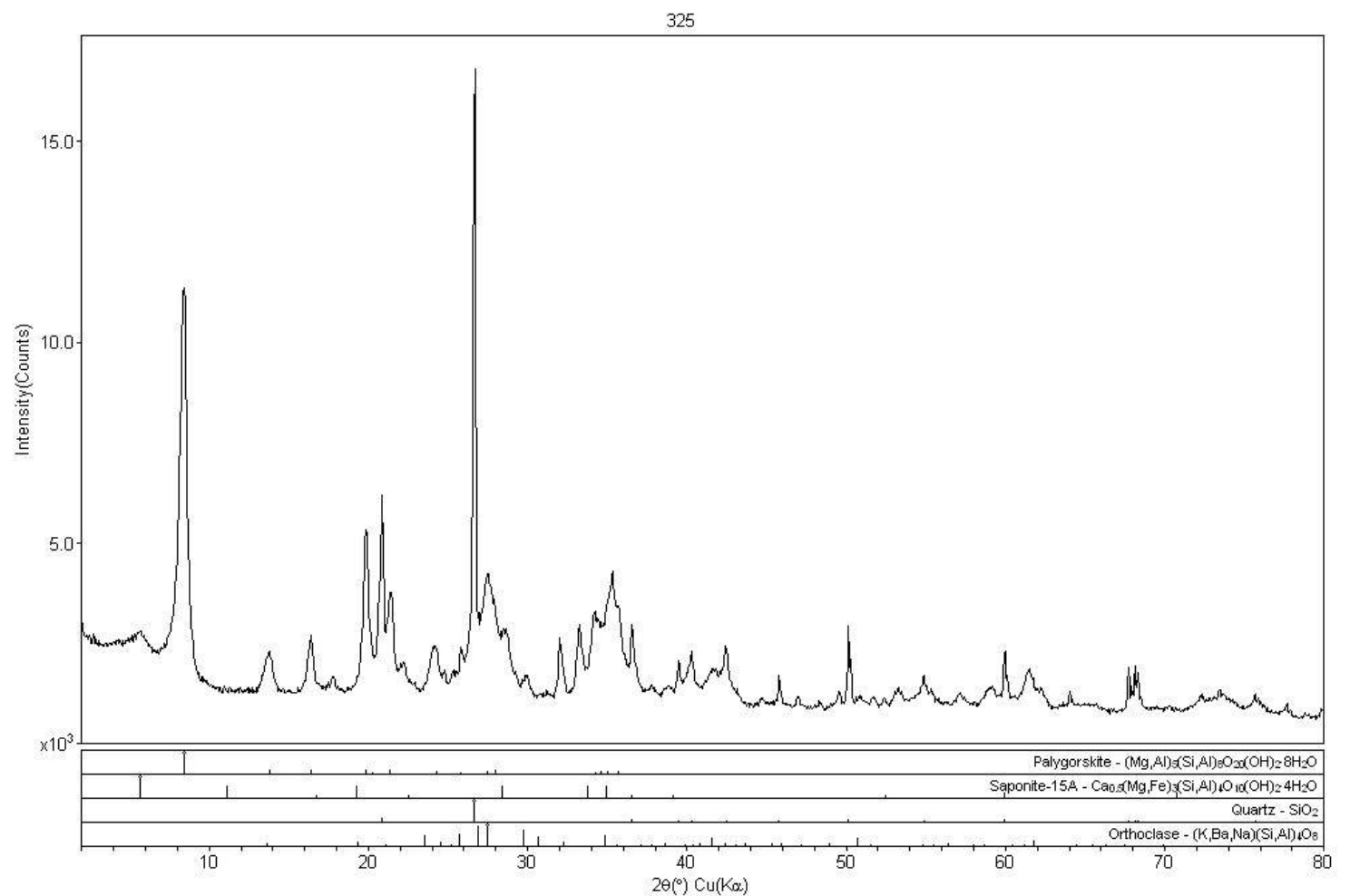

Campus Univ Darby Ribeiro

Anexo 12. Espectro de difração de raios-X da amostra FUP-000325.

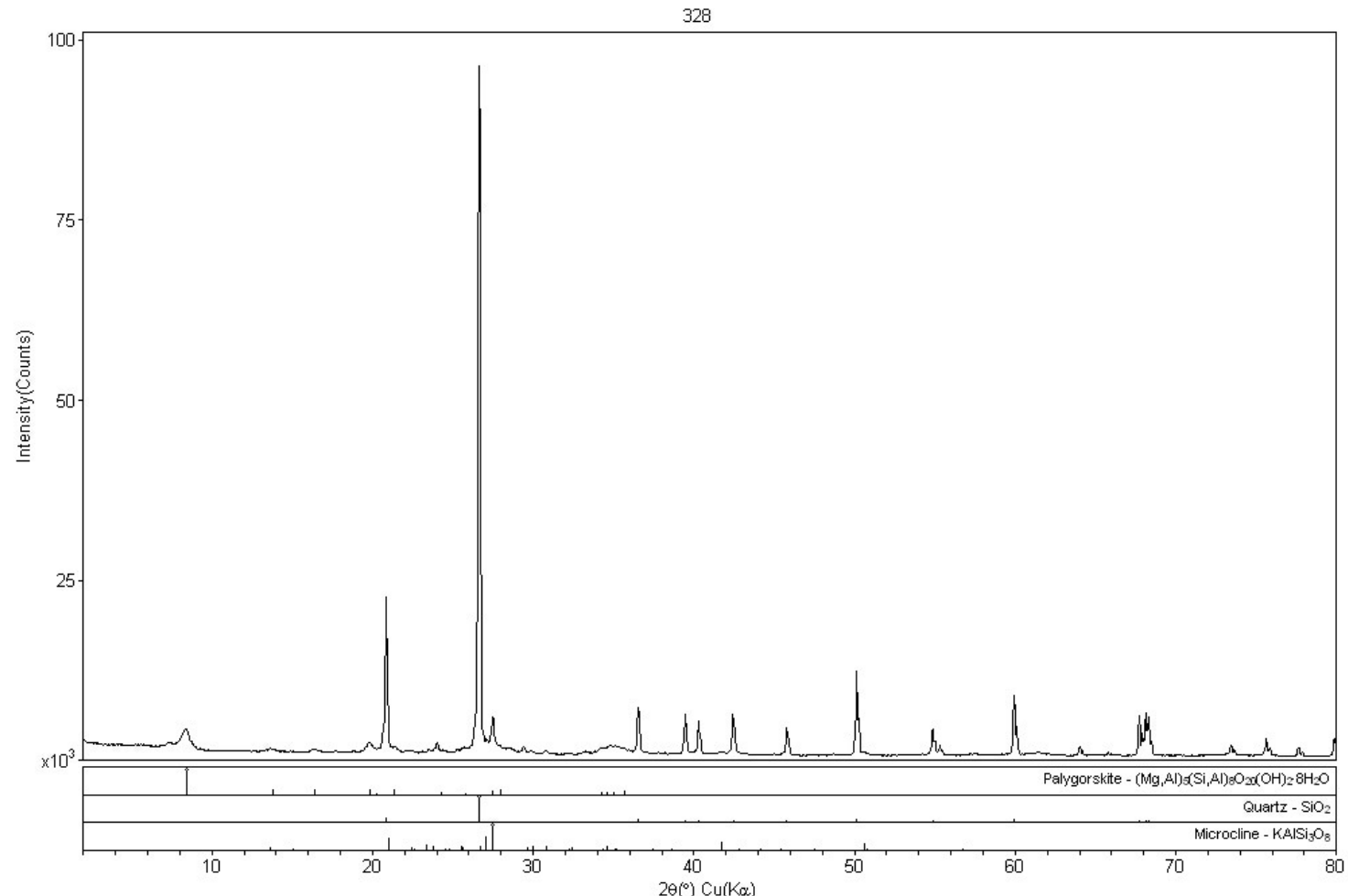

Campus Univ Darby Ribeiro

[RA|O-X||G] Wednesday, December 09, 2015 10:18a (MDIJJADE9)

Anexo 13. Espectro de difração de raios-X da amostra FUP-000328. 
333

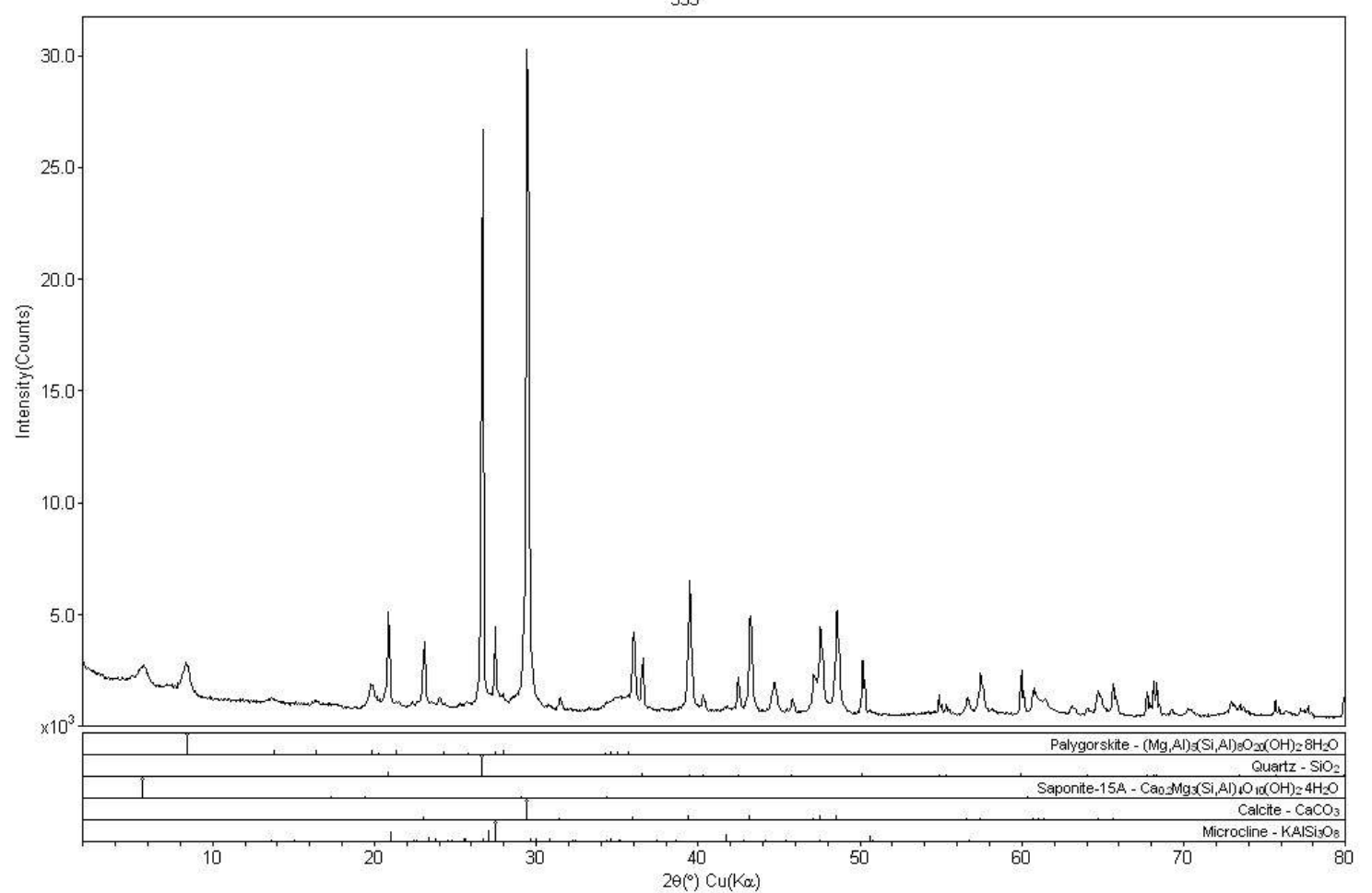

Campus Univ Darby Ribeiro

[RA0-X||G] Wednesday, December 09, 2015 10:18a (MDIJJADE9)

Anexo 14. Espectro de difração de raios-X da amostra FUP-000333. 